Aus der Klinik für Nephrologie und Rheumatologie

(Prof. Dr. med. G. A. Müller)

der Medizinischen Fakultät der Universität Göttingen

\title{
Serelaxin-vermittelte Inhibition von Fibroblastenaktivierung bei renaler Fibrogenese
}

\author{
INAUGURAL - DISSERTATION \\ zur Erlangung des Doktorgrades \\ der Medizinischen Fakultät der \\ Georg-August-Universität zu Göttingen
}

vorgelegt von

Friederike Hesse

aus

Göttingen

Göttingen 2018 
Dekan:

Referent/in

Ko-Referent/in:

Drittreferent/in:
Prof. Dr. rer. nat. H. K. Kroemer

Prof. Dr. Michael Zeisberg

PD Dr. Frauke Czepluch

Prof. Dr. Margarete Schön

Datum der mündlichen Prüfung: 03.04.2019 
Hiermit erkläre ich, die Dissertation mit dem Titel "Serelaxin-vermittelte Inhibition von Fibroblastenaktivierung bei renaler Fibrogenese" eigenständig angefertigt und keine anderen als die von mir angegebenen Quellen und Hilfsmittel verwendet zu haben.

Göttingen, den

(Unterschrift) 


\section{Inhaltsverzeichnis}

Inhaltsverzeichnis

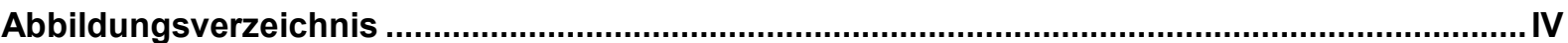

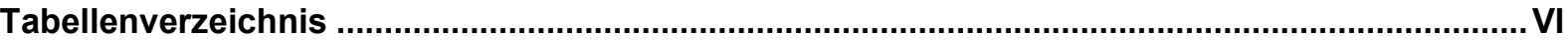

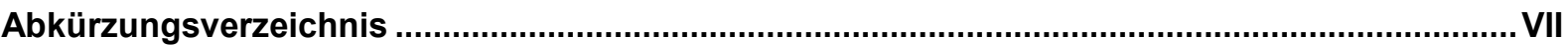

1. Einleitung

1.1 Medizinische und gesellschaftliche Relevanz von chronischen Nierenerkrankungen ........ 1

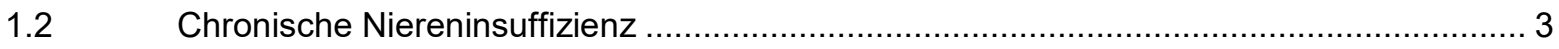

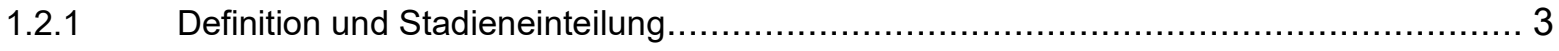

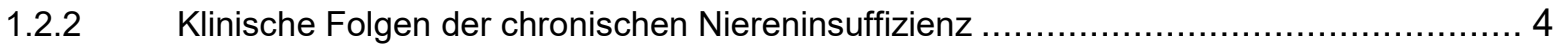

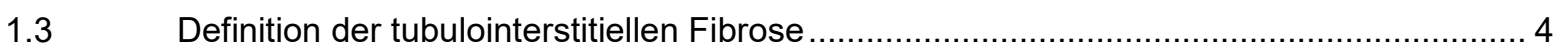

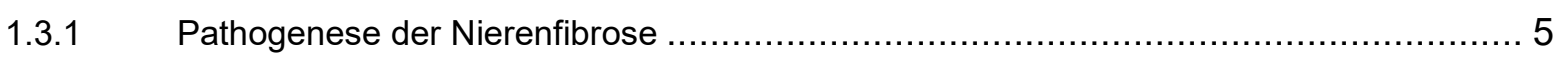

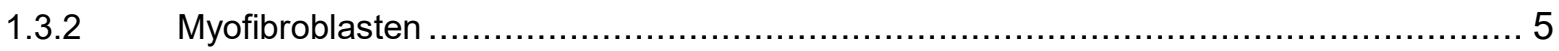

1.3.3 Therapieoptionen bei chronisch progredienter Niereninsuffizienz.......................... 6

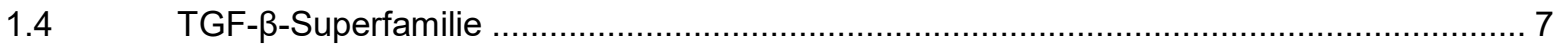

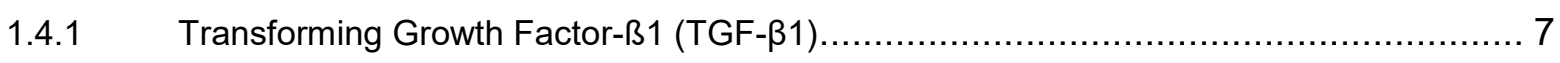

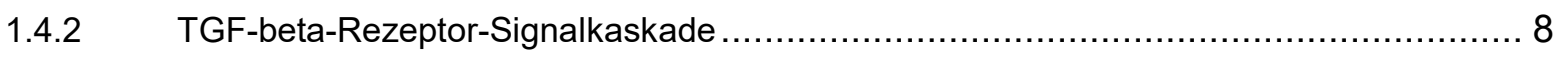

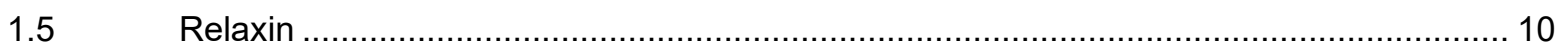

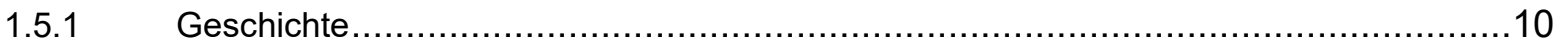

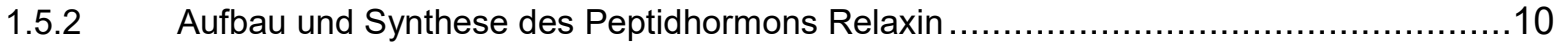

1.5.3 Expression und Sekretion von Relaxin-Peptiden im Menschen und in Mäusen .............12

1.5.4 Aktivierung der Signal-Transduktions-Wege durch Relaxin-Peptide ........................12

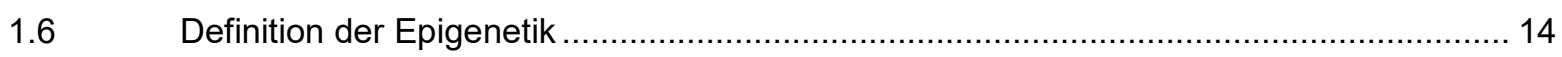

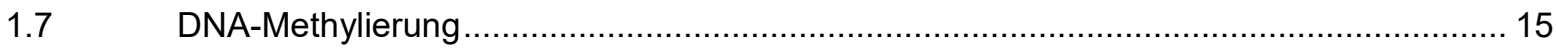

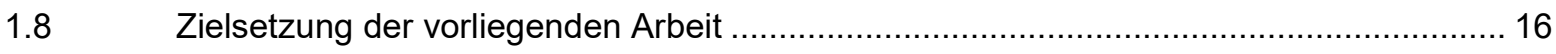

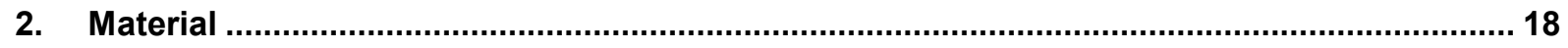

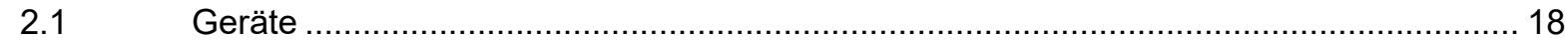

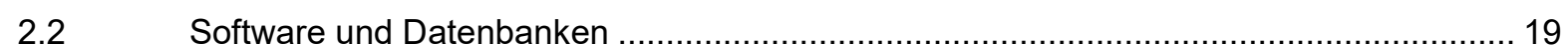

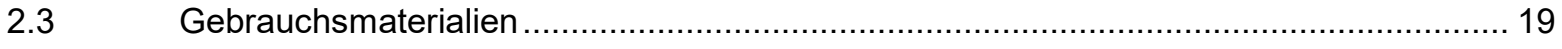

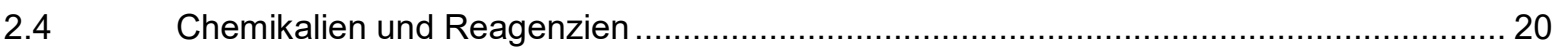

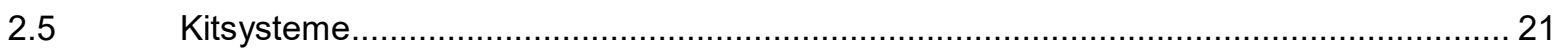

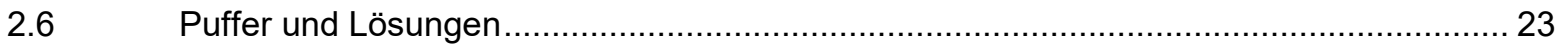

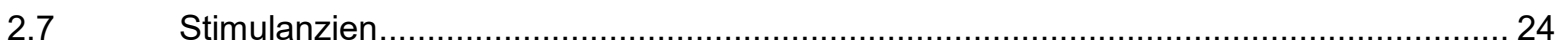

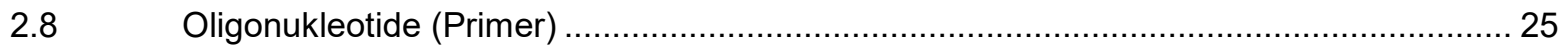

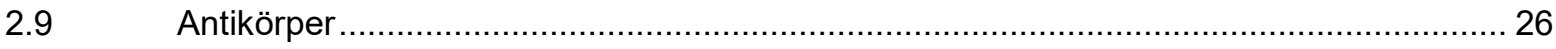


2.10 Zelllinien sowie murine und humane Gewebsproben .................................................... 27

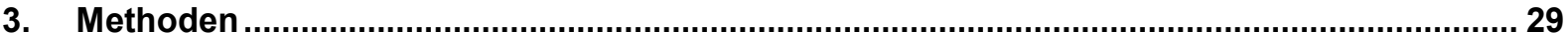

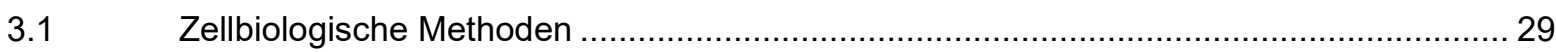

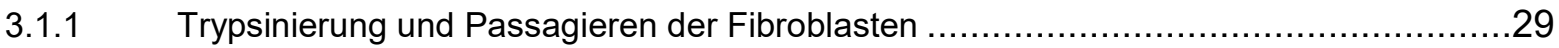

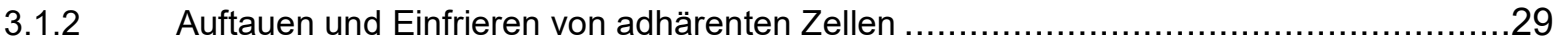

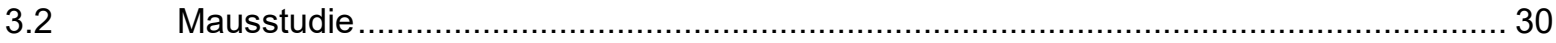

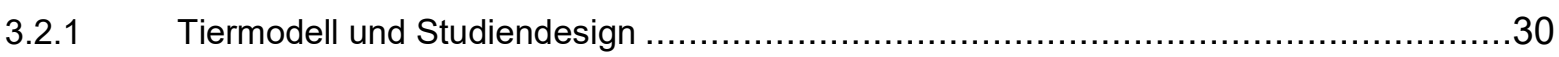

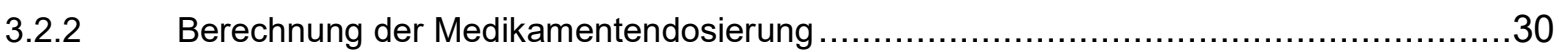

3.2.3 Funktionsweise und Implantierung der osmotischen Minipumpe ..............................31

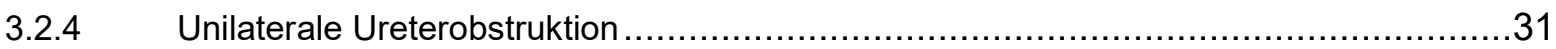

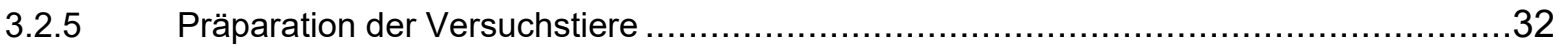

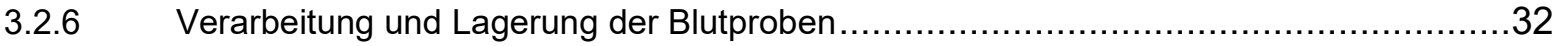

3.2.7 Zweites unabhängiges Tiermodell (medikamententoxische Verifikation mit anderem

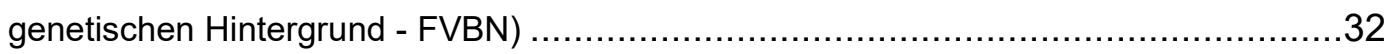

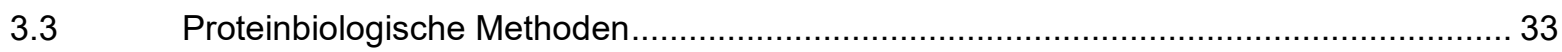

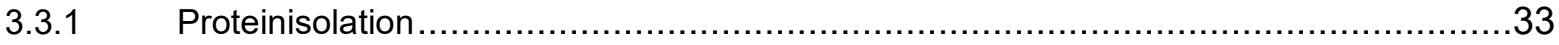

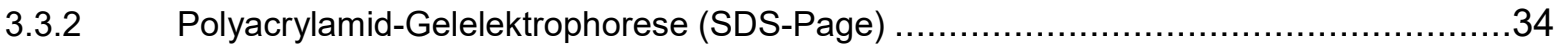

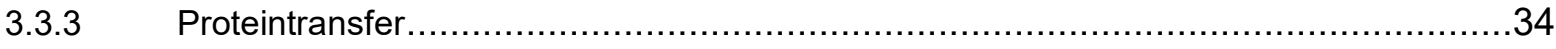

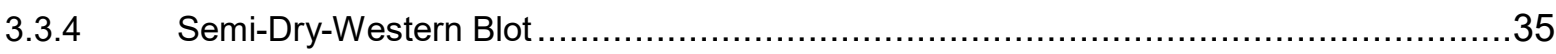

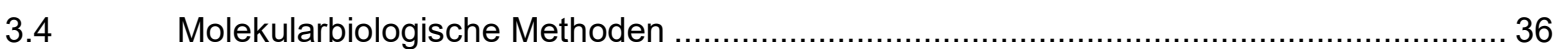

3.4.1 RNA-Isolation aus Fibroblasten und murinem Gewebe ..........................................36

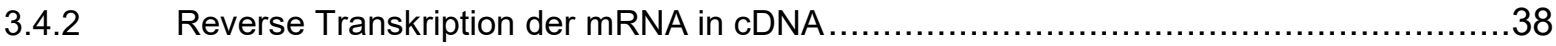

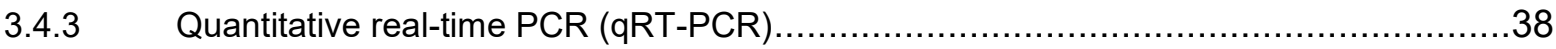

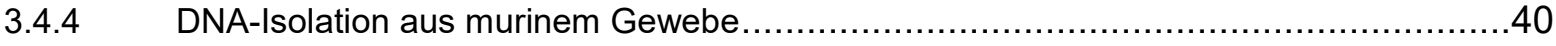

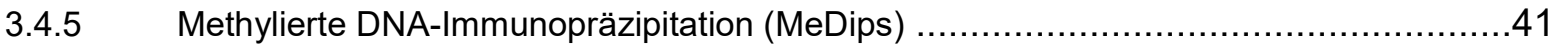

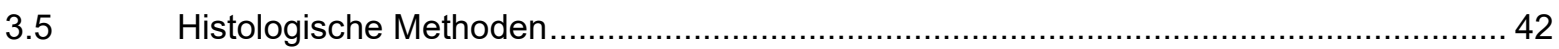

3.5.1 Anfertigung und Aufbereitung der Gewebeschnitte..........................................42

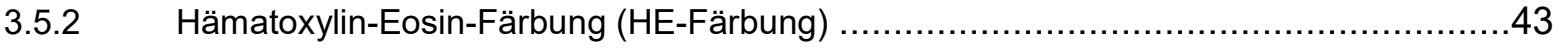

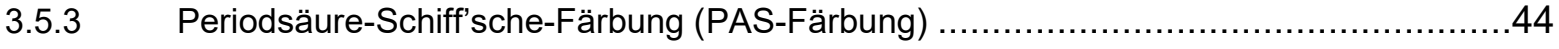

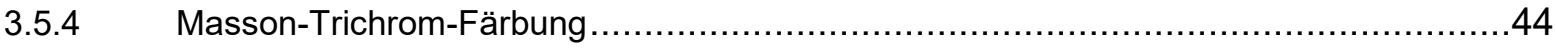

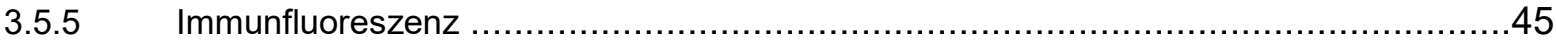

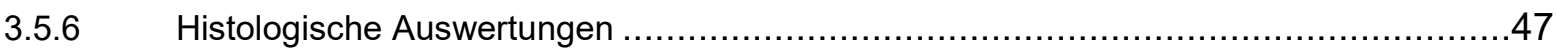

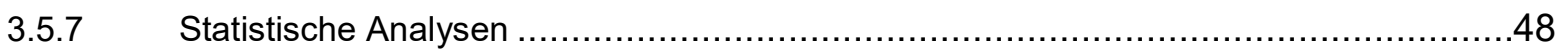

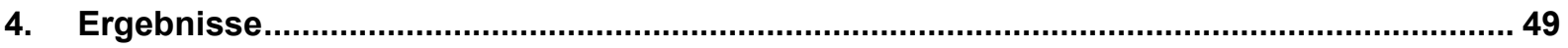

4.1 Versuche im Mausmodell der unilateralen Ureterobstruktion (UUO) …......................... 49 
4.1.1 Expression von Relaxin-1 in der murinen Niere

4.2 Lokalisation und Expression der Relaxin-Rezeptoren-1 und -2 (Rxfp1 und Rxfp2) in der

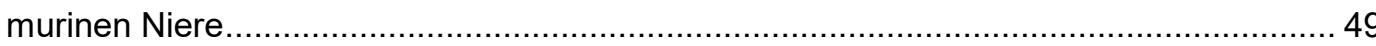

4.2.1 Erhöhte Expression in der UUO-Niere ......................................................49

4.3 Dosisabhängiger Einfluss von RLX030 auf renale Myofibroblasten-Akkumulation nach

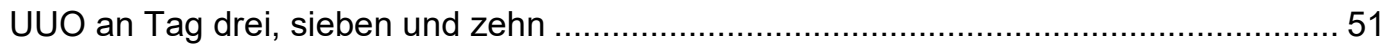

4.3.1 Geschlechtsunspezifische Wirkung von RLX030 .........................................53

$4.4 \quad$ Bestätigung der Ergebnisse in einem zweiten unabhängigen Maus-Modell ..................... 54

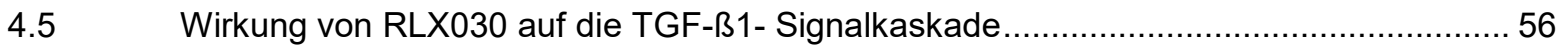

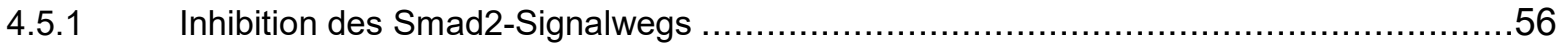

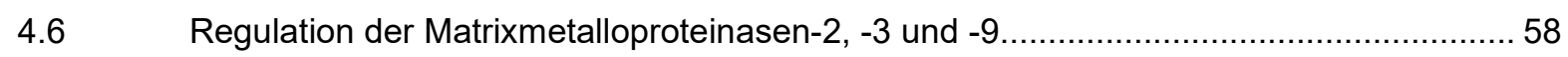

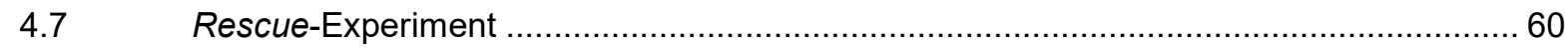

4.8 RLX030 ist äquivalent wirksam in humanen Fibroblastenkulturen ................................ 62

4.9 Expression der Relaxin-Isoformen sowie deren Rezeptoren in humanen Nierenbiopsien

4.10 Aberrante Promotermethylierung als Biomarker für endogenen Relaxin-Verlust............. 65

4.10.1 Der Verlust von intrarenalem Relaxin beruht auf aberrranter Promotermethylierung......65

4.10.2 Aberrante Relaxin-Promotermethylierung akkumuliert in Patienten mit chronischer

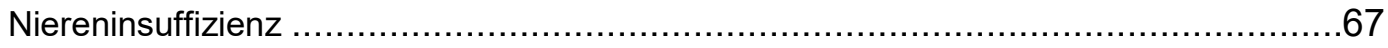

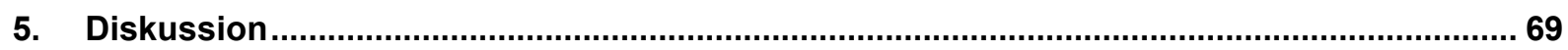

$5.1 \quad$ Studienlage RLX030

5.2 Induktion der Relaxin-Rezeptoren in der geschädigten Niere ....................................... 69

5.3 Attenuierung der renalen Fibrosierung in vivo durch Applikation von RLX030 ............... 71

5.4 Molekulare Transduktionsmechanismen zur Inhibition der renalen Fibrogenese ............. 74

5.5 Beleuchtung des intrarenalen Verlusts von Relaxin durch epigenetische

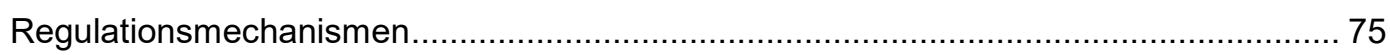

5.6 Molekulargenetische Identifikation eines therapierelevanten Biomarkers....................... 76

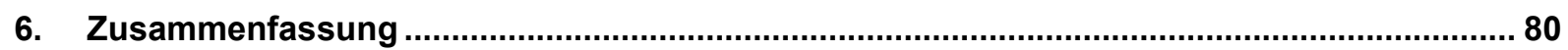

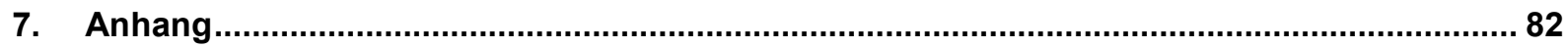

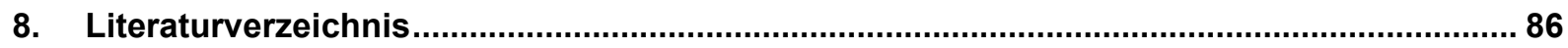




\section{Abbildungsverzeichnis}

Abbildung 1: Diagnoseverteilung der Patienten bei Therapiebeginn ………............................ 2

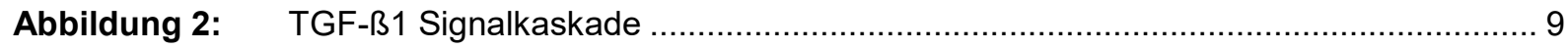

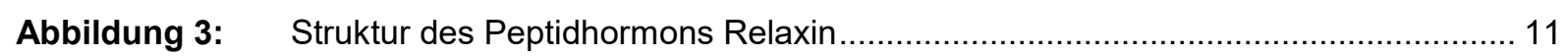

Abbildung 4: Signaltransduktion von RXFP1 vermittelt durch Relaxin ...................................... 14

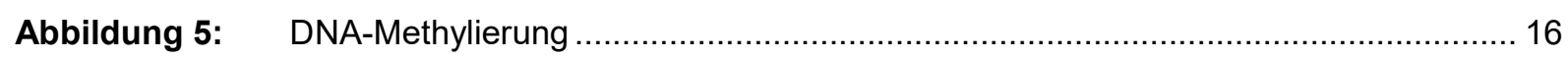

Abbildung 6: Initiales Mausmodell zur Untersuchung des inhibitorischen Effekts von

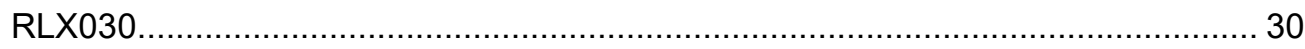

Abbildung 7: $\quad$ Osmotische Minipumpe Modell 1002 der Firma Alzet ${ }^{\circledR}$.......................................... 31

Abbildung 8: Zweites unabhängiges Mausmodell mit dem genetischen Hintergrund FVBN und

Folsäure-Applikation zur Induktion der Nierenfibrose .......................................... 33

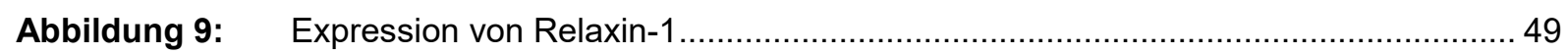

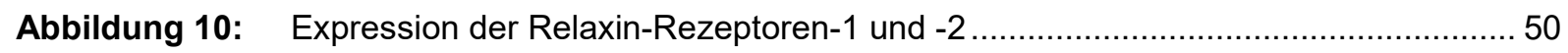

Abbildung 11: Lokalisation von Relaxin-Rezeptoren-1 und -2 in der Kontroll- sowie fibrotisch veränderten Niere.

Abbildung 12: Inhibition der experimentellen renalen Fibrogenese durch RLX030 im histopathologischen Korrelat der UUO-Niere................................................. 52

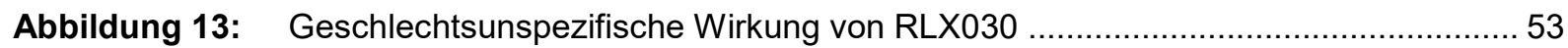

Abbildung 14: Antifibrotische Wirkung von RLX030 im Maus-Modell der Folsäure-Nephropathie. 55

Abbildung 15: Inhibition des pSmad2-Signalwegs im murinen Gewebe ....................................... 56

Abbildung 16: Inhibition des pSmad-Signalwegs in Primärkulturen muriner Fibroblasten ............. 57

Abbildung 17: RLX030 Wirkung auf murine Fibroblastenproliferation ......................................... 57

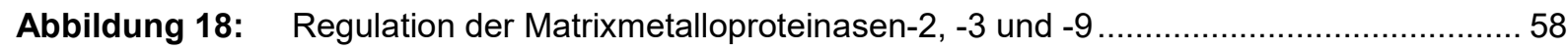

Abbildung 19: Expression von Matrixmetalloproteinasen-2 und -9 in der Immunfluoreszenzfärbung

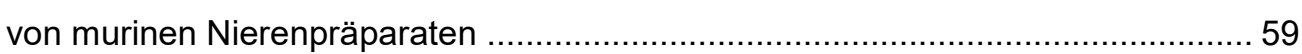

Abbildung 20: Mausmodell der Rescue-Studie über einen Zeitraum von 14 Tagen ...................... 60

Abbildung 21: RLX030 vermittelt protektive Effekte bei schon etablierter Nierenfibrose................ 61

Abbildung 22: Inhibition der humanen Fibroblastenproliferation durch RLX030 …......................... 62

Abbildung 23: Expression der Relaxin-Isoformen in humanen Nierenbiopsien .............................. 63

Abbildung 24: Heatmap: RLN1- und RLN2-Verlust assoziiert mit der Progression chronischer

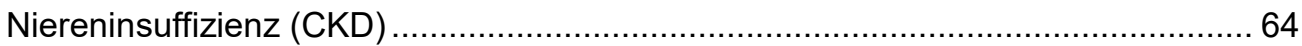

Abbildung 25: Expression der Relaxin-Rezeptoren-1 und -2 in humanen Nierenbiopsien ............. 65

Abbildung 26: Korrelation von intrarenaler RLN1/RLN2-Methylierung mit intrarenaler RLN1/RLN2

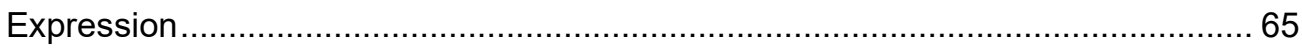

Abbildung 27: Korrelation von intrarenaler RLN1/RLN2-Methylierung mit RLN1/RLN2-Methylierung im Blut.. .66

Abbildung 28: Korrelation von RLN1/RLN2-Methylierung im Blut mit intrarenaler RLN1/RLN2 
Expression 66

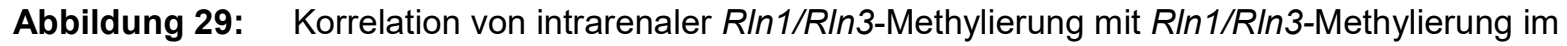

Blut 67

Abbildung 30: Nierenfunktionseinschränkung korreliert mit aberranter Relaxin-

Promotormethylierung

Abbildung 31: Heatmap der Relaxin-Isoformen und entsprechende Rezeptoren in gesunden, kontralateralen $(\mathrm{KL})$ und UUO-Nieren 70

Abbildung 32: Veränderte Relaxin-Rezeptor-1-Expression in geschädigten Nieren mit einhergehendem endogenen Relaxin-Verlust 


\section{Tabellenverzeichnis}

Tabelle 1: Diagnosekriterien chronischer Nierenerkrankungen (CKD) .................................. 3

Tabelle 2: $\quad$ Vorkommen von Relaxin und seinen Rezeptoren im humanen und murinen Nieren ... 12

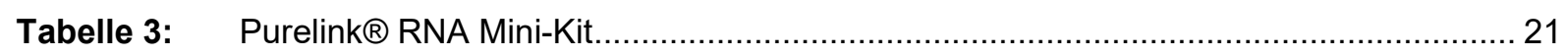

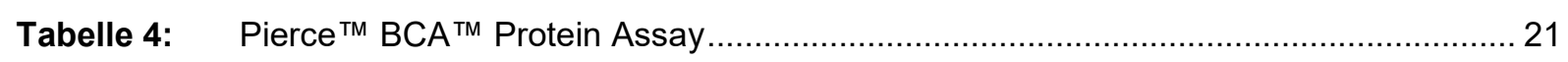

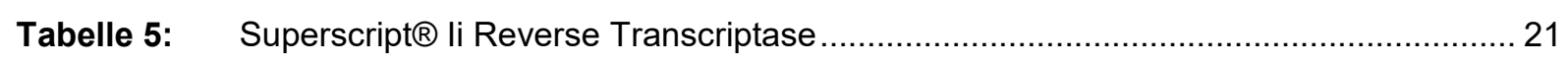

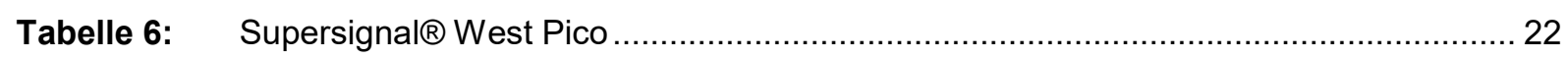

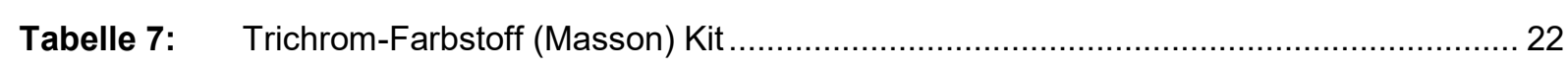

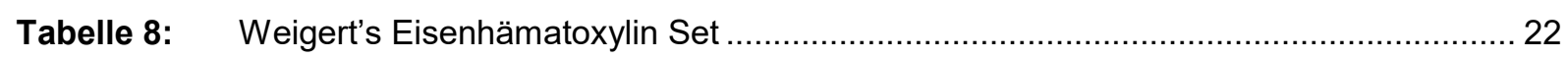

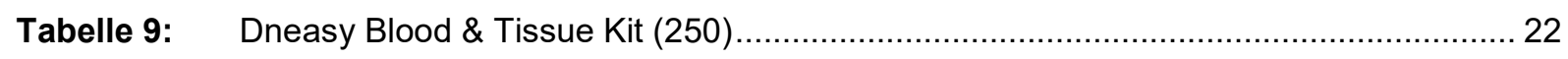

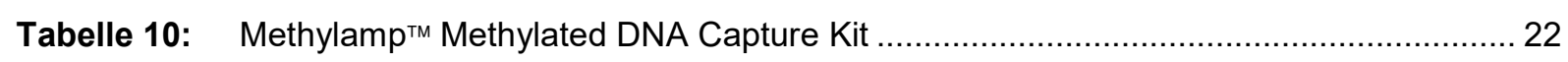

Tabelle 11: Primersequenzen von PrimerDesign für die qRT-PCR ......................................... 25

Tabelle 12: $\quad$ Primersequenzen von Eurofins MWG Operon für die qRT-PCR ...............................26

Tabelle 13: Verwendete Antikörper für Western Blot und Immunfluoreszenzfärbung ...................26

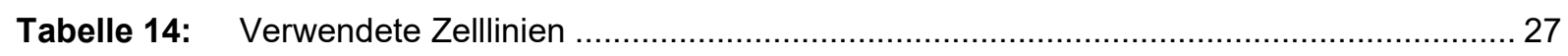

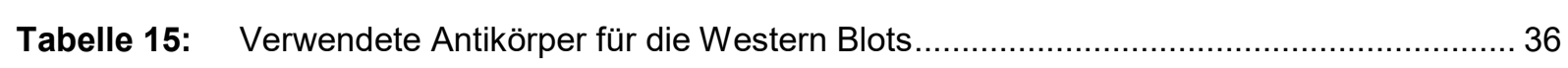

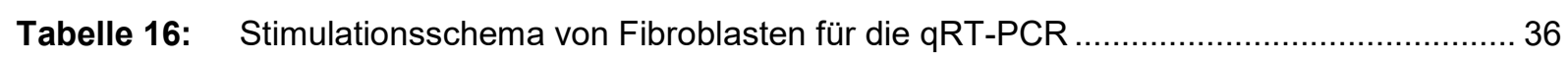

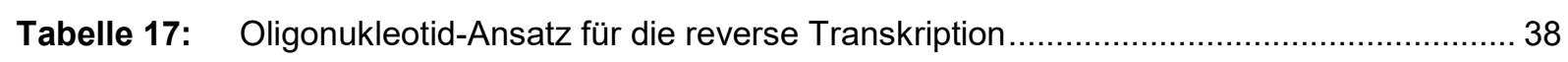

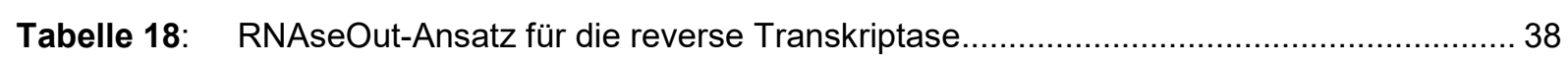

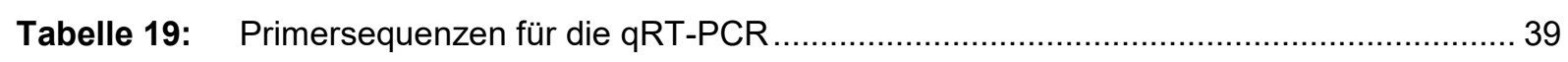

Tabelle 20: Primersequenzen für die methylierte DNA-Immunopräzipitation (MeDiP) .................42

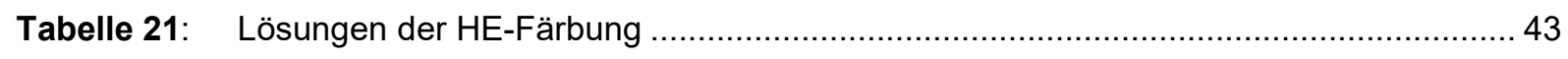

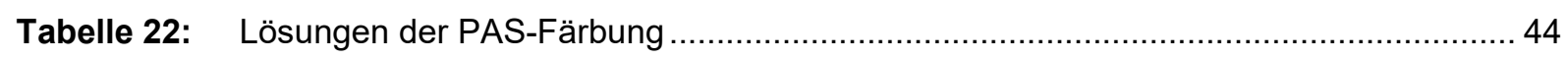

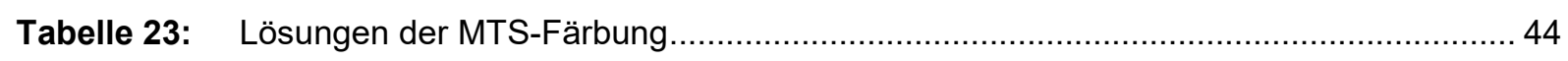

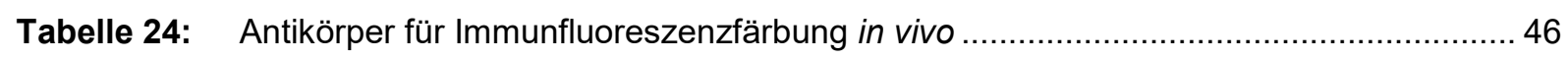

Tabelle 25: $\quad$ Antikörper für Immunfluoreszenzfärbung in vitro............................................. 47

Tabelle 26: Patientenkohorte mit chronischen Nierenerkrankungen aufgeschlüsselt hinsichtlich

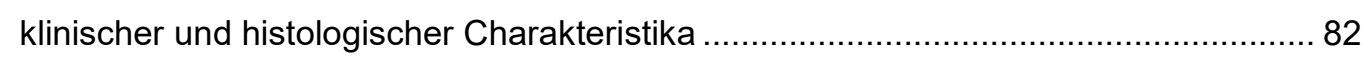




\section{Abkürzungsverzeichnis}

Nicht gesondert aufgeführt sind die im deutschen Sprachgebrauch üblichen Standardabkürzungen

\begin{tabular}{|c|c|c|c|}
\hline AK & Antikörper & DMEM & Dulbecco's Modified Eagle's \\
\hline AR & androgen receptor & & Medium \\
\hline$\alpha-S M A$ & $\alpha$-smooth muscle actin & DMSO & Dimethylsulfoxid \\
\hline AT-2 & Angiotensin-2 & DNA & $\begin{array}{l}\text { Desoxyribonukleinsäure } \\
\text { (deoxyribonucleic acid) }\end{array}$ \\
\hline a.u. & arbiträre Einheit (arbitrary unit) & dNTP & Desoxyribonukleosidtriphosphat \\
\hline Bis-Tris & $\begin{array}{l}\text { Bis(2-hydroxyethyl)amino- } \\
\text { tris(hydroxymethyl)methan }\end{array}$ & $\begin{array}{l}\text { DTT } \\
\text { EDTA }\end{array}$ & $\begin{array}{l}\text { 1,4-Dithiothreitol } \\
\text { Ethylendiamintetraessiqsäure }\end{array}$ \\
\hline BMP7 & bone morphogenetic protein 7 & & (ethylene diamine tetraacetic acid) \\
\hline bp & Basenpaare & EMT & epithelial-mesenchymale \\
\hline BSA & $\begin{array}{l}\text { Rinderserumalbumin } \\
\text { (Bovine Serum Albumin) }\end{array}$ & ESRD & $\begin{array}{l}\text { Transition } \\
\text { terminales Nierenversagen }\end{array}$ \\
\hline $\mathrm{C}_{0}$ & Talspiegel & & (end-stage renal disease) \\
\hline cDNA & $\begin{array}{ll}\text { komplementäre } & \text { DNA } \\
\text { (complementary DNA) }\end{array}$ & $\begin{array}{l}\text { EtOH } \\
\text { FSGS }\end{array}$ & $\begin{array}{l}\text { Ethanol } \\
\text { segmentale Glomerulosklerose }\end{array}$ \\
\hline CKD & $\begin{array}{l}\text { chronisch progrediente Nieren- } \\
\text { insuffizienz (chronic kidney } \\
\text { disease) }\end{array}$ & $\begin{array}{l}\text { FSP1 } \\
\text { fwd } \\
\text { GAPDH }\end{array}$ & $\begin{array}{l}\text { fibroblast-specific protein } 1 \\
\text { Vorwärtsprimer (forward primer) } \\
\text { glyceraldehyde-3-phosphate }\end{array}$ \\
\hline COL1A1 & collagen type I a1 & & dehydrogenase \\
\hline Co-SMAD & common-mediator SMAD & GFR & Glomeruläre Filtrationsrate \\
\hline $\mathrm{Ct}$ & threshold cycle & $\mathrm{h}$ & Stunde(n) \\
\hline$\Delta \mathrm{CT} / \Delta \Delta \mathrm{CT}$ & delta-CT / delta delta-CT & $\mathrm{HE}$ & Hämatoxylin-Eosin \\
\hline CYP3A4/5 & $\begin{array}{l}\text { cytochrome } P 450 \text {, family } 3 \text {, subfamily } \\
\text { A, polypeptide } 4 / \text { polypeptide }\end{array}$ & HRP & $\begin{array}{l}\text { Meerrettichperoxidase } \\
\text { (horseradish peroxidase) }\end{array}$ \\
\hline DAPI & 4',6-Diamidin-2-phenylindol & $\mathrm{IL}$ & interleukin \\
\hline DGfN & $\begin{array}{l}\text { Deutsche Gesellschaft für } \\
\text { Nephrologie }\end{array}$ & $\begin{array}{l}\lg \\
\text { I-SMAD }\end{array}$ & $\begin{array}{l}\text { Immunoglobulin } \\
\text { inhibitorisches SMAD }\end{array}$ \\
\hline DSO & $\begin{array}{l}\text { Deutsche Stiftung } \\
\text { Organtransplantation }\end{array}$ & $\mathrm{kDa}$ & Kilodalton \\
\hline DTG & $\begin{array}{l}\text { Deutsche } \\
\text { Transplantationsgesellschaft }\end{array}$ & KDIGO & $\begin{array}{l}\text { Kidney Disease: Improving } \\
\text { Global Outcome }\end{array}$ \\
\hline $\mathrm{ddH}_{2} \mathrm{O}$ & bidestilliertes Wasser & $\begin{array}{l}\text { LDS } \\
\text { M }\end{array}$ & $\begin{array}{l}\text { Lithiumdodecylsulfat } \\
\text { Molarität }\end{array}$ \\
\hline
\end{tabular}




\begin{tabular}{|c|c|}
\hline MET & mesenchymal-epitheliale \\
\hline & Transition \\
\hline $\min$ & Minute(n) \\
\hline MOPS & $\begin{array}{l}\text { 3-(N-Morpholino)- } \\
\text { propansulfonsäure }\end{array}$ \\
\hline mRNA & Boten-RNA (messenger RNA) \\
\hline MTS & $\begin{array}{l}\text { Masson-Trichrom-Färbung } \\
\text { (Masson's trichrome stain) }\end{array}$ \\
\hline $\mathrm{NCBI}$ & $\begin{array}{l}\text { National Center for Biotechnology } \\
\text { Information }\end{array}$ \\
\hline NF-kB & $\begin{array}{l}\text { nuclear factor of kappa light poly- } \\
\text { peptide gene enhancer in B-cells } 1\end{array}$ \\
\hline NFW & nukleasefreies Wasser \\
\hline NTN & nephrotoxische Serum Nephrithis \\
\hline PAS & $\begin{array}{l}\text { Perjodsäure-Schiff-Reaktion } \\
\text { (periodic acid-Schiff reaction) }\end{array}$ \\
\hline PBS & $\begin{array}{l}\text { Phosphat-gepufferte } \\
\text { Kochsalzlösung (phosphate- } \\
\text { buffered saline) }\end{array}$ \\
\hline PBS-T & phosphate-buffered saline Tween \\
\hline PCR & $\begin{array}{l}\text { Polymerasekettenreaktion } \\
\text { (polymerase chain reaction) }\end{array}$ \\
\hline Pen/Strep & Penicillin/Streptomycin \\
\hline PPlase & Peptidyl-Prolyl-cis/trans-Isomerase \\
\hline pSMAD & phosphoryliertes SMAD \\
\hline qRT-PCR & quantitative real-time PCR \\
\hline rev & Rückwärtsprimer (reverse primer) \\
\hline RNA & Ribonukleinsäure (ribonucleic acid) \\
\hline RNase & Ribonuklease \\
\hline R-SMAD & regulatorisches SMAD \\
\hline s & Sekunde(n) \\
\hline SDS & $\begin{array}{l}\text { Natriumdodecylsulfat (sodium } \\
\text { dodecyl sulfate) }\end{array}$ \\
\hline siRNA & small interfering RNA \\
\hline
\end{tabular}

SV40 Affenvirus 40 (Simian virus 40)

TBS Tris-gepufferte Kochsalzlösung (tris-buffered saline)

TBS-T tris-buffered saline Tween

TGF- $\beta 1 \quad$ transforming growth factor- $\beta 1$

TNF- $\alpha \quad$ tumor necrosis factor- $\alpha$

Tris Tris(hydroxymethyl)aminomethan

Tween 20 polyoxyethylen(20)-sorbitanmonolaurat

USRDS United States Renal Data System

UUO unilaterale Ureterobstruktion

Weitere Abkürzungen sind an entsprechender Stelle im Text ausgeführt. 


\section{Einleitung}

\subsection{Medizinische und gesellschaftliche Relevanz von chronischen Nierenerkrankungen}

Chronische Nierenerkrankungen sind ein weltweites Gesundheitsproblem. Allein in Deutschland und den USA nahm die Inzidenz und Prävalenz von chronischen Nierenerkrankungen in den letzten 10 Jahren stetig zu. Gemäß dem Annual Data Report des United States Renal Data System (USRDS) lag 1993 die Inzidenz einer terminalen Niereninsuffizienz bzw. ESRD (End Stage Renal Disease) bei 63.596 Patienten pro Jahr und stieg bis 2013 auf 117.162 Patienten per anno an. Dies entspricht einer Steigerung der Inzidenz um ca. 46\% innerhalb von 20 Jahren (USRDS 2013 Annual Data Report).

Nach dem Bericht der Gesellschaft für Qualitäts-Sicherung Niere - QuaSI-Niere von 2006/2007 können in der Bundesrepublik Deutschland vergleichbare Tendenzen beobachtet werden. 1995 wurden in Deutschland 54.656 Patienten mit einer chronischen Nierenersatztherapie behandelt, ein Jahrzehnt später betrug die Summe aller Patienten in chronischer Nierenersatztherapie schon 91.718 Patienten. Zur Nierenersatztherapie zählen Dialysebehandlungen (66.508 Patienten im Jahr 2006), welche unterteilt werden in Hämo- (63.307) und Peritonealdialyse (3.201) sowie die Nierentransplantationen (2.776 Patienten). Die Zahl der Neuaufnahmen in die chronische Nierenersatztherapie (Inzidenz) stieg von 11.731 Patienten im Jahr 1995 auf 17.548 Patienten 2006. Dies ergibt eine prozentuale Steigerung um 33\% (Frei und SchoberHalstenberg 2008).

Diese Zunahme ist nicht alleine durch den demographischen Wandel erklärbar, sondern bedarf auch einer genaueren Betrachtung der Diagnoseverteilung der Patienten bei Therapiebeginn einer Nierenersatztherapie. Die Diagnose des Diabetes mellitus wurde mit 34\% am häufigsten erfasst, wobei der größte Anteil (32\%) vom Diabetes mellitus Typ II gestellt wird (Frei und Schober-Halstenberg 2008, Whaley-Connell et al. 2009). Gleich dahinter ist die vaskuläre Nephropathie mit 24\% zu nennen, gefolgt von den Glomerulonephritiden mit $13 \%$ und der interstitiellen Nephritis mit 8\% (Frei und Schober-Halstenberg 2008, Bakris und Ritz 2009, Collins et al. 2015). Wie aus dem Bericht der QuaSI-Niere 2006/2007 hervorgeht, nehmen vor allem die altersbedingten Erkrankungen immer weiter zu. Neben dem Diabetes mellitus Typ II ist hier vor allem die vaskuläre Nephropathie zu nennen, deren prozentualer Anteil von $14 \% \mathrm{im}$ Jahr 1997 auf 24\% bis 2006 angestiegen ist. Als chronische Nierenerkrankungen bezeichnet, bedingen sie häufig eine irreversible und progressive Reduktion der Nierenfunktion, welche mit der Ausbildung einer terminalen Niereninsuffizienz einhergeht. Neben der steigenden Inzidenz und Prävalenz von Patienten in Nierenersatztherapien wird auch eine Zunahme weiterer Risikofaktoren beobachtet, welche unter anderem zu einem Anstieg der Mortalität führen. Hier stellen kardiale $(39,7 \%)$ und Infektionskrankheiten $(17,8 \%)$ die häufigsten Todesursachen bei 
Frauen und Männern dar, gefolgt von vaskulären (11,8\%) und malignen Erkrankungen $(10,3 \%)$ (Frei und Schober-Halstenberg 2008).

Mehrmalige Dialysesitzungen pro Woche oder immunsuppressive Therapien nach Nierentransplantation führen neben einer verkürzten Lebensdauer und Einschränkung der Lebensqualität auch zu einer erheblichen Kostenzunahme im Gesundheitswesen. Derzeit belaufen sich die kumulativen Kosten allein für die ambulante Dialysebehandlung pro Patient im Jahr auf etwa 40.000 Euro in Deutschland (DGfN 2014, Nebel 2003). Somit verursachen Dialysebehandlungen in der Bundesrepublik Deutschland jährlich schätzungsweise Kosten in Höhe von ca. 3 Milliarden Euro (Frei und Schober-Halstenberg 2008).

Sowohl die klinische als auch die volkswirtschaftliche Relevanz von terminaler Niereninsuffizienz und effektiven Behandlungsmethoden sind folglich essentiell und verdeutlichen die Notwendigkeit von präventiven Maßnahmen.

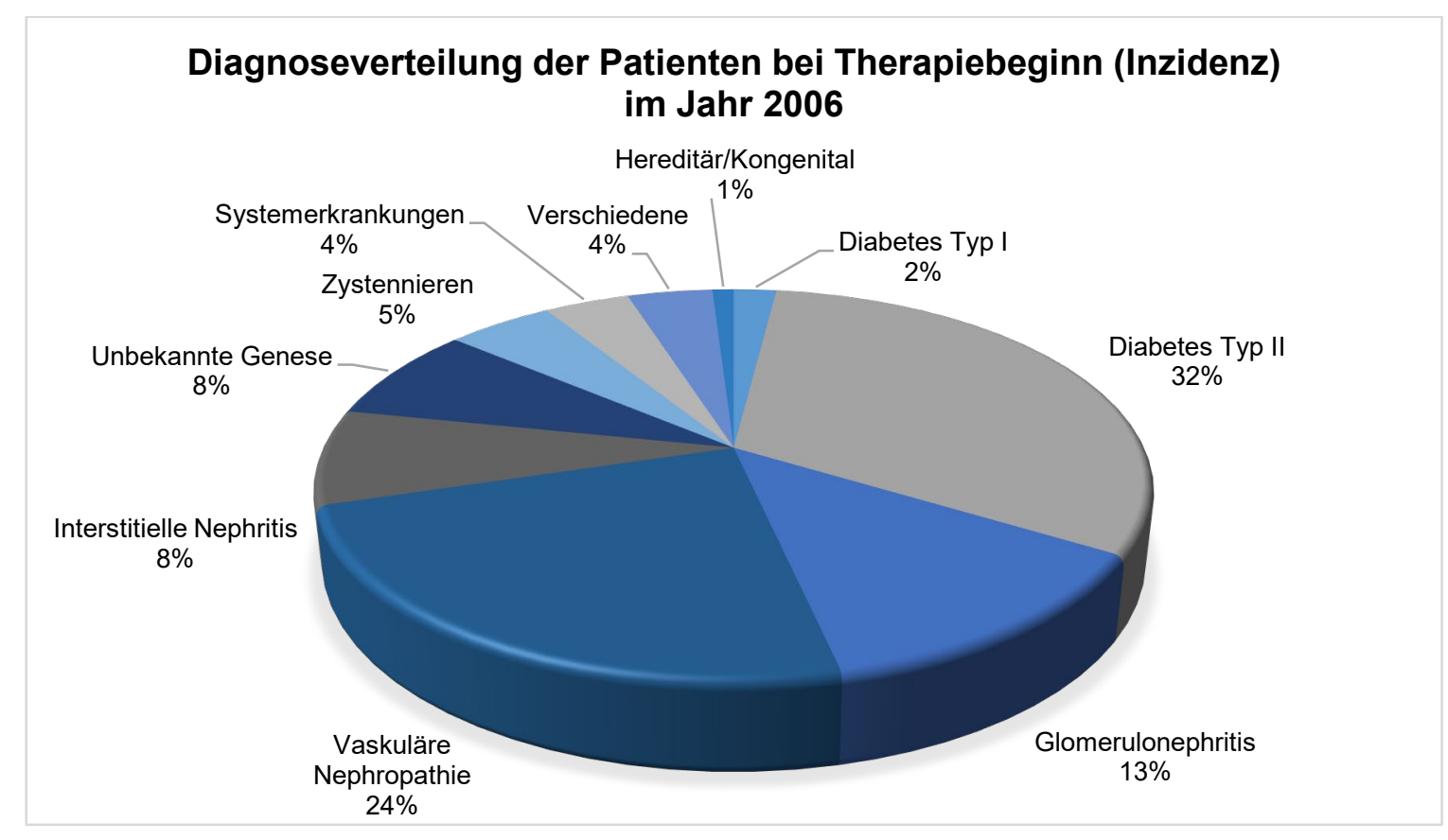

Abbildung 1: Diagnoseverteilung der Patienten bei Therapiebeginn (Inzidenz) im Jahr 2006 (modifziert nach Frei und Schober-Halstenberg 2008). 


\subsection{Chronische Niereninsuffizienz}

\subsubsection{Definition und Stadieneinteilung}

2003 wurde KDIGO - Kidney Disease - Improving Global Outcomes von der Amerikanischen Nierenstiftung (National Kidney Foundation) als eine unabhängige, gemeinnützige Organisation gegründet. Entsprechend ihrer Satzung verfolgt die KDIGO das Ziel, die Behandlung und Prognose von Patienten mit Nierenerkrankungen weltweit durch die Entwicklung und Implementierung globaler Leitlinien (kdigo.org) zu verbessern.

Der Begriff einer chronischen Nierenerkrankung ist seitdem neu definiert. Von einer chronischen Niereninsuffizienz (CKD) wird folglich gesprochen, wenn eine abnormale Nierenstruktur oder renale Funktionseinschränkung länger als 3 Monate andauert.

Marker für eine Nierenschädigung sind demnach: eine reduzierte errechnete glomeruläre Filtrationsrate (eGFR $<60 \mathrm{ml} / \mathrm{min} / 1,73 \mathrm{~m}^{2}$ ), eine Albuminurie (AER $\geq 30 \mathrm{mg} / 24 \mathrm{~h}$ ) sowie pathologische Veränderungen des Urinsediments, des Serums, der Histologie oder der Bildgebung.

Relevante Prognosefaktoren für den Behandlungserfolg der chronischen Niereninsuffizienz sind folgende Faktoren: Zum einen muss die Ursache einer chronischen Nierenerkrankung identifiziert, sowohl die eGFR- (G1-G5) als auch die Albuminurie-Kategorie (A1-A3) erfasst und weitere Risikofaktoren oder Komorbiditäten ausgeschlossen werden (KDIGO CKD Work Group. 2013).

Tabelle 1: Diagnosekriterien chronischer Nierenerkrankungen (CKD) (modifiziert nach KDIGO CKD Work Group 2013, Seite 5)

\begin{tabular}{|c|c|c|c|c|c|c|}
\hline \multirow{2}{*}{\multicolumn{4}{|c|}{ Prognose der chronischen Niereninsuffizienz }} & \multicolumn{3}{|c|}{$\begin{array}{l}\text { Albuminurie-Kategorie } \\
\text { (Albuminausscheidung im Urin in } \mathrm{mg} / \mathrm{g} \text { ) }\end{array}$} \\
\hline & & & & A1 & \multirow{2}{*}{$\begin{array}{l}\text { A2 } \\
\text { Moderat erhöht }\end{array}$} & \multirow{2}{*}{$\begin{array}{l}\text { A3 } \\
\text { Stark erhöht }\end{array}$} \\
\hline & & & & & & \\
\hline \multirow{6}{*}{$\begin{array}{l}\text { eGFR- } \\
\text { Kategorie } \\
\text { Glomeruläre } \\
\text { Filtrationsrate } \\
\left(\mathrm{ml} / \mathrm{min} / 1,73 \mathrm{~m}^{2}\right)\end{array}$} & G1 & Normal oder hoch & $\geq 90$ & 55,6 & 1,9 & 0,4 \\
\hline & G2 & Mild eingeschränkt & $60-89$ & 32,9 & 2,2 & 0,3 \\
\hline & G3a & $\begin{array}{l}\text { Mild / moderat } \\
\text { eingeschränkt }\end{array}$ & $45-59$ & 3,6 & 0,8 & 0,2 \\
\hline & G3b & $\begin{array}{l}\text { Moderat / schwer } \\
\text { eingeschränkt }\end{array}$ & $30-44$ & 1,0 & 0,4 & 0,2 \\
\hline & G4 & $\begin{array}{l}\text { Schwer } \\
\text { eingeschränkt }\end{array}$ & $15-29$ & 0,2 & 0,1 & 0,1 \\
\hline & G5 & Nierenversagen & $<15$ & 0,0 & 0,0 & 0,1 \\
\hline
\end{tabular}

Die Farbkodierung gibt das Risiko für das Vorliegen einer chronischen Niereninsuffizienz an: grün: niedriges Risiko, gelb: moderat erhöhtes Risiko, orange: hohes Risiko, rot: sehr hohes Risiko. Die aufgeführten Ziffern in den entsprechenden Feldern zeigen die prozentuale 
Verteilung der erwachsenen Bevölkerung der USA innerhalb dieser Gruppe. Vergleichbare Werte sind in Deutschland aktuell nicht verfügbar.

\subsubsection{Klinische Folgen der chronischen Niereninsuffizienz}

Häufig besteht bei Patienten mit chronischer Niereninsuffizienz eine lange Latenzphase der Beschwerdefreiheit. Erst bei bereits etablierter Niereneinschränkung im Stadium 4 (G4) der Niereninsuffizienz kommt es bei $42 \%$ der Patienten im Rahmen von Routineuntersuchungen zur Diagnosestellung (Coresh et al. 2007, Methven und MacGregor 2009). Typischerweise induziert die renale exkretorische Funktionseinschränkung nicht nur eine Störung des Volumen-, Elektrolyt- und Säure-Basen-Haushaltes mit einhergehnder Ödembildung, sondern auch eine Urämiesymptomatik. Diese ist bedingt durch fehlende Elimination harnpflichtiger Substanzen (z.B. Harnstoff-N, Polyamine, ß2-Mikroglobulin) sowie deren toxische Wirkung auf verschiedene Organe. Urämiesymptome sind vielfältig, gefürchtet sind vor allem die Entwicklung einer urämischen Perikarditis/Pleuritis sowie einer urämischen Enzephalopathie, die bis zum Koma führen kann (Vanholder et al. 2016). Darüber hinaus ist ebenfalls eine Abnahme der inkretorischen Nierenfunktion zu konstatieren. Aufgrund einer eingeschränkten Erythropoetinund Calcitriolsynthese kommt es sowohl zur Ausbildung einer renalen Anämie als auch konsekutiv, durch Entwicklung eines sekundären Hyperparathyreodismus, zur renalen Osteopathie (Keller und Geberth 2010, Vanholder et al. 2008). Die Mehrheit der Patienten mit terminaler Niereninsuffizienz versterben an kardiovaskulären Folgeerkrankungen zum einen bedingt durch koronare Herzerkrankungen bei Phosphat-und Kalziumablagerungen und zum anderen durch Herzrhythmusstörungen im Rahmen von Elektrolytstörungen, insbesondere Hyperkaliämien (Gao und Liu 2017).

\subsection{Definition der tubulointerstitiellen Fibrose}

Chronische Nierenerkrankungen, ungeachtet ihrer Genese, beruhen auf vergleichbaren Pathomechanismen, welche $\mathrm{zu}$ einer progredienten Destruktion des funktionellen Nierenparenchyms aufgrund von Vernarbungsprozessen (Fibrosierung) führen (Eddy 1996). Dieser als tubulointerstitelle Fibrose bezeichnete pathologische Vernarbungsprozess führt zu einer Zerstörung der physiologischen Organstruktur und zu einer erheblichen Einschränkung der Organfunktion (Risdon et al. 1968). Charakteristisch ist das kombinierte Auftreten einer tubulointerstitiellen Fibrose mit tubulärer Atrophie (IFTA), einer Glomerulosklerose sowie einer Rarefizierung peritubulärer Kapillaren (Bröcker et al. 2010, Boor et al. 2010, Eddy 2013). Das Ausmaß dieser Veränderungen hat einen signifikanten Einfluss auf die weitere Prognose der Nierenfunktion (Bohle et al. 1987). Der chronische Funktionsverlust von Organen wie Herz, Lunge, Leber, Knochenmark und Niere trägt geschätzt zu einem Drittel der natürlichen Todesfälle weltweit bei (Zeisberg und Kalluri 2013). 


\subsubsection{Pathogenese der Nierenfibrose}

Der Prozess der renalen Fibrogenese ist hochkomplex und wird durch multiple Einflussfaktoren bestimmt. Das Verständnis über die Pathomechanismen bei der Entstehung der Nierenfibrose ist jedoch essentiell für die Entwicklung von neuen therapeutischen Behandlungsverfahren.

Die Fibrogenese wird auch als „pathologische Wundheilung“ bezeichnet, da sie mit einer zunehmenden Akkumulation von extrazellulärer Matrix einhergeht (Bröcker et al. 2010). Sie entspricht der Gewebsantwort auf verschiedene Schädigungsreize, wie einer Hyperglykämie, Hypertonie oder Autoimmunreaktion. Die histologisch typischen Veränderungen der IFTA können als gemeinsame Endstrecke von pathogenetisch unterschiedlichen Nierenerkrankungen gesehen werden. Aufgrund der immanenten Schädigungsreize kommt es zu einem Ungleichgewicht zwischen pro- und antifibrotischen Zytokinen und der daraus resultierenden progressiven

Matrixakkumulation und reduzierten Matrixdegradation (Bröcker et al. 2010, Danobeitia et al. 2014). Im Rahmen der interstitiellen Fibrosierung erfolgt eine Akkumulation von extrazellulären Matrixproteinen und Kollagenen im Interstitium, insbesondere Kollagen-1 und -3. (Boor et al. 2010, Bröcker et al. 2010). Wohingegen bei der tubulären Atrophie drei Formen von strukturellen Veränderungen beobachtet werden können. Hierzu zählen: Verbreiterungen der tubulären Basalmembran, eine Abflachung des Tubulusepithels sowie eine Dilatation des Tubuluslumens mit PAS-positiven proteinhaltigen Detritus. Des Weiteren sind Schädigungen glomerulärer Strukturen zu beobachten, bedingt durch eine initiale kompensatorische Überfunktion, die über eine Aktivierung verschiedener Mediatoren (Prostaglandin, Angiotensin II und Wachstumsfaktoren) zu einer Glomerulosklerose beiträgt. Jedoch bleibt zu beachten, dass der Begriff "interstitielle Fibrose und Tubulusatrophie" (IFTA) keine Diagnose einer Krankheit darstellt, sondern nur eine Deskription des Krankheitsprozesses liefert (Müller et al. 2000, Bröcker et al. 2010, Zhou und Liu 2016).

\subsubsection{Myofibroblasten}

Aktivierte Fibroblasten (sog. Myofibroblasten) gelten als die wichtigste Effektorzelle in der Entwicklung der Nierenfibrose (Grupp und Müller 1999). Sie gehören neben den dendritischen Zellen und Makrophagen zu den tubulointerstitiellen Zellen der Niere (Müller et al. 1995, Roberts et al. 1997). Im gesunden Nierengewebe sind diese nur zu einem geringen Anteil präsent. Der relative Fibroblastenanteil wird nach Müller und Rodemann auf $7 \%$ geschätzt, wobei eine signifikante Zunahme in fibrotischen Nieren beschrieben wird. Hier lag der relative Fibroblastenanteil bei ca. 46\% (Müller und Rodemann 1991).

Fibroblasten sind ortsständige mesenchymale Zellen mit spindelförmiger Morphologie, die sich im fibrotischen Gewebe zu Myofibroblasten transdifferenzieren und sich durch eine gesteigerte Proliferationsfähigkeit mit erhöhter Synthese von extrazellulärer Matrix (ECM) auszeichnen 
(Strutz und Zeisberg 2006). Hierzu zählt unter anderem Fibronektin, Laminin und die Kollagene Typ 1, 3 und 5. Des Weiteren haben sie Einfluss auf die ECM-Homöostase durch die Synthese verschiedener Matrixmetalloproteinasen, die wiederum zu einer Degradation der extrazellulären Matrix führen (Gabbiani et al. 1971, Majno et al. 1971).

Charakteristisch für Myofibroblasten ist die de novo-Expression von alpha-Glattmuskelzellaktin (alpha-smooth muscle actin/ $\alpha-S M A)$, welches den Zellen kontraktile Eigenschaften verleiht und unter physiologischen Bedingungen in Form von "Tissue-Remodelling“ zum Wundverschluss führt (Tang et al. 1997, Vaughan et al. 2000, Tomasek et al. 2002, Cook 2010). Im gesunden Nierengewebe wird a-SMA in der Regel nicht von interstitiellen Fibroblasten exprimiert (Alpers et al. 1994, Clayton et al. 1997, Ina et al. 2002). Während der Aktivierung und Transition zu Myofibroblasten kommt es dagegen neben der de novo-Expression von a-SMA auch zu einer Phänotyp-Veränderung mit einer ausgeprägten Heterogenität (Strutz und Müller 2006).

Der Ursprung aktivierter, ECM-produzierender Myofibroblasten ist noch nicht vollständig geklärt. Es ist ein komplexer Prozess, der von mehreren Einflussfaktoren bestimmt wird. Zum einen können Myofibroblasten durch Aktivierung und nachfolgende Proliferation residenter Fibroblasten entstehen (Strutz und Zeisberg 2006). Diese Aktivierung residenter Fibroblasten und deren proliferative Expansion stellt nach heutiger Auffassung den zentralen Mechanismus bei renaler Fibrogenese dar (LeBleu et al. 2013). Andere Hypothesen beziehen sich auf die Aktivierung hämatopoetischer oder mesenchymaler Stammzellen des Knochenmarks. CD-4+TLymphozyten, welche die Einwanderung von Monozyten und Makrophagen beeinflussen, vermitteln ferner die Differenzierung von Monozyten zu Kollagen-produzierenden Fibrozyten (Liu 2011). Im gesunden Nierengewebe von Mäusen wird der Anteil von knochenmarksabgeleiteten Fibroblasten auf 12\% vermutet (Strutz und Müller 2006, LeBleu et al. 2013).

\subsubsection{Therapieoptionen bei chronisch progredienter Niereninsuffizienz}

Die tubulointerstitielle Fibrosierung der Niere ist das gemeinsame Korrelat von chronischen Nierenerkrankungen. Zurzeit besteht die Therapie von CKD-Patienten jedoch vor allem aus der Behandlung bzw. Prävention von Begleiterkrankungen oder kardiovaskulären Risikofaktoren, wie Hypertonus oder Diabetes.

Zu den ersten Maßnahmen gehört die Beseitigung von reversiblen Risikofaktoren. Hierzu zählt zum einen sowohl die Vermeidung von nephrotoxischen Substanzen, beispielsweise nichtsteroidale Antiphlogistika, Lithium oder Kontrastmitteln als auch die Vermeidung von Infektionen, die besonders bei immunsupprimierten Patienten nach einer Transplantation lebensbedrohlich werden können. Ein weiterer Aspekt ist die Progressionshemmung mit diätetischer Reduktion von tierischem Eiweiß auf $<0,8 \mathrm{~g} / \mathrm{kg} \mathrm{KG} /$ Tag aufgrund der toxischen Wirkung einer Hyperproteinämie auf das Tubulusepithel und die Senkung von Serum- 
Cholesterol, welches vor allem bei einer fortgeschrittenen Proteinurie ansteigt. Als Proterinurie wird die Menge an ausgeschiedenem Albumin im 24-Stunden-Sammelurin bezeichnet. Hierbei erfolgt eine Unterscheidung zwischen Mikroalbuminurie (30-300 mg Albumin/24h) und Makroalbuminurie (>300 mg Albumin/24h). Darüber hinaus ist die Behandlung von renalen Begleiterkrankungen wie der normochromen, normozytären Anämie, der renalen Osteoporose sowie einer oftmals apparenten metabolischen Azidose ein wichtiger Therapieaspekt. Ferner zählen zu den Therapieempfehlungen eine adäquate Blutdruckeinstellung auf 130/80 mm um kardiovaskuläre Risikofaktoren zu minimieren (KDIGO CKD Work Group 2013).

Nur wenige Medikamente sind für die direkte antifibrotische Behandlung von Nierenerkrankungen zugelassen und zielen auf die Blockade des intrarenalen ReninAngiotensin-Aldosteron-Systems (RAAS) ab. Zur First-Line-Therapie bei CKD-Patienten gehören die direkten Renin-Antagonisten, Angiotensin Converting Enzyme-Inhibitoren (ACEHemmer) sowie Angiotensin-II-Rezeptor-Blocker (AT1-Blocker) (Siragy und Carey 2010). Neben einer blutdrucksenkenden Wirkung zeigen diese Medikamentengruppen auch nephroprotektive Eigenschaften durch Senkung des glomerulären Filtrationsdrucks und konsekutive Abnahme der Proteinurie (Wenzel und Wolf 2005).

Oftmals gelingt es nicht, die Progression der chronischen Nierenfunktionseinschränkung trotz Optimierung von Risikofaktoren gänzlich aufzuhalten. Die Folge ist der häufige Übergang in eine terminale Niereninsuffizienz mit Notwendigkeit einer Nierenersatztherapie.

\section{$1.4 \quad$ TGF- $\beta$-Superfamilie}

\subsubsection{Transforming Growth Factor- $\beta 1$ (TGF- $\beta 1$ )}

Die Superfamilie der transforming growth factors (TGFs) gehören zur Gruppe multifunktioneller Zytokine und sind strukturverwandte, zellregulatorische Proteine, die eine wichtige Rolle in der Embryogenese durch Induktion der Zelldifferenzierung haben (Massagué 1990, Ducy und Karsenty 2000, Chang et al. 2002). Aber auch beim Adulten haben sie essentielle Bedeutungen durch die Beteiligung an Reparaturmechanismen von Geweben, Zellzykluskontrolle, Migration, Angiogenese sowie Immunreaktionen (Chang et al. 2002, Ducy und Karsenty 2000, Herpin et al. 2004, Li et al. 2006, Maeshima und Makino 2010). Roberts et al. beschrieben 1980 bereits die wachstumsstimulierende Funktion von TGFs in murinen Fibroblasten (Roberts et al. 1980, Kondo et al. 2004). Die TGF-ß-Superfamilie umfasst die Transforming Growth Factors (TGFs), Activine und Inhibine, Müllerian Inhibiting Substance (MIS), Bone Morphogenic Proteins (BMPs), Nodal, Growth Diffrentiation Factors (GDFs) und Lefty (Zhao 2003). Jedoch ist eine genaue Unterteilung schwer, da immer mehr Subfamilien beschrieben werden (Shi und Massagué 2003, Gordon und Blobe 2008).

Das erste isolierte Mitglied der TGF-ß-Superfamilie ist der Transforming Growth Factor-ß1 (TGF- $\beta 1$ ). Dieser wird als das wichtigste profibrotische Zytokin im Prozess der renalen tubulointerstitiellen Fibrose angesehen. Auch in anderen Organen, wie Leber, Lunge, 
Knochenmark, Haut oder Myokard wird er als Hauptmediator der Organfibrose bezeichnet. Eine Überexpression von TGF-ß1 führt zu einer gesteigerten Synthese sowie zu einem reduzierten Abbau extrazellulärer Matrix und einer Suppression der Immunantwort (Attisano und Wrana 2002).

Es werden in Säugetieren drei Isoformen unterschieden: TGF- $\beta 1,-\beta 2$ und - $\beta 3$. Diese sind hoch konserviert und zeigen ähnliche Wirkungen (Cheifetz et al. 1990, Border et al. 1992). TGF- $\beta 1$ ist ein ubiquitär vorkommendes, multifunktionelles Homodimer mit einer Größe von 25 kDa und wird überwiegend im Endothel, in Bindegewebszellen (Fibroblasten) und hämatopoetischen Zellen exprimiert. TGF-ß2 hingegen wird vornehmlich in Neuronen sowie im Epithel produziert und TGF- $\beta 3$ in mesenchymalen Zellen. TGF- $\beta 1$ wird in vivo von Zellen in dessen latenter Form sezerniert und bedarf einer extrazellulären Aktivierung des TGF- $\beta 1$-Homodimers. Endoproteinasen, wie Plasmin, Cathepsin G, Thrombospondin oder Integrin führen zu einer Abspaltung der aktiven Form vom Propeptid, welches als Latency Associated Protein (LAP) bezeichnet wird (Piek et al. 1999, Annes et al. 2004).

\subsubsection{TGF-beta-Rezeptor-Signalkaskade}

Die Mitglieder der TGF-ß-Superfamilie vermitteln ihre pleiotrope Wirkung über drei verschiedene Typen von TGF-ß-Rezeptoren. Typ I und II sind transmembranständige SerinThreonin-Kinase-Rezeptoren und direkt an der intrazellulären Signaltransduktion von Zellmembran zum Nucleus beteiligt (Piek et al. 1999). Der TGF-ß-Rezeptor Typ III hat keine intrazelluläre Signalfunktion, er besteht aus transmembranständigen Proteinen, Betaglykanen und Endoglin (Piek et al. 1999, Akhurst und Hata 2012).

Nach der Bindung von TGF-ß1 an deren korrespondierenden Typ II Rezeptor kommt es zur Rekrutierung des Typ I-Rezeptors in einem heterotetrameren Komplex, zur Transphosphorylierung seiner Serin- und Threonin-Residuen und resultierender Aktivierung der intrazellulären TGF- $\beta$-Signalkaskade (Heldin et al. 1997, Rahimi und Leof 2007). 


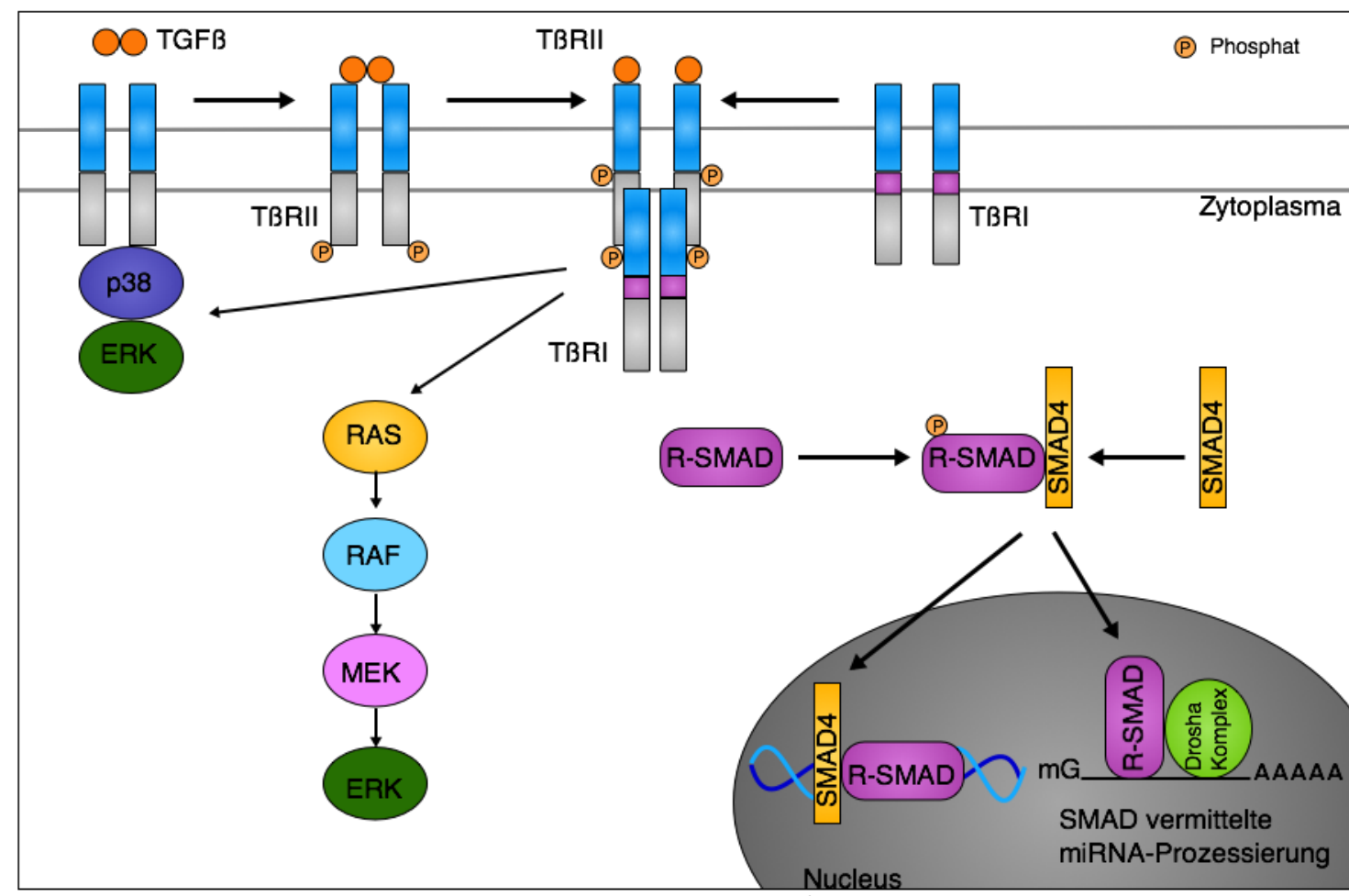

Abbildung 2: TGF-ß1 Signalkaskade. Der aktivierte TGF- $\beta$-Rezeptor-Komplex III vermittelt seine Signaltransduktion über multiple Mechanismen. Nach Phosphorylierung und konsekutiver Aktivierung der SMAD-Proteine kommt es zur Beeinflussung der Genexpression (modifiziert nach Akhurst und Hata 2012).

Diese besteht aus einer Phosphorylierung und damit Aktivierung der intrazellulären SMADSignalkaskade. Es können drei Gruppen an SMAD-Proteinen unterschieden werden. Zum einen gibt es die R-SMADs, hierzu zählen SMAD 2 und 3, welche direkt vom TGF-ß-Rezeptor Typ I phosphoryliert werden und mit SMAD 4 einen heteromeren Komplex bilden (Rahimi und Leof 2007). Sie werden als Rezeptor-regulierte SMAD-Proteine bezeichnet (Heldin et al. 1997, Attisano und Wrana 2002, Shi und Massagué 2003). SMAD 4 ist ein Co-SMAD, welches nach einer Heterodimer-Bildung mit R-SMADs in den Zellkern transloziert und dort an der DNA als Transkriptionsfaktor die Genexpression beeinflusst (Yamashita et al. 1994). Auf diese Weise kommt es zu einer Vielzahl an zellulären Wirkungen, wie beispielsweise der Aktivierung residenter Fibroblasten in der Niere mit konsekutiv gesteigerter Synthese extrazellulärer Matrix, Induktion von epithelial-mesenchymaler Transition (EMT) und Apoptose in Tubulusepithelzellen (Heino et al. 1989, Strutz und Müller 2006, Zeisberg und Kalluri 2013). Zudem sind noch sogenannte inhibitorische SMADs (SMAD 6 und 7) beschrieben, welche durch Bindung an den Typ-I-Rezeptor die Phosphorylierung der R-SMADs unterbinden (Border et al. 1990, Feng und Derynck 1997, Massagué und Chen 2000, Shi und Massagué 2003). 


\subsection{Relaxin}

\subsubsection{Geschichte}

Das Peptidhormon Relaxin wurde 1930 von Dr. Frederick Hisaw während seiner Studien im Feld der reproduktiven Endokrinologie entdeckt und benannt (Bathgate et al. 2013). Es wurde vornehmlich als zentrales Schwangerschaftshormon bekannt, da es perinatal die Eigenschaften besitzt, eine Verlängerung des Ligamentum pubicum zu vermitteln, zu einer Weitung des Geburtskanals zu führen, die spontanen Kontraktionen des Myometriums zu hemmen sowie das Wachstum und die Differenzierung der Brustdrüsen zu beeinflussen (Fevold et al. 1930).

Hisaw konnte 1926 durch eine Seruminjektion von einem schwangeren Meerschweinchen in ein nicht-schwangeres weibliches Tier zeigen, dass Relaxin bei dem mit Serum behandelten Meerschweinchen ebenfalls zu einer Verlängerung des Ligamentum pubicum und einer Weitung des Symphysenspaltes führte (Hisaw 1929, Kibblewhite D et al. 1992, Bathgate et al. 2013).

Obwohl die Mehrheit der Relaxinisoformen im Zusammenhang mit Reproduktionsmechanismen entdeckt wurde, steht heutzutage vornehmlich die Wirkung auf andere, nicht-reproduktive Zielgewebe im Vordergrund. Relaxin verfügt über zentralnervöse, vaskuläre, renale und kardiale Effekte, welche aufgrund der antifibrotischen Eigenschaften ein außerordentlich großes therapeutisches Potential bergen (Dschietzig et al. 2001, Hudson et al. 1983, Bogzil et al. 2005, Danielson et al. 2006, Nistri et al. 2007, Hewitson et al. 2007,Teichman et al. 2010, Cernaro et al. 2014, Kang et al. 2014).

\subsubsection{Aufbau und Synthese des Peptidhormons Relaxin}

Relaxin ist ein 6,3 kDa großes Peptidhormon, welches zur Hormongruppe der Relaxin Family Peptides gehört, welche einen Teil der Insulin-Superfamilie darstellen (Bani 1997). Zu diesen strukturverwandten Hormonen zählen unter anderem: Insulin, IGF-1, IGF-2, Relaxin-1, Relaxin2, Relaxin-3, Leydig cell insulin-like (INSL3) und early insulin-like (INSL4/5/6)-Peptide (Blundell und Humbel 1980, Sherwood 2004, Bathgate et al. 2006). Trotz ihrer großen Ähnlichkeit im strukturellen Aufbau und Bindungsverhalten mit Insulin besitzen die Relaxin-Peptide ihre eigenen Rezeptoren und üben unterschiedliche Wirkungen im Organismus aus.

Relaxin wird als Präprohormon durch den Prozess der posttranslationellen Prozessierung synthetisiert und muss vor Erlangen seiner Wirkung aktiviert werden (Bryant-Greenwood und Schwabe 1994). Das Prä-Pro-Relaxin besteht aus dem Signalpeptid, einer A-, B-Kette sowie dem C-Peptid. Charakteristisch sind die A- und B-Kette über zwei Disulfidbrücken verbunden. Eine weitere Disulfidbrücke ist innerhalb der A-Kette gelegen. Nach Abspaltung des Signalpeptides entsteht das sogenannte Pro-Relaxin, welches bereits über eine vergleichbare Bioaktivität wie das reife Relaxin verfügt (Bryant-Greenwood und Schwabe 1994). 


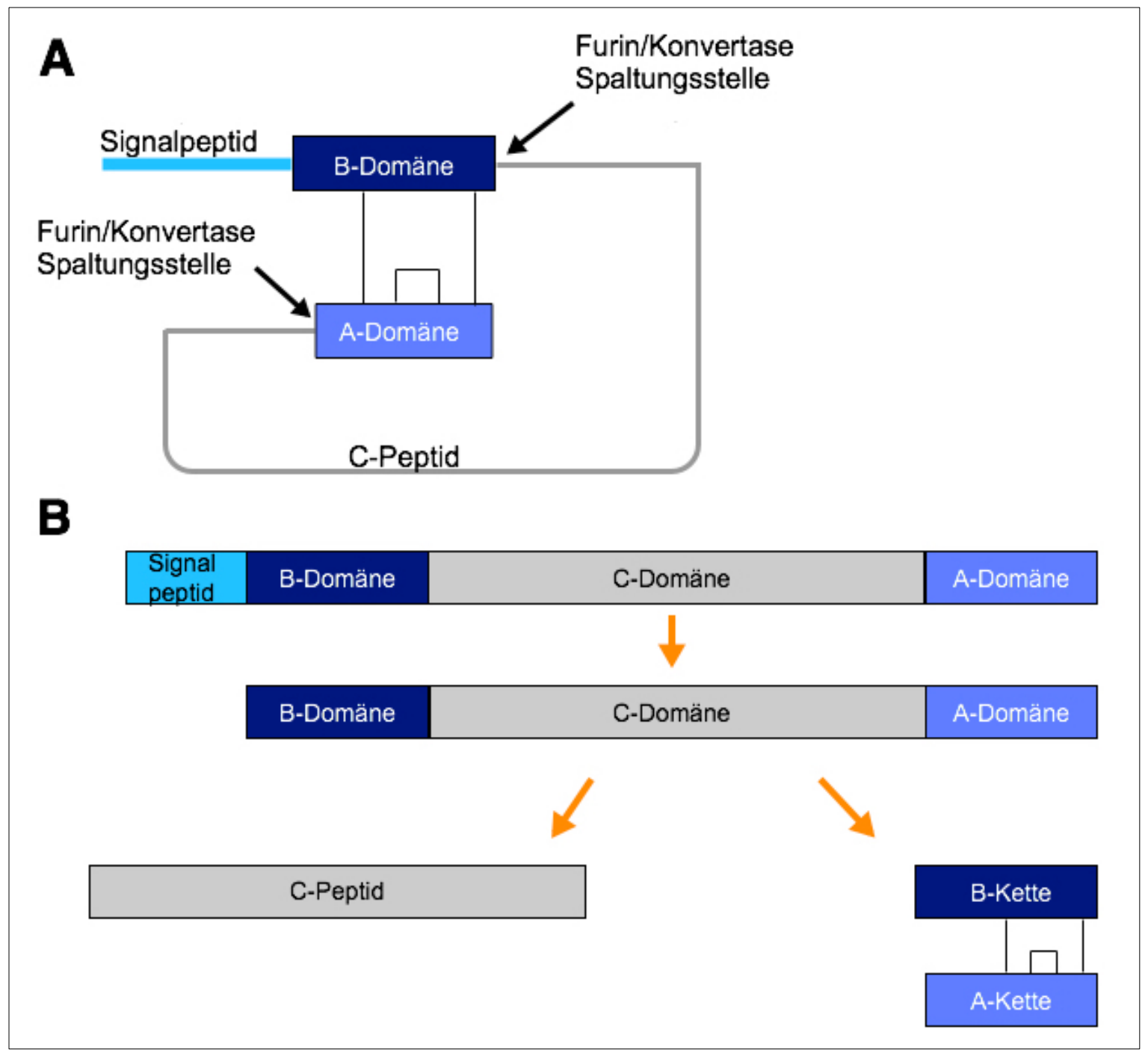

Abbildung 3: Struktur des Peptidhormons Relaxin. (A) Darstellung des Präprohormons charakterisiert durch die Drei-Domänenstruktur sowie den Disulfidbrücken innerhalb und zwischen den Domänen. (B) Intrazelluläre enzymatische Prozessierung des Prä-Pro- zu Pro-Relaxin und schließlich zum reifen heterodimeren Relaxin (modifiziert nach Ivell et al. 2011).

Abgeleitet von der Prozessierung des Prohormons Insulin wird vermutet, dass für die weitere Synthese von Relaxin die Prohormon-Konvertase PC-1 verantwortlich ist. Durch die Abspaltung des C-Peptides entsteht das reife Relaxin (Marriott et al. 1992). Die B-Kette vermittelt hauptsächlich die primäre Interaktion mit dem Rezeptor. Damit es allerdings zu einer suffizienten Bindung kommen kann, muss die dreidimensionale Konformation des Hormons durch die A-Kette aufrechterhalten werden (Bathgate et al. 2006, Hossain et al. 2011).

Der Homologiegrad zwischen Relaxin und Insulin liegt bei ca. 25\%. Dies betrifft vornehmlich die sechs Cystein-Residuen, welche an der Bildung der bei beiden Hormonen identischen Disulfidbrücken beteiligt sind (Eigenbrot et al. 1991).

Innerhalb der unterschiedlichen Säugerspezies zeigen die Relaxin-Peptide eine erkennbare Heterogenität in der Aminosäuresequenz, allerdings bewahren fast alle ein hoch konserviertes 
RXXXRXXI/V-Motiv ( $R=$ Arginin) in der B-Kette, welches essentiell für die Bioaktivität und Rezeptorbindung von Relaxin ist (Bathgate et al. 2013).

\subsubsection{Expression und Sekretion von Relaxin-Peptiden im Menschen und in Mäusen}

Gen-Isoformen

Beim Menschen sind 3 Isoformen von Relaxin bekannt: Relaxin- $\mathrm{H} 1,-\mathrm{H} 2,-\mathrm{H} 3$, welche von jeweils drei Relaxingenen kodiert werden (RLN1, RLN2, RLN3). Das Vorkommen von Relaxin$\mathrm{H} 2$ beschränkt sich hierbei auf den Menschen sowie den Menschenaffen und entspricht in anderen Säugetieren dem Relaxin-1. Relaxin-H1 und - $\mathrm{H} 2$ konnten auf dem kurzen Arm von Chromosom 9 (9p24) lokalisiert werden, wohingegen Relaxin-H3 auf Chromosom 19 liegt (Hudson et al. 1983). Serelaxin (RLX030, Novartis) ist das rekombinante Analogon des humanen Relaxin-H2, welches derzeit die einzig bekannte zirkulierende Form von Relaxin im Plasma ist (Bani 1997, Bathgate et al. 2006).

Tabelle 2: Vorkommen von Relaxin und seinen Rezeptoren im humanen und murinen Nieren (modifiziert nach Bathgate et al. 2013)

\begin{tabular}{llll}
\hline Human & \multicolumn{3}{l}{ Murin } \\
\hline \hline Gen-ID & Niere & Gen-ID & Niere \\
\hline RLN1 & x & & \\
\hline RLN2 & x & RIn1 & x \\
\hline RLN3 & x & RIn3 & x \\
RXFP1 & x & Rxfp1 & x \\
\hline RXFP2 & x & Rxfp2 & x \\
\hline RXFP3 & - & Rxfp3 & - \\
\hline RXFP4 & x & Rxfp4 & - \\
\hline
\end{tabular}

\subsubsection{Aktivierung der Signal-Transduktions-Wege durch Relaxin-Peptide}

Serelaxin vermittelt seine pleiotropen Effekte über membranständige, sieben-transmembranöse G-Protein-gekoppelte Rezeptoren, welche früher auch als leucine-rich repeat-containing Gprotein-coupled receptors (LGRs) bezeichnet wurden. Sie besitzen ein Molekulargewicht zwischen 60 und $80 \mathrm{kDa}$ und bestehen aus ca. 400-500 Aminosäuren. Intrazellulär befindet sich das C-terminale Ende, welches über die sieben-transmembranöse Domäne mit dem extrazellulär gelegenen $\mathrm{N}$-Terminus verbunden ist (lyengar 1993). Es sind vier RelaxinRezeptoren bekannt, die in zwei Gruppen gemäß ihrem Aufbau und Signaltransduktion unterteilt werden können: 2002 wurden RXFP1 (LGR7) und RXFP2 (LGR8) von Hsu et al. identifiziert. Sie führen über eine Gs-Protein-Kopplung zur Aktivierung der Adenylatcyclase. Die 
Rezeptoren RXFP3 (GPCR 135) und RXFP4 (GPCR 142) sind hingegen mit kleinen Peptidrezeptoren assoziiert und führen über ein Gi-Protein zur Hemmung der Adenylatzyklase. RXFP3 kann zudem eine Aktivierung von extracellular-signaling-regulated-kinase 1 und 2 (Erk1/2) bewirken (Bathgate et al. 2006, Huang et al. 2015). Der RXFP1 stellt die Bindungsstelle für Relaxin- $\mathrm{H} 1$ und $-\mathrm{H} 2$ bereit, RXFP2 für INSL3, Relaxin- $\mathrm{H} 1$ und $-\mathrm{H} 2, R X F P 3$ für Relaxin-H3 und RXFP4 für INSL5 und Relaxin-H3 (Bathgate et al. 2006).

Die renoprotektive Wirkung von Serelaxin (RLX030) wird insbesondere über RXFP1 vermittelt, somit stellt das Vorhandensein von RXFP1 eine essentielle Komponente für die therapeutische Wirksamkeit von Serelaxin dar. Nach der Bindung von Serelaxin an RXFP1 kommt es durch nachfolgende Aktivierung der Adenylatzyklase zu einer intrazellulären Erhöhung des cyclischen Adenosinmonophosphats (cAMP). Charakteristisch ist eine biphasische Erhöhung: Nach einem initial schnellen Anstieg der CAMP-Konzentration und einer leichten Abnahme sind konstant hohe cAMP-Spiegel zu beobachten (Bathgate et al. 2013, Chow et al. 2014). Dies ist ein atypischer Verlauf, bei allen anderen G-Protein-gekoppelten-Rezeptoren wird durch die erhöhte cAMP-Konzentration die Phosphodiesterase PDE4 aktiviert. Diese führt zum Abbau und Konzentrationsabnahme von cAMP. Konstant hohe cAMP-Spiegel haben vielfältige physiologische Wirkungen. Zum einen fördern sie über eine gesteigerte VEGF-Expression die Angiogenese. Zum anderen führen sie zu einer Dezidualisierung und Differenzierung des Myometriums während der Schwangerschaft. Wie aus Abbildung 4 ersichtlich, sind die molekularen Transduktionswege von RXFP1 sehr vielfältig. Zu den antifibrotisch relevanten Wirkungen zählt vor allem die gesteigerte Expression von Stickstoffmonoxid (NO). Es werden drei verschiedene Mechanismen unterschieden, die sich zudem von Zelltyp zu Zelltyp unterscheiden können. Die epitheliale NOS (eNOS)-Aktivierung erfolgt über den Signalweg GalProtein, PI3-K und Akt. Wohingegen die iNOS über die Proteinkinase A (PKA), eine nachfolgenden Inaktivierung von $\mathrm{I} \kappa \mathrm{B}$ und anschließende Aktivierung von NF- $\kappa B$ stimuliert wird. NO führt über eine cGMP-Erhöhung zur Phosphorylierungshemmung von SMAD2/3 in der TGFß1-Transduktionskaskade sowie zu einer Stimulation der Matrix-degradierenden Metalloproteinasen MMP-1, -2, -9 und -13 (el Nahas et al. 1991). 


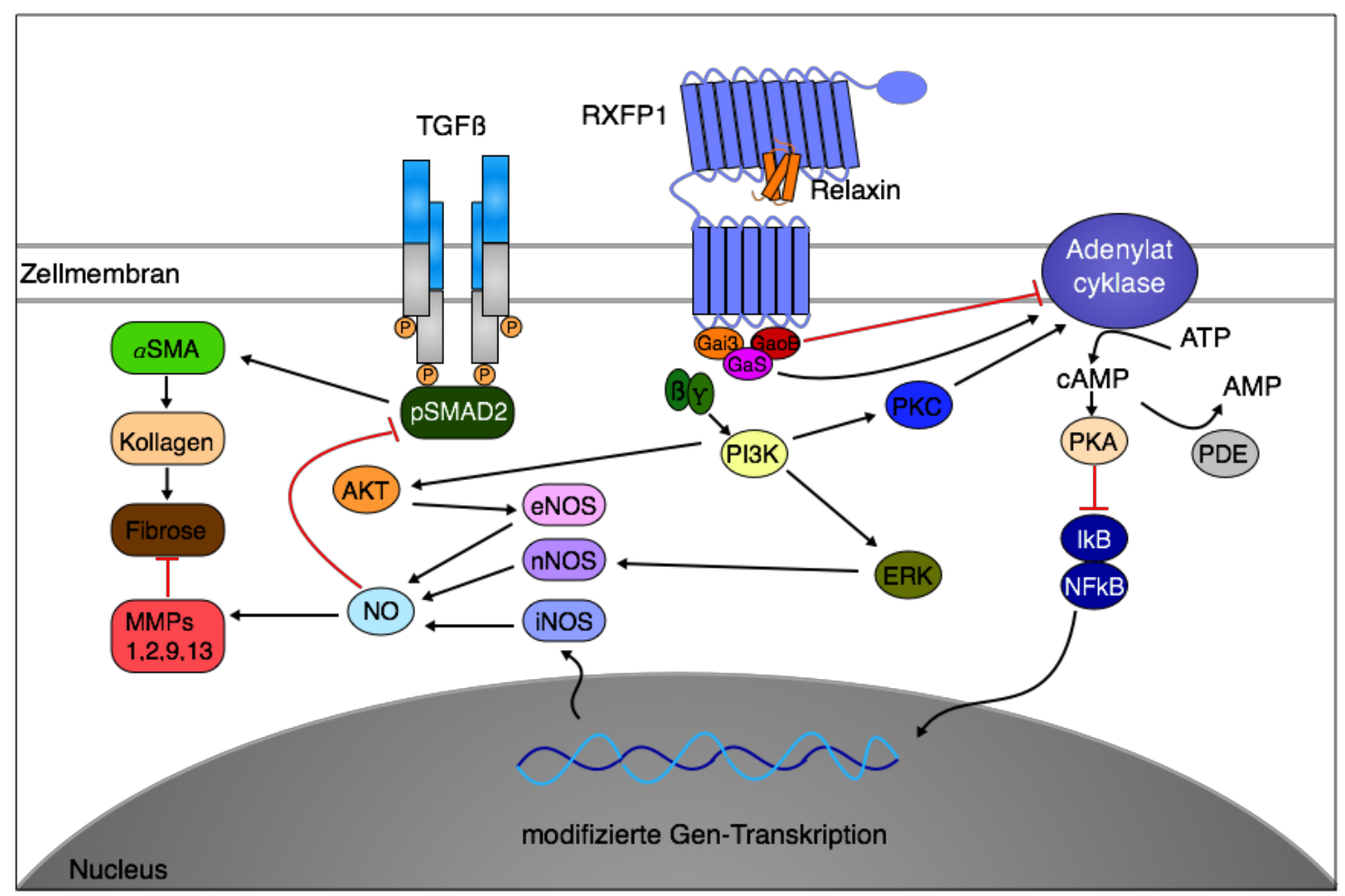

Abbildung 4: Signaltransduktion von RXFP1 vermittelt durch Relaxin. Die antifibrotische Wirkung von Relaxin wird über den RXFP1 vermittelt, der zu einer Induktion der Expression von eNOS, nNOS, iNOS und einer anschließend erhöhten Synthese von NO führt. NO verstärkt die Expression der MMPs, die zu einer Reduktion von Fibrose beitragen. Zudem kommt es zu einer Inhibition von pSMAD2 und damit einer direkten Hemmung der TGF-ß-Signalkaskade (modifiziert nach Bathgate et al. 2013).

\subsection{Definition der Epigenetik}

Die Ursprungsdefinition der Epigenetik ist auf Conrad Waddington zurückzuführen, der 1942 den Begriff prägte als „Zweig der Biologie, der die kausalen Wechselwirkungen zwischen Genen und ihren Produkten untersucht, welche den Phänotyp hervorbringen" (Waddington 1968, Dupont et al. 2009). Heutzutage wird eine explizitere Definition verwendet, hierbei untersucht die Epigenetik Vorgänge, die zu einer vererbbaren Aktivitätsänderung von Genen führten, ohne dabei die ursprüngliche DNA-Sequenz zu verändern. Zielstrukturen sind die Chromosomen, die durch DNA-Methylierung, Modifikation der Histone oder posttranskriptionelle Prozesse verändert werden. Epigenetische Regulationsmechanismen sind in viele unterschiedliche Prozesse involviert. Hier ist beispielsweise die X-chromosomale Inaktivierung in weiblichen Zellkernen oder auch das genomische Imprinting von maternalen und paternalen Genen zu nennen. Darüber hinaus beeinflusst epigenetische Modifikation das Immunabwehrsystem durch chemische

Modifikation von DNA und Histonproteinen (Bird 2002, Herman und Baylin 2003, Weinhold 2006). 


\subsection{DNA-Methylierung}

Ein zentraler Mechanismus für die epigenetische Alteration von genomischer DNA ist die DNAMethylierung von "CpG-Inseln" in spezifischen Promotorregionen von Genen. Bei dem Prozess der DNA-Methylierung wird das Nukleotid Cytosin in der palindromischen Nukleotidabfolge des Cytosin-Phosphat-Guanin-Dinukleotids $(\mathrm{CpG})$ an der C5-Position durch entsprechende DNAMethyltransferasen (DNMTs) auf beiden DNA-Strängen symmetrisch methyliert. Als Methylgruppendonor wird S-Adenosyl-L-Methionin (SAM) verwendet, welches nach der Übertragung der Methylgruppe als S-Adenosyl-Homocystein (SAH) vorliegt (Herman und Baylin 2003). Etwa $60-80 \%$ der Cytosin-Phosphat-Guanin-Dinukleotide (CpG) liegen methyliert vor. Allerdings ist die CpG-Dinukleotid Frequenz im menschlichen Genom mit 3-4\% relativ gering (Weber et al. 2007). Dies ist bedingt durch eine spontane hydrolytische Desaminierung von 5Methylcytosin, welche vom DNA-Reparatursystem nicht erkannt wird und es im Folgenden zur Transition nach Thymin kommt (Rideout et al. 1990). Das 5'-Ende von Genen im Bereich von Promotorregionen weist eine erhöhte Dichte von CpG Dinukleotiden auf, die als sogenannte CpG-Inseln bezeichnet werden (Laird und Jaenisch 1994). CpG-Inseln sind kurze Regionen von ca. 0,5-4kb Länge, die während der Evolution stark konserviert sind und eine hohe Dichte an CpG-Dinukleotiden (mindestens 55\%) aufweisen (Takai und Jones 2003). Jedoch liegt nur ein geringer Prozentsatz der CpG-Inseln in methylierter Form vor und führt zu einer stabilen Repression des assoziierten Gens (Holliday und Pugh 1975, Riggs 1975). Der weitaus größere Anteil der CpG-Inseln befindet sich im unmethylierten Zustand und ermöglicht die Expression des entsprechenden Gens. Promotoren, die eine geringe CpG-Dichte aufweisen sind jedoch oft methyliert. Beachtenswert sind Regionen um den Transkriptionsstart, die eine inverse Korrelation zwischen DNA-Methylierung und transkriptioneller Aktiviät aufweisen (Meissner et al. 2008). Folglich kann eine Hypermethylierung von DNA meist mit einer Repression der Genexpression verbunden sein, während eine Hypomethylierung zur transkriptionellen Aktivität führt (Klose und Bird 2006). Die beschriebene Transkriptionshemmung wird durch sogenannte Repressorproteine, die mittels konservierter Methyl-CpG-Bindungsdomäne spezifisch an methylierte CpGs binden, vermittelt. Hierzu gehören MeCP1 und MeCP2 als auch MethylCytosin-Bindungsproteine MBD1, 2 und 3, welche mit Chomatin-Remodelierungs-Komplexen wechselwirken (Jones und Baylin 2002). 


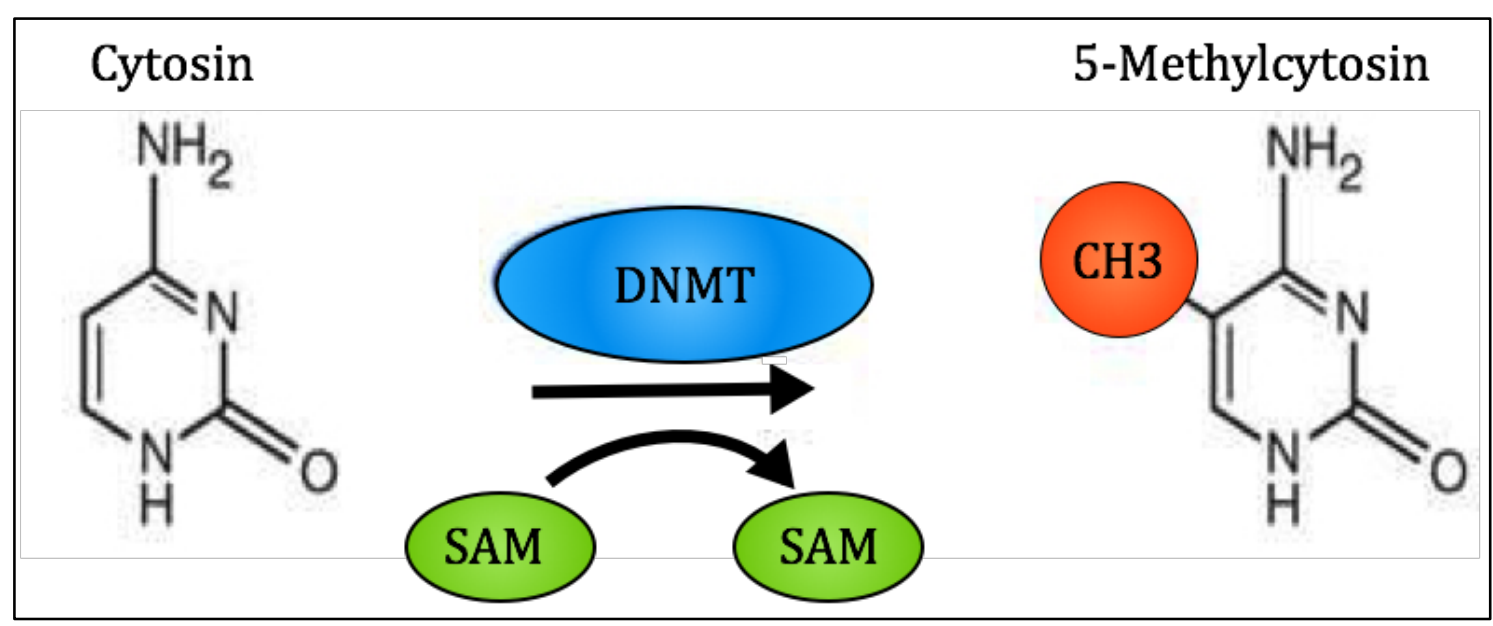

Abbildung 5: DNA-Methylierung. Methyltransferasen (DNMT) katalysieren die Methylierung des Cytosins an seiner C5-Position. Als Methylgruppendonor wird S-Adenosyl-L-Methionin (SAM) verwendet. Nach der Übertragung entsteht S-Adenosyl-Homocystein (SAH) (modifiziert nach Day und Sweatt 2010).

Die Relevanz der abarrenten Methylierung von CpG-Promotor-Inseln wurde zuerst am Beispiel der Krebsentstehung deutlich. Hier führte die DNA-Hypermethylierung zur transkriptionellen Inaktivierung spezifischer Tumorsuppressorgene (Mikeska und Craig 2014, Zeisberg und Zeisberg 2013). Tampe et al. 2015 eruierten in jüngeren Studien zudem einen weiteren Einflussbereich epigenetischer Modifikation. Hierbei handelte es sich um den Zusammenhang zwischen DNA-Hypermethylierung und der Fibroblastenaktivierung in fibrotisch destruierten Nieren (Bechtel et al. 2010).

\subsection{Zielsetzung der vorliegenden Arbeit}

Die Progression chronischer Nierenerkrankungen (CKD) mit dem histopathologischen Korrelat der tubulointerstitiellen Fibrose ist ein ungelöstes Problem in der klinischen Nephrologie. Klinische Studien über den Fibroseverlauf und weiterführende therapeutische Behandlungsmethoden sind komplex und schwer umsetzbar. Dies ist zurückzuführen auf die Rarität von adäquaten Biomarkern zur Therapiestratifizierung und Kontrolle der Krankheitsprogression. In tierexperimentellen Arbeiten konnte gezeigt werden, dass die Depletion von Relaxin-1 in Mäusen zu einer Exazerbation der Nierenfibrose führt (Samuel et al. 2003). Dagegen konnte in präklinischen Studien gezeigt werden, dass das rekombinante Analogon des humanen Relaxin-H2, Serelaxin (RLX030, Novartis) vielversprechende Effekte in Modellen des chronischen Nierenschadens vermittelt. Über die Regulation der Relaxinisoformen bei renalen Erkrankungen ist bislang nur wenig bekannt. Bechtel et al. 2010 demonstrierten, dass epigenetische Mechanismen der Promotormethylierung von spezifischen Genen zur Progression der Fibrogenese beitragen (Bechtel et al. 2010). Zudem konnte gezeigt werden, dass eine Hypermethylierung von entsprechenden Genen im fibrotischen Gewebe der 
Niere mit dem Grad der Fibrose korreliert (Tampe et al. 2015). Abschließend wurde ebenfalls konstatiert, dass methylierte DNA-Fragmente aus der Niere freigesetzt werden und im peripheren Blut von nierenkranken Patienten das Ausmaß der Promotermethylierung in der Niere reflektieren (Tampe et al. 2015).

Basierend auf diesen Erkenntnissen entwickelte sich die hypothetische Annahme, dass die Unterdrückung der endogenen Relaxin-Signaltransduktion mittels Hypermethylierung der Relaxingene (RLN1, RLN2, RLN3) zur Exazerbation der Fibrogenese beiträgt. Ziel dieser Arbeit war es daher, den Einfluss von rekombinantem Serelaxin (RLX030) auf die Inhibition der renalen Fibrogenese zu determinieren und zugrundeliegende Singaltransduktionswege näher zu untersuchen. Auf folgenden Fragestellungen lag in dieser Arbeit der Fokus:

a) Wie sind Relaxin-Rezeptoren bei Nierenfibrose als Voraussetzung für die Wirksamkeit von RLX030 reguliert?

b) Führt die dosisabhängige Applikation von RLX030 zu einer effektiven Abschwächung renaler Fibrosierung im Mausmodell der Nierenfibrose?

c) Unterliegt der Verlust von Relaxin in der Niere epigenetischen Regulationsmechanismen?

d) Lassen sich im Serum von nierenkranken Patienten zirkulierende Promotorfragmente aus der Niere detektieren und als Biomarker nutzen, um Patienten zu identifizieren, welche aufgrund eines Mangels von intrarenalem Relaxin von RLX030 profitieren könnten? 


\section{Material}

\section{$2.1 \quad$ Geräte}

Analysewaage, $1213 \mathrm{MP}$

Ausgießstation Leica EG 1120H

Autoklav

The Belly Dancer-Stovall

BRAUN Dampfgarer 3216

CO2 Incubators Heracell ${ }^{\mathrm{TM}}$ VIOS 160i

ChemiDoc $^{\mathrm{TM}}$ MP System

Eismaschine AF80

Fastblot ${ }^{\mathrm{TM}} \mathrm{B} 44$

Fluoreszenzkamera ColorView

Gefrierschrank Premium NoFrost

Gewebeinfiltrationsautomat Leica TP1020

Heizblock TR-L288

Kühlschrank

Kühlzentrifuge 3-18KS

Kühlzentrifuge, Mikroliterzentrifuge R5424

Magnetrührer (beheizbar), IKAMAG RCT

Mikroskop Axiovert S100 TV

Mikrotom Leica RM 2165

NanoDrop $^{\text {TM }}$ 2000; Spektralphotometer

Paraffinstreckbad GFL 1052

Pipettierhilfe pipetus $\mathbb{R}$

Plattformschüttler Rotamax 120

Rollermixer SRT6

Spannungsgerät MS 300V Power Supply

Sterilbank NuAire Biological Safety cabinets

StepOnePlus ${ }^{\mathrm{TM}}$ Real-Time PCR System

Stickstofftank APOLLO

Thermocycler Mastercycler ep gradient S

ThermoMixer® comfort

TissueLyser LT

Trockenschrank

Ultratiefkühlgerät (Modell: MDF-U54V)

Ultrasonic Liquid Processors S-400

Vortex Genie $2^{\mathrm{TM}}$
Sartorius, Göttingen, Deutschland

Leica Microsysteme, Wetzlar, Deutschland

Biosciences, Fernwald, Deutschland

Life science incorporated, Greenboro, USA

BRAUN GmbH, Kronberg, Deutschland

Thermo Fisher Scientific Inc., Waltham, USA

Bio-Rad, München, Deutschland

Scotsman-ice, Vernon Hills (IL), USA

Biometra, Göttingen, Deutschland

Olympus, Münster, Deutschland

LIEBHERR, Bulle, Schweiz

Leica Microsysteme, Wetzlar, Deutschland

Liebisch, Bielefeld, Deutschland

LIEBHERR, Bulle, Schweiz

Sigma, Osterode am Harz, Deutschland

Eppendorf AG, Hamburg, Deutschland

IKA Labortechnik, Staufen, Deutschland

ZEISS, Oberkochen, Deutschland

Leica Microsysteme, Wetzlar, Deutschland

Thermo Fisher Scientific Inc., Waltham, USA

GFL-GmbH, Burgwedel, Deutschland

Hirschmann®, Eberstadt, Deutschland

Heidolph, Schwabach, Deutschland

Bibby Scientific, Stuart $囚$, Staffordshire, UK

Major Science, Saratoga(CA), USA

NuAire, Plymouth(MN), USA

Applied Biosystems, Darmstadt, Deutsch.

Messer Griesheim, Deutschland

Eppendorf AG, Hamburg, Deutschland

Eppendorf AG, Hamburg, Deutschland

Qiagen, Hilden, Deutschland

Memmert GmbH, Schwabach, Deutschland

SANYO biomedical, Wood Dale (IL),USA

Misonix Sonicators, Newtown, USA

Bender \& Hobein AG, Zürich, Schweiz 
Wärmebad GFL 1083

Zentrifuge PerfectSpin $\mathrm{P}$

Lichtmikroskop

pH-Meter MP 220

\subsection{Software und Datenbanken}

\section{BLAST}

cellSens Dimension 1.6

cell^ $D$

GraphPad Prism 6.0

MS Office

StepOnePlus ${ }^{\mathrm{TM}}$ Software v2.3

Photoshop CS6,

Illustrator CS5

Image J $1.49 q$

\subsection{Gebrauchsmaterialien}

Biospere $®$ Filterspitzen 10, 100, $1000 \mu \mathrm{l}$

CELLSTAR® 6 Well Zellkulturplatte

CELLSTAR® Tubes(Falcon) 15 / 50 ml-Röhrchen

Dako Pen (Code-No. S2002)

Eindeckgläser SuperFrost $₫$ Plus

Falcon ${ }^{\circledR}$, CultureSlides 4 Well $/ 1,7 \mathrm{~cm}$. pro Well

Filterpapier

MicroAmp® Fast 8-Tube Strip, $0.1 \mathrm{ml}$

MicroAmp® Fast Optical 96-Well Reaction Plate

MicroAmp ${ }^{\mathrm{TM}}$ Optical Adhesive Film

Microscope Cover Slips $24^{\star} 40 \mathrm{~mm}$

Microscope Cover Slips $24^{*} 60 \mathrm{~mm}$

Mikroliter Pipetten 10, 100, $1000 \mu \mathrm{l}$

Nalgene Mr. Frosty ${ }^{\mathrm{TM}}$ Freezing Container

Neubauer-Zählkammer

Nunc CryoTube ${ }^{\text {TM }}$ Vials $1,8 \mathrm{ml}$

NuPAGE $®$ Novex $® 4-12 \%$ Bis-Tris Protein Gels, ( $1.5 \mathrm{~mm}, 10$ well und 15 well)

Pipetten 5, 10, $25 \mathrm{ml}$

Rotilabo® Einbettkassetten für Biopsien,

$\mathrm{RT}^{2}$ Profiler $^{\mathrm{TM}}$ PCR Array Human Transcription
GFL-GmbH, Burgwedel, Deutschland

PEQLAB Biotech., Erlangen, Deutschland

Leica, Solms, Deutschland

Mettler Toledo, Columbus, USA

\author{
http://blast.ncbi.n/m.nih.gov/Blast.cgi \\ Olympus SIS, Münster, Deutschland \\ Olympus SIS, Münster, Deutschland \\ GraphPad Software, La Jolla, USA \\ Microsoft, Redmond, USA \\ Applied Biosystems, Darmstadt, Deutsch. \\ Adobe, San Jose, Kalifornien \\ Adobe, San Jose, Kalifornien \\ $\mathrm{NIH}$, Bethesda, Maryland
}

Sarstedt AG \& Co., Nümbrecht, Deutschland

Greiner Bio-One, Frickenhausen, Deutsch.

Greiner Bio-One, Frickenhausen, Deutsch.

Dako, Glostrup, Dänemark

Gerhard Menzel, Braunschweig, Deutsch.

Fisher Scientific, Pittsburgh, USA

Bio-Rad, Kalifornien, USA

Applied Biosystems, Darmstadt, Deutsch.

Applied Biosystems, Darmstadt, Deutsch.

Applied Biosystems, Darmstadt, Deutsch.

Menzel GmbH, Braunschweig, Deutschland

Menzel GmbH, Braunschweig, Deutschland

Eppendorf AG, Hamburg, Deutschland

Thermo Fisher Scientific Inc., Waltham, USA

Marienfeld, Lauda-Königshofen,Deutschland

Thermo Fisher Scientific, Waltham, USA

life technologies ${ }^{\mathrm{TM}}$, Novex ${ }^{\circledR}$, Carlsbad, USA

Sarstedt AG \& Co., Nümbrecht, Deutschland

CARL ROTH, Karlsruhe, Deutschland

Qiagen, Hilden, Deutschland Factors 
Safe Look Tubes 1.5, $2 \mathrm{ml}$

Skalpelle

Stainless Steel Beads $5 \mathrm{~mm}$

Steril Filter Unit, 0,5-0,22 $\mu \mathrm{m}$

TC-Schale 100 Cell+

Tissue-Tek $®$ Cryomold $\circledast$ Intermediate

Tissue-Tek O.C.T. COMPOUND, $125 \mathrm{ml}$

XCell SureLock ${ }^{\mathrm{TM}}$ Electrophoresis Cell

Zellkulturflasche mit Luftfilter T75

Zellschaber

\subsection{Chemikalien und Reagenzien}

Albumin Fraktion $\mathrm{V}$

Amphotericin B, lyophilisiert

Bouin's solution

cOmplete ULTRA Tablets, Mini, EDTA-free,

Chloroform $\geq 99,8 \%\left(\mathrm{CHCl}_{3}\right)$

DAPI

DMEM High Glucose

DMEM, Low Glucose, Pyruvate

Dulbecco's PBS

Eindeckmedium Shandon ${ }^{\mathrm{TM}}$ Immu-Mount ${ }^{\mathrm{TM}}$

Entellan $®$

Essigsäure 2,5 I

Ethanol ROTHIPURAN $® \geq 99.8 \%$, p.a.

Fast SYBR® Green Master Mix

Fetal Bovine Serum

Forene ${ }^{\circledR} 100 \%$ (V/V); Wirkstoff: Isofluran

Hämalaunsäure sauer nach Mayer

Heparin- ROTEXMEDICA, 25000 I.E $/ 5$ ml

Milchpulver

2-Mercaptoethanol 99\%, p.a.

10mM dNTP Mix

Natriumchlorid $>99,8 \%$, p.a.

Nitrocellulose Blotting Membrane

Amersham $^{\mathrm{TM}}$ Protran Premium 0,45 $\mu \mathrm{m}$ NC

Novex $₫$ Sharp Pre-stained Protein standard NP40 Cell Lysis Buffer
Eppendorf AG, Hamburg, Deutschland

FEATHER Safety Razor Co., Osaka, Japan

Qiagen, Hilden, Deutschland

Millex, Billerica, MA, USA

Sarstedt AG \& Co.; Nümbrecht, Deutschland SAKURA, Alphen aan den Rijn, Niederlande SAKURA, Alphen aan den Rijn, Niederlande life technologies ${ }^{\mathrm{TM}}$, Novex $\AA$, Carlsbad, USA Sarstedt AG \& Co., Nümbrecht, Deutschland Sarstedt AG \& Co., Nümbrecht, Deutschland

CARL ROTH, Karlsruhe, Deutschland BIOCHROM, Berlin, Deutschland Sigma-Aldrich, Steinheim, Deutschland Roche Diagnostics, Mannheim, Deutschland Merck KGaA, Darmstadt, Deutschland CARL ROTH, Karlsruhe, Deutschland life technologies ${ }^{\mathrm{TM}}, \mathrm{Gibco} \circledast$, Carlsbad, USA life technologies ${ }^{\mathrm{TM}}, \mathrm{Gibco} \circledast$, Carlsbad, USA life technologies ${ }^{\mathrm{TM}}, \mathrm{Gibco} 囚$, Carlsbad, USA Thermo Fisher Scientific, Waltham, USA Merck KGaA, Darmstadt, Deutschland Merck KGaA, Darmstadt, Deutschland CARL ROTH, Karlsruhe, Deutschland Applied Biosystems $®$, Carlsbad, USA Sigma-Aldrich, Taufkirchen, Deutschland AbbVie $\mathrm{GmbH}$, Ludwigshafen, Deutschland CARL ROTH, Karlsruhe, Deutschland ROTEXMEDICA, Trittau, Deutschland CARL ROTH, Karlsruhe, Deutschland CARL ROTH, Karlsruhe, Deutschland Invitrogen ${ }^{\mathrm{TM}}$, Carlsbad, USA CARL ROTH, Karlsruhe, Deutschland Amersham Bioscience Europe $\mathrm{GmbH}$, Freiburg, Deutschland (GE Healthcare) life technologies ${ }^{\mathrm{TM}}$, Novex ${ }^{\circledR}$, Carlsbad, USA Invitrogen ${ }^{\mathrm{TM}}$, Carlsbad, USA 
Nuclease-Free Water (Cat.-No. 129114)

NuPAGE® LDS Sample Buffer (4X)

NUPAGE $®$ MOPS SDS Running Buffer

Oligo(dt) 12-18 Primer

Pierce $^{\text {TM }}$ Fast Semi- Dry Transfer Buffer (10X)

RNAseOut $^{\mathrm{TM}}$ Recombinant Ribonuclease Inhibitor Invitrogen ${ }^{\mathrm{TM}}$, Carlsbad,USA

Roti® Histofix, Formaldehydlösung 4\%

Target Retrieval Solution, pH 6 (10X)

TRIS PUFFERAN $\otimes \geq 99,9 \%$, p.a.

TRIzol® Reagent

Tween ${ }^{\circledR} 20 \%$

VECTASHIELD Mounting Medium with DAPI

Wasserstofferoxid 30\%, ROTIPURAN® p.a.,

20X LumiGLO $尺$ Reagent and 20X Peroxide

Xylol (Isomere) $>98 \%$, rein,
Qiagen, Hilden, Deutschland

life technologies ${ }^{\mathrm{TM}}$, Novex ${ }^{\circledR}$, Carlsbad, USA

life technologies ${ }^{\mathrm{TM}}$, Novex $囚$, Carlsbad, USA

Invitrogen ${ }^{\mathrm{TM}}$, Carlsbad, USA

Thermo Fisher Scientific, Waltham, USA

CARL ROTH, Karlsruhe,

Dako, Glostrup, Dänemark

CARL ROTH, Karlsruhe, Deutschland

Ambion ${ }^{\circledR}$, Carlsbad, USA

CARL ROTH, Karlsruhe, Deutschland

Vector Laboratories, Burlingame USA

CARL ROTH, Karlsruhe, Deutschland

Cell Signaling Danvers, USA

CARL ROTH, Karlsruhe, Deutschland

\section{$2.5 \quad$ Kitsysteme}

Tabelle 3: Purelink® RNA Mini-Kit

\begin{tabular}{|c|c|}
\hline Purelink® RNA Mini-Kit & Ambion ${ }^{\circledR}$, Carlsbad, USA \\
\hline $\begin{array}{l}\text { Lysis Buffer } \\
\text { Wash Buffer I } \\
\text { Wash Buffer II } \\
\text { RNAse-Free-Water }(75 \mathrm{ml})\end{array}$ & $\begin{array}{ll}\text { - } & \text { Spin Cartidges mit Collection Tubes (5x50 } \\
\text { each) } & \\
\text { - } \quad \text { Collection Tubes (5x50 each) } \\
\text { Recovery Tubes (5x50 each) }\end{array}$ \\
\hline
\end{tabular}

Tabelle 4: Pierce $^{\mathrm{TM}} \mathrm{BCA}^{\mathrm{TM}}$ Protein Assay

\begin{tabular}{lll}
\hline & Pierce $^{\mathrm{TM}}$ BCA $^{\mathrm{TM}}$ Protein Assay & \multicolumn{1}{c}{ Thermo Scientific, USA } \\
\hline \hline - & Bca $^{\mathrm{TM}}$ Reagent $\mathrm{A}, 2 \times 500 \mathrm{ml}$ & Albumin Standard Ampules, $2 \mathrm{mg} / \mathrm{ml}, 10 \mathrm{x}$ \\
- & Bca $^{\mathrm{TM}}$ Reagent $\mathrm{B}, 1 \times 25 \mathrm{ml}$ & $1 \mathrm{ml}$ \\
\hline
\end{tabular}

Tabelle 5: Superscript $₫$ li Reverse Transcriptase

\begin{tabular}{lll}
\hline & Superscript ${ }^{\circledR}$ li Reverse Transcriptase & \multicolumn{1}{c}{ Invitrogen $^{\mathrm{TM}}$, Carlsbad, USA } \\
\hline \hline - & Superscript ${ }^{\circledR}$ II, Reverse Transcriptase & 0,1 MDTT(1,4-Dithiothreitol) \\
- & 5 X First Strand Buffer & \\
\hline
\end{tabular}


Tabelle 6: Supersignal $囚$ West Pico

\begin{tabular}{|c|c|}
\hline Supersignal® West Pico & Thermo Scientific, USA \\
\hline $\begin{array}{l}\text { Supersignal }{ }^{\circledR} \text { West Pico Stable, } \\
\text { Peroxide Solution, } 100 \mathrm{ml}\end{array}$ & $\begin{array}{l}\text { - } \quad \text { Supersignal }{ }^{\circ} \text { West Pico Luminol/ } \\
\text { Enhancer Solution, } 100 \mathrm{ml}\end{array}$ \\
\hline
\end{tabular}

Tabelle 7: Trichrom-Farbstoff (Masson) Kit

\begin{tabular}{llc}
\hline Trichrom-Farbstoff (Masson) Kit & Sigma-Aldrich, Taufkirchen, Deutschland \\
\hline \hline - & Biebrich-Scharlachrot-Säurefuchsin & Phosphormolybdänsäure-Lösung, \\
Lösung, 250ml, Ht15-1 & 250ml, HT15-3 \\
Phosphorwolframlösung, 250ml, & Anilinblau-Lösung, 250ml, HT15-4 \\
HT15-2 & \\
\hline
\end{tabular}

Tabelle 8: Weigert's Eisenhämatoxylin Set

\begin{tabular}{|c|c|}
\hline Weigert's Eisenhämatoxylin Set & Sigma-Aldrich, Taufkirchen, Deutschland \\
\hline $\begin{array}{l}\text { Part A: Weigert's Eisenhämatoxylin } \\
\text { Lösung HT } 107\end{array}$ & $\begin{array}{l}\text { - } \quad \text { Part B: Weigert's Eisenhämatoxylin } \\
\text { Lösung HT } 109\end{array}$ \\
\hline
\end{tabular}

Tabelle 9: Dneasy Blood \& Tissue Kit (250)

\begin{tabular}{|c|c|}
\hline Dneasy Blood \& Tissue Kit (250) & Qiagen, Hilden, Deutschland \\
\hline $\begin{array}{ll}\text { - } & \text { Buffer ATL, AL, AE } \\
\text { - } & \text { Buffer AW } 1 \text { (Concentrate) } \\
\text { - } & \text { Buffer AW } 2 \text { (Concentrate) } \\
\text { Proteinase K }\end{array}$ & $\begin{array}{ll}\text { - } & \text { DNeasy Mini Spin Columns in } 2 \mathrm{ml} \\
\text { - } & \text { Collection Tubes } \\
\text { Collection Tubes }(2 \mathrm{ml})\end{array}$ \\
\hline
\end{tabular}

Tabelle 10: Methylamp ${ }^{\text {TM }}$ Methylated DNA Capture Kit

\begin{tabular}{llll}
\hline & Methylamp & & \\
\hline \hline - & Methylated Dna Capture Kit & & Normal (Antibody Buffer) \\
- & MC2 (Reaction Buffer) & - & Proteinase K (10mg/MI) \\
- & MC3 (Wash Buffer) & Anti-5-Methylcytosine (1mg/MI) \\
- & MC4 (Dna Release Buffer) & 8-Well Assay Strips \\
- & MC5 (Binding Buffer) & - & 8-Well Stripe Caps \\
- & MC6 (Elution Buffer) & - & F-Spin Column \\
& & - F-Collection Tube \\
\hline
\end{tabular}


2.6 Puffer und Lösungen

Allgemeine Puffer und Lösungen

10x PBS

$\mathrm{K}_{2} \mathrm{HPO}_{4} \times 3 \mathrm{H}_{2} \mathrm{O}$

$\mathrm{Na}_{2} \mathrm{HPO}_{4} \times 2 \mathrm{H}_{2} \mathrm{O}$

$\mathrm{NaCl}$

$\mathrm{ddH}_{2} \mathrm{O}$

10x TBS

$\mathrm{NaCl}$

$2,00 \mathrm{~g}$

$11,5 \mathrm{~g}$

$80,00 \mathrm{~g}$

$1000 \mathrm{ml}$

Tris

$87 \mathrm{~g}$

$\mathrm{ddH}_{2} \mathrm{O}$

\section{Einfriermedium}

FCS

$40 \mathrm{ml}$

DMSO

$10 \mathrm{ml}$

Puffer und Lösungen für Western Blot

Lysispuffer

cOmplete ULTRA Tablets

(Protease Inhibitor)

NP40 Cell Lysis Buffer

Innenpuffer

$\mathrm{dd}_{2} \mathrm{O}$

$9950 \mathrm{ml}$

NuPAGE MOPS SDS Running Buffer $50 \mathrm{ml}$

$\beta$-Mercaptoethanol

$1 \mathrm{ml}$

Außenpuffer

$\mathrm{ddH}_{2} \mathrm{O}$

$9950 \mathrm{ml}$

NuPAGE MOPS SDS Running Buffer $50 \mathrm{ml}$

\section{Sample Buffer}

NuPAGE $®$ LDS Sample Buffer

$200 \mu \mathrm{l}$

$\mathrm{H}_{2} \mathrm{O}$

$180 \mu \mathrm{l}$

$\beta$-Mercaptoethanol

$80 \mu \mathrm{l}$

Puffer und Lösungen (Immunhistofluoreszenz)

Citratpuffer

Target Retrieval Solution, pH 6 (10x) 10 ml $\mathrm{ddH}_{2} \mathrm{O}$

$90 \mathrm{ml}$ 1x T-BST

$\mathrm{ddH}_{2} \mathrm{O} \quad 900 \mathrm{ml}$

TBS

$100 \mathrm{ml}$

Tween 20\%

$1 \mathrm{ml}$

\section{Blocklösung}

BSA $(2 \% / 5 \%)$

$1 \mathrm{~g} / 2,5 \mathrm{~g}$

TBST

$50 \mathrm{ml}$

Milchpulver (2\% / 5\%)

$1 \mathrm{~g} / 2,5 \mathrm{~g}$

TBST

$50 \mathrm{ml}$

\section{Blocklösung}

BSA (1\%)

$0,5 \mathrm{~g}$

PBS

$50 \mathrm{ml}$ 
Ansatz für die real-time PCR (pro Probe)

\section{PrimerDesign}

MasterMix

Primer

nukleasefreies Wasser (NFW)

$10 \mu \mathrm{l}$
$1 \mu \mathrm{l}$
$4 \boldsymbol{\mu l}$

\section{Eurofines}

MasterMix

$10 \mu \mathrm{l}$

Primer forward $(20 \mu \mathrm{M}) \quad 0,2 \mu \mathrm{l}$

Primer reverse $(20 \mu \mathrm{M}) \quad 0,2 \mu \mathrm{l}$

NFW

$4,6 \mu \mathrm{l}$

Oligonukleotid-Mischung für die Umschreibung der mRNA in cDNA

$\begin{array}{ll}\text { RNA }(50 \mathrm{ng} / \mu \mathrm{l}) & 10 \boldsymbol{\mu l} \\ \text { dNTP-Mix } 10 \mathrm{mM} & 1 \boldsymbol{\mu l} \\ \text { Oligo-dt-Poly a-Tail } & 1 \boldsymbol{\mu l}\end{array}$

First Strand Buffer-Mischung für die Umschreibung der mRNA in cDNA

5x First Strand Buffer
$4 \mu \mathrm{l}$
$2 \mu \mathrm{l}$
$1 \mu \mathrm{l}$

$0,1 \mathrm{M}$ DTT

RNase OUT

\section{Paraformaldehyd-Lösung (PFA):}

$4 \mathrm{~g}$ Paraformaldehyd-Pulver in $100 \mathrm{ml}$ aqua dest. mischen (= 4\%)

Es entsteht eine milchig, weiße Flüssigkeit.

Zugabe von Natronlauge, bis sich das Paraformaldehyd löst (bei pH $=7$ )

Lösung nur frisch verwenden; ca. $1 \mathrm{~h}$ bei Raumtemperatur auf beheiztem Magnetrührer durchmischen. Die Lösung wird klar.

\subsection{Stimulanzien}

rhTGF-beta1 $10 \mu \mathrm{g}$

R\&D System, Wiesbaden, Deutschland

Folic acid (F7876-10G)

Sigma-Aldrich, Taufkirchen, Deutschland 


\section{$2.8 \quad$ Oligonukleotide (Primer)}

Tabelle 11: Primersequenzen von PrimerDesign für die qRT-PCR

\begin{tabular}{|c|c|c|}
\hline Ziel-mRNA & Primer-Sequenz 5' -> 3' & Spezies \\
\hline & PrimerDesign, Southampton, UK & \\
\hline$R \ln 1 F$ & TGA TAA ACT GGG TGA AGC AGA AG & Mus Musculus \\
\hline$R \ln 1 R$ & CCT CTT TTT CCG TGA ATG GGT AT & Mus Musculus \\
\hline$R \ln 3 F$ & CTT GCG GAG GCT CAC GAT & Mus Musculus \\
\hline$R \ln 3 R$ & CAG GTG GTC TGT ATT GGC TTC & Mus Musculus \\
\hline Rxfp1 F & ATT TCT CTC TGC TGT GCT GAC T & Mus Musculus \\
\hline$R \times f p 1 R$ & CGG CTG TGC GTG CTT ATT G & Mus Musculus \\
\hline$R L N 1 F$ & GGC AAC CAT CAT TAC CAG AGC & Homo sapiens \\
\hline$R L N 1 R$ & TCC AAG CCT AAG TAT TTT AAT TCT GAA & Homo sapiens \\
\hline RLN2 F & GCT CCT CAG ACA CCT AGA CC & Homo sapiens \\
\hline$R L N 2 R$ & CTG TGG CAA ATT AGC AAC AAA TTC & Homo sapiens \\
\hline$R \times F P 1 F$ & GCT GTA TGC CAT GTC AAT CAT T & Homo sapiens \\
\hline$R \times F P 1 R$ & TCT CCA CGA AAC TTT AGG TCA A & Homo sapiens \\
\hline$R X F P 2 F$ & GAT CAC TCC TTC ATG CCA AAA AG & Homo sapiens \\
\hline$R X F P 2 R$ & TGT CAC CAC AGT TCT CTT CGT & Homo sapiens \\
\hline$R X F P 3 F$ & ACC AAA TCA GTG ACC ATC GTT & Homo sapiens \\
\hline$R X F P 3 R$ & GCG TTG AAC TTG ATG AGG ATG & Homo sapiens \\
\hline GAPDH & (Cat.-No. HK-SY-hu-1200) & Homo Sapiens \\
\hline GAPDH & (Cat.-No. HK-SY-mo-1200) & Mus Musculus \\
\hline
\end{tabular}


Tabelle 12: Primersequenzen von Eurofins MWG Operon für die qRT-PCR

\begin{tabular}{|c|c|c|}
\hline Ziel-mRNA & Primer-Sequenz 5' -> 3' & Spezies \\
\hline & Eurofins MWG Operon (Ebersberg) & \\
\hline COL1A2 F & GGT GAA GTG GGT CTT CCA GG & Homo sapiens \\
\hline COL1A2 R & TAA GGC CGT TTG CTC CAG G & Homo sapiens \\
\hline$\alpha$ SMA F & AAG CAC AGA GCA AAA GAG GAA T & Homo sapiens \\
\hline$\alpha$ SMA R & ATG TCG TCC CAG TTG GTG AT & Homo sapiens \\
\hline$\alpha$ SMA F & CTC TTC CAG CCA TCT TTC ATT G & Mus musculus \\
\hline$\alpha$ SMA R & GTT GTT AGC ATA GAG ATC CTT TCC T & Mus musculus \\
\hline Col1a1 F & ATG GAT TCC CGT TCG AGT ACG & Mus musculus \\
\hline Col1a1 R & TCA GCT GGA TAG CGA CAT CG & Mus musculus \\
\hline MMP2 F & GGC AGA CAT CAT GAT CAA CT & Mus musculus \\
\hline MMP2 R & TGC TGT CAT AGG ATG TG & Mus musculus \\
\hline MMP $3 F$ & ATT CCA TGG AGC CAG GCT TTC & Mus musculus \\
\hline MMP $3 R$ & CAT TTG GGT CAA ACT CCA ACT GTG & Mus musculus \\
\hline MMP $9 F$ & TTG ACA GCG ACA AGA AGT GG & Mus musculus \\
\hline MMP $9 R$ & GTA CAT AGG GTA CAT GAG CG & Mus musculus \\
\hline
\end{tabular}

\subsection{Antikörper}

Tabelle 13: Verwendete Antikörper für Western Blot und Immunfluoreszenzfärbung

\begin{tabular}{|c|c|c|c|}
\hline Antikörper & Spezies & $\begin{array}{l}\text { Hersteller und } \\
\text { Cat.-No. }\end{array}$ & $\begin{array}{l}\text { Verwendung und } \\
\text { Verdünnung }\end{array}$ \\
\hline $\begin{array}{l}\text { Anti-Collagen 1, } \\
\text { (Cat.- No.: ab34710) }\end{array}$ & Kaninchen & $\begin{array}{l}\text { Abcam Biochemicals } \AA \text {, } \\
\text { Cambridge, UK }\end{array}$ & IF: 1:200 \\
\hline $\begin{array}{l}\text { Anti-Alpha Smooth Muscle } \\
\text { Actin, (Cat.- No.: 5228) }\end{array}$ & Maus & $\begin{array}{l}\text { Sigma-Aldrich Chemie } \\
\text { GmbH, Taufkirchen, } \\
\text { Deutschland }\end{array}$ & $\begin{array}{l}\text { IF: } 1: 100 \\
\text { WB: } 1: 5000\end{array}$ \\
\hline $\begin{array}{l}\text { Anti-p-Smad2 (Ser465/467), } \\
\text { (Cat.- No.: 3108s) }\end{array}$ & Kaninchen & $\begin{array}{l}\text { Cell Signaling } \\
\text { TECHNOLOGY®, Danvers } \\
\text { (MA), USA }\end{array}$ & $\begin{array}{l}\text { WB: } 1: 600 \\
\text { IF: } 1: 100\end{array}$ \\
\hline $\begin{array}{l}\text { Anti-p-Smad3 (Ser423/425), } \\
\text { (Cat.- No.: 9520) }\end{array}$ & Kaninchen & $\begin{array}{l}\text { Cell Signaling } \\
\text { TECHNOLOGY®, Danvers } \\
\text { (MA), USA }\end{array}$ & $\begin{array}{l}\text { WB: } 1: 1000 \\
\text { IF: } 1: 100\end{array}$ \\
\hline $\begin{array}{l}\text { Anti-Relaxin-Receptor } 1 \\
\text { (H-160), (Cat.- No.: sc-50328) }\end{array}$ & Kaninchen & $\begin{array}{l}\text { Santa Cruz Biotechnology, } \\
\text { Santa Cruz, USA }\end{array}$ & $\begin{array}{l}\text { WB: } 1: 500 \\
\text { IF: } 1: 50\end{array}$ \\
\hline $\begin{array}{l}\text { Anti-Relaxin-Receptor } 2(\mathrm{H}-150) \text {, } \\
\text { (Cat.- No.: sc-50327) }\end{array}$ & Kaninchen & $\begin{array}{l}\text { Santa Cruz Biotechnology, } \\
\text { Santa Cruz, USA }\end{array}$ & $\begin{array}{l}\text { WB: } 1: 500 \\
\text { IF: } 1: 100\end{array}$ \\
\hline $\begin{array}{l}\text { Anti-Relaxin 3-Rezeptor 1, } \\
\text { (Cat.- No.: ab138062) }\end{array}$ & Kaninchen & $\begin{array}{l}\text { Abcam Biochemicals } \AA \text {, } \\
\text { Cambridge, UK }\end{array}$ & IF: 1:100 \\
\hline $\begin{array}{l}\text { Anti-Relaxin 1, } \\
\text { (Cat.- No.: ab89919) }\end{array}$ & Ratte & $\begin{array}{l}\text { Abcam Biochemicals } \AA \text {, } \\
\text { Cambridge, UK }\end{array}$ & IF: 1:100 \\
\hline
\end{tabular}




\begin{tabular}{|c|c|c|c|}
\hline $\begin{array}{l}\text { Anti-Relaxin 2, } \\
\text { (Cat.- No.: ab183505) }\end{array}$ & Kaninchen & $\begin{array}{l}\text { Abcam Biochemicals } ® \text {, } \\
\text { Cambridge, UK }\end{array}$ & $\begin{array}{l}\text { WB: } 1: 1000 \\
\text { IF: } 1: 500\end{array}$ \\
\hline $\begin{array}{l}\text { Anti-Relaxin 3, } \\
\text { (Cat.- No.: ab89920) }\end{array}$ & Maus & $\begin{array}{l}\text { Abcam Biochemicals }{ }^{\circledR} \text {, } \\
\text { Cambridge, UK }\end{array}$ & IF: 1:100 \\
\hline $\begin{array}{l}\text { Anti Collagen IV-AF 488, } \\
\text { (Cat.- No.: 1340-30) }\end{array}$ & Ziege & $\begin{array}{l}\text { Southern BioTech } \\
\text { Birmingham, USA }\end{array}$ & IF: 1:10 \\
\hline
\end{tabular}

\begin{tabular}{|c|c|c|c|}
\hline $\begin{array}{l}\text { Alexa Fluor }{ }^{\circledR} \mathbf{5 5} \text {, Anti- } \\
\text { Kaninchen polyklonal IgG, (Cat.- } \\
\text { No.: A-31572) }\end{array}$ & Esel & $\begin{array}{l}\text { life technologies }{ }^{\mathrm{TM}} \\
\text { Invitrogen } \\
{ }^{\mathrm{TM}} \text {, Carlsbad, USA }\end{array}$ & IF: $1: 400$ \\
\hline $\begin{array}{l}\text { Alexa Fluor }{ }^{\circledR} \mathbf{4 8 8} \text {, Anti- } \\
\text { Kaninchen polyklonal IgG, (Cat.- } \\
\text { No.: A-21206) }\end{array}$ & Esel & $\begin{array}{l}\text { life technologies }{ }^{\mathrm{TM}} \\
\text { Invitrogen } \\
{ }^{\mathrm{TM}}, \text { Carlsbad, USA }\end{array}$ & IF: $1: 400$ \\
\hline $\begin{array}{l}\text { Alexa Fluor }{ }^{\circledR} 555 \text {, Anti-Maus } \\
\text { polyklonal IgG, (Cat.-No.: A- } \\
21202 \text { ) }\end{array}$ & Esel & $\begin{array}{l}\text { life technologies }{ }^{\mathrm{TM}} \text {, } \\
\text { Invitrogen }{ }^{\mathrm{TM}} \text {, Carlsbad, USA }\end{array}$ & IF: 1:400 \\
\hline $\begin{array}{l}\text { Alexa Fluor® 594, Anti-Ratte, } \\
\text { (Cat.-No.: A20185) }\end{array}$ & Esel & $\begin{array}{l}\text { life technologies }{ }^{\mathrm{TM}}, \\
\text { Invitrogen }^{\mathrm{TM}} \text {, Carlsbad, USA }\end{array}$ & IF: $1: 400$ \\
\hline $\begin{array}{l}\text { HRP-konjugiertes Ziege-anti- } \\
\text { Kaninchen polyklonal IgG } \\
\text { (Code No. P 0448) }\end{array}$ & Ziege & Dako, Glostrup, Dänemark & WB: $1: 2000$ \\
\hline $\begin{array}{l}\text { HRP-konjugiertes Kaninchen- } \\
\text { anti-Maus polyklonal IgG, } \\
\text { (Code No. P 0161) }\end{array}$ & Kaninchen & Dako, Glostrup, Dänemark & WB: $1: 2000$ \\
\hline
\end{tabular}

\subsection{Zelllinien sowie murine und humane Gewebsproben}

Alle Zelllinien, die in der vorliegenden Arbeit verwendet wurden, sind in Tabelle 14 aufgelistet.

Tabelle 14:Verwendete Zelllinien

\begin{tabular}{lllll}
\hline \multicolumn{1}{c}{ Name } & Spezies & \multicolumn{1}{c}{ Bedeutung } & Herkunft & immortalisiert \\
\hline \hline TK 173 & Mensch & Kontrolle & Uni Göttingen, G. Müller & SV40 \\
\hline TK 188 & Mensch & fibrotisch & Uni Göttingen, G. Müller & SV40 \\
mWT & Maus & Kontrolle & Uni Göttingen, M. Zeisberg & \\
\hline mWTRLX & Maus & fibrotisch, stimuliert & eigene Herstellung & \\
& & mit RLX030 & & \\
& & & & \\
\hline
\end{tabular}

\section{$\underline{\text { TK } 173}$}

Die Zelllinie TK173 wurde von Müller et al. etabliert und von der Klinik für Nephrologie und Rheumatologie der Georg-August-Universität Göttingen zur Verfügung gestellt. Hierbei handelt es sich um humane renale Fibroblasten aus dem medullären Anteil einer nicht infizierten Normalniere. Diese wurden mittels Transfektion mit dem Plasmid pSV3gpt des Simian Virus 40 immortalisiert (Schüttert et al. 2003). Hierbei behielten sie jedoch phänotypische und biochemische Eigenschaften von renalen interstitiellen Fibroblasten. Die Zelllinie TK188 stellt ein pathologisches Korrelat zur Zelllinie TK173 dar. Sie wurden aus Nieren mit tubulointerstitieller Fibrose entnommen (Dihazi et al. 2011). 


\section{Primäre renale Fibroblasten}

Primärkulturen haben eine begrenzte Lebensdauer, zeigen dafür aber vergleichbare Eigenschaften in vitro wie in vivo. Die Generierung der Primärfibroblasten erfolgte aus WildtypMäusen. Hierfür wurden die entnommenen UUO-Nieren sofort auf Eis gebettet, der kortikale Anteil des Nierengewebes entfernt und dieser unter Verwendung eines Skalpells gründlich zerkleinert. Die homogenisierte Masse wurde für drei Stunden bei $37^{\circ} \mathrm{C}$ und $650 \mathrm{U} / \mathrm{min}$ in $5 \mathrm{ml}$ DMEM mit 20\% FCS, $1 \%$ Penecillin/Streptomycin und $4 \mathrm{U} / \mathrm{ml}$ Kollagenase Typ IV im Thermorüttler inkubiert. Das Homogenat wurde anschließend durch einen cell-stainer-Filter in ein 50-ml-Falcon überführt und mit $5 \mathrm{ml}$ DMEM mit 20\% FCS gespült. Es folgte die Zentrifugation bei $1000 \mathrm{U} / \mathrm{min}$ für $5 \mathrm{~min}$, Verwerfung des Überstands und die Resuspendierung des Pellets mit $1 \mathrm{ml}$ frischem Medium. Anschließend wurden die Zellen auf eine $58 \mathrm{~cm}^{2}$ Petrischale mit $5 \mathrm{ml}$ Medium expandiert und bei $37{ }^{\circ} \mathrm{C}$ und $5 \% \mathrm{CO}_{2}$ im Inkubator kultiviert. Nach zwei Stunden und am nächsten Tag folgten erneute Mediumwechsel.

\section{Murines Nierengewebe}

Die acht bis zwölf Wochen alten Wildtyp-Mäuse C57BL/6J wurden im European Neuroscience Institute Göttingen (ENI) untergebracht. Die Haltung erfolgte tiergerecht in Käfigen bei konstanter Raumtemperatur und Luftfeuchtigkeit und einem Hell-Dunkel-Zyklus von 12 Stunden. Wasser sowie Nahrung wurden alle 48 Stunden erneuert.

Die obligate Genehmigung wurde von der Tierschutzkommission der Medizinischen Fakultät der Universität Göttingen und dem Niedersächsischen Landesamt für Verbraucherschutz und Lebensmittelsicherheit (LAVIS) erteilt (Antragsnummer: G15.1842).

\section{Humanes Nierengewebe und Vollblutproben}

Des Weiteren erfolgte die Gewebs- und Vollblutanalyse von Patienten mit chronischer Nierenerkrankung. Die Genehmigung für das Forschungsvorhaben an humanen Vollblutproben und Gewebsmaterial wurde von der Ethikkommission der Universitätsmedizin Göttingen erteilt (Antragsnummer: DOK_128_2015). Eine detaillierte Auflistung der Patientenkohorte mit chronischen Nierenerkrankungen, aufgeschlüsselt hinsichtlich klinischer und histologischer Charakteristika, ist in Tabelle 26 einsehbar. 


\section{Methoden}

\subsection{Zellbiologische Methoden}

\section{Primäre renale Fibroblasten}

Die TKs und primären Fibroblasten wurden als Monolayer in $75-\mathrm{cm}^{2}$-Zellkulturflaschen oder in Petrischalen bei $37{ }^{\circ} \mathrm{C}$ in Gegenwart von $100 \%$ relativer Luftfeuchtigkeit und $5 \% \mathrm{CO}_{2}$-Begasung im Inkubator kultiviert. Als Kulturmedium wurde Dulbecco's Modified Eagle Medium (DMEM) 300 mosmol/l mit einem niedrigen Glukosegehalt (1 g/l) verwendet, welches zusätzlich angereichert wurde mit 10\% (20\% für primäre Fibroblasten) fetalem Kälber-Serum (FCS), 1\% $0,2 \mathrm{~mol} / \mathrm{l} \mathrm{L}-$ Glutamin und $1 \% 1000 \mathrm{U} / \mathrm{ml}$ Penicillin/Streptomycin und Amphotericin B. Die Stimulation erfolgte in serumfreiem DMEM. Ein Mediumwechsel erfolgte dreimal in der Woche.

Die Zellen wurden mehrmals wöchentlich unter dem Mikroskop hinsichtlich Konfluenz, abgestorbene Zellen und möglichen Kontaminationen kontrolliert.

\subsubsection{Trypsinierung und Passagieren der Fibroblasten}

Nach Erreichen einer 80\%-Konfluenz erfolgte die Subkultivierung. Hierzu wurde zuerst das verbrauchte Medium entfernt und der Zellrasen in $10 \mathrm{ml}$ Phosphat-gepufferter Salzlösung (PBS) gewaschen. Anschließend wurden $3 \mathrm{ml}$ Trypsin/EDTA-Lösung in die Zellkulturflasche zugegeben und durch gleichmäßiges Schwenken alle Zellen damit bedeckt. Um den Ablösungsprozess des Trypsins zu unterstützen, wurden die Zelfflaschen für etwa 3 min bei 37 ${ }^{\circ} \mathrm{C}$ im Brutschrank inkubiert. Zur Zellsuspension wurde danach $5 \mathrm{ml}$ Kulturmedium hinzugegeben, um die enzymatische Reaktion des Trypsins und somit die weitere Zelllyse zu stoppen. Mittels einer Pipette wurde die Suspension in ein 15-ml-Falcon überführt. Es folgte die Zentrifugation bei $100 \mathrm{U} / \mathrm{min}$ für $5 \mathrm{~min}$ bei $21^{\circ} \mathrm{C}$. Der Überstand wurde im Anschluss verworfen, das gebildete Zellpellet mit frischem Vollmedium resuspendiert und auf mehrere Zellkulturflaschen expandiert. Zur Bestimmung der Zelldichte wurde die Zellzahl mit Hilfe einer Neubauer-Zählkammer ermittelt. Sämtliche Arbeitsschritte in der Zellkultur erfolgten unter der Sterilbank und waren von einer gründlichen Hände- und Arbeitsplatzdesinfektion begleitet.

\subsubsection{Auftauen und Einfrieren von adhärenten Zellen}

Zur längeren Aufbewahrung wurden Zellen eingefroren und im Stickstofftank gelagert. Zunächst wurden die Zellen im Vollmedium resuspendiert und zu gleichen Teilen, circa $500 \mu \mathrm{l}$, mit dem Einfriermedium in ein Kryoröhrchen überführt. Dieses verblieb über Nacht im mit Methanol gefüllten Nalgene Mr. Frosty Freezing Container und wurden bei einer Abkühlrate von $-1{ }^{\circ} \mathrm{C} / \mathrm{min}$ auf $-80^{\circ} \mathrm{C}$ heruntergekühlt. Am nächsten Tag konnte das Kryoröhrchen im Stickstofftank bei $-196{ }^{\circ} \mathrm{C}$ kryokonserviert werden. 
Für die erneute Verwendung wurden die Zellen in einem $37^{\circ} \mathrm{C}$ warmen Wasserbad aufgetaut, mit DMEM verdünnt, abzentrifugiert und anschließend auf Zellkulturflaschen bzw. Petrischalen mit $10 \mathrm{ml} / 5 \mathrm{ml}$ des entsprechenden Vollmediums verteilt.

\subsection{Mausstudie}

\subsubsection{Tiermodell und Studiendesign}

Der Effekt von RLX 030 zur Behandlung renaler Fibrogenese wurde im Tierexperiment unter Verwendung eines etablierten Mausmodells untersucht. In den entsprechenden Versuchsgruppen wurden acht bis zwölf Wochen alte männliche und weibliche Mäuse mit dem Hintergrund WT C57BL/6J und einem Körpergewicht von ungefähr $20 \mathrm{~g}$ verwendet. Die Wildtyp-Mäuse wurden drei Zeitpunkten (drei, sieben und zehn Tagen) und drei Konzentrationsgruppen mit jeweils $\geq 12$ Tieren zugewiesen. Mindestens sechs Tiere dienten pro Zeitpunkt und Konzentration jeweils als Kontrollgruppe und wurden mit PBS behandelt.

A

UUO/Minipumpe

$\mathrm{RLX030}[50 / 200 / 500 \mu \mathrm{\mu g} / \mathrm{kg} \mathrm{KG}]$

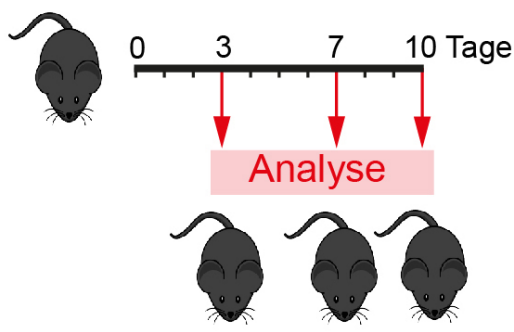

Abbildung 6: Initiales Mausmodell zur Untersuchung des inhibitorischen Effekts von RLX030. (A) Unilaterale Ureterobstruktion sowie Implantation der osmotischen Minipumpe gefüllt mit drei unterschiedlichen Konzentrationen RLX030 an Tag 0. Anschließende Sektion der Mäuse nach drei, sieben oder zehn Tagen.

\subsubsection{Berechnung der Medikamentendosierung}

Die Versuchstiere wurden mit dem Wirkstoff Relaxin030 (Novartis) behandelt, welches eine Konzentration von $4,75 \mathrm{mg} / \mathrm{ml}$ besaß. Die angestrebten Medikamentendosierungen betrugen 500-, 200- und $50 \mu \mathrm{g} / \mathrm{kg} \mathrm{KG/Tag.} \mathrm{Um} \mathrm{eine} \mathrm{konstante} \mathrm{Abgabe} \mathrm{des} \mathrm{Relaxins} \mathrm{sicherzustellen,}$ wurden den Wildtyp-Mäusen osmotische Minipumpen (Modell 1002) der Firma Alzet ${ }^{\circledR}$ intraperitoneal im Abdomen implantiert. Vor Implantierung wurde diese entsprechend der Volumengröße von $100 \mu \mathrm{l}$ bei einer Konzentration von $500 \mu \mathrm{g} / \mathrm{kg} \mathrm{KG/Tag}$ mit 35,2 $\mu \mathrm{l}$ Relaxin030 und $64,8 \mu \mathrm{l}$ PBS mittels einer Kanüle befült und über Nacht bei $37^{\circ} \mathrm{C}$ in PBS equilibriert. Für die Kontrollgruppen wurden die Pumpen mit $100 \mu \mathrm{l}$ PBS versehen. Mit einer Pumprate von $0,25 \mu \mathrm{l}$ pro Stunde wurden $6 \mu \mathrm{l}$ dieser Lösung pro Tag über drei, sieben und zehn Tage durch Osmose kontinuierlich abgegeben. 


\subsubsection{Funktionsweise und Implantierung der osmotischen Minipumpe}

Die ALZET-Pumpe besteht aus einer äußeren semipermeablen Membran, einer Salzkammer mit hochkonzentrierter Natriumchloridlösung und der inneren flexiblen impermeablen Membran, die den Medikamentenfüllraum umschließt. Aufgrund einer osmotischen Druckdifferenz strömt Körperflüssigkeit durch die semipermeable Membran zur Salzkammer. Diese drückt durch eine kontinuierliche Volumenzunahme das im Füllraum befindliche Medikament über eine Auslauföffnung am Pumpenpol in den Tierkörper. Die konstante Pumprate wird somit durch die Wasserpermeabilität der äußeren Membran bestimmt und wird nicht durch das Molekulargewicht oder die physikalischen oder chemischen Eigenschaften der abzugebenden Lösungen beeinflusst. Die Pumpen wurden sofort nach der unilateralen Obstruktion des Ureters (UUO) in die Versuchstiere eingebracht (Greenshaw 1986, Doucette et al. 2000).

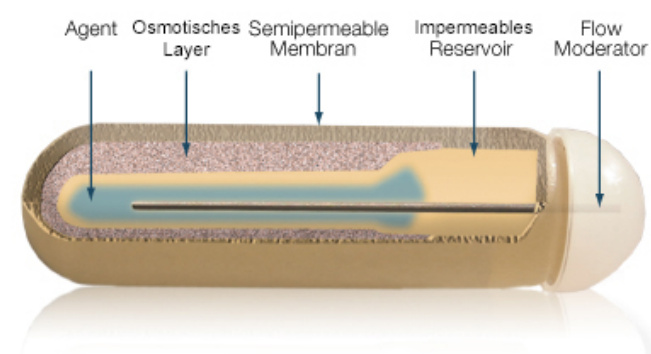

Abbildung 7: Osmotische Minipumpe Modell 1002 der Firma Alzet ${ }^{\circ}$ (modifiziert nach: alzet.com).

\subsubsection{Unilaterale Ureterobstruktion}

Die UUO-Operation diente der Induktion renaler tubulointerstitieller Fibrose und wurde von Herrn Dr. med. Björn Tampe (Klinik für Nephrologie und Rheumatologie, Universitätsmedizin Göttingen) durchgeführt. Die Wildtyp-Mäuse bekamen $20 \mathrm{~min}$ vor Operation $100 \mu \mathrm{l}$ des Analgetikums Buprenorphin ( $0,1 \mathrm{~g} / \mathrm{kg} \mathrm{KG}, 1: 10$ mit NaCl 0,9\% verdünnt) intravenös verabreicht. Weiter wurden sie kurznarkotisiert mit inhalativen Isofluran, das Bauchfell rasiert, desinfiziert und die Tiere auf dem Rücken in ein Schlauchsystem platziert. Über dieses erfolgt die weitere Anästhesie mit Isufloran. Mittels einer medianen, ca. $1 \mathrm{~cm}$ langen Laparotomie wurde der Bauch eröffnet. Nach vorsichtigen Eventerieren der Darmschlingen konnte der linke Ureter vom umliegenden Gewebe separiert und dargestellt werden. Durch zwei Ligaturen (Prolene 6-0, ETHICON, Belgien) im Abstand von $5 \mathrm{~mm}$ wurde der Ureter zwischen dem oberen und mittleren Drittel abgebunden. Die kontralaterale Niere blieb unbeeinträchtigt und fungierte als Kontrolle. Nach Zurückverlagern des Darms wurde die Alzet ${ }^{\circledR}$ Minipumpe intraperitoneal in die Bauchhöhle eingebracht. Zum Schluss erfolgte ein zweischichtiger Wundverschluss (Vicryl 4-0, ETHICON, Belgien). Sowohl vor als auch nach OP bekamen die Mäuse über das Trinkwasser 
Metamizol zur Weiteren analgetischen Behandlung (Novaminsulfon $500 \mathrm{mg} / \mathrm{ml}$ Tropfen, 15 Tropfen auf $250 \mathrm{ml}$ ).

\subsubsection{Präparation der Versuchstiere}

Nach dem dritten, siebten und zehnten postoperativen Tag wurden die Mäuse von Frau Sarah Rinkleff erneut mittels Isofluran kurznarkotisiert und innen anschließend $500 \mu \mathrm{l}$ Blut mittels Heparin-getränkten Glaspipetten retrobulbär entnommen. Das Blut wurde in ein 1,5-mlEppendorfgefäß überführt und für die Dauer der Sektion auf Eis gelagert. Danach erfolgte die Tötung durch zervikale Dislokation. Bei der Sektion wurden das Abdomen sowie der Thorax mittels Längslaparotomie eröffnet, Herz, Milz, Leber, Lunge, Pankreas, Interstitium, Uterus und beide Nieren entnommen. Die besagten Organe wurden mit Hilfe eines Skalpells gedrittelt, wobei je ein Teil in ein Kryoröhrchen, ein weiterer in Tissue-Tek® Cryomold®-Formen überführt und kurzzeitig in flüssigem Stickstoff gelagert wurde, bevor sie zur Langzeitaufbewahrung bei $80^{\circ} \mathrm{C}$ kryokonserviert wurden. Der letzte Gewebeanteil wurde auf Einbettkassetten verteilt und in $4 \%$-iger Formaldehydlösung fixiert.

\subsubsection{Verarbeitung und Lagerung der Blutproben}

Die Eppendorfgefäße mit dem Blut wurden bei $4{ }^{\circ} \mathrm{C}$ und $3500 \mathrm{U} / \mathrm{min}$ für $10 \mathrm{~min}$ zentrifugiert. Anschließend konnte das Serum im Überstand in ein weiteres 1,5-ml-Eppendorfgefäß pipettiert und bei $-80^{\circ} \mathrm{C}$ tiefgefroren werden.

\subsubsection{Zweites unabhängiges Tiermodell (medikamententoxische Verifikation mit anderem genetischen Hintergrund - FVBN)}

In einem weiteren etablierten Mausmodell wurden 12-14 Wochen alte männliche und weibliche Wildtyp-Mäuse mit dem Hintergrund FVBN und einem Körpergewicht von $25 \mathrm{~g}$ verwendet. Die Mäuse wurden vier Zeitpunkten (3, 28, 84, 140 Tage) mit jeweils $\leq 20$ Tieren zugewiesen. Mindestens fünf Tiere wurden pro Zeitpunkt mit RLX030 oder mit PBS behandelt, diese wurden abermals über eine osmotische Minipumpe von der Firma Alzet (Modell 2006) appliziert. Die angestrebte Medikamentendosierung betrug $200 \mu \mathrm{g} / \mathrm{kg} \mathrm{KG/Tag.} \mathrm{Für} \mathrm{den} \mathrm{ersten} \mathrm{Zeitpunkt} \mathrm{(Tag}$ drei) fand sowohl die Applikation der Folsäure als auch die Implantation der osmotischen Minipumpe am gleichen Tag statt. Bei den anderen Zeitpunkten erfolgte zuerst die subkutane Injizierung der Folsäure (Folic acid (F7876-10G)) und zwei Tage später dann die subkutane Implantation der Pumpe. Ein Wechsel der Pumpen wurde nach jeweils sechs Wochen durchgeführt. Die Präparation der Versuchstiere war identisch mit dem ersten Mausmodell. 
A

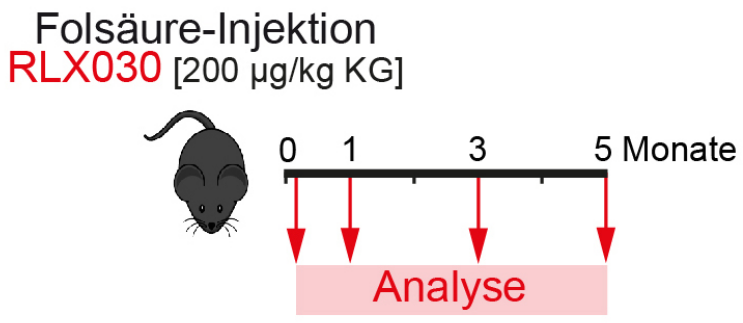

Abbildung 8: Zweites unabhängiges Mausmodell mit dem genetischen Hintergrund FVBN und Folsäure-Applikation zur Induktion der Nierenfibrose. (A) Folsäure-Injektion sowie Implantation der osmotischen Minipumpe gefüllt mit $200 \mu \mathrm{g} / \mathrm{kg} \mathrm{KG/Tag} \mathrm{RLX030.} \mathrm{Anschließende} \mathrm{Sektion} \mathrm{der} \mathrm{Mäuse} \mathrm{nach}$ drei Tagen, einem, drei und fünf Monaten.

\subsection{Proteinbiologische Methoden}

\subsubsection{Proteinisolation}

Murines Nierengewebe

Von den Nierengewebeproben wurden ca. $4 \mathrm{~mm}^{3}$ große Stücke abgetrennt, in 2-mlEppendorfgefäßen mit $350 \mu \mathrm{l}$ NP40-Lysisbuffer überführt und mittels einer Edelstahlkugel im Oszillator homogenisiert. Zum sicheren Probenaufschluss wurde das Homogenisat anschließend im Sonicator nochmals fragmentiert. Für die weitere Proteinisolierung wurde das Lysat in ein 1,5-ml-Eppendorfgefäß pipettiert.

\section{Stimulation von TK-Zellen und primären Fibroblasten}

Nach Aussaat der TK-Zellen bzw. primären Fibroblasten in T75-Zellkulturflaschen zu je $1 \times 10^{6}$ und $5 \times 10^{5}$ Zellen in $5 \mathrm{ml}$ erfolgte die Kultivierung über sechs Stunden im DMEM-Vollmedium und für weitere sechs Stunden im serumfreien Hungermedium. Anschließend wurden die Zellen mit TGF-ß1 und RLX030 in einer absteigenden Verdünnungsreihe 72 Stunden lang inkubiert. Als Kontrolle diente wiederum je eine unbehandelte Zellkulturflasche im Hungermedium. Nach Beendigung der Stimulationszeit wurde der Zellrasen mit $3 \mathrm{ml}$ PBS gewaschen und mittels eines Zellschabers bzw. Trypsin (primäre Fibroblasten) vom Zellkulturflaschenboden gelöst. Anschließend erfolgte die Zentrifugation und Zelllyse durch Hinzugabe von $150 \mu$ Z Zellysispuffer über $30 \mathrm{~min}$ auf Eis sowie das regelmäßige Vortexen alle $10 \mathrm{~min}$. Nach erneuter Zentrifugation bei $4{ }^{\circ} \mathrm{C}$ und $8000 \mathrm{U} / \mathrm{min}$. konnte der Überstand abgenommen werden.

\section{Bestimmung der Proteinkonzentration}

Zur Bestimmung der Proteinkonzentration im Überstand diente das BCA Protein Assay Kit der Firma Pierce. Das Prinzip dieser Methode basiert auf einer kombinierten Reaktion bei der zunächst unter Proteinanwesenheit im alkalischen Medium $\mathrm{Cu}^{+2} \mathrm{zu} \mathrm{Cu}^{+1}$ reduziert wird (Biuret- 
Reaktion). Das reduzierte Kupfer-Ion bildet mit zwei Molekülen Bicinchinonsäure (BCA) einen violetten und wasserlöslichen Chelatkomplex. Dieser weist eine starke Absoption bei $562 \mathrm{~nm}$ auf.

1). Protein (Peptidbindungen) $+\mathrm{Cu}^{+2} \rightarrow$ tetradentate- $\mathrm{Cu}^{+1}$ Komplex

2). $\mathrm{Cu}^{+1}+2$ Bicinchonsäure (BCA) $->\mathrm{BCA}-\mathrm{Cu}^{+1}-$ Komplex (violettgefärbt bei $562 \mathrm{~nm}$ )

Der Farbkomplex ist in seiner Extinktion proportional zur Proteinkonzentration und kann koliometrisch mittles Spektralphotometer NanoDrop ${ }^{\mathrm{TM}} 2000$ detektiert werden. Hierbei wird die Proteinmenge relativ zu einer BSA-Standardkurve ermittelt.

\subsubsection{Polyacrylamid-Gelelektrophorese (SDS-Page)}

Die Proteine können nach Verdünnung auf die entsprechende Konzentration $(25 \mu \mathrm{g})$ mittels SDS-Polyacrylamid-Gelelektrophorese nach Laemmli (Laemmli 1970) ihrer Größe nach aufgetrennt werden. Hierfür wird das Proteinlysat im Verhältnis 1:1 mit dem LDS-Sample-Buffer gemischt und für 5 min bei $95^{\circ} \mathrm{C}$ im Thermoblock denaturiert. Die hohe Wärmeexposition sowie das anionische Detergenz SDS führen zum Aufbrechen der Wasserstoffbrückenbindungen. Das Reduktionsmittel ß-Mercaptoethanol bricht darüber hinaus Dislufidbrücken auf. Die Sekundärund Tertiärstruktur der Proteine gehen somit verloren. Zudem führt das SDS zur NegativLadung aller Proteine, indem durch Anlagerung die Eigenladung der Proteine verdeckt werden. Somit kann eine ausschließliche Trennung nach Größe der Polypeptidketten stattfinden.

Für die SDS-Page wurden 4-12\% Bis-Tris-Gele eingesetzt. Pro Well wurden $25 \mu \mathrm{l}$ des ProteinPuffer-Gemisches pipettiert. Die Elektrophoresekammer wurde mit einem Innen-und Außenpuffer befüllt und unter Verwendung einer Spannungsquelle erfolgte die elektrophoretische Auftrennung der Proben bei zunächst $80 \mathrm{~V}$ für $15 \mathrm{~min}$ und anschließend bei 120 V für über zwei Stunden. Als Leiter für den Größenvergleich wurde der Novex® Sharp PreStained Protein Standard verwendet, welcher Proteine im Größenbereich zwischen 3,5 - 260 kDA umfasst.

\subsubsection{Proteintransfer}

Das Blotten dient der quantitativen sowie qualitativen Analyse der durch SDS-Page elektrophoretisch aufgetrennten Proteine. Für diese Methode wurden die Proteine aus dem BisTris-Trenngel auf eine Blotting-Membran übertragen und so mit Hilfe spezifischer Antikörper nachgewiesen. Diese Membran bestand aus Nitrozellulose, an die die Proteine durch hydrophobe Wechselwirkung gebunden werden (Bioanalytik | Friedrich Lottspeich | Springer, Rehm und Letzel 2010). Der Transfer der Proteine erfolgte nach der Semi-Dry Methode. Hierfür wurden die Membran sowie die Filterpapiere für ein paar Minuten im Transferpuffer äquilibriert. Dieser setzt sich aus dem Fast-Semi-Dry-Buffer und destilliertem Wasser im Verhältnis 1:10 
zusammen. Im Weiteren wurde ein Blot-Sandwich gebaut, welches in der Reihenfolge aus Filterpapieren, Nitrozellulosemembran, Gel und abermals Filterpapieren geschichtet auf den Fastblot eingespannt wurde. Für die Eluierung der Proteine aus dem Gel und den Transfer auf die Membran wurde eine senkrecht zum Gel gerichtete Spannung von zunächst $150 \mathrm{~mA}$ angelegt, welche nach $15 \mathrm{~min}$ auf $250 \mathrm{~mA}$ für weitere 45 min erhöht wurde.

\subsubsection{Semi-Dry-Western Blot}

Nach dem Proteintransfer wurde die Membran für eine Stunde bei Raumtemperatur mit Blockmedium (5\%iger Magermilch bzw. 5\%igem BSA in TBS-T) inkubiert, um unspezifische Antikörperbindungsstellen zu blockieren, bevor die Membran über Nacht bei $4{ }^{\circ} \mathrm{C}$ mit dem Primärantikörper in 2\%iger Magermilch oder 2\%igem BSA inkubiert wurde. Der Antikörper bindet spezifisch an eine bestimmte Aminosäuresequenz (Epitop) des Proteins. (Die Antikörperkonzentrationen sind in Tabelle 15 aufgeführt.)

Nach dreimaligem Waschen der Nitrozellulosemembran mit TBS-T für je 5 min wurde sie mit einem Meerrettich-Peroxidase (HRP)-gekoppelten Sekundärantikörper in der Verdünnung 1:2000 für eine Stunde bei Raumtemperatur im 5\%igem Blockmedium inkubiert.

Nach erneutem dreimaligem Waschen in TBS-T über jeweils $5 \mathrm{~min}$, erfolgte die Detektion mittels 20x LumiGLO $\circledast$ Reagenz und 20x Peroxidase im Verhältnis 1:1. Die MeerrettichPeroxidase (HRP) katalysiert die Reaktion des Luminols (LumiGlo) mit der Peroxidase $\left(\mathrm{H}_{2} \mathrm{O}_{2}\right.$ ) zu einem angeregten intermediären Dianion, 3-Aminophthalat. Dieses emittiert Licht (Chemilumineszenz), während es in seinen engergetischen Grundzustand zurückkehrt. (Lottspeich und Zorbas, 1998). Diese Chemilumineszenz wird im ChemiDoc ${ }^{\text {TM }}$ MP System quantifieziert und ist proportional zur Proteinmenge auf der Membran. Die densitometrische Auswertung der Western Blot-Bilder erfolgte mit dem Programm ImageJ. Zur Normalisierung erfolgt das Anfärben der Membran mit dem Housekeeping-Gen GAPDH. Hierfür wurde die Membran für 60 min bei Raumtemperatur mit dem Stripping Buffer von Thermo Scientific auf dem Roller inkubiert. Danach erfolgte nach dreimaligem Waschen in TBS-T für 5 min das Blocken der Membran in 5\%igem BSA für eine Stunde bei Raumtemperatur und die Inkubation mit dem Primärantikörper GAPDH in $2 \%$ igem BSA über Nacht bei $4{ }^{\circ} \mathrm{C}$. Am nächsten Tag wurde die Membran abermals nach dreimaligem Waschen mit dem HRP-konjugierten Sekundärantikörper in $5 \%$ igem BSA für eine Stunde bei Raumtemperatur inkubiert. Nach dreimaligem Waschen in TBS-T für jeweils 5 min erfolgte die erneute Detektion mittels des ChemiDoc ${ }^{\mathrm{TM}}$ MP System. 
Tabelle 15: Verwendete Antikörper für die Western Blots

\begin{tabular}{|c|c|c|c|c|c|}
\hline \multicolumn{3}{|l|}{ Primärantikörper } & \multicolumn{3}{|c|}{ Zugehöriger Sekundärantikörper } \\
\hline Antigen (kD) & Ursprung & Verdünnung & Ursprung & Markierung & Verdünnung \\
\hline $\begin{array}{l}\text { Anti-Alpha Smooth Muscle Actin } \\
(42 \mathrm{kDa})\end{array}$ & Maus & $1: 5000$ & Kaninchen & HRP & $1: 2000$ \\
\hline $\begin{array}{l}\text { Anti-p-Smad2 (Ser465/467), } \\
(60 \mathrm{kDa})\end{array}$ & Kaninchen & $1: 600$ & Ziege & HRP & $1: 2000$ \\
\hline $\begin{array}{l}\text { Anti-p-Smad } 3 \text { (Ser423/425), } \\
(52 \mathrm{kDa})\end{array}$ & Kaninchen & $1: 1000$ & Ziege & HRP & $1: 2000$ \\
\hline $\begin{array}{l}\text { Anti-Relaxin-Receptor } 1 \text { (H-160), } \\
\text { (85-95kDa) }\end{array}$ & Kaninchen & $1: 500$ & Ziege & HRP & $1: 2000$ \\
\hline $\begin{array}{l}\text { Anti-Relaxin-Receptor } 2 \text { (H-150), } \\
(86-103 \mathrm{kDa})\end{array}$ & Kaninchen & $1: 500$ & Ziege & HRP & $1: 2000$ \\
\hline Anti-Relaxin 2, (21kDa) & Kaninchen & $1: 1000$ & Ziege & HRP & $1: 2000$ \\
\hline
\end{tabular}

\subsection{Molekularbiologische Methoden}

\subsubsection{RNA-Isolation aus Fibroblasten und murinem Gewebe}

\section{Fibroblasten}

TK 173 und 188 wurden in 6-Well-Platten zu je 100.000 Zellen in $2 \mathrm{ml}$ Vollmedium pro Well ausgesät. Die primären Fibroblasten befanden sich hingegen in Petrischalen zu jeweils 60.000 Zellen und $5 \mathrm{ml}$ Vollmedium. Nach sechs Stunden wurde bei allen drei Zellinien ein Mediumwechsel in das serumfrei Hungermedium DMEM durchgeführt. Das Stimulanz TGF-ß1 wurde in serumfreiem DMEM auf $10 \mathrm{ng} / \mathrm{ml}$ und Relaxin030 im PBS auf eine Konzentration von $1 \mathrm{ng} / \mu \mathrm{l}$ verdünnt. Die Stimulationskonzentrationen sowie die genaue Stimulationsdauer beider Substanzen sind der folgenden Tabelle 16 zu entnehmen.

Als Kontrollen dienten in allen Experimenten unstimulierte Fibroblasten, welche simultan in reinem DMEM inkubiert wurden. Nach entsprechender Inkubationsdauer erfolgte nach dem Waschen mit PBS die Zelllysis mittels Trypsin und die anschließende Isolierung der mRNA unter Verwendung des Kitsystems PureLink® RNA Mini-Kit.

Tabelle 16: Stimulationsschema von Fibroblasten für die qRT-PCR

\begin{tabular}{|c|c|c|c|}
\hline Ziel mRNA für qRT-PCR & Medikamenten-Konz. & Kostimulanzien & Stimulationsdauer \\
\hline Acta2 & $\mathrm{RLX030} \mathrm{0,1-100 \textrm {ng } / \mu \mathrm { l }}$ & rhTGF- $\beta 1$ & 48 Stunden \\
\hline Col1a1 & $\mathrm{RLX030} \mathrm{0,1-100} \mathrm{ng/ \mu l}$ & rhTGF- $\beta 1$ & 72 Stunden \\
\hline$R \times f p 1, R x f p 2, R \times f p 3$ & & rhTGF- $\beta 1$ & 48 Stunden \\
\hline
\end{tabular}


Die zu verwendenden Zellen wurden mittels Trypsin von den 6-Well-Platten gelöst, gezählt, in $1,5 \mathrm{ml}$ Tubes für $5 \mathrm{~min}$ bei $12000 \mathrm{U} / \mathrm{min}$ abzentrifugiert und das Pellet mit $1 \mathrm{ml}$ TRIzol®-Lösung gründlich homogenisiert. Das entstandene Lysat wurde für 5 min bei Raumtemperatur inkubiert, um eine komplette Auflösung der Nukleoprotein-Komplexe zu gewährleisten.

Für eine optimale Phasentrennung wurde das Zelllysat mit $200 \mu \mathrm{l} \mathrm{Chloroform} \mathrm{angereichert,}$ einige Sekunden lang kräftig geschüttelt und für 15 min bei $4{ }^{\circ} \mathrm{C}$ und $12000 \mathrm{U} / \mathrm{min}$ zentrifugiert. Anschließend wurden vorsichtig $500 \mu \mathrm{l}$ der oberen transparenten Phase in ein neues $1,5-\mathrm{ml}-$ Eppendorf-Gefäß überführt, welches noch mit der gleichen Menge an $70 \%$ igem Ethanol versetzt wurde. In zwei Arbeitsschritten wurde dann das gesamte Zellextrakt auf eine SilikatGelmembran einer Spin-Säule aufgetragen. Es erfolgte die Zentrifugation für 15 Sekunden bei $12000 \mathrm{U} / \mathrm{min}$ und das Verwerfen des Durchflusses. Zur weiteren Aufbereitung wurden verschiedene Waschpufferlösungen hinzugefügt:

- $\quad 1 \times 700 \mu \mathrm{l}$ Wash Buffer I

- $\quad 2 \times 500 \mu \mathrm{l}$ Wash Buffer II

Jeder Waschschritt war gefolgt von einer 15-sekündigen Zentrifugation bei $12000 \mathrm{U} / \mathrm{min}$. Zum Schluss konnte nach einer 2-minütigen Trockenzentrifugation die RNA mit $50 \mu$ nukleasefreiem Wasser und einem letzten Zentrifugationsschritt von der Membran gelöst werden.

Zur photometrischen Konzentrationsbestimmung der isolierten RNA wurde das NanoDrop ${ }^{\mathrm{TM}}$ 2000 Spektralphotometer verwendet. Hierfür wurden $1 \mu \mathrm{l}$ des RNA-Eluats auf die Probenhalterung aufgetragen und die Absorption im Verhältnis zum nukleasefreien Wasser bestimmt. Zur Sicherstellung der Qualität der RNA-Probe wurde der Quotient der Absorptionskoeffizienten bei $260 \mathrm{~nm}$ und $280 \mathrm{~nm}$ definiert. Dabei entspricht ein Wert von 2,0 reiner RNA. Liegen Abweichungen über dem angegebenen Wert vor, spricht dies für Proteinkontaminationen.

\section{Murines Nierengewebe}

Die bei der Maus-Sektion gewonnenen Gewebeproben wurden zum sicheren Probenaufschluss zuerst in ca. $2 \mathrm{~mm}^{3}$ große Gewebestücke geschnitten, in 2-ml-Eppendorfgefäße mit $1 \mathrm{ml}$ Trizol und einer Edelstahlkugen (Bead) überführt. Im Tissue Lyser wurde das Gewebe bei $50 \mathrm{~Hz}$ für 5 min homogenisiert. Anschließend wurde $1 \mathrm{ml}$ des Lysats in ein neues Eppendorfgefäß pippetiert und die RNA, wie schon beschrieben, mit dem PureLink ${ }^{\circledR}$ RNA Mini Kit System isoliert. 


\subsubsection{Reverse Transkription der mRNA in cDNA}

Die aufgereinigte mRNA wurde im Anschluss unter Verwendung des Thermocyclers Mastercycler ep gradient $S$ in die entsprechende cDNA umgeschrieben. Hierfür wurden $50 \mathrm{ng}$ der mRNA mit $2 \mu \mathrm{l}$ des Oligonukleotid-Ansatzes gemischt und für 5 min bei $65^{\circ} \mathrm{C}$ inkubiert. Das Oligo-dT ist komplementär zur Poly-Adenosin-Sequenz und spezifisch für mRNAs.

\section{Oligonukleotid-Ansatz (ProProbe)}

Tabelle 17: Oligonukleotid-Ansatz für die reverse Transkription

\begin{tabular}{lcc}
\hline \multicolumn{1}{c}{ Reagenz } & Volumen \\
\hline \hline Oligo-dT & $1 \mu \mathrm{l}$ \\
\hline $\mathrm{dNTP}$ Mix $10 \mathrm{mM}$ & $1 \mu \mathrm{l}$ \\
\hline \multicolumn{3}{c}{$5 \mathrm{~min}$ bei $65^{\circ} \mathrm{C}$} \\
\hline
\end{tabular}

Für den Verdau endogener RNasen wurde der Ansatz für 2 min bei $42^{\circ} \mathrm{C}$ mit dem Ribonuklease-Inhibitor RNaseOut ${ }^{T M}$ inkubiert.

\section{RNAseOut-Ansatz ${ }^{\mathrm{TM}}$ (Pro Probe)}

Tabelle 18: RNAseOut-Ansatz für die reverse Transkriptase

\begin{tabular}{lc}
\hline \multicolumn{1}{c}{ Reagenz } & Volumen \\
\hline \hline $5 \times$ First Strand Buffer & $4 \mu \mathrm{l}$ \\
\hline 0,1 MDTT & $2 \mu \mathrm{l}$ \\
\hline RNAseOut ${ }^{\mathrm{TM}}$ & $1 \mu \mathrm{l}$ \\
\hline & $2 \min$ bei $42^{\circ} \mathrm{C}$ \\
\hline
\end{tabular}

Die Umschreibung der mRNA in cDNA erfolgte nach Zugabe von $1 \mu$ der Reversen Transkriptase SuperScript $\circledast$ II und Inkubation über $50 \mathrm{~min}$ bei $42^{\circ} \mathrm{C}$. Anschließend wurde diese bei $70{ }^{\circ} \mathrm{C}$ für 15 min inaktiviert.

Die umgeschriebene cDNA konnte nun mit $80 \mu$ nukleasefreiem Wasser auf eine Endkonzentration von $50 \mathrm{ng} / \mu \mathrm{l}$ verdünnt und bis zur weiteren Verwendung bei $-20{ }^{\circ} \mathrm{C}$ gelagert werden.

\subsubsection{Quantitative real-time PCR (qRT-PCR)}

Die Polymerase-Kettenreaktion (PCR) ist eine von Mullis und Faloona etablierte in vitro-Technik zur gezielten Amplifikation von DNA-Fragmenten (Mullis und Faloona 1987). Nach thermischer Denaturierung und Dissoziation der doppelsträngigen DNA in Einzelstränge folgt die 
Hybridisierung spezifischer Primerpaare (Oligonukleotide von 10-30 Basenpaaren Länge) an die Einzelsträngige-DNA. Dieser Prozess wird als Annealing bezeichnet. Die Vorwärts- und Rückwärtsprimer binden bei ihrer spezifischen Annealingstemperatur $\left(65-72{ }^{\circ} \mathrm{C}\right)$ an die komplementären DNA-Strukturen. Sie fungieren so über ihre freie 3'-OH Gruppe für die thermostabile DNA-Polymerase aus dem Bacterium Thermus aquaticus, als Ausganspunkt für die Synthese eines neuen komplementären DNA-Strangs (Elongation). Die quantitative realtime PCR ist ein Verfahren, welches von Higuchi et al. etabliert wurde und bei dem in Echtzeit die Akkumulation von PCR-Produkten verfolgt werden kann, um so die exponentielle Phase der Reaktion zu identifizieren. Dies ist für die anschließende Quantifizierung der Templatmenge entscheidend. Die Messung erfolgt in Form eines spezifischen Fluoreszenzsignals, welches von der gebildeten PCR-Produktmenge abhängig ist. Das produktabhängige Fluoreszenzsignal wird durch spezifische DNA-bindende Fluoreszenzfarbstoffe ermöglicht. Für die folgenden qRTPCRs wurde SYBER-Green I verwendet, ein Farbstoff, welcher sequenzunabhängig in der kleinen Furche doppelsträngiger DNA bindet und proportional fluoresziert. Folglich kann nach jedem Zyklus die Menge an PCR-Produkten gemessen und mit einem Fluoreszenzschwellenwert, bei dem das Fluoreszenzsignal sich deutlich vom Hintergrundsignal abhebt, verglichen werden. Die Zykluszahl, welche diesen Schwellenwert erreicht, wird als Threshold-Zyklus bzw. $\mathrm{C}_{\mathrm{T}}$ Wert bezeichnet. Je mehr cDNA enthalten ist, desto kleiner ist der $\mathrm{C}_{\mathrm{T}}$ Wert.

$\mathrm{Zu}$ beachten ist jedoch, dass man bei der Verwendung des CYBER Green I nicht zwischen Produkt und sogenannten Nebenprodukten wie zum Beispiel Primerdimern oder unspezifischen Amplifikationsprodukten unterscheiden kann. Aus diesem Grund wird anschließend eine Schmelzkurvenanalyse durchgeführt. Die beiden farbstoffassoziierten DNA-Einzelstränge werden bei ansteigender Temperatur in Abhängigkeit vom Schmelzwert Tm des Doppelstrangs unterschiedlich stark voneinander getrennt. Auf diese Weise wird das CYBER Green I wieder freigesetzt und führt so zu einer Abnahme der Fluoreszenz. Diese erreicht ihr Maximum, wenn beide Stränge vollständig voneinander getrennt werden. Ein spezifischer Primer führt zu einem Hochpunkt für das Hauptprodukt, wohingegen mehrere Maxima für unspezifische Nebenprodukte sprechen und nicht erscheinen sollten. In Tabelle 19 sind die spezifischen Primersequenzen für die qRT-PCR abgebildet.

Tabelle 19: Primersequenzen für die qRT-PCR

\begin{tabular}{lllll}
\hline $\begin{array}{l}\text { Ziel- } \\
\text { mRNA }\end{array}$ & $\begin{array}{l}\text { mRNA- } \\
\text { Nummer }\end{array}$ & $\begin{array}{l}\text { Primer Vorwärtsstrang 5’-3’ } \\
\text { Primer Rückwärtsstrang 5’-3' }\end{array}$ & $\begin{array}{l}\text { Ta } \\
{\left[{ }^{\circ} \mathbf{C}\right]}\end{array}$ & $\begin{array}{l}\text { Fragmentlänge } \\
{[\mathbf{b p}]}\end{array}$ \\
\hline \hline \multirow{2}{*}{ Acta2 } & NM_007392 & $\begin{array}{l}\text { CTC TTC CAG CCA TCT TTC ATT G } \\
\text { GTT GTT AGC ATA GAG ATC CTT CCT }\end{array}$ & 58,4 & 111 \\
\hline \multirow{2}{*}{ Col1a1 } & \multirow{2}{*}{ NM_007742 } & $\begin{array}{l}\text { ATG GAT TCC CGT TCG AGT ACG } \\
\text { TCA GCT GGA TAG CGA CAT CG }\end{array}$ & \multirow{2}{*}{59,7} & \multirow{2}{*}{63} \\
\hline
\end{tabular}




\begin{tabular}{|c|c|c|c|c|}
\hline \multirow{2}{*}{$R \ln 1$} & \multirow{2}{*}{ NM_011272 } & TGA TAA ACT GGG TGA AGC AGA AG & 57,4 & \multirow{2}{*}{82} \\
\hline & & СCT CTT TTT CCG TGA ATG GGT AT & 57,5 & \\
\hline \multirow{2}{*}{ RIn3 } & \multirow{2}{*}{ NM_173184 } & CTT GCG GAG GCT CAC GAT & 57,2 & \multirow{2}{*}{95} \\
\hline & & CAG GTG GTC TGT ATT GGC TTC & 56,9 & \\
\hline \multirow{2}{*}{ Rxfp 1} & \multirow{2}{*}{ NM_212452 } & ATT TCT CTC TGC TGT GCT GAC T & 58,2 & \multirow{2}{*}{102} \\
\hline & & CGG CTG TGC GTG CTT ATT G & 58,0 & \\
\hline \multirow{2}{*}{ Rxfp 2} & \multirow{2}{*}{ NM_080468 } & ACG AAC TCC ACC TTC CTA ACG & 58,0 & \multirow{2}{*}{88} \\
\hline & & AAA ATG TCT TCT CTG GAA CAA AAC C & 57,6 & \\
\hline \multirow{2}{*}{ RLN1 } & \multirow{2}{*}{ NM_006911 } & GGC AAC CAT CAT TAC CAG AGC & 57,6 & \multirow{2}{*}{148} \\
\hline & & TCC AAG CCT AAG TAT TTT AAT TCT GAA & 56,7 & \\
\hline \multirow{2}{*}{ RLN2 } & \multirow{2}{*}{ NM_134441 } & GCT CCT CAG ACA CCT AGA CC & 56,9 & \multirow{2}{*}{105} \\
\hline & & CTG TGG CAA ATT AGC AAC AAA TTC & 57,0 & \\
\hline \multirow{2}{*}{ RXFP 1} & \multirow{2}{*}{ NM_021634 } & GCT GTA TGC CAT GTC AAT CAT T & 56,0 & \multirow{2}{*}{99} \\
\hline & & TCT CCA CGA AAC TTT AGG TCA A & 55,8 & \\
\hline \multirow{2}{*}{$R X F P 2$} & \multirow{2}{*}{ NM_130806 } & GAT CAC TCC TTC ATG CCA AAA AG & 57,0 & \multirow{2}{*}{128} \\
\hline & & TGT CAC CAC AGT TCT CTT CGT & 57,5 & \\
\hline \multirow{2}{*}{ RXFP 3} & \multirow{2}{*}{ NM_016568 } & ACC AAA TCA GTG ACC ATC GTT & 56,1 & \multirow{2}{*}{95} \\
\hline & & GCG TTG AAC TTG ATG AGG ATG & 55,9 & \\
\hline
\end{tabular}

\subsubsection{DNA-Isolation aus murinem Gewebe}

Die Aufreinigung der DNA erfolgte aus humanem und murinem Nierengewebe sowie Vollblutproben. Es wurde das DNeasy Blood \& Tissue Kit (250) (Cat.-No. 69506) verwendet. $100 \mu \mathrm{l}$ des Vollbluts bzw. $20 \mathrm{~g}$ schwere Gewebsstücke wurden mit $20 \mu \mathrm{l}$ der Proteinase $\mathrm{K}$ in einem 1,5-ml-Tube gemischt und mit PBS bis $220 \mu$ aufgefüllt. Hierbei kam zu einer gezielten Aufspaltung der Peptidbindungen. Anschließend wurden $200 \mu \mathrm{l}$ des AL-Puffers hinzugefügt und die Lösung sofort mittels eines Vortexers ausreichend durchmischt, sodass eine homogene Lösung entstand. Diese wurde dann für $10 \mathrm{~min}$ bei $56{ }^{\circ} \mathrm{C}$ inkubiert. Bei den Gewebsproben erfolgte eine Inkubation über Nacht. Weiter wurde das Lysat mit $100 \mu$ l Ethanol (100\%) versetzt und erneut gut durchmischt. Die Mixtur wurde auf eine DNeasy Mini Spin Säule pipettiert, bei $\geq$ $6000 \times \mathrm{g}$ für $1 \mathrm{~min}$ bei Raumtemperatur zentrifugiert und der Durchfluss verworfen und anschließend mit zwei Wasch-Puffern AW 1 und 2 (je $500 \mu \mathrm{l}$ ) für 1 und 3 min bei $\geq 6000$ und 20000 x g zentrifugiert. Abschließend wurde die Säule in ein neues Mikrozentrifugen Tube überführt und die Membran mit $200 \mu \mathrm{l}$ des AE-Puffers für 1 min bei Raumtemperatur inkubiert. Die DNA konnte so im Puffer gelöst werden und befand sich nach erneuter Zentrifugation im Durchfluss. Für eine höhere DNA-Konzentration konnte der letzte Zentrifugationsschritt wiederholt werden. Mit Hilfe des NanoDrops wurde photometrisch die DNA-Konzentration bestimmt. 


\subsubsection{Methylierte DNA-Immunopräzipitation (MeDips)}

\section{Prinzip}

Epigenetische Modifikationen haben Einfluss auf die Aktivität von Genen. Ein zentraler Mechanismus für die epigenetische Alteration von genomischer DNA ist die Hypermethylierung von CpG-Inseln in spezifischen Promotorregionen von Genen und eine globale DNAHypomethylierung. Hierbei beeinflussen methylierte CpG-Inseln den Prozess, in dem DNAMethyltransferasen (Dnmts) eine Methylgruppe vom S-Adenosyl-L-Methionin zum fünften Kohlenstoffatom (C5) eines Cytosins übertragen.

Die DNA-Methylierung kann unter anderem mittels methylierter DNA-Immunopräzipitation untersucht werden. Bei dieser Methode wird ein Antikörper gegen 5-Methyl-Cytosin eingesetzt, der die methylierten DNA-Abschnitte anreichert. Diese können anschließend für eine Standard-

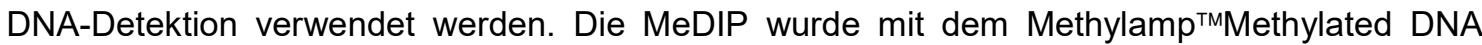
Capture Kit von Epigentek, nach Angaben des Herstellers, durchgeführt. Die isolierte DNA wurde zusammen mit dem Reaktions-Puffer MC2 durch einen Sonicators mittels Ultraschall in 500-1000 bp große Fragmente zerkleinert und für 2 min bei $95{ }^{\circ} \mathrm{C}$ inkubiert. Zur Vorbereitung wurden Strip-Wells mit $100 \mu \mathrm{l} \mathrm{MC1}$ (Antikörper-Puffer) und $1 \mu \mathrm{l}$ mit Anti-5-Methylcytosin für die Proben angesetzt. Nach 1 Stunde Inkubation bei Raumtemperatur folgten zwei Waschschritte mit je $150 \mu \mathrm{l}$ MC1 und MC3. Anschließend wurden $100 \mu \mathrm{l}$ der fragmentierten DNA pro Well aufgetragen und abermals für $120 \mathrm{~min}$ auf einem Shaker (Belly Dancer 50-100 U/min) inkubiert. Nach erneutem Waschen mit MC3 wurden $60 \mu \mathrm{l}$ MC4 (DNA Release Buffer) mit $1 \mu$ Proteinase $\mathrm{K}$ angesetzt und jeweils $60 \mu \mathrm{l}$ auf jedes Well pipettiert. Zudem wurden Wells als Negativkontrolle angesetzt mit Input-DNA. Nach einer Stunde Inkubation im Wasserbad bei 65 ${ }^{\circ} \mathrm{C}$ wurden $180 \mu \mathrm{l} \mathrm{EtOH} \mathrm{(100 \% )} \mathrm{auf} \mathrm{die} \mathrm{Wells} \mathrm{gegeben,} \mathrm{resuspendiert} \mathrm{und} \mathrm{auf} \mathrm{die} \mathrm{Spin} \mathrm{Säule}$ übertragen, die kurz vorher mit $100 \mu \mathrm{l}$ MC5 (Binding Buffer) behandelt wurde. Es schlossen sich drei Zentrifugationsschritte für $20 \mathrm{~s}$ bei $12000 \mathrm{U} / \mathrm{min}$ an, wobei die Säule mit $200 \mu \mathrm{l} 90 \%$ igem $\mathrm{EtOH}$ behandelt wurde. Nach Verwerfen des Durchflusses wurde die Säule auf ein neues Eppendorfgefäß platziert, die Filtermembran mit $20 \mu \mathrm{l}$ MC6 (Elutions-Puffer) behandelt und abschließend erneut bei $12000 \mathrm{U} / \mathrm{min}$ für $20 \mathrm{~s}$ zentrifugiert. Das Eluat enthielt die gereinigte methylierte DNA. Die DNA-Sequenz wird mit Primern, die für die Promoterregionen von Relaxin-1, -2 und -3 spezifisch sind, in einer qRT-PCR-Reaktion amplifiziert. Unter Verwendung der StepOne ${ }^{\top M}$ Software von Applied Biosystem kann das PCR-Produkt sequenziert und die Sequenz analysiert werden.

Beim Designen der Primer wurde darauf geachtet, dass die PCR-Produkte nicht länger als 200 bp waren. Zudem war zu beachten, dass die Primer-Region Cytosin beinhaltete. Dieses wird durch Thymin ersetzt und führt zu einer spezifischen Amplifikation von methylierter DNA. 
Für die humanen $R L N 1, R L N 2, R L N 3$, murinen $R / n 1$ und $R / n 3$ wurden Reaktionsansätze hergestellt, die $10 \mu \mathrm{l}$ CyberGreen, 4,6 $\mu \mathrm{l}$ nukleasefreies Wasser und jeweils 0,2 $\mu \mathrm{l}$ Primer Vorwärtsstrang $(20 \mu \mathrm{l})$ und Primer Rückwärtsstrag (20 $\mu \mathrm{l})$ enthielten.

\section{Programm der qRT-PCR RLN1, RLN2, RLN3 sowie RIn1 und RIn3:}

$20 \mathrm{~s} 95^{\circ} \mathrm{C}$, (3 s $95^{\circ} \mathrm{C}, 30 \mathrm{~s}$ Annealing + Elongation) x50 Annealing-Temperatur:

$\begin{array}{llll}\text { RLN1 } & 59^{\circ} \mathrm{C} & \mathrm{R} \ln 1 & 66^{\circ} \mathrm{C} \\ R L N 2 & 63^{\circ} \mathrm{C} & \operatorname{R} \ln 3 & 68{ }^{\circ} \mathrm{C} \\ \text { RLN3 } & 65^{\circ} \mathrm{C} & & \end{array}$

Tabelle 20: Primersequenzen für die methylierte DNA-Immunopräzipitation (MeDiP)

\begin{tabular}{|c|c|c|c|}
\hline Ziel-Gen & $\begin{array}{l}\text { Primer Vorwärtsstrang 5'-3' } \\
\text { Primer Rückwärtsstrang 5'-3' }\end{array}$ & $\mathrm{Ta}\left[{ }^{\circ} \mathrm{C}\right]$ & Fragmentlänge [bp] \\
\hline RLN1 & $\begin{array}{l}\text { CCA GGA AGA TGC TCC TCA GAC } \\
\text { CCG GTG AGA TTC CCA GTG AGA C }\end{array}$ & $59^{\circ} \mathrm{C}$ & $250 \mathrm{bp}$ \\
\hline RLN2 & $\begin{array}{l}\text { GGC CCA GGA TGC CTC GCC TG } \\
\text { CCT TTT GCT CCA GGT GCT CAT GCC }\end{array}$ & $63^{\circ} \mathrm{C}$ & $173 b p$ \\
\hline RLN3 & $\begin{array}{l}\text { CGC CTT ACG GGG TCA GGC TTT GC } \\
\text { GGG CAG GTG TCC CTG GCT GAA TGT G }\end{array}$ & $65^{\circ} \mathrm{C}$ & $200 \mathrm{bp}$ \\
\hline$R \ln 1$ & $\begin{array}{l}\text { GCT CCA GCT CCT GGG GTT CTG GC } \\
\text { CCA GTG GCT TGC CTG GCA AGC AGA G }\end{array}$ & $66^{\circ} \mathrm{C}$ & $195 \mathrm{bp}$ \\
\hline$R \ln 3$ & $\begin{array}{l}\text { GCT CGG GCT GCT GCT GCT GGC TTC C } \\
\text { GCG CTT ACC AGG ACA CCT GTT CCA GG }\end{array}$ & $68^{\circ} \mathrm{C}$ & $224 \mathrm{bp}$ \\
\hline
\end{tabular}

\subsection{Histologische Methoden}

\subsubsection{Anfertigung und Aufbereitung der Gewebeschnitte}

\section{Fixierung}

Um autolytische Vorgänge nach dem Tod zu verhindern und die Gewebemorphologie in weitgehend natürlichem Zustand zu erhalten, erfolgte die Fixierung in 4\%igem Formaldehyd. Dieses führt zur Ausbildung von Methylbrücken zwischen freien Aminogruppen der Proteine und somit zu deren Blockierung. Die so entstandene Proteinvernetzung hat eine bessere Strukturerhaltung zum Ziel.

\section{Paraffineinbettung}

Die über Nacht in 4\%igem Formaldehyd gelagerten Biopsate wurden anschließend in Paraffin eigebettet. Dazu wurden die Gewebeproben am folgenden Tag zunächst unter laufendem 
Leistungswasser vier Stunden lang bewässert, um das Fixiermittel auszuwaschen. Anschließend wurden die Organpräparate im Gewebeinfiltrationsautomat von Leica über eine aufsteigende Alkoholreihe in Paraffin gebettet. (1,5 h: 1 x 50\%, 1 x 70\%, 1 x 80\%, 2 × 95\%, 2 x 100\%, $2 \times$ Chloroform und $3 \times$ Paraffin für je eine Stunde) Im Anschluss wurden sie in der Ausgießstation in Paraffinblöcke gegossen und auf der Kühlplatte heruntergekühlt, sodass im nächsten Schritt aus jedem Block mittels eines Mikrotoms, Gewebeschnitte von je $3 \mu \mathrm{m}$ Dicke angefertigt werden konnten. Diese wurden zuerst in ein Wasserbad überführt zur besseren Entfaltung und anschließend auf SuperFrost-Objektträger übertragen. Zur besseren Adäsion des Gewebes an den Objektträgern erfolgte eine Trocknung über Nacht bei $37^{\circ} \mathrm{C}$. Die histologischen Präparate konnten danach bis zur histologischen Weiterverarbeitung in Präparatekästen bei Raumtemperatur aufbewahrt werden

Vorbereitung der Gewebeschnitte

Vor jeder histologischen Färbung wurden die Gewebeschnitte zunächst für zweimal 10 min in $100 \%$ igem Xylol entparaffiniert und durchliefen anschließend die folgende absteigende Alkoholreihe: 2 × 5 min EtOH 100\%, 1 x 5 min EtOH 80\%, 1 x 5 min EtOH 50\%, 1 x 5 min EtOH $30 \%$. Abschließend kamen die Schnitte für 5 min in Aqua dest. zur weiteren Bewässerung.

\subsubsection{Hämatoxylin-Eosin-Färbung (HE-Färbung)}

\section{Prinzip}

Die Hämatoxylin-Eosin-Färbung stellt eine Standardfärbung im histologischen Labor dar, deren Ziel die Darstellung von Gewebestrukturen und Beurteilung pathologischer Veränderungen im Gewebeschnitt ist.

Die basophilen Zellkerne werden mit Eisen-Hämatoxylin blau gefärbt und rot kontrastiert durch den azido- oder eosinophilen Zytoplasmafarbstoff Eosin.

Tabelle 21: Lösungen der HE-Färbung

\begin{tabular}{lllc}
\hline Färbelösung & Ansatz & Einwirkdauer \\
\hline \hline Hämalaun nach Meyer (CARL ROTH) & & 6 min \\
& & & \\
\hline \multirow{2}{*}{ Eosin pH 5} & Eosin-G & $200 \mathrm{ml}$ & \multirow{2}{*}{$1-2 \mathrm{~min}$} \\
& Salzsäure/Essigsäure & $1-2$ Tropfen & \\
\hline
\end{tabular}

\section{Färbung}

Die Schnitte wurden für die Kernfärbung zuerst 5 min in Meyers Hämalaunlösung gelegt und unter fließendem Leitungswasser gebläut. Anschließend erfolgte die Plasmafärbung in der mit 100\%iger Essigsäure angesäuerten Eosinlösung (pH5). Abschließend wurden die Schnitte jeweils zweimal kurz mittels einer aufsteigenden Alkoholreihe (EtOH 96\% und EtOH 100\%) entwässert, sowie $2 \times 5$ min in Xylol geklärt. Das Eindecken der Präparate wurde mit dem Eindeckmittel Entellan vorgenommen. 


\subsubsection{Periodsäure-Schiff'sche-Färbung (PAS-Färbung)}

\section{Prinzip}

Die PAS-Färbung ist ebenfalls eine Routinefärbung. Hierbei kommt es zur magenta-roten Färbung von glykogenhaltigen Zellbestandteilen und der extrazellulären Matrix wie beispielsweise Glykogen, Muco- und Glykoproteinen oder neutralen Mucopolysacchariden.

Die Perjodsäure ist ein starkes Oxidationsmittel und führt dazu, dass freie Hydroxylgruppen der Saccharide zu Aldehydgruppen oxidiert werden. Diese bilden dann mit der im Schiff-Reagenz vorhandenen Fuchsin-schwefeligen Säure einen rot-pinken Komplex.

Tabelle 22: Lösungen der PAS-Färbung

\begin{tabular}{ll}
\hline Färbelösung & Einwirkdauer \\
\hline \hline Perjodsäure 1\% & $10 \mathrm{~min}$ \\
\hline Schiff's Reagenz & $20 \mathrm{~min}$ \\
\hline Hämalaun nach Meyer (CARL ROTH GmbH \& Co. KG) & $5 \mathrm{~min}$ \\
\hline
\end{tabular}

\section{Färbung}

Die entparaffinierten Präparate wurden für $10 \mathrm{~min}$ in $1 \%$ iger Perjodsäure gestellt, für weitere 10 min unter fließendem Leitungswasser gewaschen und kurz mit Aqua dest. gespült. Es folgte die 20-minütige Inkubation im Schiff'schen Reagenz und das anschließende Waschen unter warmen Leitungswasser. Für die Kernfärbung kamen die Gewebeschnitte für 5 min ins Hämalaun nach Meyer und wurden unter fließendem Leitungswasser 10 min gebläut. Wie bereits beschrieben erfolgte abschließend das Entwässern über eine aufsteigende Alkoholreihe und das blasenfreie Eindecken mit Entellan.

\subsubsection{Masson-Trichrom-Färbung}

\section{Prinzip}

Die MTS-Färbung dient der differenzierten Bindegewebsdarstellung sowie der Quantifizierung des Fibrosegrads im Nierenparenchym. Hierbei färben sich die Zellkerne bräunlich-schwarz und das Zytoplasma rot an. Die Kollagenfasern heben sich von der Umgebung durch eine blaue Kontrastierung ab.

Tabelle 23: Lösungen der MTS-Färbung

\begin{tabular}{llll}
\hline Färbelösung & Ansatz & Einwirkdauer \\
\hline \hline Bouins Lösung & & & $15 \mathrm{~min}$ \\
\hline Weigerts Hämatoxylin-Lösung (Sigma-Aldrich) & Part A & $100 \mathrm{ml}$ & \multirow{2}{*}{$5 \mathrm{~min}$} \\
& Part B & $100 \mathrm{ml}$ & \\
\hline Säurefuchsin & & & $5 \mathrm{~min}$ \\
\hline
\end{tabular}




\begin{tabular}{|c|c|c|}
\hline Phosphorwolframsäure- & Phosphorwolframsäure $50 \mathrm{ml}$ & \\
\hline /Phosphormolybdänsäure-Arbeitslösung & Phosphormolybdänsäure 50 ml & $5 \mathrm{~min}$ \\
\hline (Sigma-Aldrich) & $\mathrm{ddH}_{2} \mathrm{O}$ & \\
\hline Anilinblau & & $10 \min$ \\
\hline Essigsäure & & kurz eintauchen \\
\hline
\end{tabular}

\section{Färbung}

Im Anschluss an die Entparaffinierung wurden die Schnitte bei $56{ }^{\circ} \mathrm{C} 15 \mathrm{~min}$ in der vorgewärmten Bouins Lösung fixiert, im Leitungswasser für 10 min heruntergekühlt und zum Auswaschen der gelben Farbe unter fließendes Leitungswasser gestellt. Des Weiteren wurden die Präparate zur Zellkernfärbung 5 min in Weigert's Eisenhämatoxylin-Lösung getaucht, erneut für 5 min gebläut unter fließendem Leitungswasser und schließlich dreimal mit destilliertem Wasser gespült. Anschließend erfolgte das Eintauchen der Gewebeschnitte in die BieberichScharlachrot-Säurefuchsin-Lösung für $5 \mathrm{~min}$ und drei weitere Spülungen mit destilliertem Wasser. Nachdem die Schnitte für abermals $5 \mathrm{~min}$ mit der Phosphorwolframsäure/Phosphormolybdän-Arbeitslösung behandelt worden waren, erfolgte die Inkubation der Präparate in Anilinblau zum Kollagennachweis. Ein leichtes Auswaschen der Farben wurde durch kurzeitiges Eintauchen in 1\%iger Essigsäure und destiliertem Wasser erreicht. Abschließend wurden die Schnitte wieder jeweils zweimal kurz mittels einer aufsteigenden Alkoholreihe (EtOH 96\% und EtOH 100\%) entwässert, sowie $2 \times 5$ min in Xylol geklärt. Das Eindecken der Präparate erfolgte mit dem Eindeckmittel Entellan.

\subsubsection{Immunfluoreszenz}

in vivo

Bei der Immunfluoreszenz werden Antikörper mit gekoppeltem Fluoreszenz-Farbstoff verwendet. Es lassen sich Proteine und somit spezifische Strukturen in Zellen als auch in Geweben genau lokalisieren. Bei den durchgeführten Färbungen wurde die Methode der indirekten Immunfluoreszenz verwendet. Der Antikörper, welcher an das spezifische Protein (Epitop) bindet ist unmarkiert. Die eigentliche Färbung erfolgt erst im zweiten Schritt. Hier bindet ein zweiter mit Fluorochrom markierter Antikörper spezifisch an den ersten Antikörper. Im Anschluss an die Entparaffinierung folgten zwei weitere Waschschritte in PBS für jeweils 5 min und die Überführung der Gewebeschnitte in den Citratpuffer $\mathrm{pH}$ 6. Zur Antigendemaskierung wurden die Schnitte für 40 min bei $95{ }^{\circ} \mathrm{C}$ in den Dampfgarer gestellt, anschließend abgekühlt 
bei Raumtemperatur und erneut in PBS für 5 min gewaschen. In einer Feuchtkammer wurden die Gewebeschnitte 30 min mit einer Blocklösung aus 1\% BSA in PBS inkubiert. Dieser Schritt diente der Absättigung freier Bindungsstellen und verhinderte somit unspezifische Antikörperbindungen. Es folgte die Auftragung der primären Antikörper in der Blocklösung und die Inkubation über Nacht bei $4{ }^{\circ} \mathrm{C}$ ebenfalls in einer Feuchtkammer.

Nach dreimaligem Waschen der Präparate mit PBS für je $5 \mathrm{~min}$, wurden sie mit einem Fluoreszenz (Alexa Fluor ${ }^{\circledR} 555$ oder 488) -markierten Sekundärantikörper, welcher in der Blocklösung verdünnt wurde, für eine Stunde bei Raumtemperatur in der Dunkelkammer inkubiert. Nach drei weiteren Waschschritten erfolgte die Kernfärbung mittels 4',6-Diamidin-2phenylindol (DAPI) 1:1000 für 5 min. Abschließend wurde erneut mit PBS gewaschen und die Schnitte mit Immu-Mount (Fisher Diagnostics Cat.No. 9990412) eingedeckt.

Tabelle 24: Antikörper für Immunfluoreszenzfärbung in vivo

\begin{tabular}{|c|c|c|c|c|c|}
\hline \multicolumn{3}{|l|}{ Primärantikörper } & \multicolumn{3}{|c|}{ zugehöriger Sekundärantikörper } \\
\hline Antigen & Ursprung & Verdünnung & Ursprung & Markierung & Verdünnung \\
\hline$\alpha$ SMA & Maus & $1: 100$ & Esel & Alexa Fluor®555 & $1: 400$ \\
\hline Collagen I & Kaninchen & $1: 200$ & Esel & Alexa Fluor®488 & $1: 400$ \\
\hline Relaxin-Rezeptor 1 & Kaninchen & $1: 50$ & Esel & Alexa Fluor®555 & $1: 400$ \\
\hline Relaxin-Rezeptor 2 & Kaninchen & $1: 100$ & Esel & Alexa Fluor®555 & $1: 400$ \\
\hline Relaxin-Rezeptor 3 & Kaninchen & $1: 100$ & Esel & Alexa Fluor®555 & $1: 400$ \\
\hline Relaxin 1 & Ratte & $1: 100$ & Esel & Alexa Fluor®555 & $1: 400$ \\
\hline Relaxin 2 & Kaninchen & $1: 500$ & Esel & Alexa Fluor®555 & $1: 400$ \\
\hline Relaxin 3 & Maus & $1: 100$ & Esel & Alexa Fluor®555 & $1: 400$ \\
\hline Anti Collagen IV & Ziege & $1: 10$ & & & \\
\hline
\end{tabular}

Zellkultur

Pro 4-Well-Chamber Slides wurden je 10.000 Zellen humaner TK173 bzw. primäre Fibroblasten aus murinen Nieren ausgesät. Anschließend erfolgte die Kultivierung über sechs Stunden im DMEM-Vollmedium und über weitere sechs Stunden im serumfreien Hungermedium. Darauffolgend wurden die Zellen für zwei bzw. 48 Stunden mit $10 \mathrm{ng} / \mathrm{ml}$ rh TGF-ß1 alleine und mit 1-100 ng/ml Relaxin030 stimuliert, wobei die gleichzeitige Inkubation von je zwei Chamber Slides im serumfreien Hungermedium als Kontrolle dienten.

Nach Beendigung der Stimulationsdauer wurde der Zellrasen für $3 \times 5$ min in PBS gewaschen und anschließend in 4\%iger Paraformaldehyd-Lösung (PFA) für 10 min fixiert. Nach drei weiteren Waschschritten schloss sich die Inkubation im Triton-X 100 für 10 min an. Zur Blockierung von unspezifischen Antigenen wurden die Zellen für $30 \mathrm{~min}$ in einer $3 \%$ igen BSA/PBS-Blocklösung behandelt und anschließend über Nacht bei $4{ }^{\circ} \mathrm{C}$ mit dem spezifischen Primärantikörper inkubiert. Nach dreimaligen Waschen in PBS wurde der fluoreszenzmarkierte Sekundärantikörper, ebenfalls in Blockmedium verdünnt, für eine Stunde bei Raumtemperatur 
in einer Dunkelkammer aufgetragen. Nach erneutem dreimaligen Waschen mit PBS erfolgte die Zellkernfärbung durch eine zehnminütige Inkubation mit 4',6-Diamino-2-Phenylindol (DAPI). Es schloss sich eine letzte Waschung der Schnitte in PBS und das Eindecken mit Immu-Mount an.

Tabelle 25: Antikörper für Immunfluoreszenzfärbung in vitro

\begin{tabular}{|c|c|c|c|c|c|}
\hline \multicolumn{3}{|l|}{ Primärantikörper } & \multicolumn{3}{|c|}{ zugehöriger Sekundärantikörper } \\
\hline Antigen & Ursprung & Verdünnung & Ursprung & Markierung & Verdünnung \\
\hline$\alpha$ SMA & Maus & $1: 100$ & Esel & Alexa Fluor®555 & $1: 400$ \\
\hline pSmad2 & Kaninchen & $1: 100$ & Esel & Alexa Fluor@488 & $1: 400$ \\
\hline pSmad3 & Kaninchen & $1: 100$ & Esel & Alexa Fluor®488 & $1: 400$ \\
\hline Relaxin-Rezeptor 1 & Kaninchen & $1: 50$ & Esel & Alexa Fluor®555 & $1: 400$ \\
\hline Relaxin-Rezeptor 2 & Kaninchen & $1: 100$ & Esel & Alexa Fluor®555 & $1: 400$ \\
\hline Relaxin -Rezeptor 3 & Kaninchen & $1: 100$ & Esel & Alexa Fluor®555 & $1: 400$ \\
\hline Relaxin 1 & Ratte & $1: 100$ & Esel & Alexa Fluor®555 & $1: 400$ \\
\hline Relaxin 2 & Kaninchen & $1: 500$ & Esel & Alexa Fluor®555 & $1: 400$ \\
\hline Relaxin 3 & Maus & $1: 100$ & Esel & Alexa Fluor®555 & $1: 400$ \\
\hline MMP 2 (2C1) & Maus & $1: 100$ & Esel & Alexa Fluor®555 & $1: 400$ \\
\hline MMP 9 (E-11) & Maus & $1: 100$ & Esel & Alexa Fluor®555 & $1: 400$ \\
\hline
\end{tabular}

\subsubsection{Histologische Auswertungen}

Die histologischen Bildaufnahmen der PAS- und MTS-Gewebsschnitte wurden am Lichtmikroskop Olympus BX43 unter Verwendung der cellSense Dimension 1.6 Software erstellt. Die zufällig ausgewählten Gesichtsschnitte wurden an 10 unterschiedlichen Bereichen am Übergang zwischen renalem Kortex und Medulla mit einer 200-fachen Vergrößerung abfotografiert. Die morphometrische Analyse der MTS-Gewebsschnitte fand im Hinblick auf ihren prozentualen Fibrosegrad statt. Dies erfolgte durch die Verwendung eines Folienrasters mit 638 x 10 $\mathrm{mm}^{2}$ Quadraten bei 400 -facher Vergrößerung. Als positive Quadrate wurden charakteristisch blau gefärbte Kollagenfasern des tubulointerstitiellen Nierengewebes determiniert. Weitere blau gefärbte Areale, wie die Glomeruli oder die Adventitia von Gefäßen wurden für die Analysen außer Acht gelassen. Der prozentuale Anteil an fibrotisch veränderten, positiven Quadraten ergab sich aus dem Mittelwert, dividiert durch die Gesamtanzahl vorhandener Folienrasterquadrate. Die Auswertung der Immunfluoreszenz-Färbungen erfolgte am Mikroskop Axiovert S100TV mittels der Fluoreszenzkamera Olympus XM10 bei 400-facher 
Vergrößerung. Pro zufällig ausgewählten Gewebeschnitt wurden 10 Gesichtsfelder am Übergang von renalem Kortex und Medulla, unter Verwendung der cell^ $D$ Software, analysiert. Mit Hilfe eines Folienrasters mit $638 \times 10 \mathrm{~mm}^{2}$ Quadraten, konnte der prozentuale Anteil der Antigen-positiven Quadrate ermittelt werden. Die Anzahl der positiven Quadrate wurde quantifiziert, der Mittelwert durch die Gesamtanzahl der Folienrasterquadrate (638) dividiert und multipliziert mit dem Faktor 100. Die Aufnahmen der Immunfluoreszenz-Färbungen wurden durch Herrn Dr. med. Björn Tampe am Konfokalmikroskop erstellt.

\subsubsection{Statistische Analysen}

Die Ergebnisse wurden nach mindestens dreimaliger Durchführung der Experimente als Mittelwert mit Standardabweichung und Signifikanzniveau angegeben, welches bei paarweisen Vergleichen mittels studentischen t-Tests und multiplen Vergleichen mittels ANOVA und Bonferroni-Abgleich ermittelt wurde. Als statistisch signifikant wurde ein $p$-Wert kleiner 0,05 definiert. Ein $p<0,05$ wurde mit *, $p<0,01$ mit ${ }^{* *}, p<0,001$ mit ${ }^{* * *}$ und $p<0,0001$ mit **** in den einzelnen Graphen gekennzeichnet, welche mit dem Programm GraphPad Prism 6 erstellt wurden. 


\section{Ergebnisse}

\subsection{Versuche im Mausmodell der unilateralen Ureterobstruktion (UUO)}

\subsubsection{Expression von Relaxin-1 in der murinen Niere}

Renale Fibrogenese führt im UUO-Mausmodell zu einer Reduktion von Relaxin-1. Die quantitative Veränderung der Relaxin-1-Expression in der UUO-Niere nach 10 Tagen Obstruktion wurde mittels qRT-PCR und Western-Blot-Analysen untersucht. Die qRT-PCR zeigt die verminderte Expression von Relaxin-1 im murinen Gewebe (Abbildung 9A). Der Relaxin-Verlust konnte ebenfalls auf Proteinebene mittels Western Blot bestätigt werden (Abbildung 9B,C). Beide Methoden zeigten eine signifikante Reduktion der Expression von Relaxin-1 im fibrotisch veränderten Nierengewebe.
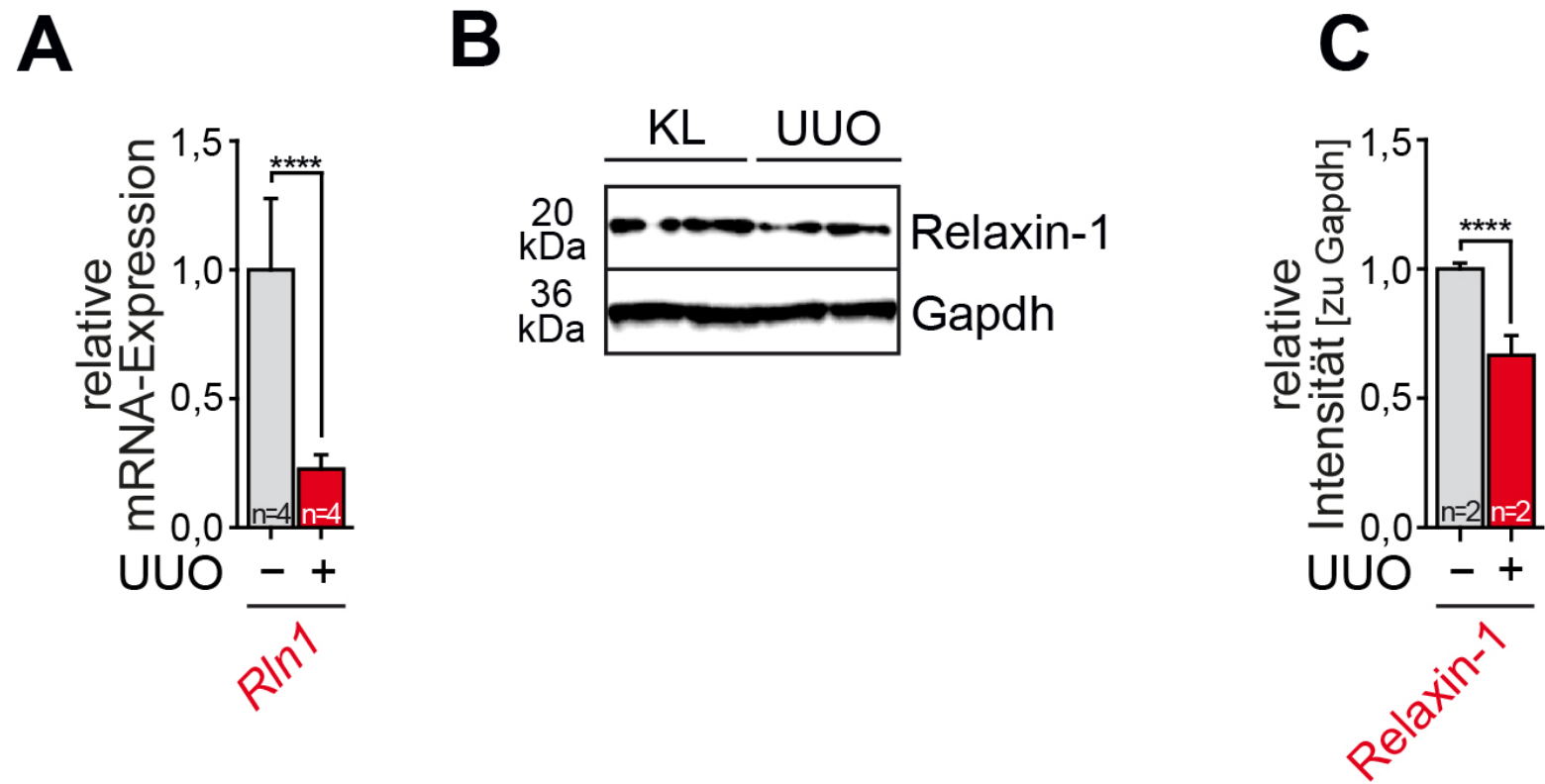

Abbildung 9: Expression von Relaxin-1. (A) Die mRNA-Expression von R/n1 wurde mittels qRT-PCR in Nierenlysaten analysiert ( $\mathrm{n}$ von biologischen Replikaten wie angegeben, Analyse in technischen Triplikaten, der Graph zeigt Mittelwerte \pm Standardabweichungen, $\left.{ }^{* * * *} p<0,0001\right)$. (B,C) Intrarenale Proteinlevels von Relaxin-1 wurden mittels Western Blot analysiert, die relative Bandenintensität wurde zu Gapdh normalisiert. Zur statistischen Analyse wurde die absolut optometrisch quantifizierbare Expression von Kontrollnieren arbiträr auf den Wert eins festgelegt. ( $\mathrm{n}$ von biologischen Replikaten wie angegeben, der Graph zeigt Mittelwerte \pm Standardabweichungen, ${ }^{* * *} p<0,0001$; Kalkulation der $p$-Werte in Relation zur Kontrollniere mit Kontrollpuffer-behandelter Mäuse).

4.2 Lokalisation und Expression der Relaxin-Rezeptoren-1 und -2 (Rxfp1 und Rxfp2) in der murinen Niere

\subsubsection{Erhöhte Expression in der UUO-Niere}

Die quantitative Veränderung der Rxfp1 und Rxfp2-Expression in der murinen Niere 10 Tage nach Obstruktion wurde mittels qRT-PCR, Western-Blot-Analysen und Doppelimmunfluoreszenz bestimmt. Auf mRNA-Ebene kam es zu einer signifikanten Zunahme der Expression von Rxfp1 und Rxfp2 (Abbildung 10A). Dieses Ergebnis konnte im Western Blot auf Proteinebene bestätigt werden 
(Abbildung 10B,C). Alle Verfahren zeigten eine deutlich erhöhte Expression von Rxfp1 und Rxfp2 in der UUO-Niere im Vergleich zur kontralateralen Kontrollniere (KL).

A

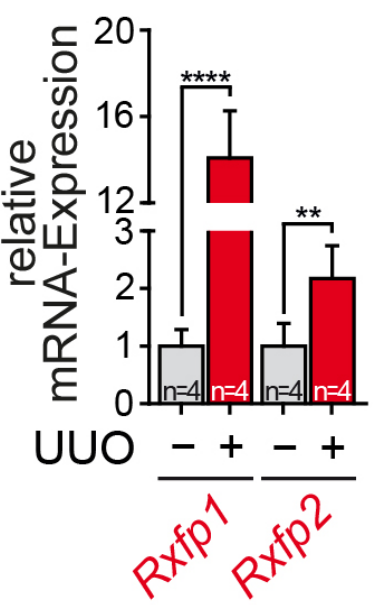

B

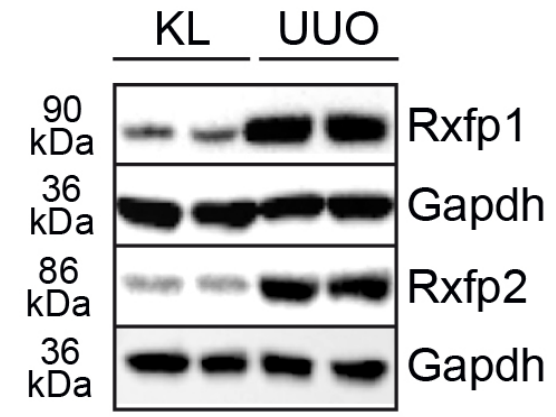

C

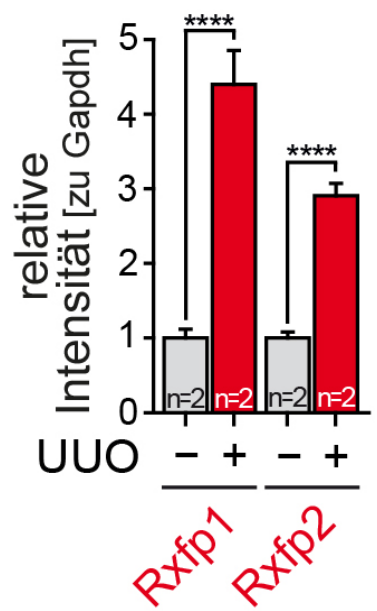

Abbildung 10: Expression der Relaxin-Rezeptoren-1 und -2. (A) Die mRNA-Expression von Rxfp1 und Rxfp2 wurde mittels qRT-PCR in Nierenlysaten analysiert ( $n$ von biologischen Replikaten wie angegeben, Analyse in technischen Triplikaten, der Graph zeigt Mittelwerte \pm Standardabweichungen, $\left.{ }^{* *} p<0,01,{ }^{* * * *} p<0,0001\right)$. (B,C) Intrarenale Proteinlevels von Rxfp1 und Rxfp2 wurden mittels Western Blot analysiert, die relative Bandenintensität wurde zu Gapdh normalisiert ( $n$ von biologischen Replikaten wie angegeben, der Graph zeigt Mittelwerte \pm Standardabweichungen, ${ }^{* * * *} p<0,0001$; Kalkulation der $p$-Werte in Relation zur Kontrollniere mit PBSbehandelter Mäuse).

Die Lokalisation der Relaxin-Rezeptoren Rxfp1 und Rxfp2 in der murinen Kontrollniere (KL) bzW. obstruktiven Niere (UUO) an Tag 10 wurde mit Hilfe einer Doppelimmunfluoreszenzfärbung untersucht. Wie den folgenden Abbildungen zu entnehmen ist, sind die Rezeptoren Rxfp1 und Rxfp2 insbesondere in interstitiellen Fibroblasten lokalisiert (Abbildung 11). In Tubulusepithelzellen konnte hingegen keine Expression festgestellt werden. 
A
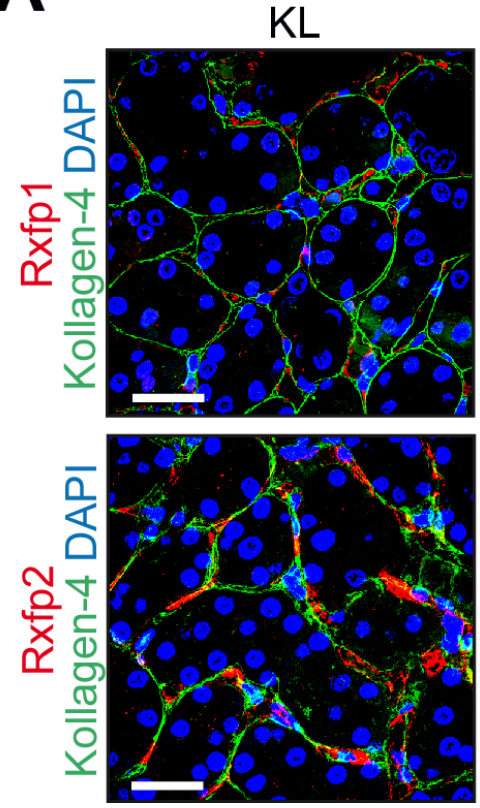

UUO
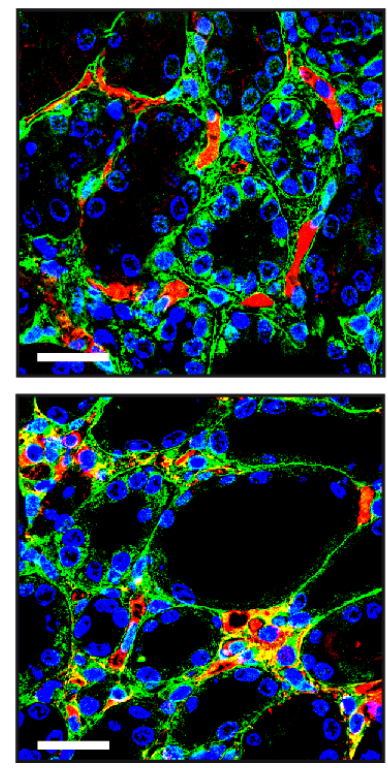

B

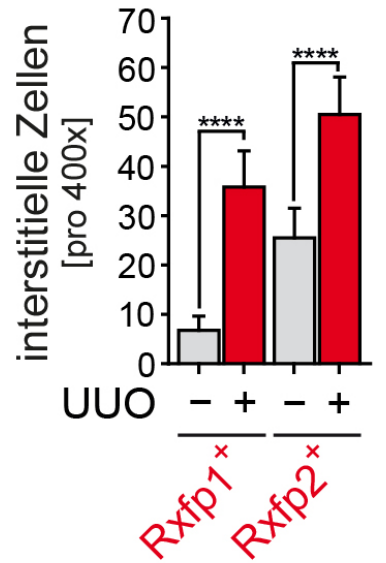

Abbildung 11: Lokalisation von Relaxin-Rezeptoren-1 und -2 in der Kontroll- sowie fibrotisch veränderten Niere. (A) Repräsentative Mikrofotographie von immunfluoreszenzmarkierten Gewebeschnitten gegen Rxfp1 und Rxfp2. Die Bildausschnitte zeigen Kontrollnieren und UUO-Präparate (Messbalken $25 \mu \mathrm{m}$ ). (B) Anzahl interstitieller Zellen positiv auf die Marker Rxfp1 und Rxfp2 (Die Bildanalyse erfolgte in je zehn Gesichtsfeldern pro Niere bei 400x Vergrößerung, $n=4$ in jeder Gruppe, der Graph zeigt Mittelwerte \pm Standardabweichungen, ${ }^{* * * *}$ $p<0,0001$; Kalkulation der $p$-Werte in Relation zur Kontrollniere mit PBS-behandelter Mäuse).

\subsection{Dosisabhängiger Einfluss von RLX030 auf renale Myofibroblasten-Akkumulation nach UUO an Tag drei, sieben und zehn}

Die antifibrotischen Eigenschaften von RLX030 konnten histologisch durch Periodic acid-Schiff (PAS), Masson Trichrom (MTS) sowie durch quantitative Veränderungen der mesenchymalen Fibrosemarker alpha-smooth muscle actin ( $\alpha$-SMA) und Kollagen-1 mittels Immunfluoreszenz in C57BL/6J-Mäusen nach UUO detektiert werden. In den Kontrollen kam es zu einer deutlichen Zunahme an Kollagenablagerungen im interstitiellen Kompartiment (Abbildung 12A,B). Die MTS-Färbung zeigte im Vergleich zwischen den behandelten und Kontrolltieren signifikante Differenzen. Diese Ablagerungen waren bei den mit RLX030 behandelten Mäusen deutlich geringer erkennbar. Innerhalb der behandelten Gruppen zeigten die Mäuse, welche mit $500 \mu \mathrm{g} / \mathrm{kg}$ und $200 \mu \mathrm{g} / \mathrm{kg}$ Körpergewicht (KG) RLX030 behandelt wurden, eine deutlich geringere Kollagenablagerung, verglichen mit den niedrig dosierten Mäusen (50 $\mu \mathrm{g} / \mathrm{kg} \mathrm{KG}$ ) (Abbildung 12A,B). In der Immunfluoreszenz zeigte sich bestätigend eine dosisabhängig verminderte Expression von interstitiellem Kollagen-1 sowie $\alpha$-SMA nach Behandlung mit $500 \mu \mathrm{g} / \mathrm{kg}, 200 \mu \mathrm{g} / \mathrm{kg}$ und $50 \mu \mathrm{g} / \mathrm{kg} \mathrm{KG}$. Die mit $500 \mu \mathrm{g} / \mathrm{kg}$ und $200 \mu \mathrm{g} / \mathrm{kg} \mathrm{KG}$ behandelte RLX030-Kohorte zeigte im Vergleich zur Kontrollgruppe einen signifikant geringeren Flächenanteil an interstitiellem Kollagen-1 sowie $\alpha$-SMA (Abbildung 12C,D). 
A

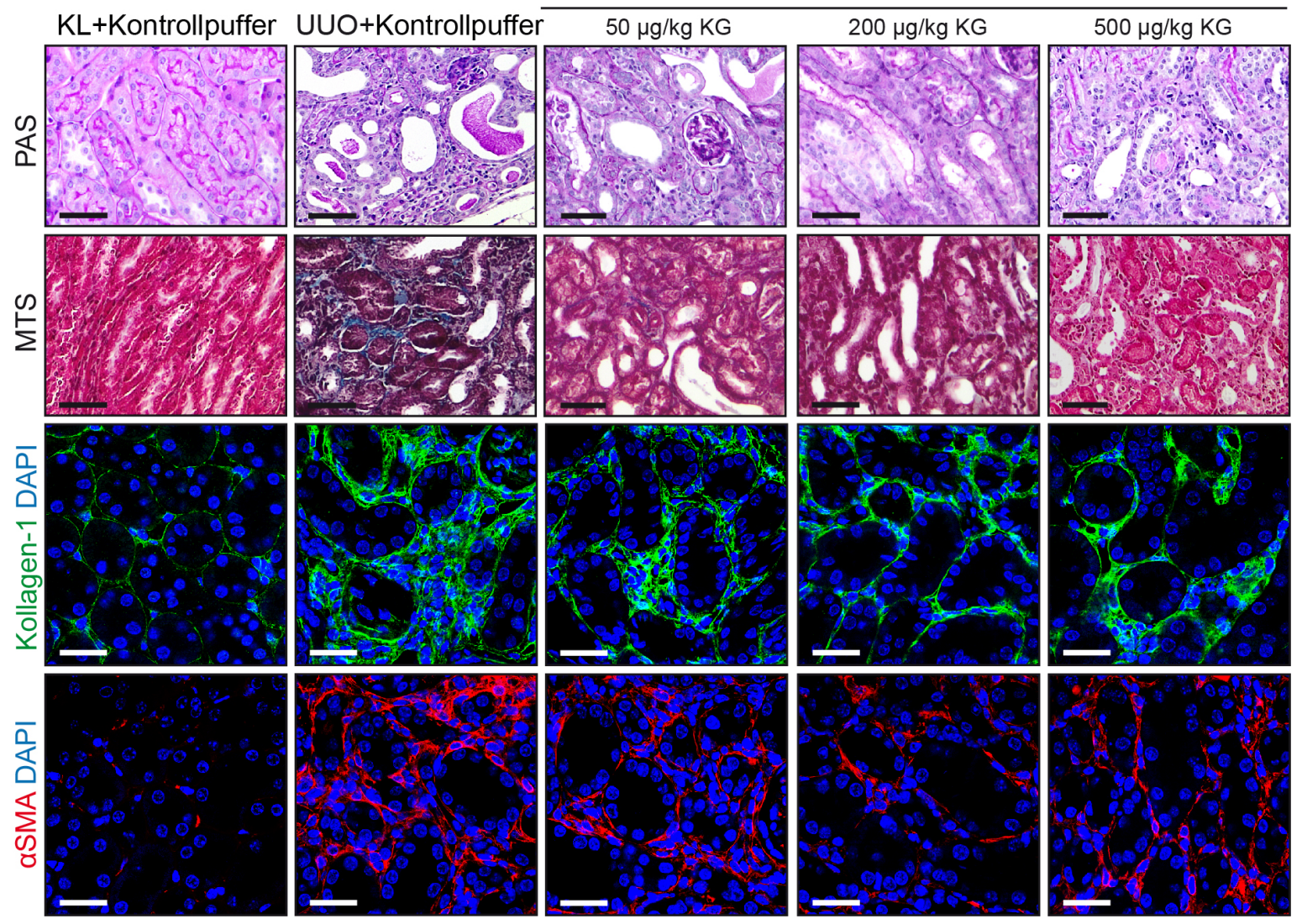

B

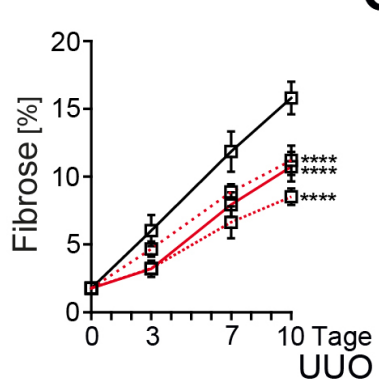

$\mathrm{C}$

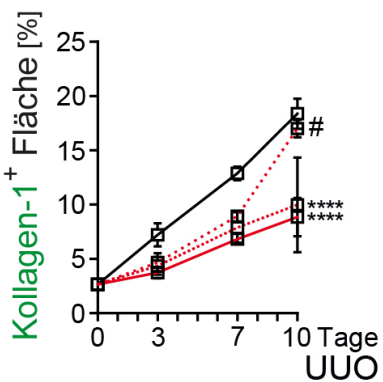

UUO+RLX030

D

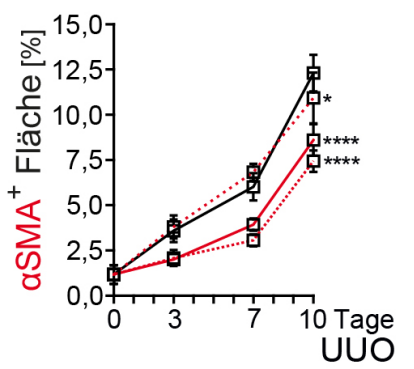

-5- UUO+Kontrollpuffer

. UUO+RLX030 [50 $\mu \mathrm{g} / \mathrm{kg} \mathrm{KG}]$

.... UUO+RLXO30 [200 $\mu \mathrm{g} / \mathrm{kg} \mathrm{KG}]$

兵 UUO+RLXO30 [500 $\mu \mathrm{g} / \mathrm{kg} \mathrm{KG}]$

Abbildung 12: Inhibition der experimentellen renalen Fibrogenese durch RLX030 im histopathologischen Korrelat der UUO-Niere. (A) Repräsentative Mikrofotografie von Perjodsäure-Schiff-Reaktion (PAS) und Masson-Trichrom (MTS) gefärbten Nierenpräparaten (Messbalken $50 \mu \mu m)$ sowie von immunfluoreszenzmarkierten Gewebsschnitten gegen Kollagen-1 und a-SMA (Messbalken $25 \mu \mathrm{m}$ ). Die Bildausschnitte zeigen Kontrollnieren sowie fibrotisch veränderte UUO-Nieren von Kontrollpuffer-behandelten und RLX030-behandelten Mäusen mit drei unterschiedlichen Konzentrationen zehn Tage nach unilateraler Ureterobstruktion. (B-D) Morphometrische Quantifizierung der interstitiellen Fläche, positiv für Fibrose, Kollagen-1 und a-SMA im zeitlichen Verlauf. (Die Bildanalyse erfolgte in je zehn Gesichtsfeldern pro Niere bei 200x bzw. 400x Vergrößerung, $n=6$ in jeder Gruppe, die Graphen zeigen Mittelwerte \pm Standardabweichungen, * $p<0,05,{ }^{* * * *}$ $\mathrm{p}<0,0001$, \# keine Signifikanz). 


\subsubsection{Geschlechtsunspezifische Wirkung von RLX030}

Die Applikation von RLX030 (500 $\mu \mathrm{g} / \mathrm{kg} \quad \mathrm{KG})$ attenuierte unabhängig vom Geschlecht die Akkumulation von interstitiellen Kollagen-1 und a-SMA im UUO-Mausmodell (Abbildung 13).

A
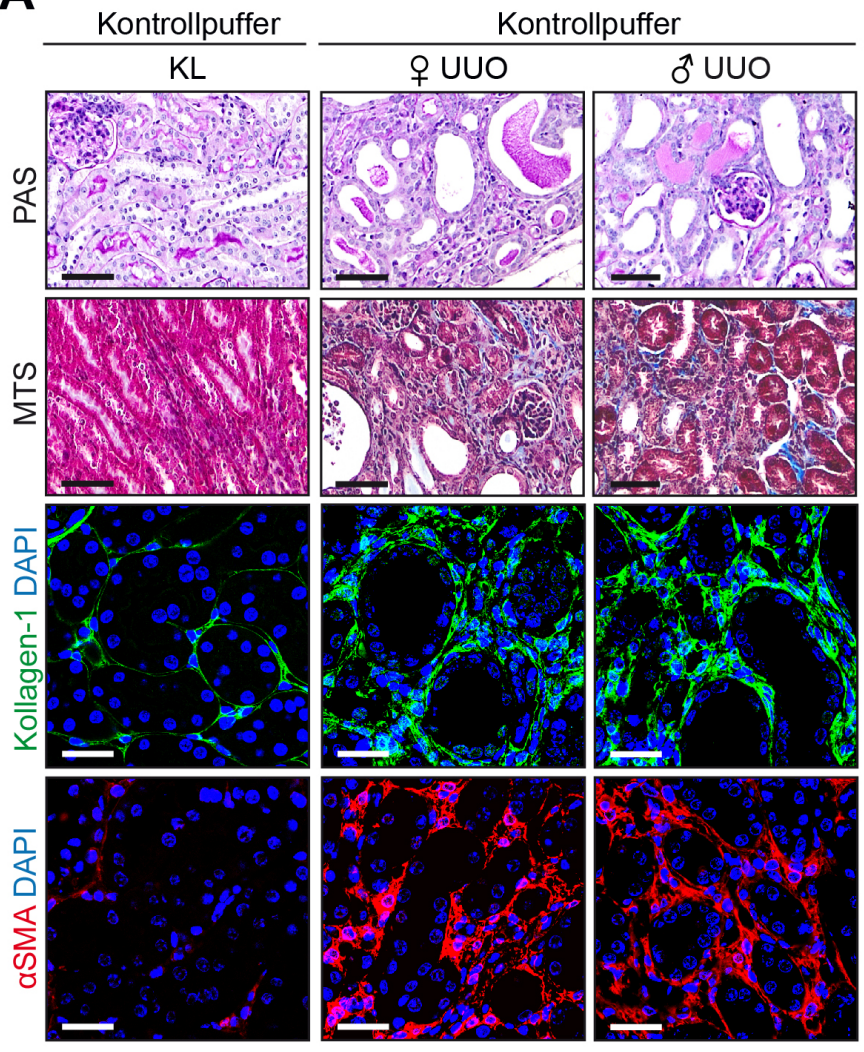

$\frac{\operatorname{RLX030[500\mu g/kg~KG]}}{\text { o UUO }}$

B
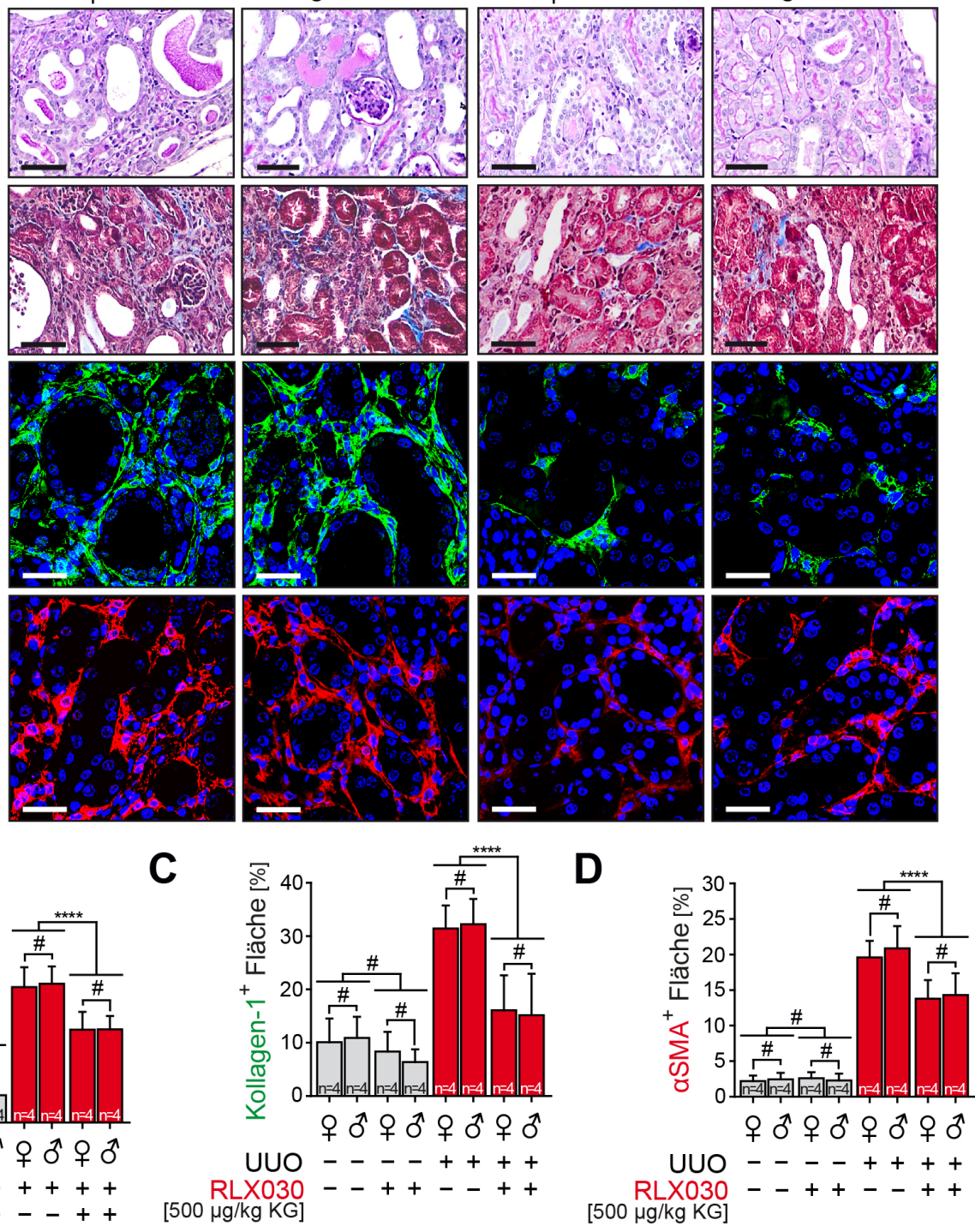
$[500 \mu \mathrm{g} / \mathrm{kg} \mathrm{KG}]$
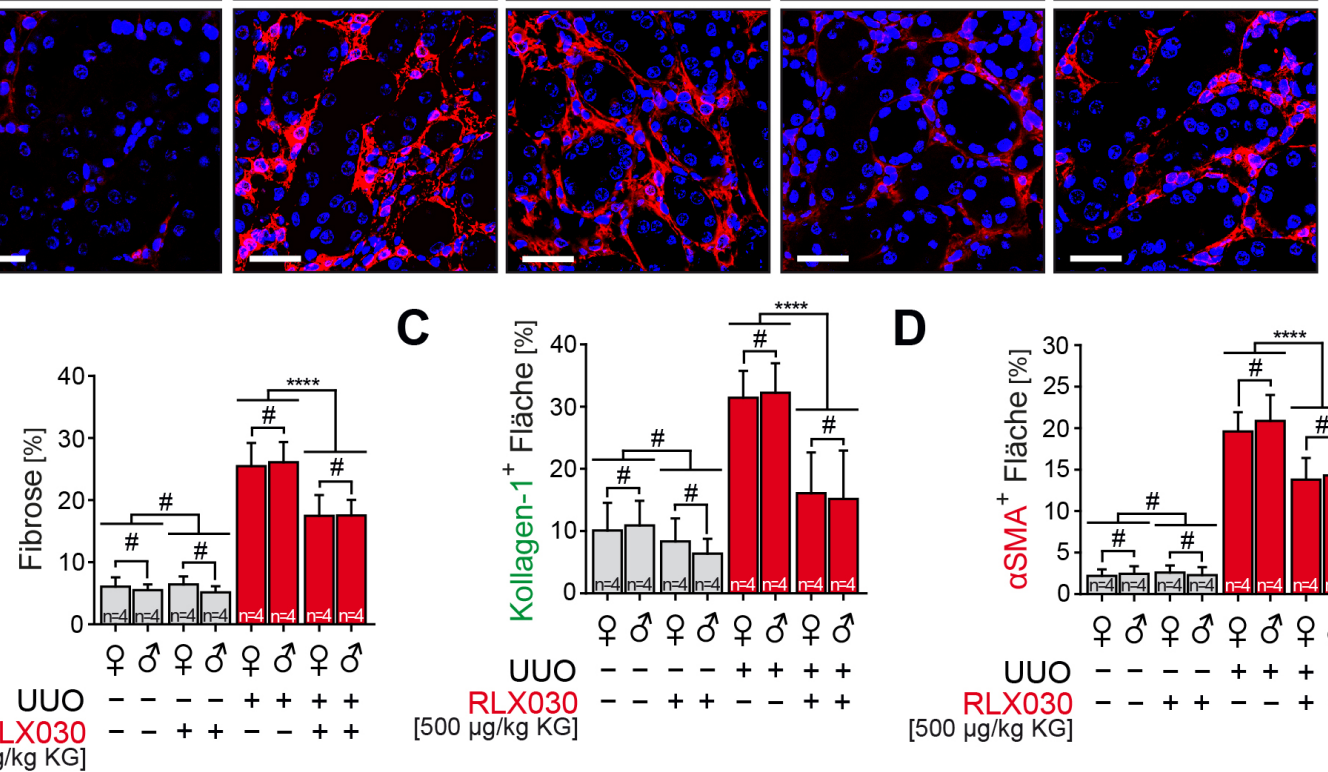

Abbildung 13: Geschlechtsunspezifische Wirkung von RLX030. (A) Repräsentative Mikrofotographie von PAS- und MTS-gefärbten weiblichen und männlichen Nierenpräparaten (Messbalken $50 \mu m$ ) sowie von immunfluoreszenzmarkierten Gewebsschnitten gegen Kollagen-1 und a-SMA (Messbalken $25 \mu m$ ). Die Bildausschnitte zeigen Kontrollnieren sowie fibrotisch veränderte UUO-Nieren von Kontrollpuffer-behandelten und RLX030-behandelten Mäusen. (B) Morphometrische Quantifizierung der interstitiellen Fibrose in MTS-gefärbten Gewebsschnitten. (C-D) Morphometrische Quantifiezierung der Kollagen-1- und a-SMA-Expression zur Beurteilung der Fibroblasten-Akkumulation in Nierenpräparaten. (Die Bildanalyse erfolgte in je zehn Gesichtsfeldern pro Niere bei 200x bzw. 400x Vergrößerung, $n$ in biologischen Replikaten wie angegeben, die Graphen zeigen Mittelwerte \pm Standardabweichungen, ${ }^{* * * *} p<0,0001$, \# keine Signifikanz). 


\subsection{Bestätigung der Ergebnisse in einem zweiten unabhängigen Maus-Modell}

Die antifibrotische Wirkung von RLX030 (200 $\mu \mathrm{g} / \mathrm{kg} \mathrm{KG)} \mathrm{konnte} \mathrm{ebenfalls} \mathrm{in} \mathrm{einem} \mathrm{zweiten,}$ unabhängigen Maus-Modell der Folsäure-Nephropathie (FAN) und anderem genetischen Hintergrund $(F V B / N)$ nachgewiesen werden. Die initiale tubulotoxische Injektion $(250 \mu \mathrm{g} / \mathrm{g} \mathrm{KG})$ der Folsäure führt zu einer akuten Niereninsuffizienz und im Anschluss zur renalen Fibrosierung und ist durch eine langsamere Krankheitsprogression charakterisiert. Histologisch zeigte sich eine dosisabhängig verminderte Akkumulation von interstitieller Fibrose, Kollagen-1 sowie $\alpha$-SMA nach Behandlung mit $200 \mu \mathrm{g} / \mathrm{kg} \mathrm{KG} \mathrm{RLX030} \mathrm{(Abbildung} \mathrm{14).} \mathrm{Aus} \mathrm{vorangegangenen} \mathrm{Experimenten} \mathrm{zur} \mathrm{Dosisfindung} \mathrm{zeigten}$ beide RLX030 Konzentrationen ( $200 \mu \mathrm{g} / \mathrm{kg} \mathrm{KG}$ und $500 \mu \mathrm{g} / \mathrm{kg} \mathrm{KG}$ ) äquivalente Ergebnisse im Hinblick auf die Inhibition renaler interstitieller Fibrose. Aus diesem Grund wurde für dieses Modell die niedrigere Medikamentenkonzentration von $200 \mu \mathrm{g} / \mathrm{kg}$ KG gewählt. 
A

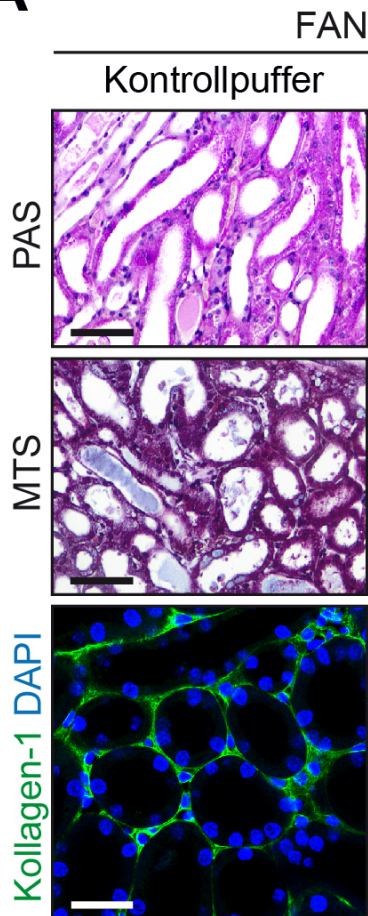

FAN [Tag 3]

FAN [Monat 5]
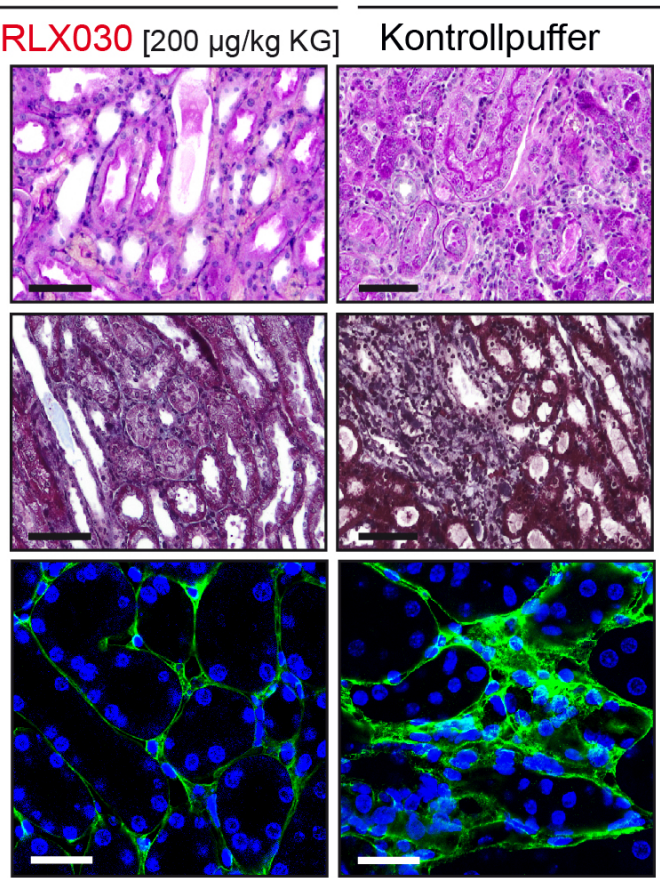

$\mathrm{RLX030}[200 \mu \mathrm{g} / \mathrm{kg} \mathrm{KG}]$
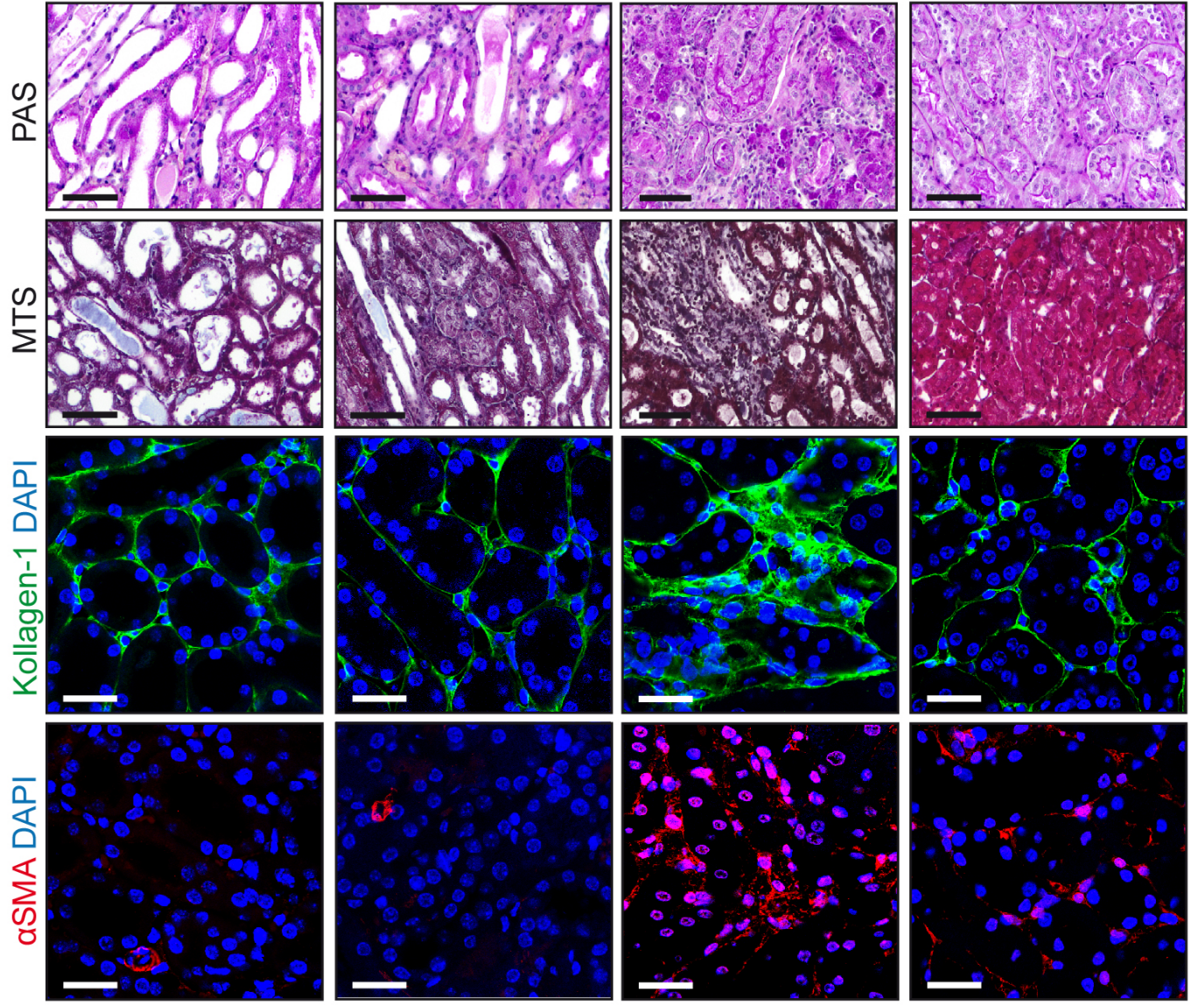

B

C
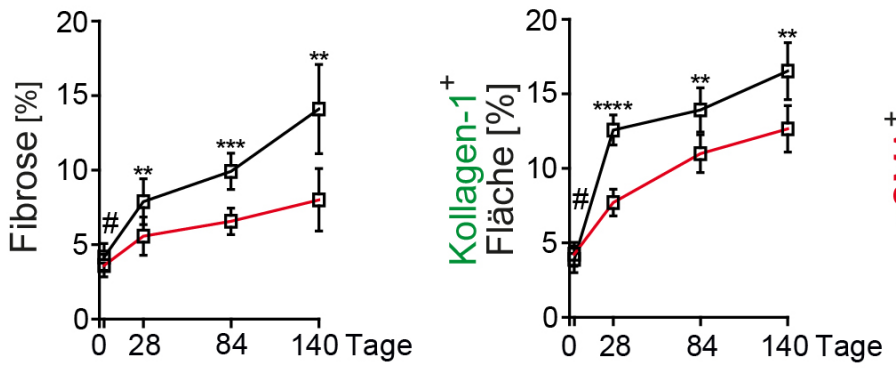

D
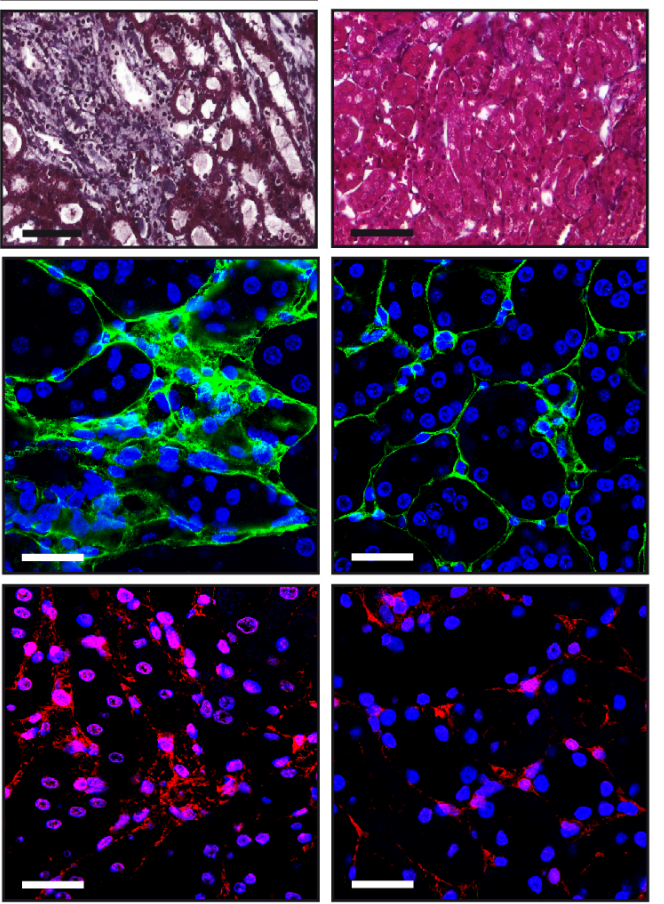

-

豆 FAN+RLX030 [200 $\mu \mathrm{g} / \mathrm{kg} \mathrm{BW]}$

Abbildung 14: Antifibrotische Wirkung von RLX030 im Maus-Modell der Folsäure-Nephropathie. (A) Repräsentative Mikrofotographie von PAS- und MTS-gefärbten renalen Gewebspräparaten (Messbalken $50 \mu \mathrm{m}$ ) sowie von immunfluoreszenzmarkierten Nierenpräparaten gegen Kollagen-1 und a-SMA (Messbalken $25 \mu \mathrm{m}$ ). Die Bildausschnitte zeigen Folsäure-induzierte Nierenschäden von mit Kontrollpuffer- und RLX030-behandelten Mäusen zu zwei Zeitpunkten. (B-D) Morphometrische Quantifizierung der interstitiellen Flächen positiv für Fibrose, Kollagen-1 und $\alpha$-SMA im zeitlichen Verlauf. (Die Bildanalyse erfolgte in je zehn Gesichtsfeldern pro Niere bei 200x bzw. 400x Vergrößerung, $n=5$ in jeder Gruppe, die Graphen zeigen Mittelwerte \pm Standardabweichungen, ${ }^{* *} p<0,01$, ${ }^{* * *} p<0,001,{ }^{* * * *} p<0.0001$, \# keine Signifikanz; Kalkulation der $p$ Werte in Relation zu Kontrollpuffer-behandelter Mäuse). 


\subsection{Wirkung von RLX030 auf die TGF-ß1- Signalkaskade}

\subsubsection{Inhibition des Smad2-Signalwegs}

Der antagonisierende Effekt von RLX030 auf die TGF- $\beta 1$-induzierte Phosphorylierung von Smad2 (pSmad2) wurde mittels histologischer Analysen verglichen. Die unbehandelte UUO-Niere wies gegenüber der KL-Niere eine Induktion der Expression von pSmad2 auf (Abbildung 15). Dieser Effekt konnte durch eine Behandlung mit $500 \mu \mathrm{g} / \mathrm{kg}, 200 \mu \mathrm{g} / \mathrm{kg}$ und $50 \mu \mathrm{g} / \mathrm{kg} \mathrm{KG} \mathrm{RLX030} \mathrm{dosisabhängig} \mathrm{und}$ signifikant reduziert werden (Abbildung 15).

A

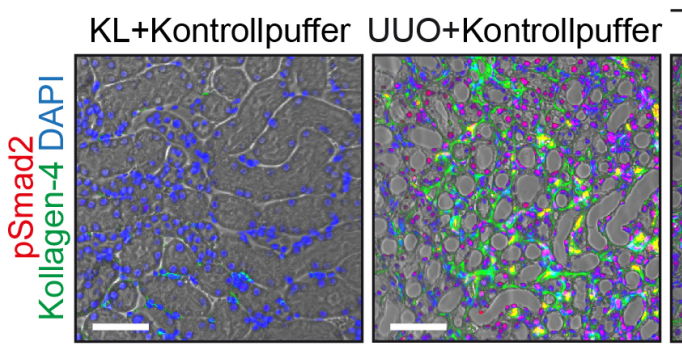

UUO+RLX030

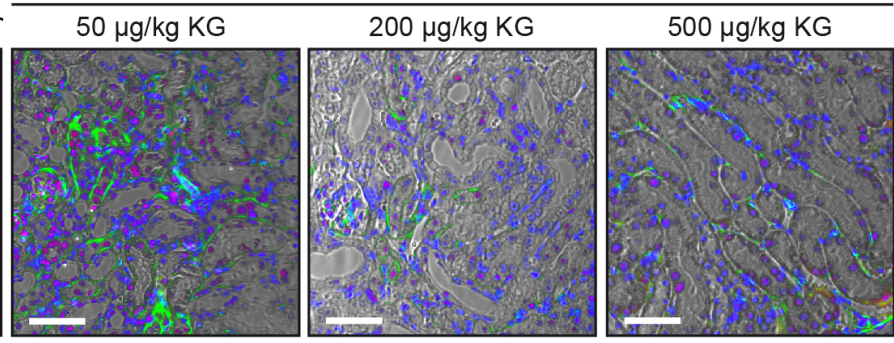

B

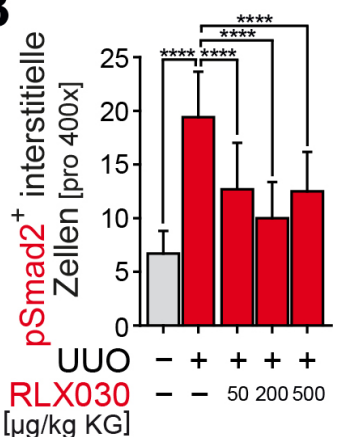

Abbildung 15: Inhibition des pSmad2-Signalwegs im murinen Gewebe. (A) Repräsentative Mikrofotographie von immunfluoreszenz mit primären Antikörpern gegen pSmad2 und Kollagen-4 markierten Nierenpräparaten (Messbalken $50 \mu \mathrm{m}$ ). Die Bildausschnitte zeigen Kontroll- und UUO-Nieren mit von Kontrollpuffer- und RLX030behandelten Mäusen zehn Tage nach Operation. (B) Morphometrische Quantifizierung interstitieller Zellen positiv für pSmad2 (Die Bildanalyse erfolgte in je zehn Gesichtsfeldern pro Niere bei 400x Vergrößerung, $n=4$ in jeder Gruppe, der Graph zeigt Mittelwerte \pm Standardabweichungen, ${ }^{* * * *} p<0,0001$; Kalkulation der $p$-Werte in Relation zur Kontrollniere bzw. zur UUO-Niere Kontrollpuffer-behandelter Mäuse).

Diese Effekte konnten in Primärkulturen muriner Fibroblasten bestätigt werden. Der Einfluss von RLX030 auf die TGF- $\beta 1$-induzierte Induktion der Smad2-Signalkaskade und konsekutiver Fibroblastenaktivierung wurde nach Stimulation von murinen Fibroblastenkulturen mit TGF- $\beta 1$ (10 $\mathrm{ng} / \mathrm{mL}$ ) allein oder in Kombination mit RLX030 in unterschiedlichen Dosierungen untersucht. Die Supplementation des Kulturmediums mit RLX030 reduzierte dosisabhängig die TGF- $\beta 1$-induzierte Akkumulation von pSmad2 (Abbildung 16). 
A

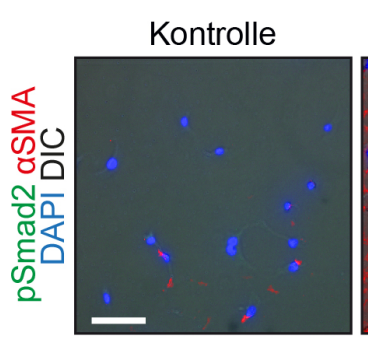

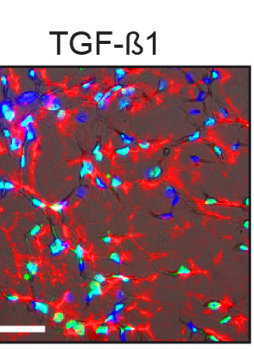

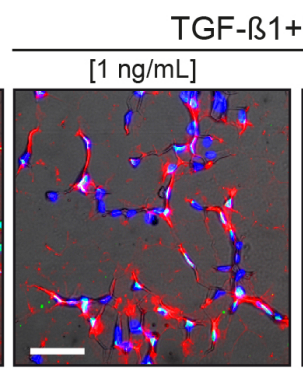

B

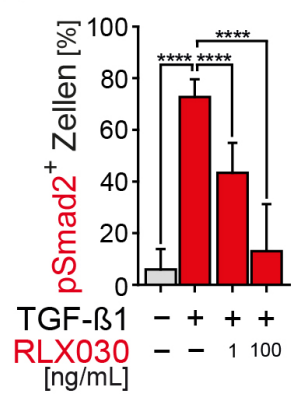

Abbildung 16: Inhibition des pSmad-Signalwegs in Primärkulturen muriner Fibroblasten. (A) Repräsentative Mikrophotographie von immunfluoreszenzmarkierten murinen Fibroblasten mit primären Antikörpern gegen pSmad2 und a-SMA (Messbalken $50 \mu \mathrm{m}$ ). Die Bildausschnitte zeigen als Kontrolle mit PBSbehandelte Fibroblasten im Vergleich zu TGF-ß1- und TGF-ß1 mit RLX030-behandelte Fibroblasten in zwei Konzentrationen. (B) Morphometrische Quantifizierung der Zellen positiv für pSmad2 (Die Bildanalyse erfolgte in je zehn Gesichtsfeldern pro 4-Well-Chamber Slide bei 400x Vergrößerung, der Graph zeigt Mittelwerte \pm Standardabweichungen, ${ }^{* * *} p<0,0001$; Kalkulation der $p$-Werte in Relation zur PBS-behandelten Kontrolle bzw. zu TGF-ß1-behandelten Fibroblasten).

Diese Hemmung TGF- $\beta 1$-induzierter pSmad-Akkumulation korrelierte mit Inhibition der Fibroblastenproliferation Abbildung 17 A/B, sowie mRNA-Expression von Collagen-1a1 (Col1a1) und a-SMA (Acta2) Abbildung 17 C/D.

A

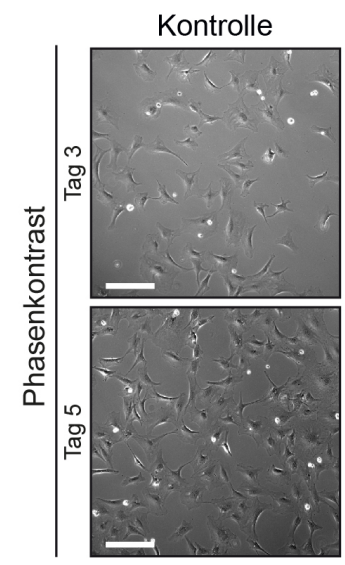

C

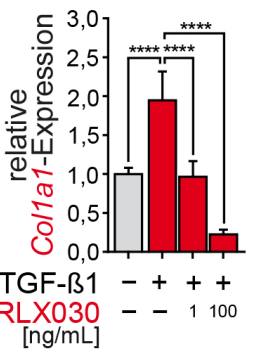

D

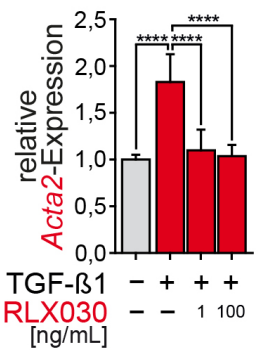

B
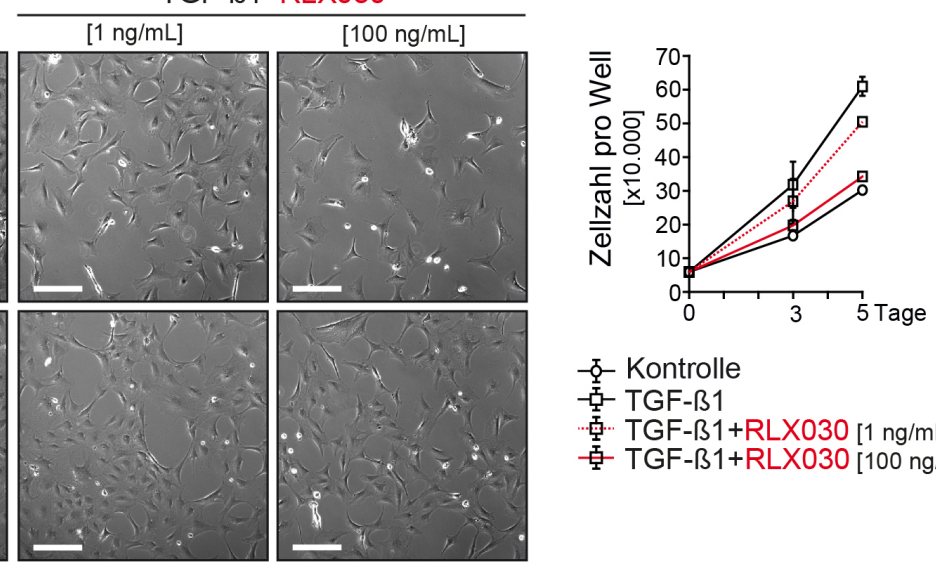

- Kontrolle

- TGF-ß1

." TGF-ß1+RLX030 [1 ng/mL]

- TGF-ß1+RLX030 [100 ng/mL]

Abbildung 17: RLX030 Wirkung auf murine Fibroblastenproliferation. (A) Repräsentative Phasenkontrastbilder von kultivierten Primärkulturen renaler Fibroblasten aus Mäusen nach Stimulation mit TGF$\beta 1$ und angezeigten Konzentrationen von RLX030 (Messbalken $50 \mu \mathrm{m}$ ). (B) Morphometrische Bestimmung der Zellproliferation. (Die Bildanalyse erfolgte in je zehn Gesichtsfeldern pro Well bei 400x Vergrößerung, der Graph 
zeigt Mittelwerte \pm Standardabweichungen). (C,D) Die mRNA-Expression von Col1a1 und Acta2 wurde mittels qRT-PCR bestimmt (Analyse in technischen Triplikaten, die Graphen zeigen Mittelwerte \pm Standardabweichungen, **** $p<0,0001$; Kalkulation der $p$-Werte in Relation zur PBS-behandelten Kontrolle bzw. zu TGF-ß1-behandelten Fibroblasten).

\subsection{Regulation der Matrixmetalloproteinasen-2, -3 und -9}

Die antifibrotischen Effekte von RLX030 äußern sich zudem bei der Stimulation von Matrixmetalloproteinasen (MMPs). Auf mRNA-Ebene konnten diese mittels qRT-PCR bestimmt werden. Kohorten, welche mit $500 \mu \mathrm{g} / \mathrm{kg} \mathrm{KG} \mathrm{RLX030} \mathrm{behandelt} \mathrm{wurden} \mathrm{zeigten} \mathrm{an} \mathrm{Tag} 10$ nach Obstruktion eine signifikante Induktion insbesondere von Mmp2 und Mmp9 im Vergleich zur UUOKontrollgruppe (Abbildung 18).

A

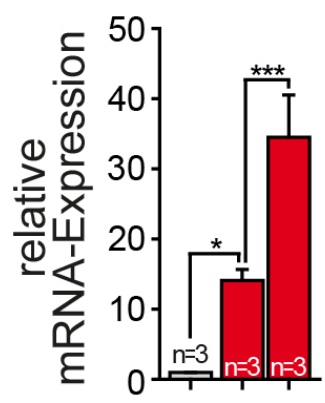

$$
\text { UUO }-++
$$

$\mathrm{RLX030--+}$

$[500 \mu \mathrm{g} / \mathrm{kg} \mathrm{KG}]$

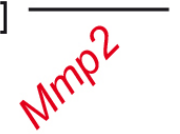

B

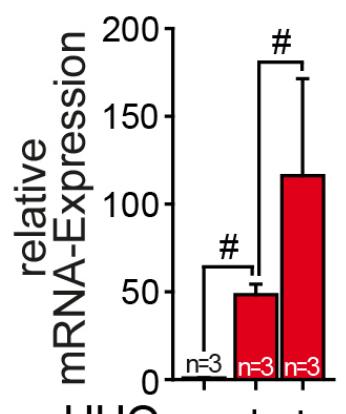

UUO -++

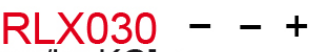

C

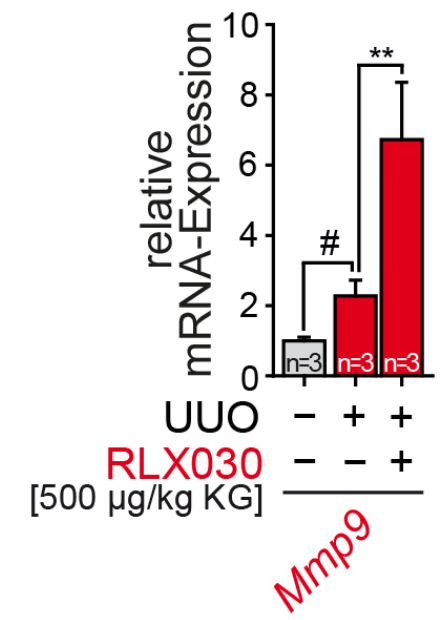

Abbildung 18: Regulation der Matrixmetalloproteinasen-2, -3 und -9. (A-C) Die intrarenale mRNA-Expression der Matrixmetalloproteinasen Mmp2, Mmp3 und Mmp9 aus murinen Nierenpräparaten zehn Tage nach UUO wurde mittels qRT-PCR bestimmt ( $\mathrm{n}$ von biologischen Replikaten wie angegeben, Analyse in technischen Triplikaten, die Graphen zeigen Mittelwerte \pm Standardabweichungen, ${ }^{* *} p<0,01,{ }^{* * *} p<0,001$, \# keine Signifikanz; Kalkulation der p-Werte in Relation zur Kontrollniere bzw. zur UUO-Niere Kontrollpuffer-behandelter Mäuse).

Dies wurde mittels Immunfluoreszenzfärbung bestätigt, die Applikation von $500 \mu \mathrm{g} / \mathrm{kg} \mathrm{KG} \mathrm{RLX030}$ induzierte die Matrixmetalloproteinasen Mmp2 und Mmp9 insbesondere im interstitiellen Kompartiment (Abbildung 19). 
A
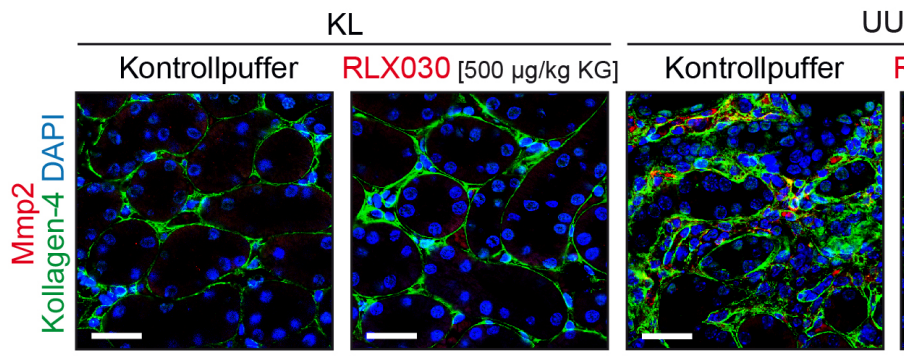

UUO

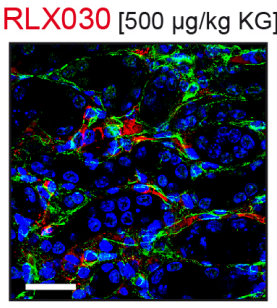

C

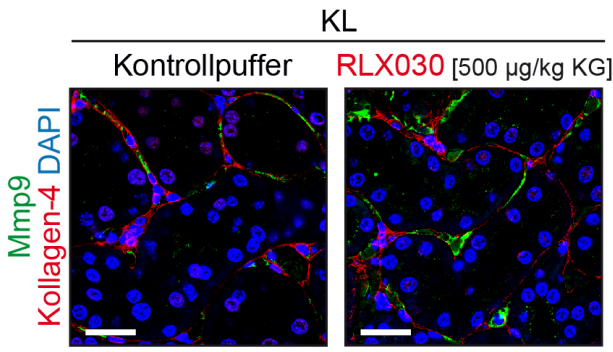

B

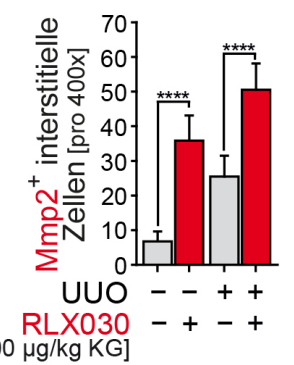

D

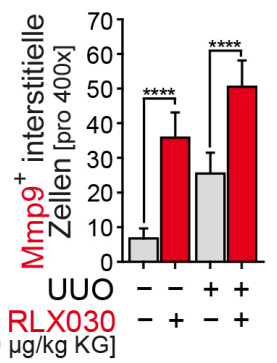

Abbildung 19: Expression von Matrixmetalloproteinasen-2 und -9 in der Immunfluoreszenzfärbung von murinen Nierenpräparaten. $(\mathbf{A}+\mathbf{C})$ Repräsentative Mikrofotographie von renalen Gewebsschnitten nach Immunfluoreszenzmarkierung gegen Mmp2 und Mmp9 (Messbalken $25 \mu \mathrm{m}$ ). Die Bildausschnitte zeigen gesunde Kontroll- sowie fibrotische UUO-Nieren von Kontrollpuffer- und RLX030-behandelten Mäusen zehn Tage nach UUO. (B+D) Morphometrische Quantifizierung interstitieller Zellen positiv für Mmp2 und Mmp9 (Die Bildanalyse erfolgte in je zehn Gesichtsfeldern pro Niere bei 400x Vergrößerung, n= 4 in jeder Gruppe, die Graphen zeigen Mittelwerte \pm Standardabweichungen, ${ }^{* * *} p<0,0001$; Kalkulation der $p$-Werte in Relation zur Kontrollniere bzw. zur UUO-Niere Kontrollpuffer-behandelter Mäuse). 


\subsection{Rescue-Experiment}

MMPs besitzen eine essentielle Funktion bei der Degradation von Extrazellulärer Matrix (ECM). Neben der Induktion von Matrixmetalloproteinasen im Interstitium konnte gleichzeitig eine Reduktion von interstitieller Kollagen-1 sowie a-SMA-Akkumulation identifiziert werden. Basierend auf diesen Ergebnissen entstand die Hypothese, dass RLX030 (500 $\mu \mathrm{g} / \mathrm{kg} \mathrm{KG)}$ auch noch nach einer verzögerten Applikation zu einer Inhibition interstitieller Fibrose führen kann.
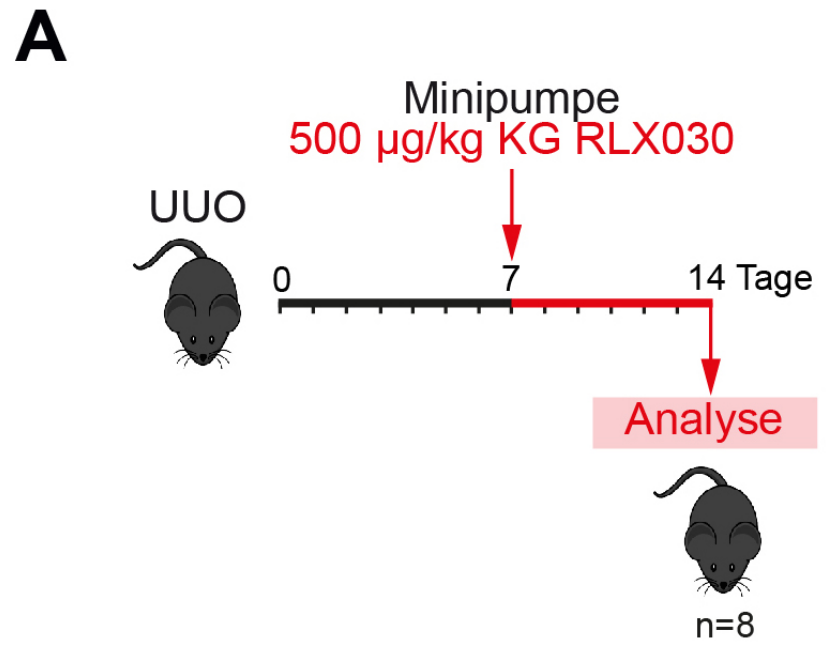

Abbildung 20: Mausmodell der Rescue-Studie über einen Zeitraum von 14 Tagen (A) Unilaterale Ureterobstruktion an Tag 0. Die Implantation der osmotischen Minipumpe gefüllt mit $500 \mu \mathrm{g} / \mathrm{kg} \mathrm{KG}$ RLX030 erfolgte sieben Tage nach UUO. Anschließende Sektion der Mäuse nach weiteren sieben Tagen (Tag 14).

Im Rahmen dieses Studiendesigns bekamen die UUO-Kohorten erst mit einer Verzögerung von sieben Tagen postoperativ die osmotische Minipumpe mit RLX030 implantiert. Eine Quantifizierung des Fibrosegrads erfolgte ebenfalls mittels histologischer Analysen. Hierbei wies die unbehandelte UUO-Kohorte eine ausgeprägte Akkumulation von interstitieller Matrix und $\alpha$-SMA auf. Im Gegensatz dazu zeigte die mit RLX030 $500 \mu \mathrm{g} / \mathrm{kg} \mathrm{KG}$ behandelte Kohorte eine signifikante Reduktion der renalen Fi-brosierung (Abbildung 21). 
A

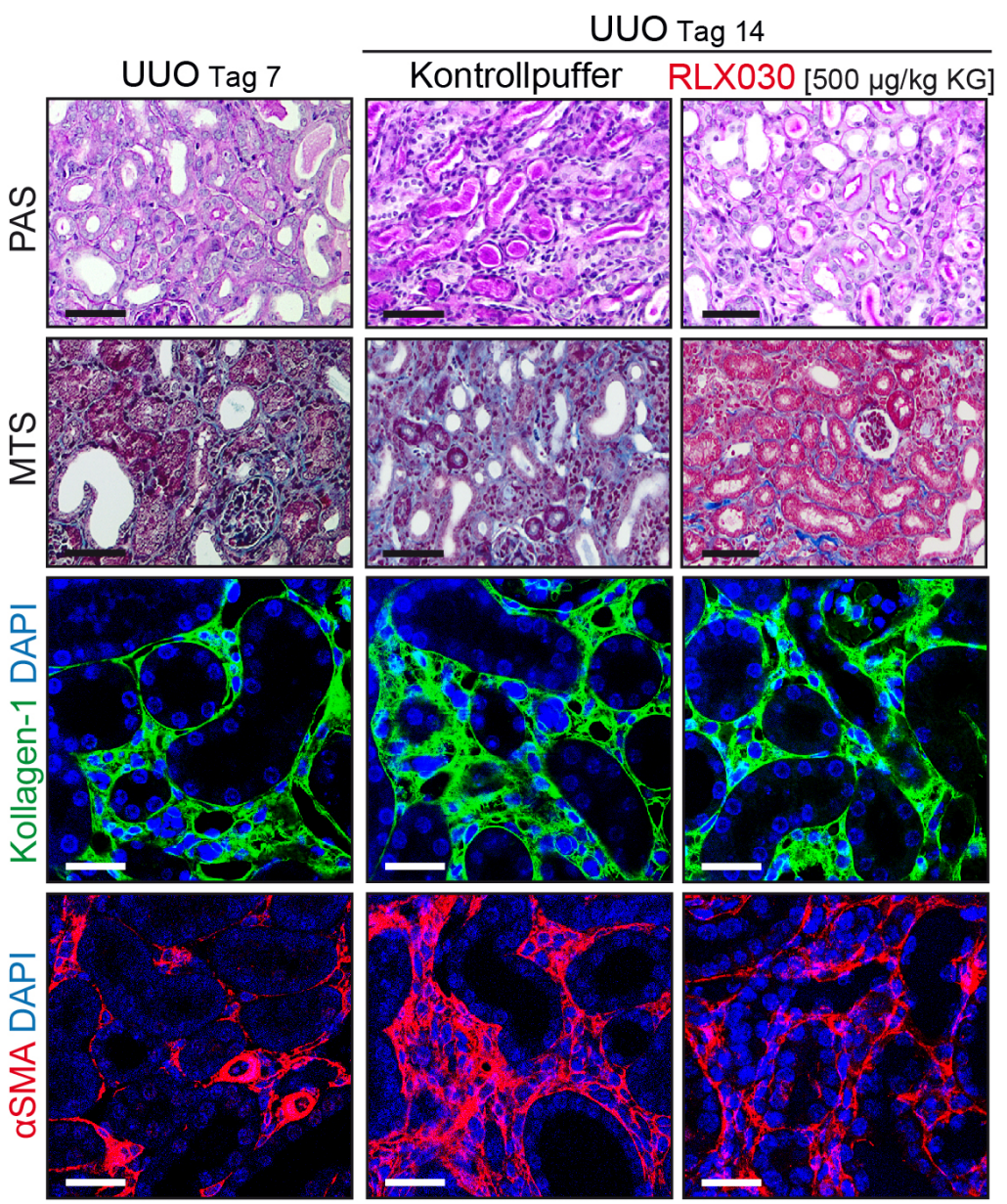

B

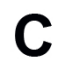

D
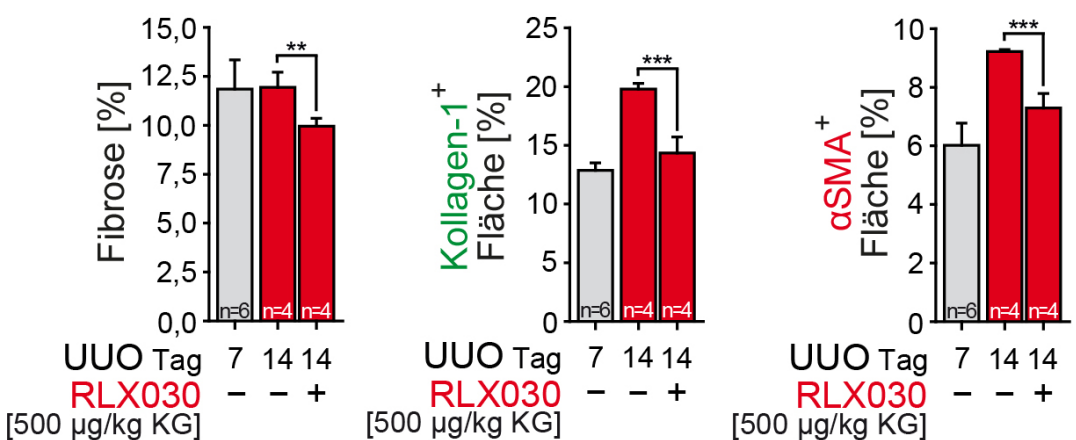

Abbildung 21: RLX030 vermittelt protektive Effekte bei schon etablierter Nierenfibrose. (A) Repräsentative Mikrofotographie PAS- und MTS-gefärbten renalen Gewebspräparaten (Messbalken $50 \mu \mathrm{m}$ ) sowie von immunfluoreszenzmarkierten Nierenpräparaten gegen Kollagen-1 und a-SMA (Messbalken $25 \mu m$ ). Die Bildausschnitte zeigen fibrotisch veränderte UUO-Nieren von Kontrollpuffer-behandelten und RLX030behandelten Mäusen sieben sowie 14 Tage nach unilateraler Ureterobstruktion. (B-D) Morphometrische Quantifizierung interstitieller Flächen positiv für Fibrose, Kollagen-1 und $\alpha-S M A$. (Die Bildanalyse erfolgte in je zehn Gesichtsfeldern pro Niere bei 200x bzw. 400x Vergrößerung, n=6 bzw. $n=4$ in jeder Gruppe, die Graphen zeigen Mittelwerte \pm Standardabweichungen, ${ }^{* *} p<0,01,{ }^{* *} p<0,001$; Kalkulation der $p$-Werte in Relation zur UUONiere Kontrollpuffer-behandelter Mäuse). 


\subsection{RLX030 ist äquivalent wirksam in humanen Fibroblastenkulturen}

Die antifibrotische Wirkung von RLX030 kann ebenfalls im humanen System detektiert werden. In einem äquivalenten Zellkulturversuch führt RLX030 zu einer Inhibition humaner Fibroblastenproliferation. Die Zellkohorte mit der höchsten RLX030 Konzentration (100 ng/ml) zeigt hierbei eine deutlich reduzierte Proliferationsrate im Vergleich zur alleinigen mit TGF- $\beta 1$-stimulierten Kultur (Abbildung 22).

A

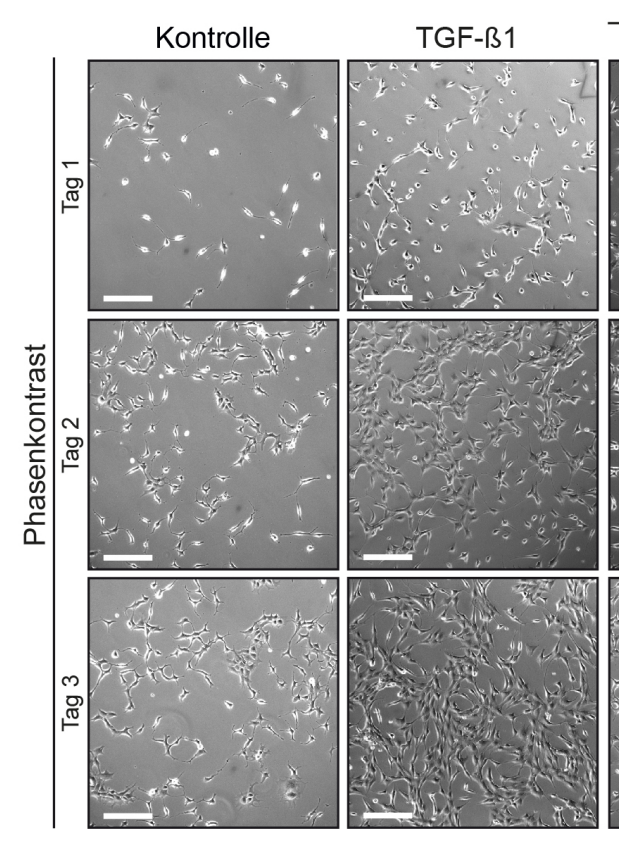

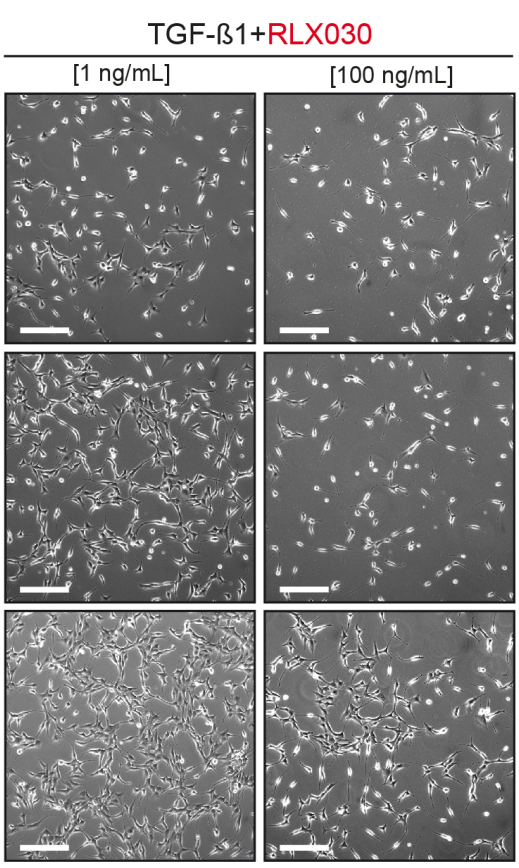

B

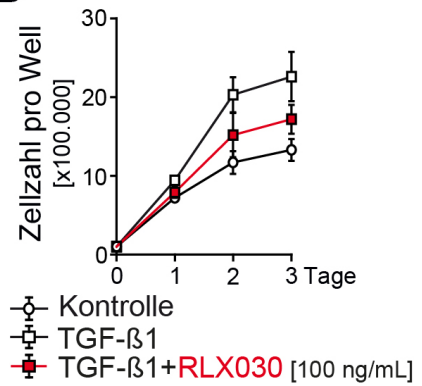

Abbildung 22: Inhibition der humanen Fibroblastenproliferation durch RLX030. (A) Repräsentative Phasenkontrastbilder von kultivierten human Fibroblastenkulturen nach Stimulation mit TGF- $\beta 1$ und angezeigten Konzentrationen RLX030 (Messbalken $50 \mu \mathrm{m}$ ). (B) Morphometrische Bestimmung der Zellproliferation. (Die Bildanalyse erfolgte in je zehn Gesichtsfeldern pro Well bei 400x Vergrößerung, der Graph zeigt Mittelwerte \pm Standardabweichungen).

\subsection{Expression der Relaxin-Isoformen sowie deren Rezeptoren in humanen Nierenbiopsien}

Die Reduktion von Relaxin-1 und -2 (RLN1 und RLN2) bei renaler Fibrogenese ist nicht nur in murinen Nieren detektierbar, sondern lässt sich auch in humanen Nierenbiopsien mit unterschiedlichen Grunderkrankungen mittels qRT-PCR untersuchen. Für RLN1 ist eine Verminderung der Expression vor allem bei der fokal-segmentaler Glomerulosklerose (FSGS), systemischem Lupus Erythematodes (SLE), benigner Sklerose, membranöser Glomerulosklerose (GN), Minimal Change-Nephropathie, C3vermittelter Glomerulonephritis (GN), IgA-Nephropathie (IgAN) mit FSGS sowie nekrotisierender Glomerulonephritis (GN) festzustellen (Abbildung 23A). Bei RLN2 ist eine deutlich verminderte Expression für folgende Erkrankungen der Niere zu konstatieren: die fokal-segmentale Glomerulosklerose (FSGS), systemischer Lupus Erythematodes (SLE), benigne Sklerose, membranöse Glomerulosklerose (GN), Minimal Change-Nephropathie, C3-vermittelte Glomerulonephritis (GN), IgA-Nephropathie (IgAN) mit FSGS sowie nekrotisierender 
Glomerulonephritis (GN, Abbildung 23B). Dagegen zeigt sich keine Veränderung von RLN1 oder RLN2 im akuten Nierenversagen (AKI, Abbildung 23) und bestätigt die Assoziation mit insbesondere chronischen Nierenerkrankungen.

A

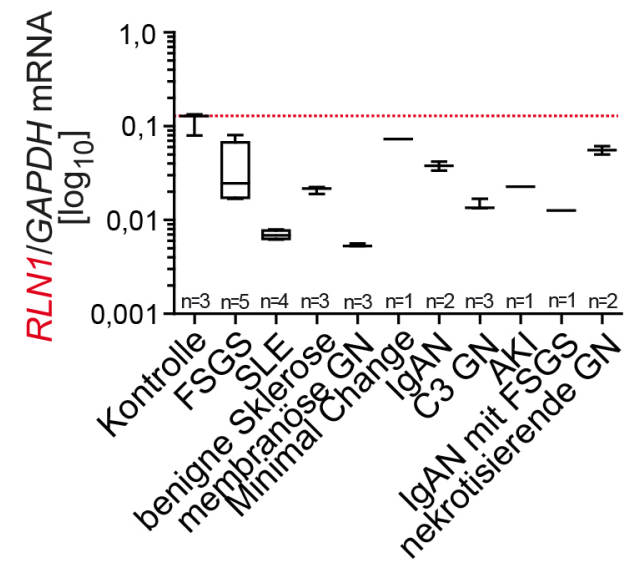

B

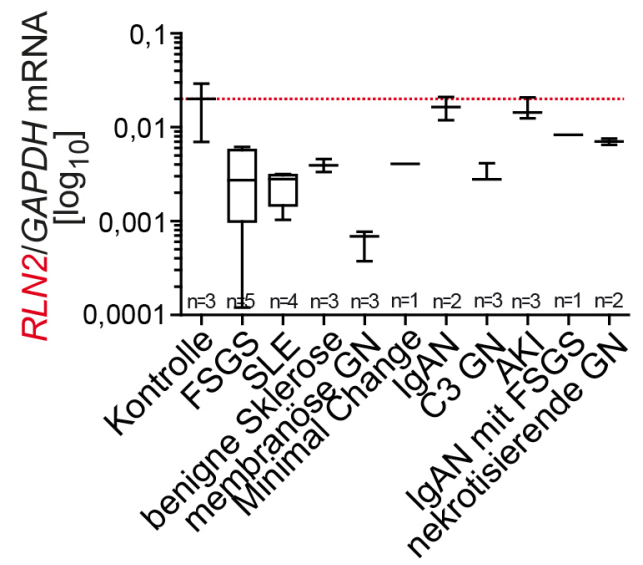

Abbildung 23: Expression der Relaxin-Isoformen in humanen Nierenbiopsien. $(A, B)$ Die intrarenale mRNAExpression von RLN1 und RLN2 relativ zu GAPDH wurde mittels qRT-PCR bestimmt (n von biologischen Replikaten wie angegeben, Analyse in technischen Triplikaten, die Graphen zeigen $\log _{10}$-transformierte Mittelwerte \pm Minimum/Maximum).

Weitere Anhaltspunkte hierfür konnten durch die webbasierte Datenbank NephroSeq gefunden werden, hier ergibt sich eine robuste Korrelation zwischen Verlust der Nierenfunktion (eGFR-Verlust) und intrarenaler Expression von insbesondere RLN1 (Ju et al. 2015). 
$n=192$

Ju et al.

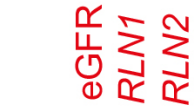

$\frac{\% \text { quantil }}{1050 \quad 90}$
eGFR (MDRD)
$\log _{2}$ median centered intensity
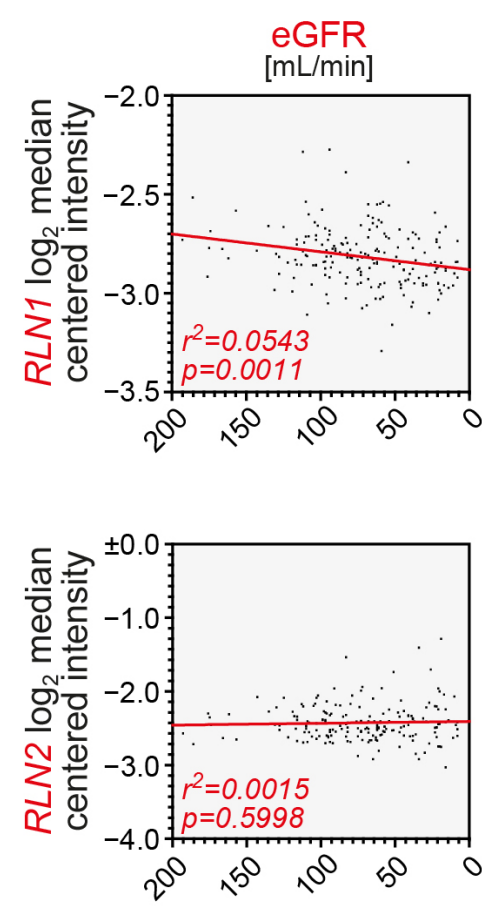

Abbildung 24: Heatmap: RLN1- und RLN2-Verlust assoziiert mit der Progression chronischer Niereninsuffizienz (CKD). Die Heatmap illustriert durchschnittliche Expressionslevel der Genexpression von RLN1- und RLN2 in Abhängigkeit von der eGFR. Eine Abnahme der eGFR ist mit einem gleichzeitigen Verlust von RLN1 und RLN2 assoziiert (modifiziert nach: Ju et al. 2015).

Konsistent mit Beobachtungen in murinen Nieren kommt es in allen analysierten Erkrankungen der Niere zu einer intrarenalen Induktion der Relaxin-Rezeptoren RXFP1 und RXFP2 (Abbildung 25). 
A

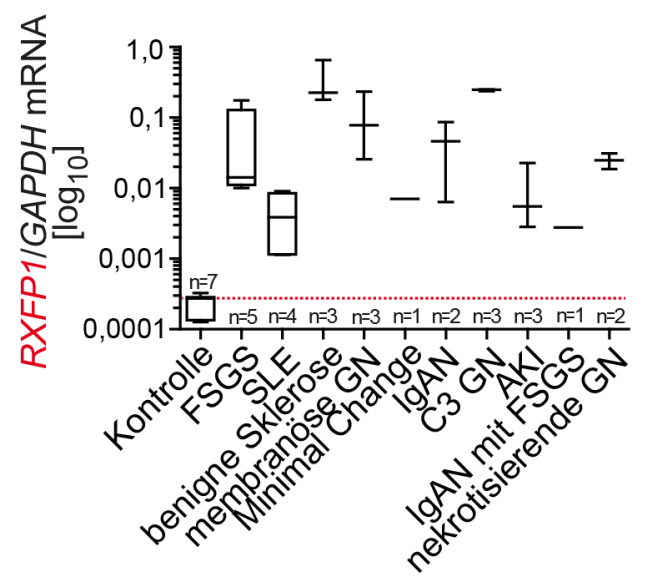

B

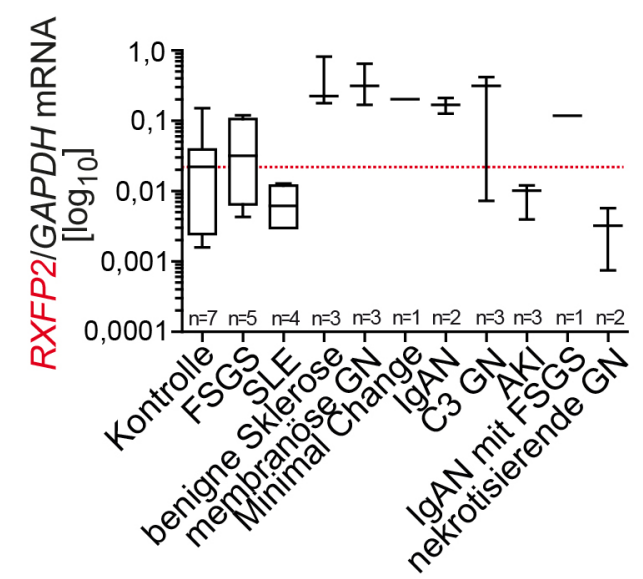

Abbildung 25: Expression der Relaxin-Rezeptoren-1 und -2 in humanen Nierenbiopsien. (A,B) Die intrarenale mRNA-Expression von RXFP1 und RXFP2 relativ zu GAPDH wurde mittels qRT-PCR bestimmt (n von biologischen Replikaten wie angegeben, Analyse in technischen Triplikaten, die Graphen zeigen $\log _{10}$ transformierte Mittelwerte \pm Minimum/Maximum).

\subsection{Aberrante Promotermethylierung als Biomarker für endogenen Relaxin-Verlust}

\subsubsection{Der Verlust von intrarenalem Relaxin beruht auf aberrranter Promotermethylierung}

Aberrante Promotermethylierung stellt einen epigenetischen Mechanismus dar, welcher zu einer stabilen Suppression der Genexpression führt. Aufbauend auf Vorarbeiten der Arbeitsgruppe erfolgte die Analyse aberranter Relaxin-Promotermethylierung mittels MeDIP. Es zeigte sich eine inverse Korrelation zwischen RLN1-Methylierung (5mC-RLN1) und intrarenaler RLN1-Expression (Abbildung 26A). Ein ähnlicher Zusammenhang konnte für RLN2 etabliert werden (Abbildung 26B), dies ist indikativ für epigenetische Regulationsmechanismen.

A

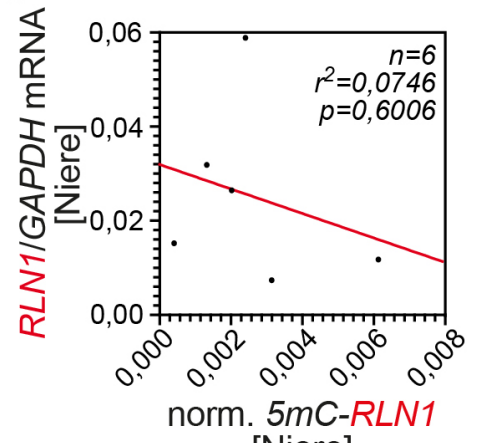

[Niere]
B

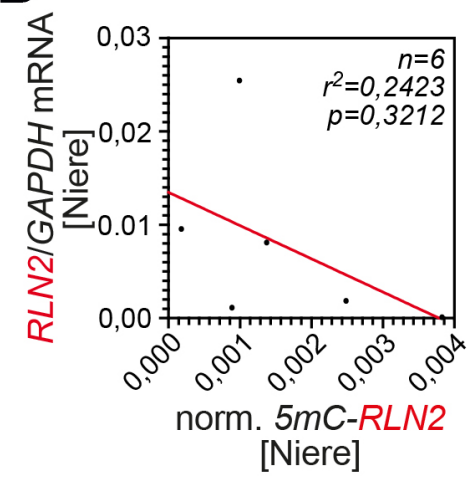

Abbildung 26: Korrelation von intrarenaler RLN1/RLN2-Methylierung mit intrarenaler RLN1/RLN2Expression. (A,B) Analyse der intrarenalen RLN1/RLN2-Methylierung in Korrelation mit der intrarenaler RLN1/RLN2-Expression in fibrotisch veränderten humanen Nierengewebe. ( $\mathrm{n}$ von biologischen Replikaten wie angegeben, Analyse in technischen Triplikaten, die Graphen zeigen lineare Regressionsanalysen mit $r^{2}$ und $p$ Werten). 
Da aberrante Promotermethylierung in der Niere auch im Blut detektiert werden kann, erfolgte die Analyse von 5mC-RLN1 und 5mC-RLN2 im Blut in Korrelation mit der Niere. Es konnte eine positive Korrelation etabliert werden (Abbildung 27).

A

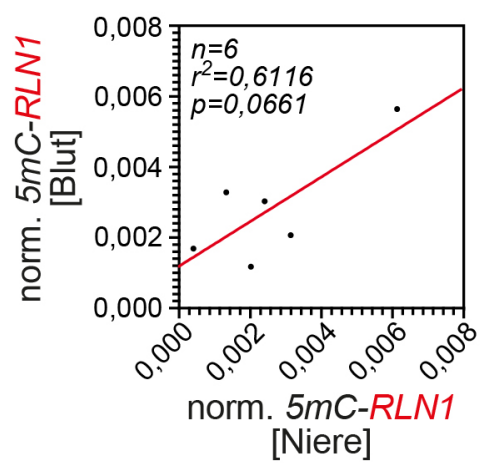

B

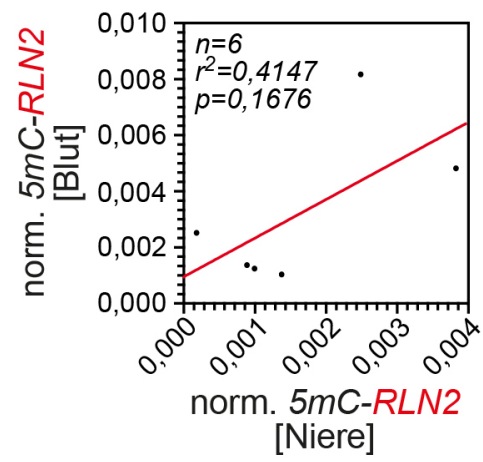

Abbildung 27: Korrelation von intrarenaler RLN1/RLN2-Methylierung mit RLN1/RLN2-Methylierung im Blut. (A,B) Analyse der intrarenalen RLN1/RLN2-Methylierung aus humanem Nierengewebe in Korrelation mit der RLN1/RLN2-Methylierung im Blut von entsprechend nierenerkrankten Patienten. ( $\mathrm{n}$ von biologischen Replikaten wie angegeben, Analyse in technischen Triplikaten, die Graphen zeigen lineare Regressionsanalysen mit $r^{2}$ und $p$-Werten).

Im nächsten Schritt wurde die 5mC-RLN1 und 5mC-RLN2 im Blut mit intrarenaler mRNA-Expression von RLN1 und RLN2 verglichen. Hier zeigte sich eine inverse Korrelation (Abbildung 28), indikativ für einen Nutzen von aberranter $5 m C-R L N 1$ und $5 m C$-RLN2 im Blut als Biomarker für endogenen Verlust von Relaxin in der Niere.

A

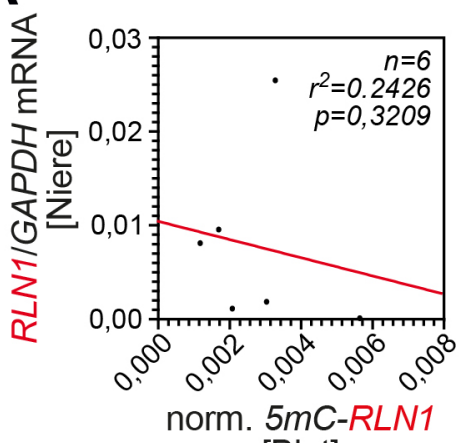

[Blut]
B

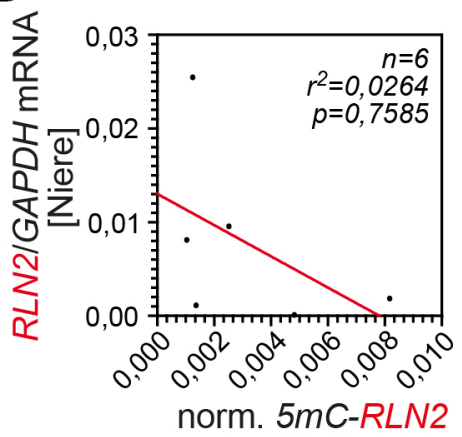

[Blut]

Abbildung 28: Korrelation von RLN1/RLN2-Methylierung im Blut mit intrarenaler RLN1/RLN2-Expression. $(\mathbf{A}, \mathbf{B})$ Analyse der RLN1/RLN2-Methylierung im Blut von nierenerkrankten Patienten in Korrelation mit der entsprechenden intrarenalen RLN1/RLN2-Expression. (n von biologischen Replikaten wie angegeben, Analyse in technischen Triplikaten, die Graphen zeigen lineare Regressionsanalysen mit $r^{2}$ und $p$-Werten).

Eine ähnliche Korrelation ließ sich in nierenkranken UUO-Mäusen etablieren, auch hier waren RIn1/RIn3-Methylierung in gleicher Weise in der Niere und korrespondierendem Blut nachweisbar (Abbildung 29). 
A

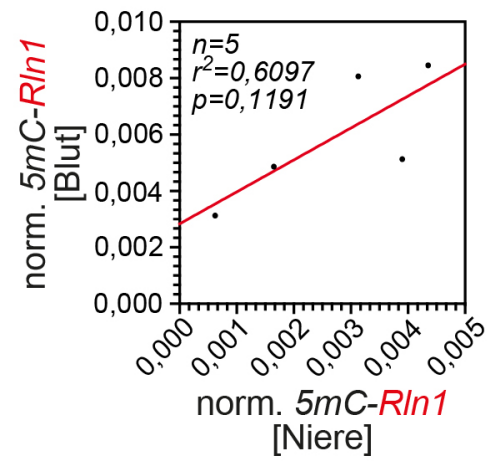

B

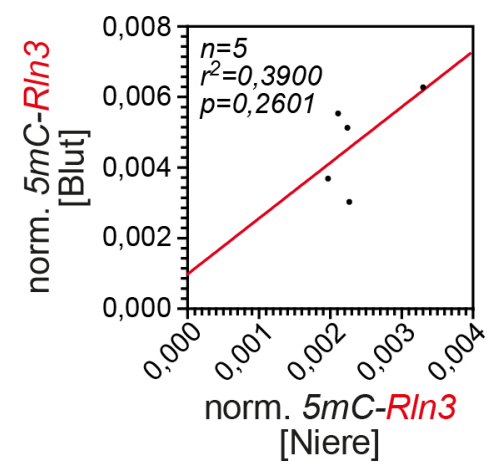

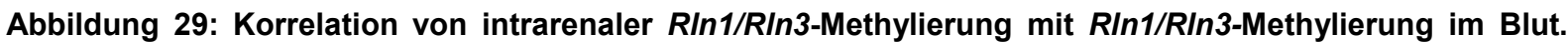
$(\mathbf{A}, \mathbf{B})$ Analyse der intrarenalen R/n1/R/n3-Methylierung aus UUO-Nieren von PBS-behandelten Mäusen in Korrelation mit der R/n1/R/n3-Methylierung im Blut der Mäuse. ( $\mathrm{n}$ von biologischen Replikaten wie angegeben, Analyse in technischen Triplikaten, die Graphen zeigen lineare Regressionsanalysen mit $r^{2}$ und $p$-Werten).

\subsubsection{Aberrante Relaxin-Promotermethylierung akkumuliert in Patienten mit chronischer Niereninsuffizienz}

Aufbauend auf einem korrelativen Zusammenhang zwischen intrarenalem Verlust von Relaxin und Akkumulation von Relaxin-Promotermethylierung im Blut erfolgte die Validierung in einer unabhängigen Kohorte aus nierenkranken Patienten Tabelle 26. Hier ließ sich ein signifikanter Zusammenhang zwischen Nierenfunktionseinschränkung (Anstieg von Kreatinin, eGFR-Verlust und Harnstoff-N-Erhöhung) und Akkumulation von $5 m C-R L N 1,5 m C-R L N 2$ und $5 m C-R L N 3$ nachweisen (Abbildung 30) Erneut, dies könnte einen Nutzen von aberranter 5mC-RLN1-3 im Blut als Biomarker für endogenen Verlust von Relaxin in der Niere indizieren. 
A
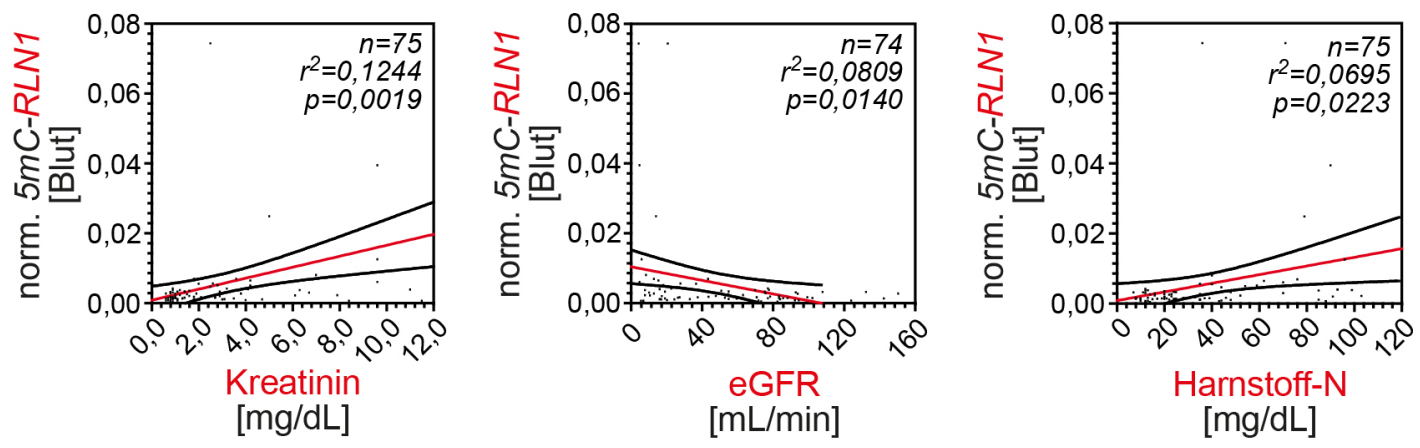

B
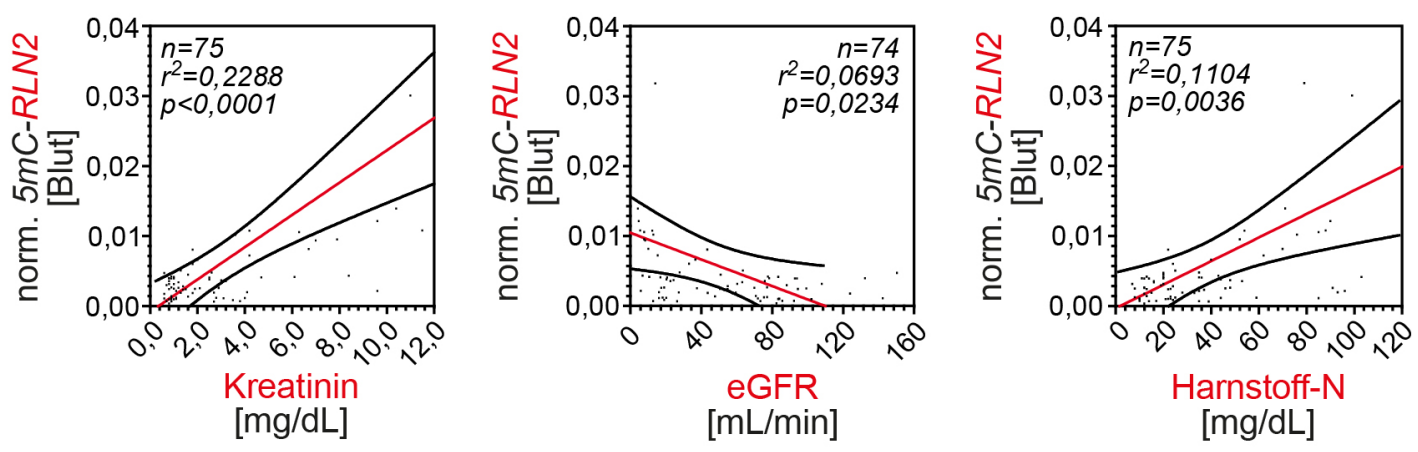

C
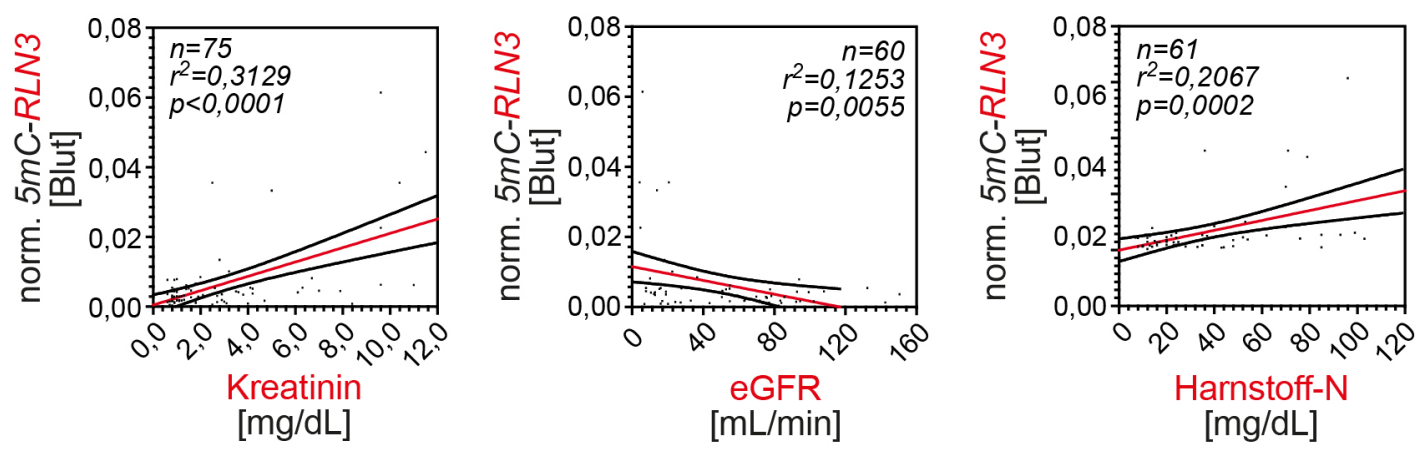

Abbildung 30: Nierenfunktionseinschränkung korreliert mit aberranter Relaxin-Promotormethylierung. (A-C) Analyse der Nierenfunktionseinschränkung mittels Anstieg von Kreatinin, eGFR-Verlust und Harnstoff-NErhöhung in Korrelation mit RLN1-3-Methylierung im Blut nierenerkrankter Patienten. (n von biologischen Replikaten wie angegeben, Analyse in technischen Triplikaten, die Graphen zeigen lineare Regressionsanalysen mit $r^{2}$ und $p$-Werten). 


\section{Diskussion}

Das humane Relaxin weist zahlreiche pleiotrope Effekte auf, die bereits in vorangegangenen Studien, insbesondere durch den Wissenschaftler Frederick Hisaw, beschrieben wurden (Bani 1997, Collino et al. 2013, Conrad und Novak 2004). Neben der Niere können weitere Effekte vor allem kardiovaskulär, im Gehirn sowie in den Reproduktionsorganen nachgewiesen werden (Bani 1997). Im Rahmen dieser Arbeit fand vor allem eine Auseinandersetzung mit der Inhibition renaler Fibrogenese und der Früherkennung renaler Erkrankungen statt. Die antifibrotischen Effekte von Serelaxin (RLX030) in murinen (Hewitson et al. 2010) als auch humanen renalen Fibroblasten (Heeg et al. 2005) und ihre Vermittlung über die Inhibition der TGF-ß-Signalkaskade sind schon von mehreren tierexperimentellen Studien dokumentiert worden (Sasser 2014, Bathgate et al. 2013, Heeg et al. 2005, Mookerjee et al. 2009).

\subsection{Studienlage RLX030}

Sowohl die Effizienz, Tolerierbarkeit als auch die Sicherheit von RLX030 zur Behandlung von Patienten wurde von der Firma Novartis primär in Studien zur akuten Herzinsuffizienz untersucht (Díez 2014, Wilson et al. 2015, Díez und Ruilope 2016). Im Juni 2013 wurde zwar eine Phase-I-Studie „PK of Serelaxin in Severe Renal Impairment and ESRD (CRLX030A2102)“ zur Evaluierung des Medikaments in Patienten mit schwerwiegenden Nierenerkrankungen oder terminaler Niereninsuffizienz angelegt, jedoch sind bisher noch keine Ergebnisse dieser Studie publiziert worden (clinicaltrials.gov).

RELAX-AHF-2 (NCT01870778) war eine multizentrale, randomisierte Doppelblindstudie in der Phase III mit den folgenden zwei Zielsetzungen: Die Reduktion kardiovaskulär bedingter Todesfälle sowie die Verhinderung des Voranschreitens von Herzinsuffizienzsymptomen. Im Oktober 2013 wurde die Studie initialisiert und umfasste 6.600 Patienten, welche aufgrund von akuter Herzinsuffizienz (AHF) hospitalisiert wurden. Aufgrund unzureichender Erfolge wurde sie jedoch im März 2017 eingestellt (Novartis provides update on Phase III study of RLX030 (serelaxin) in patients with acute heart failure).

\subsection{Induktion der Relaxin-Rezeptoren in der geschädigten Niere}

Sowohl in der murinen wie auch in der humanen Niere sind die sieben-transmembranen RelaxinRezeptoren -1 und -2 (Rxfp1,2 und RXFP1,2) vorhanden und vermitteln über eine G-Proteingekoppelte Kaskade die pleiotropen Wirkungen von Relaxin (Halls et al. 2007, Bathgate et al. 2013, Sasser 2014). Im Rahmen von immunhistochemischen Färbungen konnte die Lokalisation der Rezeptoren RXFP1 und RXFP2 in renalen Fibroblasten konstatiert werden, wohingegen eine Expression in Tubulusepithelzellen oder glomerulären Zellen nicht beobachtet werden konnte. In tierund humanexperimentellen Daten von Halls et al. sowie Bathgate et al. lassen sich bereits ähnliche Ergebnisse finden. Weiterführend konnte im Rahmen dieser Arbeit jedoch ein neuer, essentieller Aspekt detektiert werden: Hierbei wurde bei Patienten mit chronischen Nierenerkrankungen, 
ungeachtet ihrer zugrundeliegenden Erkrankung, bzw. in UUO-geschädigten murinen Nieren, eine Hochregulation der entsprechenden Relaxin-Rezeptoren (Rxfp1,2 und RXFP 1,2) etabliert. Der genaue Mechanismus der Hochregulation ist bisher jedoch noch unbekannt und bedarf weiterführender Forschung. Darüber hinaus konnte in diesen fibrotisch geschädigten Mausnieren ein intrarenaler Verlust des Hormons Relaxin konstatiert werden. Erste Ergebnisse hierzu wurden bereits in Vorversuchen von der Arbeitsgruppe Zeisberg erbracht (Lovisa et al. 2015) und konnten in der vorliegenden Arbeit mittels Western-Blot-Analysen auf Proteinebene sowie PCR-Auswertungen auf mRNA-Ebene validiert werden.

A

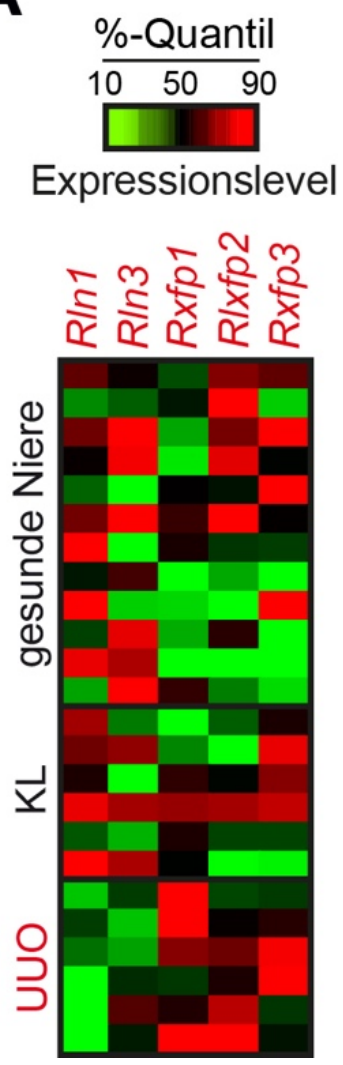

Abbildung 31: Heatmap der Relaxin-Isoformen und entsprechende Rezeptoren in gesunden, kontralateralen (KL) und UUO-Nieren. Die Heatmap illustriert durchschnittliche Expressionslevel der Genexpression von RIn1, RIn3, Rxfp1, Rxfp2 und Rxfp3 sowohl in UUO-geschädigten, als auch gesunden Nieren (modifiziert nach: Lovisa et al. 2015).

Es konnte folglich eine Korrelation zwischen dem endogenen Verlust von Relaxin in geschädigten Nieren und einer simultanen Induktion der entsprechenden Rezeptoren beobachtet werden. Basierend auf diesen Ergebnissen, ergaben sich zwei wichtige Konsequenzen: Zum einen ließ sich hieraus auf eine erhöhte Empfänglichkeit für die Applikation von RLX030 in fibrotisch geschädigten Nieren schließen. Zum anderen warf dies die Vermutung auf, dass geringere Konzentrationen bei der 
Applikation von RLX030 benötigt werden, um einen therapeutisch relevanten antifibrotischen Effekt zu erzielen.

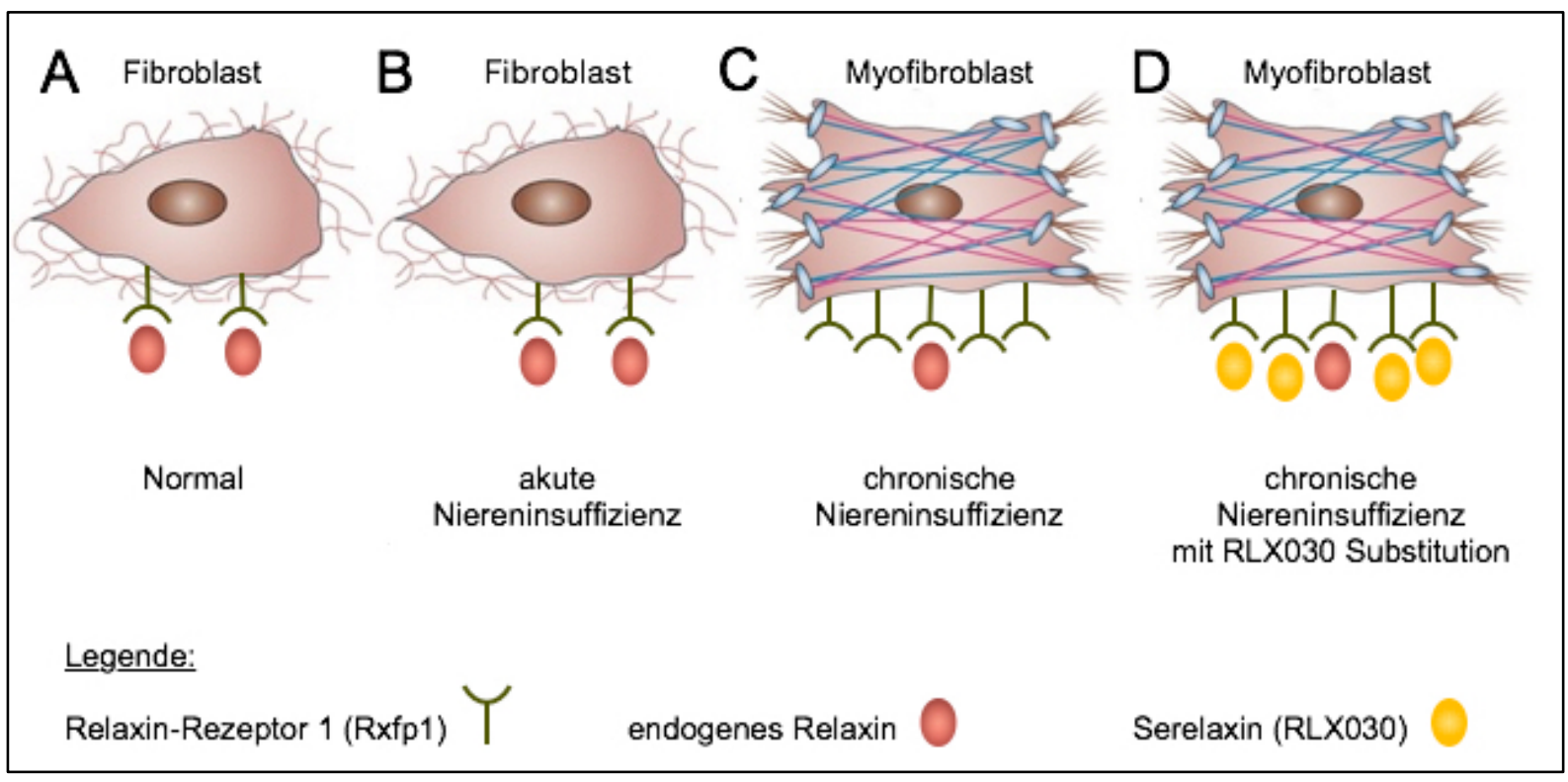

Abbildung 32: Veränderte Relaxin-Rezeptor-1-Expression in geschädigten Nieren mit einhergehendem endogenen Relaxin-Verlust. (A) Reguläre Relaxin-Rezeptor-1-Expression von nierengesunden Fibroblasten. (B) Unveränderte Rxfp1-Expression bei akuter Niereninsuffizienz. (C) Induktion der Rxfp1-Expression bei chronischer Niereninsuffizienz mit gleichzeitigem Verlust von endogenem Relaxin. (D) Induktion der Rxfp1Expression mit Supplementation von Serelaxin (RLX030) bei chronischer Niereninsuffizienz (modifiziert nach Falke et al. 2015).

\subsection{Attenuierung der renalen Fibrosierung in vivo durch Applikation von RLX030}

Die tubulointerstitielle Fibrose, wie sie bei Patienten mit terminaler Niereninsuffizienz untersucht werden kann, geht einher mit einer interstitieller Fibrose sowie einer tubulären Atrophie. Ein etabliertes Nagermodell stellt hierbei die chirurgisch durchgeführte unilaterale Ureterobstruktion (UUO) dar, welche im Hinblick auf den zeitlichen Ablauf, die Dauer und Schwere der Ausprägung beeinflusst werden kann. Zu Beginn entsteht aus der obstruierten Niere aufgrund der tubulären Dilatation eine Hydronephrosis. Die anschließende kortikale Atrophie sowie interstitielle Inflammation resultieren in der irreversiblen Nierenfibrose (Klahr und Morrissey 2002). Vorteilhaft ist darüber hinaus eine geringe Mortalität postoperativ bei den Tieren sowie die interne Kontrollierbarkeit der Methode aufgrund der erhaltenen Funktionalität der kontralateralen Niere (Ucero et al. 2013). Aufgrund dessen dient es einmal sowohl als Model der irreversiblen akuten Niereninsuffizienz als auch der Progression eines Nierenversagens (Chevalier et al. 2009). Zur Untersuchung der globalen Nierenfunktion und ihrer Funktionsparameter ist dieses Model allerdings nicht geeignet. Nachteilig ist zudem, dass kein signifikant glomerulärer Schaden detektiert werden kann und darüber hinaus die dauerhafte Ureterobstruktion zu einer, im Vergleich zum chronisch nierenkranken Patienten, aggressiven Progression der renalen Destruktion führt (Rossant und McKerlie 2001, Justice et al. 2011). Resultierend ist eine früh anhaltende renale Vasokonstriktion verbunden mit einer verminderten 
Nierenperfusion. Dies gilt es bei Applikation von Medikamenten und der Übertragbarkeit von Dosierungen zu bedenken (Eddy et al. 2012).

Insgesamt konnte zu allen Zeitpunkten (nach drei, sieben und zehn Tagen) in obstruierten Nieren des RLX030-behandelten Mauskollektivs eine signifikante Reduktion der progredienten renalen Fibrosierung detektiert werden. Morphometrische Bildanalysen von Masson-Trichrom sowie Immunfluoreszenzfärbungen von $\alpha$-SMA und Kollagen-1 verdeutlichten anschaulich die Progression tubulointerstit-ieller Fibrose in den Kontrollkohorten, als auch deren deutliche Suppression unter dosisabhängiger RLX030-Applikation. Die antifibrotische Wirkung von RLX030 konnte auch von Samuel et al. bestätigt werden, jedoch zeigten sich hier in vorangegangen Versuchen Geschlechterunterschiede bei der Entwicklung von Altersfibrose in männlichen Relaxin-1-KnockoutMäusen (Danielson et al. 2000, Sasser 2013, Hewitson et al. 2012). Bei entsprechend weiblichen Mäusen konnte keine signifikante Zunahme von tubulointerstitieller Fibrose detektiert werden (Samuel et al. 2004b). Darauf basierend, erfolgte im UUO-Mausmodell die Untersuchung des Mausgeschlechts auf die RLX030-Wirkung. Es wurden jeweils vier weibliche und vier männliche Mäuse mit RLX030 für 10 Tage behandelt. Ein geschlechtsspezifischer Wirkungsunterschied bei exogener RLX030Applikation konnte nach morphometrischen Bildanalysen in dieser Studie jedoch nicht festgestellt werden.

Methodische Diskrepanzen im Vergleich zu anderen Arbeiten von beispielsweise Hewitson et al. und Heeg et al. sind unter anderem in der dosisveränderten Applikation des Medikaments zu sehen (Hewitson et al. 2010, Heeg et al. 2005). Die beobachtete Induktion von Relaxin-Rezeptoren-1 und -2 in der murinen wie auch humanen fibrotisch destruierten Niere bot einen ersten Anhaltspunkt für dieses Studiendesign.

Nach dem Vorbild klinischer Dosierungsfindungsstudien ermöglichte die Applikation von verschiedenen Konzentrationen des Medikaments RLX030 das effektivste Wirkungsspektrum zu identifizieren. Hierbei verdeutlichte sich in den tierexperimentellen Analysen, dass bereits die mittlere Stimulationsdosis $(200 \mu \mathrm{g} / \mathrm{g} \mathrm{KG})$ den deutlichsten Effekt des Medikaments zeigte. Fraglich ist jedoch, in welchem Maße eine Übertragbarkeit dieser Ergebnisse auf den chronisch nierenkranken Patienten möglich ist. Trotz offenkundiger Differenzen zur Sequenzierung des murinen Transkriptoms sowie Epigenoms bietet die Hausmaus ein noch immer etabliertes Untersuchungsmodel zum Studium von humanen Erkrankungen und der Wirksamkeit von Medikamenten (Peters et al. 2007, Rosenthal und Brown 2007).

Eruiert wurde somit nicht nur der antifibrotische Effekt von RLX030, sondern zudem die therapeutische Mindestdosis, bei der eine noch deutliche antifibrotische Wirkung sichtbar war. Die Applikation von $200 \mu \mathrm{g} / \mathrm{kg} \mathrm{KG} \mathrm{RLX030} \mathrm{konnte} \mathrm{dementsprechend} \mathrm{als} \mathrm{effektivste} \mathrm{Dosierung} \mathrm{ermittelt}$ werden. Gestützt wurden diese Erkenntnisse neben den morphometrischen Untersuchungen durch PCR-Analysen auf mRNA-Ebene. Die Applikation des Medikaments fand bei allen erwähnten Arbeitsgruppen mit Hilfe einer osmotischen Minipumpe statt, die im Vergleich zu einer repetitiven 
subkutanen Injektion einen konstanten Medikamentenspiegel in den Versuchstieren sicherte (Doucette et al. 2000).

Weitere Differenzen zur Methodik der Arbeitsgruppe Hewitson et al. bestehen ferner im Zeitpunkt der Applikation des Medikaments. Sie verabreichten das Medikament bereits vier Tage vor der unilateralen Ureterobstruktion, um eine konstante RLX030-Konzentration von $20-40 \mathrm{ng} / \mathrm{ml} \mathrm{im}$ Blut zu erreichen (Hewitson et al. 2010). Diese Konzentration entsprach endogenen Relaxinspiegeln von schwangeren Mäusen (Samuel et al. 2016). Überlegungen der vorliegenden Arbeit befassten sich jedoch vor allem mit der Vergleichbarkeit des Mausmodells und dem Erkrankungsablauf von chronisch nierenerkrankten Patienten. Die Einnahme des Medikaments erfolgt im klinischen Krankheitsverlauf erst nach Detektion der Erkrankung, so dass die Implantation der osmotischen Minipumpe erst nach bzw. bei akuter Niereninsuffizienz stattfinden durfte. Die Versuche wurden aus diesem Grund in zwei Phasen durchgeführt. Zu Beginn erfolge die Implantation der osmotischen Minipumpen befüllt mit dem Medikament und die unilaterale Ureterobstruktion simultan. In einem anschließend durchgeführten Rescue-Experiment fand die Implantation der Pumpe erst sieben Tage post-UUO statt, sodass sich die Wildtypmäuse bei Implantation bereits im manifesten Nierenversagen befanden. Auch hier konnte eine Inhibition von tubulointerstitiellem Kollagen-1 und alpha smooth muscle actin-positiven Zellen in immunhistologischen Gewebsanalysen und MTS-Auswertungen nachgewiesen werden.

Die Inhibition der renalen Fibrogenese von RLX030 im UUO-Mausmodell konnte in einem zweiten unabhängigen Modell validiert werden. Hohe Dosen von Folsäure $(250 \mu \mathrm{g} / \mathrm{gKG})$, die Wildtyp-Mäusen mit dem genetischen Hintergrund FVB/N subkutan appliziert wurden, führten zur Induktion einer renalen interstitiellen Fibrose. Hierbei entsteht in der akuten Phase (1-14 Tagen) eine tubuläre Nekrose, für die zwei mögliche Ursachen diskutiert werden: Zum einen die tubuläre Obstruktion, die durch Folsäurekristalle hervorgerufen wird und zum anderen der direkt toxische Effekt der Folsäure auf die Tubuluszellen. Im Verlauf kommt es dann partiell jedoch zu einer Regeneration der tubulären Epithelzellen, sodass in der chronischen Phase (Tag 28-42) die interstitielle Fibrose dominiert. Das Modell wurde bereits in vorangegangen Studien der Arbeitsgruppe Zeisberg zur Induktion interstitieller Fibrose verwendet (Bechtel et al. 2010), anhand derer auch die Untersuchungszeitpunkte Tag 28, 84 und 140 bestimmt wurden. Verglichen mit dem UUO-Model kann in diesem Mausmodel die Nierenfunktion als Maß für die Entwicklung der chronischen Niereninsuffizienz bestimmt werden. Hingegen besteht im Folsäure-Modell ein Nachteil in Bezug auf die Homogenität der Ergebnisse. Bei manchen Mäusen wird eine spontane Regeneration nach 42 Tagen beobachtet (Long et al. 2001, Yang et al. 2010, Doi et al. 2006). Im Rahmen dieser Studie wurde die Krankheitsprogression mittels Kreatinin- und Harnstoffkonzentrationsbestimmungen im Serum kontrolliert.

Mittels Immunfluoreszenzfärbungen von a-SMA und Kollagen-1 sowie MTS-Färbungen in histologischen Gewebsschnitten ergab die Fibrosequantifizierung ab Tag 28 einen signifikanten Unterschied zwischen RLX030-behandelten Mäusen und der Kontrollkohorte. Da an Tag drei keine signifikanten Unterschiede zwischen der Kontroll- und der behandelten Gruppe detektiert wurden, 
erfolgte die Pumpenimplantation mit RLX030 für die nachfolgenden Zeitpunkte erst zwei Tage nach Folsäure-Injektion. Die Applikation fand somit bei bereits bestehender akuter Niereninsuffizienz statt. Zusammenfassend ließ sich die antifibrotische Wirkung von RLX030 in zwei unabhängigen Mausmodellen (UUO und FAN) mit zusätzlich unterschiedlichem genetischen Hintergrund (respektive $C 57 B L / 6$ und $F V B / N)$ bestätigen.

\subsection{Molekulare Transduktionsmechanismen zur Inhibition der renalen Fibrogenese}

Die Wirkung von Relaxin auf die renale Gewebsmorphologie wird hauptsächlich über den eingangs beschriebenen Relaxin-Rezeptor-1 vermittelt. Die genauen Transduktionswege sind zentrale Aspekte in der aktuellen Forschung, um neue therapeutisch nutzbare Angriffspunkte detektieren zu können. Die Progression renaler Fibrogenese wird wesentlich durch das Zytokin TGF-ß1 beeinflusst (Border und Noble 1997, Peters et al. 1998, López-Hernández und López-Novoa 2012). Bathgate et al. beschrieben im Hinblick auf antifibrotische Effekte zwei wichtige Signaltransduktionwege in humanen und murinen renalen Myofibroblasten: Diskutiert wird eine verstärkte Relaxin-induzierte Synthese des diatomischen Radikals NO (nitric oxide) über Proteinkinasen - PI3K und ERK -, welche zu einer Induktion der Matrixmetalloproteinasen-1 (Kollagenase-1),-3 (Stromelysin-1), -9 (Gelantinase B) und 13 (Kollagenase-3) führen (Baccari und Bani 2008). Weiterhin wird eine direkte Interaktion von NO in die Signaltransduktion von TGF-ß vermutet (Garber et al. 2001, Masterson et al. 2004), welches über eine Inhibition der TGF-ß-induzierten Phosphorylierung von Smad2, den antifibrotischen Effekt von Relaxin vermittelt (Heeg et al. 2005, Mookerjee et al. 2009). Dieser Signalweg konnte unter anderem in vitro an ventrikulären Fibroblasten aus Ratten beobachtet werden (Conrad 2010). Danielson et al. unterstützten diese Hypothese, indem sie Ratten simultan mit rekombinanten Relaxin $\mathrm{H} 2$ und einem NO-Synthase-Inhibitor (Nomega-nitro-L-arginine methyl ester) behandelten (Danielson et al. 1999). Die zuvor beobachtete Zunahme der eGFR sowie des renalen Plasmaflusses (ERPF) wurde nach Applikation des NO-Synthase-Inhibitors unterbunden. Folglich konnte NO als ein essentieller Mediator für die antifibrotische Wirkung von Relaxin bestimmt werden. Im Rahmen dieser Arbeit wurden weiterführende Versuche im tierexperimentellen Model der tubulointerstitiellen Fibrose in vivo durchgeführt. In Gewebsschnitten von Tag 10-geopferten Mäusen, die mit einer Konzentration von 200 und $500 \mu \mathrm{g} / \mathrm{kg} \mathrm{KG}$ Serelaxin behandelt wurden, konnte anhand von immunhistologischen Gewebsanalysen eine deutliche Degradation von pSmad2 in den Medikamenten-behandelten Gewebsschnitten untersucht werden (Chow et al. 2012).

Renale tubulointerstitielle Fibrose resultiert nicht nur aus einer Überproduktion von extrazellulärer Matrix, sondern auch aus einer beeinträchtigten Degradation von Matrixproteinen. Dies wird vor allem durch eine Herabregulation von Matrixmetalloproteinasen (MMPs) oder einer Induktion von TIMPs (tissue inhibitor of matrix metalloproteinase) herbeigeführt (Eddy 2000, Sasser 2013). Das Wirkungsspektrum der Matrixmetalloproteinasen besitzt eine hohe Diversität. Neben der Abwehrfunktion und Wundheilung sind sie zudem auch an Gefäßneubildungen beteiligt (Bonnema et al. 2007). Sie gehören zur Gruppe der extrazellulären Endopeptidasen und sind an der Regulation von 
Auf-und Abbauprozessen des Matrixgewebes beteiligt (Giannandrea und Parks 2014). Die Aktivität der MMPs kann über verschiedene Mechanismen reguliert werden: Auf Transkriptionseben, durch die Aktivierung von latenten pro-MMPs und durch die Inhibition der TIMPs (Giannandrea und Parks 2014, Chow et al. 2012). Entsteht ein Ungleichgewicht im Zusammenspiel von MMPs und TIMPs, hat dies großen Einfluss auf das tissue remodeling. Eine erhöhte Induktion führt zur verstärkten Degradation der Extrazellulären Matrix, wohingegen eine prominente TIMPs Expression zu einer deutlichen Fibrosierung des Gewebes führt (Giannandrea und Parks 2014, Madlener 1998). In der vorliegenden Arbeit konnte mittels qRT-PCR-Analysen auf mRNA-Ebene in Gewebsproben von unbehandelten und mit RLX030-behandelten Wildtypmäusen an Tag sieben und zehn eine deutlich erhöhte Expression von Mmp-2, und -9 festgestellt werden. Ähnliche Ergebnisse konnten auch schon in anderen Arbeitsgruppen beobachtet werden. Samuel et al wiesen eine Relaxin vermittelte Stimulation von Mmp-2 nicht nur in experimentellen Fibrosemodellen der Niere in vivo nach, sondern auch in Modellen der Herz-und Lungenfibrose (Unemori et al. 1996, Rideout et al. 1990, Samuel et al. 2004a). Eine genaue Aktivitätsbestimmung der MMPs mittels Gelatin-Zymographie (Jeyabalan et al. 2006) erfolgte in der vorliegenden Arbeit allerdings nicht. Diese Methode ist zwar sensitiver, allerdings auch sehr Zeit- und Materialaufwendig. Zudem war inm Rahmen dieser Arbeit vor allem die relative Expressionsmenge von MMP-2 und MMP-9 interessant, die ebenfalls auf mRNA-Ebene und morphometrischen Färbungsuntersuchungen bestimmt werden konnte. Der genaue molekulare Mechanismus zur Inhibition der renalen Fibrogenese durch MMPs ist noch immer nicht vollends verstanden. Giannandrea und Parks führen, basierend auf ihren Arbeiten, an, dass MMPs einen direkten Einfluss auf Inflammationsprozesse sowie die Aktivierung von Myofibroblasten haben und somit nicht nur auf Effekte der EZM-Umwandlung limitiert sind (Kapila et al. 2009).

\subsection{Beleuchtung des intrarenalen Verlusts von Relaxin durch epigenetische Regulationsmechanismen}

Der endogene Verlust von Relaxin hat eine hohe therapeutische Relevanz. Die genauen Regulationsmechanismen der Relaxinisoformen bei Nierenerkrankungen sind allerdings zurzeit wenig erforscht. In vorangegangen Arbeiten konnte gezeigt werden, dass Methylierungsprozesse von Promotorregionen spezifischer Gene zur Exazerbation der Fibrogenese führen (Bechtel et al. 2010, Tampe und Zeisberg 2014). Tampe et al. eruierten spezifisch den Mechanismus der Hypermethylierung von entsprechenden Genen (RASAL1) in fibrotisch destruierten Nierenparenchym, die mit der Ausprägung der Fibrose korrelieren (Tampe et al. 2015).

Bei der DNA-Methylierung erfolgt am Cytosin, welches Teil von so genannten CpG-Inseln ist, eine Methylierung an der C5-Position, sodass 5-Methyl Cytosin entsteht. Dieser Prozess wird funktionell relevant, wenn die CpG-Inseln Teil von Gen-Promotorregionen sind, da dies zu einer Suppression der Transkription führt (Zeisberg und Zeisberg 2013). Wie bereits eingangs erwähnt, wurde die Relevanz der abarrenten Methylierung von CpG-Promotor-Inseln zuerst am Beispiel der Krebsentstehung 
deutlich. Hier führte die DNA-Methylierung zur Inaktivierung spezifischer Tumorsuppressorgene (Mikeska und Craig 2014, Zeisberg und Zeisberg 2013, Dawson et al. 2013).

Unter der Verwendung der integrativen disease platform NephroSeq (NephroSeq.org) konnte initial die Hypothese der Relaxin-DNA-Promotor-Hypermethylierung und der damit einhergehende Verlust des endogenen Relaxins in der Niere entwickelt werden. Die Datenbank implementierte, dass im murinen Genom Relaxin-1, Relaxin-3, Relaxin-Rezeptor-2 und -3 sowie im humanen Genom Relaxin1, Relaxin-2, Relaxin-3 und Relaxin-Rezeptor-3 proximal gelegene CpG-Promotor-Inseln aufweisen. Dementsprechend wurde in Vorversuchen zu dieser Arbeit eine limitierte Anzahl an fibrotisch veränderten murinen Nieren untersucht. Hierbei wurde die renale Schädigung durch unterschiedliche Mausmodelle erzeugt: STZ-induzierte diabetische Nephropathie (DN), Nephrotoxische Serum Nephritis (NTN) und Unilaterale Ureterobstruktion (UUO). Die renale Fibrogenese war in allen Modellen mit einer deutlichen Zunahme der DNA-Promotor-Methylierung von Relaxin-1 und Relaxin-3 assoziiert.

Diese Beobachtungen konnten in einer größeren Mauskohorte in der vorliegenden Arbeit bestätigt werden. Weiterhin bot sich die Möglichkeit, eine mögliche Übertragbarkeit der Mechanismen auf den Menschen in humanen Nierenbiopsien zu untersuchen. Unabhängig der chronischen renalen Grunderkrankungen (Membranoproliferative GN, Lupus Nephritis, FSGN, Complement-GN und Diffus nekrotisierende GN) konnte stichprobenhaft eine Hypermethylierung der entsprechenden intrarenalen DNA-Promotorfragmente konstatiert werden. Eine Ausnahme bestand jedoch für Patienten mit akuter Niereninsuffizienz. Bei dieser Kohorte konnte zum einen kein signifikanter Verlust von RLN1 und RLN2 detektiert werden, zum anderen blieb die Induktion der Rezeptoren RXFP1 und RXFP2 aus. Interessant ist hierbei vor allem, welche Rolle die epigenetische Regulation bei der Entwicklung von akuter Niereninsuffizienz einnimmt. Epigenetische Modifikation scheint vor allem einen Einfluss auf die Transition von akuter (AKI) zur chronischen Niereninsuffizienz (CKD) zu haben (Tampe et al. 2017). Während AKI-Episoden sind Tubulusepithelzellen einem hypoxischen Milieu ausgesetzt, welches nicht nur zur Modifikation vom zellulären Metabolismus führt, sondern auch Einfluss auf Chromatinstrukturen und die Bindungsaffinität verschiedener Transkriptionsfaktoren hat (Bomsztyk und Denisenko 2013). Pratt et al. 2006 zeigten zudem einen Zusammenhang zwischen der Hochregulation des Komplementfaktors C3, bedingt durch einen Anstieg an demethylierten CpGDinukleotiden im C3-DNA-Promotor von Rattennieren. Epigenetische Modifikation scheint somit vor allem essentiell an der Persistenz von Inflammation und EMT, die schlussendlich zu CKD führen, beteiligt zu sein. Ausgehend von diesen Studien lassen sich neue Möglichkeiten im Hinblick auf Diagnostik und Therapie ableiten (Reddy und Natarajan 2015, Rodríguez-Romo et al. 2015).

\subsection{Molekulargenetische Identifikation eines therapierelevanten Biomarkers}

Ein wichtiger aktueller Forschungsschwerpunkt in wissenschaftlichen Studien ist die Identifikation von Biomarkern zur Therapiestratifizierung. Ausgehend von dem Prinzip der personalisierten Medizin, 
besteht die Hypothese, dass Patienten mit identischer Diagnose auf die Behandlung mit dem gleichen Medikament unterschiedlich ansprechen (Collins und Varmus 2015). Während die Therapie für den einen Patienten effektiv und wirksam ist, lassen sich für den anderen keine adäquaten Therapieerfolge verzeichnen. Die verlässliche Vorhersage des Therapieeffektes nimmt eine immer wichtigere Rolle in der patientenbezogenen Medizin ein (Collins und Varmus 2015). Aktuell eingesetzte Funktionsparameter umfassen zum einen die errechnete glomeruläre Filtrationsrate (eGFR), die auf der Bestimmung des Kreatinin-Werts beruht, zum anderen den Nachweis von Proteinen im Urin (Proteinurie) (Lassus et al. 2010, Gupta et al. 2012, Levin et al. 2014). Der große Nachteil von beiden Funktionsparametern ist erstens der Zeitfaktor und zweitens die Undifferenziertheit. Es kommt erst zu einer Veränderung der Messwerte nach bereits erfolgter bzw. bestehender Schädigung der Niere. Dementsprechend wird ein Biomarker benötigt, der bereits vor einem irreversiblen Verlust der Nierenfunktion zu bestimmen ist (Ärzteblatt). Zum anderen wird das Prinzip der individualisierten Medizin vernachlässigt. Es werden Biomarker benötigt, welche Patienten identifizieren, die einen deutlichen therapeutischen Nutzen aus der Behandlung mit RLX030 ziehen.

Zur effektiven Quantifizierung der renalen Fibrose wird immer noch eine Nierenbiopsie benötigt. Nachteilig bei dieser Art der Diagnostik ist die Invasivität, eine eingeschränkte vielfache Wiederholbarkeit sowie die Ungenauigkeit in Bezug auf molekulare Fragestellungen. Ein effizienter und prognostisch-wertvoller Biomarker sollte das Vorkommen renaler Fibrose reflektieren sowie Aussagen über den Outcome eines Patienten bieten. Eine nicht-invasive Probengewinnung ist essentiell. In vergangenen Jahren wurde die Etablierung der sogenannten liquid biopsy (Flüssigbiopsie) vorangetrieben zur Identifikation von DNA-Fragmenten im Blut (Fackler et al. 2014, Genovese et al. 2014, Lee et al. 2014, Mischak 2015, Di Meo et al. 2017, Magalhães et al. 2017). Zurzeit wird diese Methode vor allem bei der Früherkennung von Tumorerkrankungen genutzt (Leon et al. 1977). Interessant ist nicht nur die Detektion von DNA-Fragmenten, sondern auch die Exploration von DNA-Modifikation im Hinblick auf DNA-Methylierung (Li et al. 2012).

In bereits publizierten Studien (Mikeska und Craig 2014) wurde konstatiert, dass quantitative Veränderungen von Methylierungsstrukturen einen erheblichen Nutzen als Biomarker bergen (Tampe et al. 2015, Papageorgiou et al. 2011). Insbesondere im Vergleich zu anderen Verfahren, wie der Histonmodifikation oder microRNAs, sind sie spezifischer in ihrem Detektionsspektrum (Zeisberg und Zeisberg 2015, Papageorgiou et al. 2011). DNA-Methylierungsmuster werden bereits während der Embryonalentwicklung bestimmt, sodass Veränderungen im DNA-Methylierungsmuster entweder durch Alterungsprozesse oder durch Krankheiten bedingt sind (Dahl und Guldberg 2003). Zurzeit werden vielversprechende DNA-Methylierungs-Biomarker vor allem in klinischen Studien der Krebsforschung zur Früherkennung eingesetzt (Mikeska und Craig 2014). Die Bedeutsamkeit von aberrante Methylierung der CpG-Promotor-Inseln wird verdeutlicht durch die Wirksamkeit von 5'Azacytidin, dem ersten de-methylierenden Agens, welches für den klinischen Gebrauch bei Patienten mit MDS und Akuter Myeloischer Leukämie (AML) zugelassen wurde (Tampe et al. 2015, Zeisberg 
und Zeisberg 2013). Basierend auf diesen Ergebnissen lässt sich ableiten, dass DNAPromotormethylierung einen reversiblen epigenetischen Prozess darstellt und folglich einen weiteren Angriffspunkt, nicht nur zur Therapie von Tumorerkrankungen, sondern auch zur Umkehr von Organfibrosen bieten könnte. Erste Erkenntnisse wurden bereits von Tampe et al. 2015 erbracht. Die Arbeitsgruppe zeigte, dass der hypermethyierte Rasal1-DNA-Promotor in fibrotisch destruierten Nieren nach der Behandlung mit dem Bone morphogenetic protein 7 (BMP7) normalisiert werden kann.

Des Weiteren sind Untersuchungen in Bezug auf den Methylierungsgrad von bestimmten Genen interessant, um das individuelle Risiko eines Patienten fibrotisch destruierte Nieren zu entwickeln, abschätzen zu können, oder den Nutzen einer Demethylierungstherapie bestimmen zu können. Weiterentwickelt wurden diese Ergebnisse von der Arbeitsgruppe Zhang et al. Sie konnten mit dem Hormon Klotho und dessen Repression durch entsprechende methylierte DNA-Promotorfragmente in fibrotisch veränderten humanen und murinen Nieren, neben RASAL1, einen vermeidlich weiteren Biomarker zur frühzeitigen Identifikation renaler Fibrose bestimmen (Zhang et al. 2016).

Effiziente Nachweismethoden zur Analyse von DNA-Methylierung sind wichtige Voraussetzungen zur Bestimmung von Biomarkern. Es gibt verschiedenste Nachweismethoden, die jeweils auf unterschiedlichen Ebenen Informationen über DNA-Promotormethylierung liefern. Die Spannbreite reicht hierbei von einer genomweiten Methylierungsanalyse bis zur Bestimmung von Methylierungsmustern eines einzelnen Gens (Dahl und Guldberg 2003). In der vorliegenden Arbeit wurde das MeDIP-Verfahen zur Detektion methylierter DNA-Fragmente gewählt. Hierbei kommt es zu einer Anreicherung von Fragmenten in Abhängigkeit von der Dichte methylierter CpGs. Folglich kann somit genomweit nach hypermethylierten CpG-reichen Sequenzen gesucht werden. Diese Eigenschaft ist insbesondere für die Suche nach neuen Biomarkern essentiell. Das Verfahren zeigt jedoch auch Limitationen. Die Qualität und Spezifität der Antikörper sowie eine deutlich reduzierte Anreicherungseffizienz in Regionen mit vermindertem CpG-Auftreten sind zwei wichtige Punkte, die es zu bedenken gilt (Olkhov-Mitsel und Bapat 2012).

In der vorliegenden Arbeit dienten zunächst Blutproben von Wildtypmäusen (C57BL/6) als Versuchsmaterial. In den zugehörigen Blutproben konnte bei den nierengeschädigten Tieren eine signifikant gesteigerte Konzentration an zirkulierenden $R / n 1$ und RIn3 DNA-Promotorfragmenten festgestellt werden. Basierend auf diesen Ergebnissen wurden Blutproben einer Patientenkohorte bestehend aus 75 Volontären in Bezug auf DNA-Promotorfragment-Methylierung untersucht. Es konnte gezeigt werden, dass beim Patienten mit chronischer Niereninsuffizienz zirkulierende methylierte CpG-Promotorfragmente von RLN1, RLN2 und RLN3 mit dem Grad an intrarenaler Methylierung der entsprechenden Gene sowie an interstitieller renaler Fibrose korrelieren. Als Nierenfunktionsparameter dienten die eGFR, der Serum-Kreatinin, Harnstoffspiegel (BUN), die Clearance sowie der renale Fibrosegrad. Besonders sensitiv korrelierten die zirkulierenden methylierten RLN2 DNA-Promotorfragmente mit der Serum-Kreatinin- und Harnstoffkonzentration. Die Induktion der Biomarker war zudem unabhängig von der chronischen Grunderkrankung des Patienten 
erkennbar. Dies bestätigt die Hypothese der Arbeitsgruppe Mao, dass epigenetische Veränderungen, die an der Ausbildung von Krankheiten beteiligt sind, eine Gewebsspezifität aufweisen (Mao 2014). $\mathrm{Zu}$ bedenken gilt jedoch, dass Methylierungsmuster von DNA-Promotorfragmenten abhängig vom Alter der Patienten variieren können, da epigenetische Veränderungen Teil des natürlichen Alterungsprozesses sind (Bocklandt et al. 2011, Stubbs et al. 2017). Beispielsweise konnten unterschiedliche methylierterte Promotorfragmentspiegel in nierengesunden Patienten verschiedenen Alters bestimmt werden. Demzufolge kann die Konzentration an methylierten zirkulierenden DNAPromotorfragmenten bei Patienten mit der gleichen renalen Erkrankung teils unterschiedlich ausfallen. Dagegen zeigte die Patientenkohorte im Rahmen dieser Arbeit deutliche Tendenzen, die auf eine positive Korrelation zwischen Anstieg der Nierenretentionswerte und zirkulierenden methylierten Promotorfragmenten schließen lassen.

Der genaue Mechanismus der Freisetzung der methylierten CpG-Promotorfragmente in die Blutbahn ist noch nicht eindeutig geklärt. Vermutungen gehen von einer unspezifischen Freisetzung aus destruierten Zellen aus, ähnlicher der Freisetzung von DNA-Fragmenten bei Krebserkrankungen (Tampe et al. 2015).

Im Rahmen dieser Arbeit konnte ein weiterer molekularer Biomarker identifiziert werden, der zum einen in enger Korrelation mit Nierenfunktionsparametern Rückschlüsse auf den Funktionsstatus der Nieren bietet und zum anderen Grund zur Annahme gibt, dass zirkulierende methylierte RLN1 und RLN2 DNA-Promotorfragmente im Blut ohne weitere Biopsien als therapeutische relevante Biomarker bei chronischer Niereninsuffizienz dienen können, um spezifisch Patienten zu identifizieren, welche von einer entsprechenden Therapie mit RLX030 profitieren könnten. 


\section{Zusammenfassung}

Die Progression chronischer Nierenerkrankungen sowie die daraus resultierende terminale Niereninsuffizienz mit dem histopathologischen Korrelat der tubulären Atrophie und interstitiellen Fibrosierung (sog. tubulointerstitielle Fibrose) sind immer noch ein gesundheitliches und sozioökonomisches Problem im klinischen Alltag der Nephrologie. Dies ist vor allem bedingt durch mangelnde Therapiekonzepte und -strategien. Im Rahmen der RELAX-AHF-2 (NCT01870778)-Studie fielen bei Patienten mit akuter Herzinsuffizienz neben einer Reduktion der kardial bedingten Dyspnoe ebenfalls positive Effekte des Medikaments auf Nierenfunktionsparameter auf. Weiterhin konnten in präklinischen Studien vielversprechende Effekte zur Inhibition der chronischen Nierenschädigung gezeigt werden. Daraus abgeleitet ergaben sich mögliche neue Behandlungskonzepte, um zielgerichtet Fibrosierungsprozesse inhibieren zu können. Während des progressiven Strukturverlusts der Niere kommt es zu einem Verlust der endogenen Relaxin-Expression, wohingegen der zugehörige Relaxin-Rezeptor (RXFP1) in interstitiellen Fibroblasten sowohl im murinen Niereninsuffizienzmodell als auch bei nierenerkrankten Patienten beträchtlich induziert wird. Ziele der vorliegenden Arbeit waren daher, zum einen die Determinierung der Relaxin-Rezeptor-Expression in murinen wie auch humanen Gewebsproben als mögliches Therapieziel zu untersuchen. Zudem sollte die genaue Testung von RLX030 im Mausmodell mit Dosierungsfindung zu verschiedenen Zeitpunkten erfolgen sowie die Identifizierung eines möglichen Biomarkers etabliert werden, welcher eine Identifikation von nierenkranken Patienten zulässt, die von einer Substitution mit RLX030 profitieren würden.

Es konnte eine deutliche Induktion der Relaxin-Rezeptoren (RXFP1, 2 und 3) im Interstitium von murinen sowie humanen fibrotischen Nieren identifiziert werden. Diese Untersuchungen fanden mittels qRT-PCR auf mRNA-Ebene, durch Western Blot und histologische Gewebsanalysen auf Protein- und morphometrischer Ebene statt. Verbunden mit einem simultanen Verlust des endogenen Relaxins resultierte die Annahme, dass eine Substitution mit RLX030 essentiell zur Inhibition der renalen Fibrogenese beitragen könnte. Weiterhin konnte die mittlere Konzentrationsdosis von RLX030 (200 $\mu \mathrm{g} / \mathrm{kg}$ Körpergewicht) als effektivste Dosierung zur Antagonisierung der renalen Fibrogenese nach zehntägiger unilateraler Ureterobstruktion (UUO) in C57BL/6J-Mäusen etabliert werden. Im Vergleich zur PBS-behandelten Kontrollkohorte ergab sich unter RLX030-Supplementation eine deutliche Reduktion der tubulointerstitiellen Fibrose mit simultan verminderter tubulärer Atrophie. Die korrespondierenden profibrotischen Markerproteine $\alpha$-SMA und Kollagen-1 wurden in histomorphologischen Untersuchungen ebenfalls supprimiert detektiert. Entsprechende Ergebnisse konnten ebenfalls zu weiteren Zeitpunkten an den Tagen drei und sieben nach UUO etabliert werden. Eine Bestätigung der Ergebnisse erfolgt in einem zweiten, unabhängigen Mausmodell durch Induktion einer chronischen Niereninsuffizienz mittels Folsäure. Die Analysen der Gewebeproben erfolgten an den Tagen 3, 28, 84 und 140 nach Folsäureinjektion. Nach anfänglich indifferenter akuter Niereninsuffizienz zwischen Kontroll- und RLX030-behandelter Kohorte ergaben sich signifikante Unterschiede im weiteren chronischen Verlauf der Niereninsuffizienz. Histomorphologisch manifestierte sich ebenfalls eine verminderte Akkumulation von interstitiellen Kollagen-1- und $\alpha$-SMA- 
positiven Myofibroblasten. Ferner wurde die antifibrotische Wirkung von RLX030 mittels interventionellen Therapieansatzes untersucht. Im Rahmen dessen wurde ein chronisches Nierenversagen mittels UUO induziert, die Applikation von RLX030 erfolgte hierbei mit einer Verzögerung von sieben Tagen nach UUO, wenn renale Fibrose bereits etabliert ist für weitere sieben Tage. Gewebeanalysen im Hinblick auf Akkumulation von Extrazellulärmatrix und Myofibroblasten ergaben eine deutliche Reduktion der spezifischen Fibrosemarker auch bei interventioneller Applikation von RLX030. Die Degradation von Extrazelulärmatrix beruht hierbei auf Induktion der Matrixmetalloproteinasen MMP-2 und MMP-9. Molekularbiologische Analysen in Primärkulturen von murinen Fibroblasten unter der Exposition von RLX030 bestätigten die anti-fibrotische sowie proliferationshemmende Wirkung des Medikaments. Zur Spezifizierung des endogenen RelaxinVerlusts erfolgten Analysen epigenetischer Regulationsmechanismen. Hierbei konnte mittels DNAImmunoprezipitation methylierter genomischer DNA (MeDIP) etabliert werden, dass der transkriptionelle Verlust von endogenem Relaxin auf aberranter Promotermethylierung beruht. Zudem lassen sich diese methylierten Promoterfragmente auch im Blut nachweisen, korrelieren mit dem Methylierungsstatus in der Niere und zeigen somit endogene Expressionslevel von Relaxin an.

Zusammenfassend konnte gezeigt werden, dass chronisch-progressive Nierenerkrankungen mit einem zunehmenden Verlust von Relaxin assoziiert sind, wogegen dessen Rezeptoren vermehrt exprimiert werden. Die Supplementation des synthetischen exogenen Relaxin-Analogons RLX030 vermittelt in zwei unabhängigen murinen Niereninsuffizienzmodellen anti-fibrotische Effekte und führt zu einer signifikanten Inhibition der renalen Fibrogenese. Mechanistisch wird dies über Induktion spezifischer MMPs vermittelt, welche Extrazellulärmatrix degradieren und auch im interventionellen Therapieansatz effektiv sind. Der Verlust des endogenen Relaxins durch aberrante Promotermethylierung lässt sich als im Blut zirkulierende Promotorfragmente nachweisen. Diese könnten als Biomarker zur Identifikation von Patienten dienen, welche von RLX030 profitieren. 


\section{Anhang}

Tabelle 26: Patientenkohorte mit chronischen Nierenerkrankungen aufgeschlüsselt hinsichtlich klinischer und histologischer Charakteristika

\begin{tabular}{|c|c|c|c|c|c|c|c|c|}
\hline $\begin{array}{l}\text { Patient } \\
\text { en ID }\end{array}$ & Histologische Diagnose & $\begin{array}{l}\text { Geschlec } \\
\text { ht }\end{array}$ & Alter & \begin{tabular}{|l|} 
Fibrosierun \\
gsgrad in \\
$\%$
\end{tabular} & $\begin{array}{l}\text { Kreatinin } \\
{[\mathrm{mg} / \mathrm{dll}]}\end{array}$ & $\begin{array}{l}\text { eGFR } \\
(\mathrm{MDRD}) \\
{[\mathrm{ml} / \mathrm{min}]} \\
\end{array}$ & $\begin{array}{l}\text { BUN } \\
{[\mathrm{mg} / \mathrm{dl}]}\end{array}$ & Clearance \\
\hline P1 & $\begin{array}{l}\text { Z.n. Nierentransplantation } \\
\text { (NTx) }\end{array}$ & $\mathrm{m}$ & 69 & $<10$ & 1,9 & 38,76 & 38 & 37 \\
\hline P2 & $\begin{array}{l}\text { Mesangioproliferative GN } \\
\text { vom Typ IgA -Nephritis } \\
\end{array}$ & $\mathrm{m}$ & 35 & $<5$ & 9,2 & 7,60 & 50 & 49 \\
\hline P3 & $\begin{array}{l}\text { Z.n. NTx, benigne } \\
\text { Nephrosklerose, FSGS }\end{array}$ & w & 53 & 30 & 1,2 & 52,36 & 21 & 52,5 \\
\hline P4 & $\begin{array}{l}\text { Z.n. NTx, Globalsklerose, } \\
\text { benigne Nephrosklerose }\end{array}$ & w & 76 & 40 & 2,9 & 17,31 & 57 & \\
\hline P5 & $\begin{array}{l}\text { Mesangioproliferative GN } \\
\text { vom Typ IgA-Nephritis }\end{array}$ & $\mathrm{m}$ & 80 & 45 & 7 & 8,39 & 40 & 2 \\
\hline P6 & FSGS & $\mathrm{m}$ & & 30 & & & & \\
\hline P7 & Benigne Nephrosklerose & $\mathrm{m}$ & 59 & $30-40$ & 7,9 & 7,84 & 52 & 1,2 \\
\hline P8 & Benigne Nephrosklerose & $\mathrm{m}$ & 53 & $<25$ & 1,5 & 54,82 & 22 & 43 \\
\hline P9 & $\begin{array}{l}\text { Z.n. NTx, fokal akuter und } \\
\text { chronifizierter Schaden }\end{array}$ & $\mathrm{m}$ & 67 & 10 & 1,5 & 51,27 & 66 & 46,9 \\
\hline P10 & Lupus-Nephritis & $\mathrm{m}$ & 51 & $<15$ & 2,1 & 37,56 & 46 & 106,5 \\
\hline P11 & $\begin{array}{l}\text { Mesangioproliferative GN } \\
\text { vom Typ IgA-Nephritis }\end{array}$ & w & & 15 & & & & \\
\hline P12 & $\begin{array}{l}\text { Akuter Tubulusschaden } \\
\text { des Cortex }\end{array}$ & w & 53 & $<10$ & 4,2 & 12,40 & 54 & \\
\hline $\mathrm{P} 14$ & FSGS & w & 67 & 0 & 1,1 & 55,01 & 35 & 96 \\
\hline P15 & & $\mathrm{m}$ & 75 & 20 & 8,4 & 6,88 & 43 & 23 \\
\hline P16 & FSGS mit IgA-Nephritis & $\mathrm{m}$ & 59 & $<15$ & 1,5 & 53,55 & 25 & 138 \\
\hline $\mathrm{P} 17$ & Lupus-Nephritis & w & 53 & 0 & 1 & 64,62 & 15 & 58 \\
\hline P19 & FSGS & w & 84 & $30-40$ & 1,6 & 33,49 & 22 & 34 \\
\hline $\mathrm{P} 20$ & & $\mathrm{~m}$ & 65 & 15 & 0,8 & 107,89 & 7 & 87 \\
\hline $\mathrm{P} 22$ & $\begin{array}{l}\text { Mesangioproliferative GN } \\
\text { vom Typ IgAN }\end{array}$ & w & 44 & $20-25$ & 0,9 & 77,62 & 13 & 86 \\
\hline $\mathrm{P} 23$ & $\begin{array}{l}\text { Mesangioproliferative GN } \\
\text { vom Typ IgAN } \\
\end{array}$ & $\mathrm{m}$ & 64 & $5-10$ & 1,4 & 57,02 & 25 & 102 \\
\hline P24 & & $\mathrm{m}$ & & 40 & 4,2 & 15,41 & 62 & 3 \\
\hline $\mathrm{P} 25$ & $\begin{array}{l}\text { Chronisch- } \\
\text { tubulointerstitieller } \\
\text { Schaden } \\
\end{array}$ & $\mathrm{m}$ & & 20 & & & & \\
\hline P26 & $\begin{array}{ll}\text { FSGS, } & \text { benigne } \\
\text { Nephrosklerose } & \\
\end{array}$ & w & & 30 & 0,8 & 102,18 & 10 & 112,6 \\
\hline $\mathrm{P} 27$ & Interstitielle Nephritis & w & 60 & 0 & 6,5 & 7,25 & 62 & 8 \\
\hline P28 & \begin{tabular}{|ll} 
Primär & maligne \\
Nephrosklerose & \\
\end{tabular} & $\mathrm{m}$ & 48 & $30-40$ & 5 & 14,03 & 79 & 15,6 \\
\hline P29 & $\begin{array}{l}\text { Z.n. NTx, FSGS, schwere } \\
\text { Nephrosklerose }\end{array}$ & w & 56 & $40-50$ & 3,6 & 14,47 & 67 & 13,5 \\
\hline P30 & $\begin{array}{l}\text { Membranoproliferative } \\
\text { GN, FSGS }\end{array}$ & $\mathrm{m}$ & 28 & $25-30$ & 1,9 & 50,51 & 23 & 30,2 \\
\hline P31 & $\begin{array}{l}\text { Glomeruläre } \\
\text { thrombotische } \\
\text { Mikroangiopathie }\end{array}$ & w & 55 & 40 & 9,6 & 4,78 & 90 & \\
\hline
\end{tabular}




\begin{tabular}{|c|c|c|c|c|c|c|c|c|}
\hline \begin{tabular}{l|l} 
Patient & \\
en ID
\end{tabular} & Histologische Diagnose & $\begin{array}{l}\text { Geschlec } \\
\text { ht }\end{array}$ & Alter & $\begin{array}{l}\text { Fibrosierun } \\
\text { gsgrad in } \\
\%\end{array}$ & $\begin{array}{l}\text { Kreatinin } \\
{[\mathrm{mg} / \mathrm{dl}]}\end{array}$ & \begin{tabular}{|l|} 
eGFR \\
(MDRD) \\
[ml/min] \\
\end{tabular} & $\begin{array}{l}\text { BUN } \\
{[\mathrm{mg} / \mathrm{dll}]}\end{array}$ & Clearance \\
\hline P32 & Benigne Nephrosklerose & $\mathrm{m}$ & 76 & $10-15$ & 1,3 & 59,45 & 15 & \\
\hline P33 & $\begin{array}{lll}\text { Lupus-Nephritis } & \text { Typ } \\
\text { und IIIC } & & \\
\end{array}$ & w & 61 & 0 & 3,9 & 12,92 & 41 & 18,4 \\
\hline P34 & FSGS mit IgAN & w & 44 & 0 & 0,9 & 77,12 & 12 & 103,7 \\
\hline P35 & $\begin{array}{l}\text { Membranoproliferative } \\
\text { GN, FSGS }\end{array}$ & $\mathrm{m}$ & & 70 & 9,6 & 4,80 & 70 & 8 \\
\hline P36 & Benigne Nephrosklerose & $\mathrm{m}$ & 73 & $<25$ & 1,4 & 54,94 & 24 & 65 \\
\hline P37 & FSGS & $\mathrm{m}$ & & $<10$ & & & & \\
\hline P38 & $\begin{array}{l}\text { Membranoproliferative GN } \\
\text { Typ } 1\end{array}$ & w & & $>60$ & 2 & 36,66 & 40 & \\
\hline P40 & $\begin{array}{l}\text { Benigne Nephrosklerose } \\
\text { mit IgAN }\end{array}$ & $\mathrm{m}$ & 44 & $>90$ & 11,5 & 5,57 & 88 & \\
\hline P41 & Normalbefund & w & 31 & 0 & 0,9 & 85,73 & 17 & 129,5 \\
\hline P42 & FSGS & w & & $>50$ & 9,6 & 5,86 & 96 & \\
\hline P43 & Lupus-Nephritis Typ IIIC & w & 37 & 15 & 0,8 & 94,48 & 13 & 74 \\
\hline P44 & Lupus-Nephritis IIIC & w & & 15 & & & & \\
\hline P45 & & w & 51 & 5 & & & & \\
\hline P46 & FSGS & $\mathrm{m}$ & 57 & 25 & 3 & 24,40 & 48 & 32 \\
\hline P47 & $\begin{array}{l}\text { Z.n. NTx, chronischer } \\
\text { tubulointerstitieller } \\
\text { Schaden }\end{array}$ & w & 81 & kA & 2,1 & 24,68 & 44 & 23,7 \\
\hline P48 & & $\mathrm{m}$ & & 10 & 0,9 & 77,12 & 8 & \\
\hline P49 & MPAN & $\mathrm{m}$ & & 40 & & & & \\
\hline P50 & FSGS & $w$ & & 35 & & & & \\
\hline P51 & $\begin{array}{l}\text { Diabetische Nephropathie, } \\
\text { benigne Nephrosklerose }\end{array}$ & $\mathrm{m}$ & 57 & $>50$ & 3,2 & 22,65 & 53 & 30 \\
\hline P52 & $\begin{array}{l}\text { Benigne } \\
\text { mit IgAN }\end{array}$ & w & 54 & $30-35$ & 1,8 & 33,12 & 24 & \\
\hline P53 & $\begin{array}{l}\text { Nekrotisierend- } \\
\text { proliferative GN mit IgAN }\end{array}$ & $\mathrm{m}$ & 47 & 50 & 6,7 & 10,12 & 70 & 1 \\
\hline P54 & & w & 58 & $<10$ & 2,1 & 26,72 & 39 & 27,1 \\
\hline P55 & & $\mathrm{m}$ & & 60 & 6,3 & 7,84 & 85 & \\
\hline P56 & Benigne Nephrosklerose & w & 55 & 10 & 0,9 & 73,34 & 14 & 62 \\
\hline P57 & FSGS & $\mathrm{m}$ & 57 & $>70$ & 6,1 & 10,61 & 103 & \\
\hline P59 & FSGS mit IgAN & & & 5 & 11 & & 99 & \\
\hline $\mathrm{P} 60$ & Renale Amyloidose & $\mathrm{m}$ & 77 & 0 & 1,1 & 71,86 & 23 & 40 \\
\hline P61 & Benigne Nephrosklerose & w & 68 & & 1,3 & 45,03 & 22 & 95,8 \\
\hline P62 & IgAN & w & 67 & 0 & 0,6 & 110,73 & 18 & 114,3 \\
\hline P63 & Benigne Nephrosklerose & w & 76 & $>40$ & 2,5 & 20,67 & 36 & 22 \\
\hline P64 & $\begin{array}{l}\text { Mesangioproliferative GN } \\
\text { vom Typ IgAN }\end{array}$ & $\mathrm{m}$ & & 20 & 0,7 & 92,34 & 10 & 110,3 \\
\hline P65 & $\begin{array}{l}\text { Membranöse GN, benigne } \\
\text { Nephrosklerose }\end{array}$ & $\mathrm{m}$ & 63 & 25 & 1 & 83,40 & 20 & \\
\hline P66 & Minimal change GN & w & & 5 & & & & \\
\hline P67 & Membranöse GN & w & 54 & 60 & 10,4 & 4,29 & 71 & 2,5 \\
\hline P68 & FSGS mit IgAN & $\mathrm{m}$ & 32 & 25 & 0,8 & 132,36 & 11 & 114 \\
\hline
\end{tabular}




\begin{tabular}{|c|c|c|c|c|c|c|c|c|}
\hline \begin{tabular}{l|l} 
Patient & \\
en ID
\end{tabular} & Histologische Diagnose & $\begin{array}{l}\text { Geschlec } \\
\text { ht }\end{array}$ & Alter & $\begin{array}{l}\text { Fibrosierun } \\
\text { gsgrad in } \\
\%\end{array}$ & $\begin{array}{l}\text { Kreatinin } \\
{[\mathrm{mg} / \mathrm{dl}]}\end{array}$ & \begin{tabular}{|l|} 
eGFR \\
(MDRD) \\
{$[\mathrm{ml} / \mathrm{min}]$} \\
\end{tabular} & $\begin{array}{l}\text { BUN } \\
{[\mathrm{mg} / \mathrm{dll}]}\end{array}$ & Clearance \\
\hline P69 & $\operatorname{IgAN}$ & $\mathrm{m}$ & 49 & 60 & 2 & 39,94 & 27 & 59,1 \\
\hline P70 & & $\mathrm{m}$ & 52 & $<10$ & 1,6 & 50,88 & 20 & 95 \\
\hline P71 & $\operatorname{IgAN}$ & $\mathrm{m}$ & 67 & 20 & 1,6 & 47,76 & 23 & 64,8 \\
\hline P73 & FSGS mit IgAN & w & 75 & $30-35$ & 2,8 & 18,20 & 59 & 26,2 \\
\hline P74 & $\begin{array}{lrr}\text { Z.n. NTx } & \text { NTx } \\
\text { Nephrosklerose } & \\
\end{array}$ & w & 76 & 20 & 3,1 & 16,08 & 85 & 19,1 \\
\hline P75 & $\begin{array}{l}\text { Mesangioproliferative GN } \\
\text { vom Typ IgAN }\end{array}$ & $\mathrm{m}$ & 64 & $>7,5$ & 2,7 & 26,41 & 39 & 41,8 \\
\hline P76 & $\begin{array}{l}\text { Benigne Nephrosklerose } \\
\text { mit lgAN }\end{array}$ & $\mathrm{m}$ & 85 & 25 & 1,4 & 52,95 & 37 & 49 \\
\hline P78 & Benigne Nephrosklerose & $\mathrm{m}$ & & 40 & & & & \\
\hline P79 & $\begin{array}{l}\text { Benigne Nephrosklerose } \\
\text { mit IgAN }\end{array}$ & $\mathrm{m}$ & 87 & 20 & 1,2 & 63,08 & 16 & 89 \\
\hline $\mathrm{P} 80$ & $\begin{array}{l}\text { FSGS mit IgAN, benigne } \\
\text { Nephrosklerose }\end{array}$ & $\mathrm{m}$ & 58 & $<10$ & 1,2 & 69,91 & 12 & 84 \\
\hline P81 & Nephrosklerose mit FSGS & $\mathrm{m}$ & 59 & 30 & 1,8 & 43,39 & 22 & 42,4 \\
\hline P82 & FSGS & w & 41 & 0 & 0,6 & 123,93 & 12 & 159,6 \\
\hline P83 & $\begin{array}{l}\text { Diabetische Nephropathie, } \\
\text { FSGS }\end{array}$ & w & 75 & 50 & 2,2 & 24,04 & 44 & 48 \\
\hline P84 & $\begin{array}{lcr}\text { Z.n. } \quad \text { NTx, } & \text { benigne } \\
\text { Nephrosklerose } & \\
\end{array}$ & $\mathrm{m}$ & 62 & 35 & 1,9 & 39,92 & 52 & 42,3 \\
\hline P85 & $\begin{array}{lr}\text { IgAN } & \text { mit } \\
\text { mesangioproliferativer } \mathrm{GN}\end{array}$ & w & 81 & 20 & 0,7 & 88,18 & 19 & 117.1 \\
\hline P86 & & w & 88 & & 0,9 & 64,88 & 20 & 72,9 \\
\hline P87 & & w & & 15 & 0,8 & 75,81 & 16 & \\
\hline P88 & $\begin{array}{l}\text { Kryoglobulinämie- } \\
\text { assoziierte } \\
\text { Immunkomplex-Nephritis }\end{array}$ & $\mathrm{m}$ & 57 & 10 & 2,7 & 27,30 & 28 & 22,1 \\
\hline P89 & $\begin{array}{l}\text { Diabetische Nephropathie, } \\
\text { FSGS }\end{array}$ & w & 77 & 35 & 2,9 & 17,36 & 91 & 25 \\
\hline $\mathrm{P} 90$ & M. Wegener & w & 68 & 0 & 5,1 & 9,27 & 59 & 3 \\
\hline P91 & $\begin{array}{l}\text { Z.n. NTx 1996, fokale } \\
\text { Tubulusatrophie mit IgAN }\end{array}$ & w & 52 & $<25$ & 2,2 & 26,41 & 32 & 40 \\
\hline P92 & & $\mathrm{m}$ & 34 & 35 & 4,7 & 16,97 & 35 & 15 \\
\hline P93 & $\begin{array}{l}\text { Mikroskopische } \\
\text { Polyangiitis }\end{array}$ & $\mathrm{m}$ & 75 & 70 & 3,3 & 20,16 & 40 & 1,4 \\
\hline P94 & Benigne Nephrosklerose & $\mathrm{m}$ & 65 & 30 & 2,6 & 27,80 & 35 & \\
\hline P95 & FSGS & w & & & & & & \\
\hline P96 & $\begin{array}{l}\text { FSGS mit interstitieller } \\
\text { Nephritis }\end{array}$ & $\mathrm{m}$ & 35 & 0 & 4 & 20,25 & 44 & \\
\hline P97 & FSGS & $\mathrm{m}$ & & $>50$ & 1,1 & 75,31 & 25 & 105,3 \\
\hline P98 & Minimal Change GN & w & 66 & 0 & 0,6 & 110,32 & 8 & 106,7 \\
\hline P99 & $\begin{array}{l}\text { Mesangioproliferative GN } \\
\text { vom Typ IgAN }\end{array}$ & $\mathrm{m}$ & 69 & 20 & 0,6 & 150,38 & 20 & 80,2 \\
\hline P100 & Membranöse GN & w & 76 & 0 & 0,8 & 78,30 & 20 & \\
\hline P101 & $\begin{array}{l}\text { Benigne Nephrosklerose } \\
\text { mit IgAN }\end{array}$ & $\mathrm{m}$ & 62 & 20 & 1 & 83,40 & 21 & 87,1 \\
\hline P102 & Interstitielle Nephritis & $\mathrm{m}$ & 73 & $<10$ & 1,8 & 43,58 & 33 & \\
\hline P103 & Lupus-Nephritis IIIC & w & 32 & $<5$ & 0,9 & 84,01 & 22 & 153,2 \\
\hline
\end{tabular}




\begin{tabular}{|c|c|c|c|c|c|c|c|c|}
\hline $\begin{array}{l}\text { Patient } \\
\text { en ID }\end{array}$ & Histologische Diagnose & $\begin{array}{l}\text { Geschlec } \\
\text { ht }\end{array}$ & Alter & $\begin{array}{l}\text { Fibrosierun } \\
\text { gsgrad in } \\
\%\end{array}$ & $\begin{array}{l}\text { Kreatinin } \\
{[\mathrm{mg} / \mathrm{dl}]}\end{array}$ & $\begin{array}{l}\text { eGFR } \\
\text { (MDRD) } \\
{[\mathrm{ml} / \mathrm{min}]} \\
\end{array}$ & $\begin{array}{l}\text { BUN } \\
{[\mathrm{mg} / \mathrm{dl}]}\end{array}$ & Clearance \\
\hline P105 & FSGS & $\mathrm{m}$ & 43 & $<15$ & 1 & 93,90 & 14 & 87 \\
\hline P106 & Z.n. NTX 2001, IgAN & $\mathrm{m}$ & 65 & 0 & 1,9 & 39,46 & 27 & 58,6 \\
\hline P108 & Morbus Fabry & w & 55 & 10 & 0,8 & 82,44 & 12 & 138,1 \\
\hline P109 & Benigne Nephrosklerose & $\mathrm{m}$ & 68 & 10 & 4,1 & 16,12 & 93 & 16,9 \\
\hline $\mathrm{P} 110$ & FSGS & $\mathrm{m}$ & 43 & 15 & 0,6 & 167,02 & 17 & 131 \\
\hline P111 & & $\mathrm{m}$ & & 10 & 1,3 & 63,45 & 25 & \\
\hline P112 & $\begin{array}{l}\text { Interstitielle Nephritis mit } \\
\text { reaktiver FSGS }\end{array}$ & w & 74 & 0 & 3,8 & 12,84 & 35 & 23 \\
\hline P113 & $\begin{array}{l}\text { Diabetische Nephropathie, } \\
\text { FSGS }\end{array}$ & $\mathrm{m}$ & 72 & 80 & 3,5 & 19,09 & 24 & 18,7 \\
\hline P114 & $\begin{array}{l}\text { Interstitielle Nephritis mit } \\
\text { reaktiver FSGS }\end{array}$ & w & 51 & 90 & 2,9 & 19,10 & 48 & 25,3 \\
\hline P115 & & w & & 15 & 1 & 60,32 & 20 & \\
\hline P116 & Komplementfaktor-GN & $\mathrm{m}$ & 34 & 0 & 1 & 99,31 & 8 & 131,5 \\
\hline $\mathrm{P} 117$ & $\begin{array}{l}\text { Mesangioproliferative GN } \\
\text { vom Typ IgAN }\end{array}$ & $\mathrm{m}$ & 66 & 10 & 0,9 & 92,78 & 12 & 156,9 \\
\hline P118 & & $\mathrm{m}$ & 71 & 0 & 0,6 & 142,41 & 10 & \\
\hline P119 & $\begin{array}{ll}\text { IgAN, } & \text { benigne } \\
\text { Nephrosklerose } & \\
\end{array}$ & w & 59 & 0 & 0,9 & 70,73 & 13 & 73,7 \\
\hline P120 & $\begin{array}{l}\text { Benigne Nephrosklerose, } \\
\text { FSGS }\end{array}$ & w & 80 & $40-50$ & 2,5 & 20,36 & 44 & 34,4 \\
\hline P121 & Benigne Nephrosklerose & $\mathrm{m}$ & 93 & 0 & 3,6 & 12,90 & 76 & 16,3 \\
\hline P123 & Benigne nephrosclerose & $\mathrm{m}$ & & & 1,2 & & 12 & \\
\hline P125 & Benigne nephrosclerose & w & & & 1,3 & & & \\
\hline $\mathrm{P} 127$ & $\begin{array}{l}\text { Benigne nephrosclerose } \\
\text { TX }\end{array}$ & $\mathrm{m}$ & & & 3 & & 99 & \\
\hline P128 & Benigne nephrosclerose & $\mathrm{m}$ & & & 7,1 & & & \\
\hline P132 & FSNGN & $\mathrm{m}$ & & & 1,1 & & & \\
\hline
\end{tabular}




\section{Literaturverzeichnis}

Akhurst RJ, Hata A (2012): Targeting the TGF $\beta$ signalling pathway in disease. Nat Rev Drug Discov $\underline{11}, 790-811$

Alpers CE, Hudkins KL, Floege J, Johnson RJ (1994): Human renal cortical interstitial cells with some features of smooth muscle cells participate in tubulointerstitial and crescentic glomerular injury. J Am Soc Nephrol JASN $\underline{5}, 201-209$

Alzet® osmotic pumps: http://www.alzet.com/products/ALZET_Pumps/howdoesitwork.htmI (Zugriff am 14.01.2017)

Annes JP, Chen Y, Munger JS, Rifkin DB (2004): Integrin aV $\beta 6$-mediated activation of latent TGF- $\beta$ requires the latent TGF- $\beta$ binding protein-1. J Cell Biol $\underline{165}, 723-734$

Ärzteblatt DÄG Redaktion Deutsches. http://www.aerzteblatt.de/nachrichten/64812 (Zugriff am 03.08.2016)

Attisano L, Wrana JL (2002): Signal transduction by the TGF-beta superfamily. Science 296, 16461647

Baccari MC, Bani D (2008): Relaxin and nitric oxide signalling. Curr Protein Pept Sci $\underline{9}$, 638-645

Bakris GL, Ritz E (2009): The message for World Kidney Day 2009: hypertension and kidney disease: a marriage that should be prevented. Kidney Int $\underline{75}$, 449-452

Bani D (1997): Relaxin: A pleiotropic hormone. Gen Pharmacol Vasc Syst 2으, 13-22

Bathgate RA, Ivell R, Sanborn BM, Sherwood OD, Summers RJ (2006): International Union of Pharmacology LVII: Recommendations for the Nomenclature of Receptors for Relaxin Family Peptides. Pharmacol Rev $\underline{58}, 7-31$

Bathgate RA, Halls ML, Westhuizen ET van der, Callander GE, Kocan M, Summers RJ (2013): Relaxin Family Peptides and Their Receptors. Physiol Rev $\underline{93}$, 405-480

Bechtel W, McGoohan S, Zeisberg EM, Müller GA, Kalbacher H, Salant DJ, Müller CA, Kalluri R, Zeisberg M (2010): Methylation determines fibroblast activation and fibrogenesis in the kidney. Nat Med 16, 544-550

Bird A (2002): DNA methylation patterns and epigenetic memory. Genes Dev 16, 6-21

Blundell TL, Humbel RE (1980): Hormone families: pancreatic hormones and homologous growth factors. Nature 287, 781-787

Bocklandt S, Lin W, Sehl ME, Sánchez FJ, Sinsheimer JS, Horvath S, Vilain E (2011): Epigenetic Predictor of Age. PLoS ONE $\underline{6, \text { e14821 }}$

Bogzil AH, Eardley R, Ashton N (2005): Relaxin-induced changes in renal sodium excretion in the anesthetized male rat. Am J Physiol - Regul Integr Comp Physiol 288, R322-R328 
Bohle A, Mackensen-Haen S, von Gise H (1987): Significance of tubulointerstitial changes in the renal cortex for the excretory function and concentration ability of the kidney: a morphometric contribution. Am J Nephrol $\underline{7}, 421-433$

Bomsztyk K, Denisenko O (2013): Epigenetic alterations in acute kidney injury. Semin Nephrol $\underline{33}$, 327-340

Bonnema DD, Webb CS, Pennington WR, Stroud RE, Leonardi AE, Clark LL, McClure CD, Finklea L, Spinale FG, Zile MR (2007): Effects of age on plasma matrix metalloproteinases (mmps) and tissue inhibitor of metalloproteinases (TIMPs). J Card Fail $\underline{13}, 530-540$

Boor P, Ostendorf T, Floege J (2010): Renal fibrosis: novel insights into mechanisms and therapeutic targets. Nat Rev Nephrol $\underline{6}, 643-656$

Border WA, Noble NA (1997): TGF-beta in kidney fibrosis: a target for gene therapy. Kidney Int $\underline{51}$, 1388-1396

Border WA, Okuda S, Languino LR, Sporn MB, Ruoslahti E (1990): Suppression of experimental glomerulonephritis by antiserum against transforming growth factor beta 1. Nature $\underline{346}, 361-364$

Border WA, Noble NA, Yamamoto T, Harper JR, Yamaguchi Y, Pierschbacher MD, Ruoslahti E (1992): Natural inhibitor of transforming growth factor-beta protects against scarring in experimental kidney disease. Nature $\underline{360}, 1476-4687$

Bröcker V, Kreipe H, Haller H (2010): Tubulointerstitial fibrosis. Nephrol $\underline{5}$, 284-292

Bryant-Greenwood GD, Schwabe C (1994): Human relaxins: chemistry and biology. Endocr Rev $\underline{15}$, $5-26$

Cernaro V, Lacquaniti A, Lupica R, Buemi A, Trimboli D, Giorgianni G, Bolignano D, Buemi M (2014): Relaxin: new pathophysiological aspects and pharmacological perspectives for an old protein. Med Res Rev $\underline{34}, 77-105$

Chang H, Brown CW, Matzuk MM (2002): Genetic analysis of the mammalian transforming growth factor-beta superfamily. Endocr Rev $\underline{23}, 787-823$

Cheifetz S, Hernandez H, Laiho M, Dijke P ten, Iwata KK, Massagué J (1990): Distinct transforming growth factor-beta (TGF-beta) receptor subsets as determinants of cellular responsiveness to three TGF-beta isoforms. J Biol Chem $\underline{265}$, 20533-20538

Chevalier RL, Forbes MS, Thornhill BA (2009): Ureteral obstruction as a model of renal interstitial fibrosis and obstructive nephropathy. Kidney Int $\underline{75}, 1145-1152$

Chow BSM, Chew EGY, Zhao C, Bathgate RAD, Hewitson TD, Samuel CS (2012): Relaxin Signals through a RXFP1-pERK-nNOS-NO-cGMP-Dependent Pathway to Up-Regulate Matrix Metalloproteinases: The Additional Involvement of iNOS. PLoS ONE $\underline{7}, 1932-6203$ 
Chow BSM, Kocan M, Bosnyak S, Sarwar M, Wigg B, Jones ES, Widdop RE, Summers RJ, Bathgate RAD, Hewitson TD, Samuel CS (2014): Relaxin requires the angiotensin II type 2 receptor to abrogate renal interstitial fibrosis. Kidney Int $\underline{86}, 75-85$

Clayton A, Steadman R, Williams JD (1997): Cells isolated from the human cortical interstitium resemble myofibroblasts and bind neutrophils in an ICAM-1--dependent manner. J Am Soc Nephrol 8 , $604-615$

ClinicalTrials: NIH U.S National Library of Medicine. Efficacy, Safety and Tolerability of Serelaxin When Added to Standard Therapie in AHF (RELAX-AHF-2) https://clinicaltrials.gov/ct2/show/NCT01870778 (Zugriff am 19.01.2017)

ClinicalTrials: PK of Serelaxin in Severe Renal Impairment and ESRD (CRLX030A2102) https://clinicaltrials.gov/ct2/show/results/NCT01875523?term=Serelaxin\&rank=8 (Zugriff am 19.01.2017)

Collino M, Rogazzo M, Pini A, Benetti E, Rosa AC, Chiazza F, Fantozzi R, Bani D, Masini E (2013): Acute treatment with relaxin protects the kidney against ischaemia/reperfusion injury. $\mathrm{J}$ Cell Mol Med 17, 1494-1505

Collins FS, Varmus H (2015): A new initiative on precision medicine. N Engl J Med $\underline{372}, 0028-4793$

Collins AJ, Foley RN, Gilbertson DT, Chen S-C (2015): United States Renal Data System public health surveillance of chronic kidney disease and end-stage renal disease. Kidney Int Suppl $\underline{5}, 2-7$

Conrad KP (2010): Unveiling the vasodilatory actions and mechanisms of relaxin. Hypertension $\underline{56}$, 2-9

Conrad KP, Novak J (2004): Emerging role of relaxin in renal and cardiovascular function. Am J Physiol - Regul Integr Comp Physiol 287, R250-R261

Cook HT (2010): The Origin of Renal Fibroblasts and Progression of Kidney Disease. Am J Pathol 176, 22-24

Coresh J, Selvin E, Stevens LA, Manzi J, Kusek JW, Eggers P, Lente FV, Levey AS (2007): Prevalence of Chronic Kidney Disease in the United States. JAMA 298, 2038-2047

Dahl C, Guldberg P (2003): DNA methylation analysis techniques. Biogerontology $\underline{4}, 233-250$

Danielson LA, Sherwood OD, Conrad KP (1999): Relaxin is a potent renal vasodilator in conscious rats. J Clin Invest $\underline{103}, 525-533$

Danielson LA, Kercher LJ, Conrad KP (2000): Impact of gender and endothelin on renal vasodilation and hyperfiltration induced by relaxin in conscious rats. Am J Physiol - Regul Integr Comp Physiol $\underline{279}$, R1298-R1304

Danielson LA, Welford A, Harris A (2006): Relaxin Improves Renal Function and Histology in Aging Munich Wistar Rats. J Am Soc Nephrol 17, 1325-1333 
Danobeitia JS, Djamali A, Fernandez LA (2014): The role of complement in the pathogenesis of renal ischemia-reperfusion injury and fibrosis. Fibrogenesis Tissue Repair $\underline{7}, 1755-1536$

Dawson SJ, Tsui DW, Murtaza M, Biggs H, Rueda OM, Chin SF, Dunning MJ, Gale D, Forshew T, Mahler-Araujo B, et al. (2013): Analysis of circulating tumor DNA to monitor metastatic breast cancer. N Engl J Med 368, 1199-1209

Day JJ, Sweatt JD (2010): DNA methylation and memory formation. Nat Neurosci $\underline{13}, 1319-1323$

DGfN, Deutsche Gesellschaft für Nephrologie (2014): Daten und Fakten zur Nephrologie. https://www.dgfn.eu/hintergrundmaterial.html (Zugriff am 19.01.2017).

Di Meo A, Bartlett J, Cheng Y, Pasic MD, Yousef GM (2017): Liquid biopsy: a step forward towards precision medicine in urologic malignancies. Mol Cancer $\underline{16}, 80$

Díez J (2014): Serelaxin: A Novel Therapy for Acute Heart Failure with a Range of Hemodynamic and Non-Hemodynamic Actions. Am J Cardiovasc Drugs 14, 275-285

Díez J, Ruilope LM (2016): Serelaxin for the treatment of acute heart failure: a review with a focus on end-organ protection. Eur Heart J-Cardiovasc Pharmacother 2, 119-130

Dihazi H, Dihazi GH, Mueller C, Lahrichi L, Asif AR, Bibi A, Eltoweissy M, Vasko R, Mueller GA (2011): Proteomics characterization of cell model with renal fibrosis phenotype: osmotic stress as fibrosis triggering factor. J Proteomics $\underline{74}, 304-318$

Doi K, Okamoto K, Negishi K, Suzuki Y, Nakao A, Fujita T, Toda A, Yokomizo T, Kita Y, Kihara Y, et al. (2006): Attenuation of Folic Acid-Induced Renal Inflammatory Injury in Platelet-Activating Factor Receptor-Deficient Mice. Am J Pathol 168, 1413-1424

Doucette TA, Ryan CL, Tasker RA (2000): Use of osmotic minipumps for sustained drug delivery in rat pups: effects on physical and neurobehavioural development. Physiol Behav $\underline{71}$, 207-212

Dschietzig T, Richter C, Bartsch C, Laule M, Armbruster FP, Baumann G, Stangl K (2001): The pregnancy hormone relaxin is a player in human heart failure. FASEB J $\underline{15}, 2187-2195$

Ducy P, Karsenty G (2000): The family of bone morphogenetic proteins. Kidney Int $\underline{57}, 2207-2214$

Dupont C, Armant DR, Brenner CA (2009): Epigenetics: Definition, Mechanisms and Clinical Perspective. Semin Reprod Med 27, 351-357

Eddy AA (1996): Molecular insights into renal interstitial fibrosis. J Am Soc Nephrol $\underline{7}, 2495-2508$

Eddy AA (2000): Molecular basis of renal fibrosis. Pediatr Nephrol Berl Ger 15, 290-301

Eddy AA (2013): The origin of scar-forming kidney myofibroblasts. Nat Med $\underline{19}$, 964-966

Eddy AA, Okamura DM, Yamaguchi I, López-Guisa JM (2012): Investigating Mechanisms of Chronic Kidney Disease in Mouse Models. Pediatr Nephrol Berl Ger 27, 1233-1247 
Eigenbrot C, Randal M, Quan C, Burnier J, O'Connell L, Rinderknecht E, Kossiakoff AA (1991): X-ray structure of human relaxin at $1.5 \mathrm{~A}$. Comparison to insulin and implications for receptor binding determinants. J Mol Biol 221, 15-21

Fackler MJ, Lopez Bujanda Z, Umbricht C, Teo WW, Cho S, Zhang Z, Visvanathan K, Jeter S, Argani $P$, Wang $C$, et al. (2014): Novel methylated biomarkers and a robust assay to detect circulating tumor DNA in metastatic breast cancer. Cancer Res $\underline{74}, 0008-5472$

Falke LL, Gholizadeh S, Goldschmeding R, Kok RJ, Nguyen TQ (2015): Diverse origins of the myofibroblast[mdash]implications for kidney fibrosis. Nat Rev Nephrol 11, 233-244

Feng XH, Derynck R (1997): A kinase subdomain of transforming growth factor-beta (TGF-beta) type I receptor determines the TGF-beta intracellular signaling specificity. EMBO J $\underline{16}, 3912-3923$

Fevold HL, Hisaw FL, Meyer RK (1930): The relaxative hormone of the corpus luteum. its purification and concentration1. J Am Chem Soc 52, 3340-3348

Frei U, Schober-Halstenberg H-J: Jahresbericht 2006/2007 - Nierenersatztherapie in Deutschland Bericht über Dialysebehandlung und Nierentransplantation in Deutschland 2006/2007. QuaSi-Niere, Berlin 2008

Gabbiani G, Ryan GB, Majne G (1971): Presence of modified fibroblasts in granulation tissue and their possible role in wound contraction. Experientia 27, 549-550

Gao H, Liu S (2017): Role of uremic toxin indoxyl sulfate in the progression of cardiovascular disease. Life Sci $\underline{185}, 23-29$

Garber SL, Mirochnik Y, Brecklin CS, Unemori EN, Singh AK, Slobodskoy L, Grove BH, Arruda JA, Dunea $G$ (2001): Relaxin decreases renal interstitial fibrosis and slows progression of renal disease. Kidney Int $\underline{59}, 876-882$

Genovese F, Manresa AA, Leeming DJ, Karsdal MA, Boor P (2014): The extracellular matrix in the kidney: a source of novel non-invasive biomarkers of kidney fibrosis? Fibrogenesis Tissue Repair $\underline{7}, 4$

Giannandrea M, Parks WC (2014): Diverse functions of matrix metalloproteinases during fibrosis. Dis Model Mech ㄱ, 193-203

Gordon KJ, Blobe GC (2008): Role of transforming growth factor-beta superfamily signaling pathways in human disease. Biochim Biophys Acta 1782, 197-228

Greenshaw AJ (1986): Osmotic mini-pumps: A convenient program for weight-adjusted filling concentrations. Brain Res Bull $\underline{16}$, 759-761

Grupp C, Müller GA (1999): Renal fibroblast culture. Exp Nephrol ㅁ, 377-385

Gupta J, Mitra N, Kanetsky PA, Devaney J, Wing MR, Reilly M, Shah VO, Balakrishnan VS, Guzman NJ, Girndt M, et al. (2012): Association between albuminuria, kidney function, and inflammatory biomarker profile in CKD in CRIC. Clin J Am Soc Nephrol $\underline{7}$, 1938-1946 
Halls ML, van der Westhuizen ET, Bathgate RAD, Summers RJ (2007): Relaxin Family Peptide Receptors - former orphans reunite with their parent ligands to activate multiple signalling pathways. $\mathrm{Br} \mathrm{J}$ Pharmacol $\underline{150}, 677-691$

Heeg MHJ, Koziolek MJ, Vasko R, Schaefer L, Sharma K, Müller GA, Strutz F (2005): The antifibrotic effects of relaxin in human renal fibroblasts are mediated in part by inhibition of the Smad2 pathway2. Kidney Int $\underline{68}, 96-109$

Heino J, Ignotz RA, Hemler ME, Crouse C, Massagué J (1989): Regulation of cell adhesion receptors by transforming growth factor-beta. Concomitant regulation of integrins that share a common beta 1 subunit. J Biol Chem 264, 380-388

Heldin C-H, Miyazono K, ten Dijke P (1997): TGF- $\beta$ signalling from cell membrane to nucleus through SMAD proteins. Nature $\underline{390}, 465-471$

Herman JG, Baylin SB (2003): Gene silencing in cancer in association with promoter hypermethylation. N Engl J Med $\underline{349}, 2042-2054$

Herpin A, Lelong C, Favrel P (2004): Transforming growth factor-beta-related proteins: an ancestral and widespread superfamily of cytokines in metazoans. Dev Comp Immunol $\underline{28}, 461-485$

Hewitson TD, Ho WY, Samuel CS (2010): Antifibrotic Properties of Relaxin: In Vivo Mechanism of Action in Experimental Renal Tubulointerstitial Fibrosis. Endocrinology 151, 4938-4948

Hewitson TD, Mookerjee I, Masterson R, Zhao C, Tregear GW, Becker GJ, Samuel CS (2007): Endogenous Relaxin Is a Naturally Occurring Modulator of Experimental Renal Tubulointerstitial Fibrosis. Endocrinology $\underline{148}, 660-669$

Hewitson TD, Zhao C, Wigg B, Lee SW, Simpson ER, Boon WC, Samuel CS (2012): Relaxin and castration in male mice protect from, but testosterone exacerbates, age-related cardiac and renal fibrosis, whereas estrogens are an independent determinant of organ size. Endocrinology $\underline{153}, 188-$ 199

Hisaw FL (1929): The Corpus Luteum Hormone. I. Experimental Relaxation of the Pelvic Ligaments of the Guinea Pig. Physiol Zool 2, 59-79

Holliday R, Pugh JE (1975): DNA modification mechanisms and gene activity during development. Science $\underline{187}, 226-232$

Hossain MA, Rosengren KJ, Samuel CS, Shabanpoor F, Chan LJ, Bathgate RAD, Wade JD (2011): The Minimal Active Structure of Human Relaxin-2. J Biol Chem 286, 37555-37565

Huang Z, Myhr C, Bathgate RAD, Ho BA, Bueno A, Hu X, Xiao J, Southall N, Barnaeva E, Agoulnik IU, et al. (2015): Activation of Relaxin Family Receptor 1 from Different Mammalian Species by Relaxin Peptide and Small-Molecule Agonist ML290. Front Endocrinol $\underline{6}, 1664-2392$

Hudson P, Haley J, John M, Cronk M, Crawford R, Haralambidis J, Tregear G, Shine J, Niall H (1983): Structure of a genomic clone encoding biologically active human relaxin. Nature $\underline{301}, 628-631$ 
Ina K, Kitamura H, Tatsukawa S, Takayama T, Fujikura Y, Shimada T (2002): Transformation of interstitial fibroblasts and tubulointerstitial fibrosis in diabetic nephropathy. Med Electron Microsc $\underline{35}$, 87-95

Ivell R, Kotula-Balak M, Glynn D, Heng K, Anand-Ivell R (2011): Relaxin family peptides in the male reproductive system—a critical appraisal. Mol Hum Reprod 17, 71-84

lyengar R (1993): Molecular and functional diversity of mammalian Gs-stimulated adenylyl cyclases. FASEB J $\underline{7}, 768-775$

Jeyabalan A, Kerchner LJ, Fisher MC, McGuane JT, Doty KD, Conrad KP (2006): Matrix metalloproteinase-2 activity, protein, mRNA, and tissue inhibitors in small arteries from pregnant and relaxin-treated nonpregnant rats. J Appl Physiol 100, 1955-1963

Jones PA, Baylin SB (2002): The fundamental role of epigenetic events in cancer. Nat Rev Genet $\underline{3}$, $415-428$

Ju W, Nair V, Smith S, Zhu L, Shedden K, Song PXK, Mariani LH, Eichinger FH, Berthier CC, Randolph A, et al. (2015): Tissue transcriptome-driven identification of epidermal growth factor as a chronic kidney disease biomarker. Sci Transl Med $\underline{7}$, 316ra193-316ra193

Justice MJ, Siracusa LD, Stewart AF (2011): Technical approaches for mouse models of human disease. Dis Model Mech $\underline{4}, 305-310$

Kang Y-M, Choi Y-R, Yun C-O, Park J-O, Suk K-S, Kim H-S, Park M-S, Lee B-H, Lee H-M, Moon S-H (2014): Down-regulation of collagen synthesis and matrix metalloproteinase expression in myofibroblasts from dupuytren nodule using adenovirus-mediated relaxin gene therapy. J Orthop Res $\underline{32}, 515-523$

Kapila S, Wang W, Uston K (2009): Matrix metalloproteinase induction by relaxin causes cartilage matrix degradation in target synovial joints. Ann N Y Acad Sci 1160, 322-328

KDIGO (Kidney Disease: Improving Global Outcomes): Mission KDIGO.

https://kdigo.org/mission/\#history (Zugriff am 20.03.2017)

KDIGO (Kidney Disease: Improving Global Outcomes) CKD Work Group (2013): KDIGO 2012 Clinical Practice Guideline for the Evaluation and Management of Chronic Kidney Disease. Kidney inter Suppl 3, 1-150

Keller CK, Geberth SK: Praxis der Nephrologie. 3. Auflage; Springer Medizin Verlag, Heidelberg 2010

Kibblewhite D, Larrabee WF, Jr, Sutton D (1992): THe effect of relaxin on tissue expansion. Arch Otolaryngol Neck Surg 118, 153-156

Klahr S, Morrissey J (2002): Obstructive nephropathy and renal fibrosis. Am J Physiol Renal Physiol $\underline{283}$, F861-875

Klose RJ, Bird AP (2006): Genomic DNA methylation: the mark and its mediators. Trends Biochem 
Sci 31, 89-97

Kondo S, Kagami S, Urushihara M, Kitamura A, Shimizu M, Strutz F, Müller GA, Kuroda Y (2004): Transforming growth factor- $\beta 1$ stimulates collagen matrix remodeling through increased adhesive and contractive potential by human renal fibroblasts. Biochim Biophys Acta BBA - Mol Cell Res 1693, 91100

Laird PW, Jaenisch R (1994): DNA methylation and cancer. Hum Mol Genet $\underline{3}$, 1487-1495

Lassus JPE, Nieminen MS, Peuhkurinen K, Pulkki K, Siirilä-Waris K, Sund R, Harjola V-P, FINNAKVA study group (2010): Markers of renal function and acute kidney injury in acute heart failure: definitions and impact on outcomes of the cardiorenal syndrome. Eur Heart J 31, 2791-2798

LeBleu VS, Taduri G, O'Connell J, Teng Y, Cooke VG, Woda C, Sugimoto H, Kalluri R (2013): Origin and function of myofibroblasts in kidney fibrosis. Nat Med $\underline{19}, 1047-1053$

Lee CC, Fecher LA, Gallia GL, Gibbs P, Le D, Giuntoli RL, Goggins M, Hogarty MD, Holdhoff M, Hong SM, et al. (2014): Detection of circulating tumor DNA in early- and late-stage human malignancies. Sci Transl Med 6, 1946-6234

Leon SA, Shapiro B, Sklaroff DM, Yaros MJ (1977): Free DNA in the serum of cancer patients and the effect of therapy. Cancer Res $\underline{37}, 646-650$

Levin A, Rigatto C, Barrett B, Madore F, Muirhead N, Holmes D, Clase CM, Tang M, Djurdjev O (2014): Biomarkers of inflammation, fibrosis, cardiac stretch and injury predict death but not renal replacement therapy at 1 year in a Canadian chronic kidney disease cohort. Nephrol Dial Transpl $\underline{29}$, 1037-1047

Li L, Choi J-Y, Lee K-M, Sung H, Park SK, Oze I, Pan K-F, You W-C, Chen Y-X, Fang J-Y, et al. (2012): DNA Methylation in Peripheral Blood: A Potential Biomarker for Cancer Molecular Epidemiology. J Epidemiol 22, 384-394

Li MO, Wan YY, Sanjabi S, Robertson A-KL, Flavell RA (2006): Transforming growth factor-beta regulation of immune responses. Annu Rev Immunol 24, 99-146

Liu Y (2011): Cellular and molecular mechanisms of renal fibrosis. Nat Rev Nephrol $\underline{7}, 684-696$

Long DA, Woolf AS, Suda T, Yuan HT (2001): Increased Renal Angiopoietin-1 Expression in Folic Acid-Induced Nephrotoxicity in Mice. J Am Soc Nephrol 12, 2721-2731

López-Hernández FJ, López-Novoa JM (2012): Role of TGF- $\beta$ in chronic kidney disease: an integration of tubular, glomerular and vascular effects. Cell Tissue Res $\underline{347}, 141-154$

Lottspeich F, Engels JW (Hrsg.): Bioanalytik. 3. Auflage; Springer Spektrum, Berlin Heidelberg 2012

Lovisa S, LeBleu VS, Tampe B, Sugimoto H, Vadnagara K, Carstens JL, Wu C-C, Hagos Y, Burckhardt BC, Pentcheva-Hoang T, et al. (2015): Epithelial-to-mesenchymal transition induces cell cycle arrest and parenchymal damage in renal fibrosis. Nat Med 21, 998-1009

Madlener M: Matrixmetalloproteinasen: vielfältige Modulatoren der Wundheilung. Herbert Utz Verlag, 
München 1998

Maeshima Y, Makino H (2010): Angiogenesis and chronic kidney disease. Fibrogenesis Tissue Repair $\underline{3}, 1755-1536$

Magalhães $P$, Pejchinovski M, Markoska K, Banasik M, Klinger M, Švec-Billá D, Rychlík I, Rroji M, Restivo A, Capasso G, et al. (2017): Association of kidney fibrosis with urinary peptides: a path towards non-invasive liquid biopsies? Sci Rep $\underline{7}, 16915$

Majno G, Gabbiani G, Hirschel BJ, Ryan GB, Statkov PR (1971): Contraction of granulation tissue in vitro: similarity to smooth muscle. Science $\underline{173}, 548-550$

Mao Y (2014): Hypermethylation of RASAL1: A Key for Renal Fibrosis. EBioMedicine 2

Marriott D, Gillece-Castro B, Gorman CM (1992): Prohormone convertase-1 will process prorelaxin, a member of the insulin family of hormones. Mol Endocrinol $\underline{6}, 1441-1450$

Massagué J (1990): The transforming growth factor-beta family. Annu Rev Cell Biol $\underline{6}, 597-641$

Massagué J, Chen Y-G (2000): Controlling TGF- $\beta$ signaling. Genes Dev $\underline{14}, 627-644$

Masterson R, Hewitson TD, Kelynack K, Martic M, Parry L, Bathgate R, Darby I, Becker G (2004):

Relaxin down-regulates renal fibroblast function and promotes matrix remodelling in vitro. Nephrol Dial Transplant $\underline{19}$, 544-552

Meissner A, Mikkelsen TS, Gu H, Wernig M, Hanna J, Sivachenko A, Zhang X, Bernstein BE, Nusbaum C, Jaffe DB, et al. (2008): Genome-scale DNA methylation maps of pluripotent and differentiated cells. Nature $\underline{454}, 766-770$

Methven S, MacGregor MS (2009): Clinical management of chronic kidney disease. Clin Med $\underline{9}, 269$ 272

Mikeska T, Craig JM (2014): DNA Methylation Biomarkers: Cancer and Beyond. Genes $\underline{5}, 821-864$

Mischak H (2015): Pro: urine proteomics as a liquid kidney biopsy: no more kidney punctures! Nephrol Dial Transplant Off Publ Eur Dial Transpl Assoc - Eur Ren Assoc 30, 532-537

Mookerjee I, Hewitson TD, Halls ML, Summers RJ, Mathai ML, Bathgate RAD, Tregear GW, Samuel CS (2009): Relaxin inhibits renal myofibroblast differentiation via RXFP1, the nitric oxide pathway, and Smad2. FASEB J $\underline{23}, 1219-1229$

Müller GA, Rodemann HP (1991): Characterization of human renal fibroblasts in health and disease: I. Immunophenotyping of cultured tubular epithelial cells and fibroblasts derived from kidneys with histologically proven interstitial fibrosis. Am J Kidney Dis Off J Natl Kidney Found 17, 680-683

Müller GA, Zeisberg M, Strutz F (2000): The importance of tubulointerstitial damage in progressive renal disease. Nephrol Dial Transplant Off Publ Eur Dial Transpl Assoc - Eur Ren Assoc 15 Suppl 6 , 76-77 
Müller GA, Frank J, Rodemann HP, Engler-Blum G (1995): Human renal fibroblast cell lines (tFKIF and $\mathrm{tNKF}$ ) are new tools to investigate pathophysiologic mechanisms of renal interstitial fibrosis. Exp Nephrol $\underline{3}, 127-133$

el Nahas AM, Bassett AH, Cope GH, Le Carpentier JE (1991): Role of growth hormone in the development of experimental renal scarring. Kidney Int $\underline{40}, 29-34$

Nebel M: Kosten der Nierenersatztherapie. In: Dialyseverfahren in Theorie und Praxis; hrsg. v. Hörl WH, Wanner C; 6. Auflage; Georg Thieme Verlag, Stuttgart 2003, 619-629

Nistri S, Bigazzi M, Bani D (2007): Relaxin as a Cardiovascular Hormone: Physiology, Pathophysiology and Therapeutic Promises. Cardiovasc Hematol Agents Med Chem Former Curr Med Chem - Cardiovasc Hematol Agents $\underline{5}, 101-108$

Novartis: Novartis provides update on Phase III study of RLX030 (serelaxin) in patients with acute heart failure. https://www.novartis.com/news/media-releases/novartis-provides-update-phase-iii-studyrlx030-serelaxin-patients-acute-heart (Zugriff am 20.07.2017)

Olkhov-Mitsel E, Bapat B (2012): Strategies for discovery and validation of methylated and hydroxymethylated DNA biomarkers. Cancer Med 1, 237-260

Papageorgiou EA, Karagrigoriou A, Tsaliki E, Velissariou V, Carter NP, Patsalis PC (2011): Fetalspecific DNA methylation ratio permits noninvasive prenatal diagnosis of trisomy 21 . Nat Med $\underline{17}$, $510-513$

Peters H, Border WA, Noble NA (1998): Targeting TGF- $\beta$ overexpression in renal disease: Maximizing the antifibrotic action of angiotensin II blockade. Kidney Int $\underline{54}, 1570-1580$

Peters LL, Robledo RF, Bult CJ, Churchill GA, Paigen BJ, Svenson KL (2007): The mouse as a model for human biology: a resource guide for complex trait analysis. Nat Rev Genet $\underline{8}, 58-69$

Piek E, Heldin C-H, Dijke PT (1999): Specificity, diversity, and regulation in TGF- $\beta$ superfamily signaling. FASEB J $\underline{13}, 2105-2124$

Pratt JR, Parker MD, Affleck LJ, Corps C, Hostert L, Michalak E, Lodge JPA (2006): Ischemic epigenetics and the transplanted kidney. Transplant Proc $\underline{38}, 3344-3346$

Rahimi RA, Leof EB (2007): TGF-beta signaling: a tale of two responses. J Cell Biochem 102, 593608

Reddy MA, Natarajan R (2015): Recent developments in epigenetics of acute and chronic kidney diseases. Kidney Int $\underline{88}$, 250-261

Rehm H, Letzel T: Der Experimentator: Proteinbiochemie/Proteomics. 6. Auflage; Spektrum Akademischer Verlag, Heidelberg 2010

Rideout WM, Coetzee GA, Olumi AF, Jones PA (1990): 5-Methylcytosine as an endogenous mutagen in the human LDL receptor and p53 genes. Science $\underline{249}, 1288-1290$ 
Riggs AD (1975): X inactivation, differentiation, and DNA methylation. Cytogenet Cell Genet $\underline{14}$, 9-25

Risdon RA, Sloper JC, Wardener HE (1968): Relationship between renal function and histological changes found in renal-biopsy specimens from patients with persistent glomerular nephritis. Lancet $\underline{2}$, 363-366

Roberts IS, Burrows C, Shanks JH, Venning M, McWilliam LJ (1997): Interstitial myofibroblasts: predictors of progression in membranous nephropathy. J Clin Pathol $\underline{50}, 123-127$

Roberts AB, Lamb LC, Newton DL, Sporn MB, De Larco JE, Todaro GJ (1980): Transforming growth factors: isolation of polypeptides from virally and chemically transformed cells by acid/ethanol extraction. Proc Natl Acad Sci U S A $\underline{77}$, 3494-3498

Rodríguez-Romo R, Berman N, Gómez A, Bobadilla NA (2015): Epigenetic regulation in the acute kidney injury to chronic kidney disease transition. Nephrology 20, 736-743

Rosenthal N, Brown S (2007): The mouse ascending: perspectives for human-disease models. Nat Cell Biol $\underline{9}, 993-999$

Rossant J, McKerlie C (2001): Mouse-based phenogenomics for modelling human disease. Trends Mol Med $\underline{7}, 502-507$

Samuel CS, Summers RJ, Hewitson TD (2016): Antifibrotic Actions of Serelaxin - New Roles for an Old Player. Trends Pharmacol Sci $\underline{37}$, 485-497

Samuel CS, Zhao C, Bond CP, Hewitson TD, Amento EP, Summers RJ (2004b): Relaxin-1-deficient mice develop an age-related progression of renal fibrosis. Kidney Int $\underline{65}, 2054-2064$

Samuel CS, Unemori EN, Mookerjee I, Bathgate RAD, Layfield SL, Mak J, Tregear GW, Du X-J (2004a): Relaxin modulates cardiac fibroblast proliferation, differentiation, and collagen production and reverses cardiac fibrosis in vivo. Endocrinology $\underline{145}, 4125-4133$

Sasser JM (2013): The emerging role of relaxin as a novel therapeutic pathway in the treatment of chronic kidney disease. Am J Physiol - Regul Integr Comp Physiol 305, R559-R565

Sasser JM (2014): New targets for renal interstitial fibrosis: relaxin family peptide receptor $1-$ angiotensin type 2 receptor heterodimers. Kidney Int $\underline{86}, 9-10$

Schüttert JB, Liu MH, Gliem N, Fiedler GM, Zopf S, Mayer C, Müller GA, Grunewald RW (2003): Human renal fibroblasts derived from normal and fibrotic kidneys show differences in increase of extracellular matrix synthesis and cell proliferation upon angiotensin II exposure. Pflüg Arch Eur $\mathrm{J}$ Physiol 446, 387-393

Sherwood OD (2004): Relaxin's Physiological Roles and Other Diverse Actions. Endocr Rev $\underline{25}$, 205234

Shi Y, Massagué J (2003): Mechanisms of TGF- $\beta$ Signaling from Cell Membrane to the Nucleus. Cell $\underline{113}, 685-700$ 
Siragy HM, Carey RM (2010): Role of the intrarenal renin-angiotensin-aldosterone system in chronic kidney disease. Am J Nephrol 31, 541-550

Strutz F, Zeisberg M (2006): Renal Fibroblasts and Myofibroblasts in Chronic Kidney Disease. J Am Soc Nephrol 17, 2992-2998

Strutz F, Müller GA (2006): Renal fibrosis and the origin of the renal fibroblast. Nephrol Dial Transplant 21, 3368-3370

Stubbs TM, Bonder MJ, Stark A-K, Krueger F, von Meyenn F, Stegle O, Reik W (2017): Multi-tissue DNA methylation age predictor in mouse. Genome Biol $\underline{18}, 1474-7596$

Takai D, Jones PA (2003): The CpG island searcher: a new WWW resource. In Silico Biol $\underline{3}$, 235-240

Tampe B, Zeisberg M (2014): Evidence for the involvement of epigenetics in the progression of renal fibrogenesis. Nephrol Dial Transpl 29, 0931-0509, 1460-2385

Tampe B, Tampe D, Zeisberg EM, Muller GA, Bechtel-Walz W, Koziolek M, Kalluri R, Zeisberg M (2015): Induction of Tet3-dependent epigenetic remodeling by low-dose hydralazine attenuates progression of chronic kidney disease. EBioMedicine 2, 2352-3964

Tampe B, Steinle U, Tampe D, Carstens JL, Korsten P, Zeisberg EM, Müller GA, Kalluri R, Zeisberg $M$ (2017): Low-dose hydralazine prevents fibrosis in a murine model of acute kidney injury-to-chronic kidney disease progression. Kidney Int $\underline{91}, 157-176$

Tang WW, Van GY, Qi M (1997): Myofibroblast and alpha 1 (III) collagen expression in experimental tubulointerstitial nephritis. Kidney Int $\underline{51}$, 926-931

Teichman SL, Unemori E, Teerlink JR, Cotter G, Metra M (2010): Relaxin: Review of Biology and Potential Role in Treating Heart Failure. Curr Heart Fail Rep ㄱ, 75-82

Tomasek JJ, Gabbiani G, Hinz B, Chaponnier C, Brown RA (2002): Myofibroblasts and mechanoregulation of connective tissue remodelling. Nat Rev Mol Cell Biol $\underline{3}, 349-363$

Ucero AC, Benito-Martin A, Izquierdo MC, Sanchez-Niño MD, Sanz AB, Ramos AM, Berzal S, RuizOrtega M, Egido J, Ortiz A (2013): Unilateral ureteral obstruction: beyond obstruction. Int Urol Nephrol $\underline{46}, 765-776$

Unemori EN, Pickford LB, Salles AL, Piercy CE, Grove BH, Erikson ME, Amento EP (1996): Relaxin induces an extracellular matrix-degrading phenotype in human lung fibroblasts in vitro and inhibits lung fibrosis in a murine model in vivo. J Clin Invest $\underline{98}, 2739-2745$

USRDS (United States Renal Data System) 2013 Annual Data Report: Atlas of Chronic Kidney Disease and End-Stage Renal Disease in the United States, National Institutes of Health, National Institute of Diabetes and Diges-tive and Kidney Diseases, Bethesda, MD, 2013.

https://www.usrds.org/atlas13.aspx (Zugriff am 28.10.2017)

Vanholder R, Van Laecke S, Glorieux G (2008): What is new in uremic toxicity? Pediatr Nephrol Berl 
Ger $\underline{23}, 1211-1221$

Vanholder R, Fouque D, Glorieux G, Heine GH, Kanbay M, Mallamaci F, Massy ZA, Ortiz A, Rossignol $P$, Wiecek A, et al. (2016): Clinical management of the uraemic syndrome in chronic kidney disease. Lancet Diabetes Endocrinol 4 , 360-373

Vaughan MB, Howard EW, Tomasek JJ (2000): Transforming growth factor-beta1 promotes the morphological and functional differentiation of the myofibroblast. Exp Cell Res $\underline{257}, 180-189$

Waddington $\mathrm{CH}$ (1968): Towards a theoretical biology. Nature $\underline{218}, 525-527$

Weber M, Hellmann I, Stadler MB, Ramos L, Pääbo S, Rebhan M, Schübeler D (2007): Distribution, silencing potential and evolutionary impact of promoter DNA methylation in the human genome. Nat Genet $\underline{39}$, 457-466

Weinhold B (2006): Epigenetics: The Science of Change. Environ Health Perspect 114, A160-A167

Wenzel U, Wolf G (2005): Blutdruckunabhängige Wirkungen von Antihypertensiva. Internist $\underline{46}, 548-$ 556

Whaley-Connell A, Sowers JR, McCullough PA, Roberts T, McFarlane SI, Chen S-C, Li S, Wang C, Collins AJ, Bakris GL, KEEP Investigators (2009): Diabetes mellitus and CKD awareness: the Kidney Early Evaluation Program (KEEP) and National Health and Nutrition Examination Survey (NHANES). Am J Kidney Dis Off J Natl Kidney Found $\underline{53}$, S11-21

Williams EJ, Benyon RC, Trim N, Hadwin R, Grove BH, Arthur MJ, Unemori EN, Iredale JP (2001): Relaxin inhibits effective collagen deposition by cultured hepatic stellate cells and decreases rat liver fibrosis in vivo. Gut $\underline{49}, 577-583$

Wilson SS, Ayaz SI, Levy PD (2015): Relaxin: A Novel Agent for the Treatment of Acute Heart Failure. Pharmacother J Hum Pharmacol Drug Ther 35, 315-327

Yamashita H, Ichijo H, Grimsby S, Morén A, ten Dijke P, Miyazono K (1994): Endoglin forms a heteromeric complex with the signaling receptors for transforming growth factor-beta. J Biol Chem $\underline{269}, 1995-2001$

Yang H-C, Zuo Y, Fogo AB (2010): Models of chronic kidney disease. Drug Discov Today Dis Models $\underline{7}, 13-19$

Zeisberg EM, Zeisberg M (2013): The role of promoter hypermethylation in fibroblast activation and fibrogenesis. J Pathol $\underline{229}, 1096-9896$

Zeisberg M, Kalluri R (2013): Cellular Mechanisms of Tissue Fibrosis. 1. Common and organ-specific mechanisms associated with tissue fibrosis. Am J Physiol. Cell Physiol. $\underline{304}$, C216-C225

Zeisberg M, Zeisberg EM (2015): Precision renal medicine: a roadmap towards targeted kidney fibrosis therapies. Fibrogenesis Tissue Repair $\underline{8}, 16$

Zhang Q, Yin S, Liu L, Liu Z, Cao W (2016): Rhein reversal of DNA hypermethylation-associated Klotho suppression ameliorates renal fibrosis in mice. Sci Rep $\underline{6}$, 2045-2322 
Zhao G-Q (2003): Consequences of knocking out BMP signaling in the mouse. Genesis $\underline{35}, 43-56$

Zhou D, Liu Y (2016): Renal fibrosis in 2015: Understanding the mechanisms of kidney fibrosis. Nat Rev Nephrol 12, 68-70 


\section{Danksagung}

Zunächst möchte ich meinem Doktorvater Herrn Prof. Dr. med. Michael Zeisberg für die Überlassung des Themas, die Unterstützung und die konstante Betreuung während der Durchführung der Experimente und der Erstellung dieser Dissertation danken.

Ein besonderer Dank gebührt darüber hinaus Herrn Dr. med. Björn Tampe. Seine konstruktiven und wertvollen inhaltlichen Anmerkungen, die außerordentliche Unterstützung bei der Planung, Umsetzung und Auswertung der Experimente haben wesentlich zur Erstellung dieser Arbeit beigetragen. Insbesondere danke ich für die ausgezeichnete Hilfestellung bei der Korrektur dieser Dissertation.

Ein großer Dank gilt außerdem den medizinisch-technischen Assistentinnen Frau Annika Faust, Frau Anika Krüger und Frau Sarah Rinkleff für die professionelle Einarbeitung in die Methodik der Laborarbeiten, ihren konstanten fachlichen und moralischen Beistand bei der Durchführung vieler Experimente sowie den täglichen kollegialen Austausch.

Ein weiterer Dank gebührt meiner Doktorandenvorgängerin Frau Dr. med. Friederike Klöpper für ihre große Unterstützung bei der Einarbeitung in die Zellkultur sowie ihre differenzierten und konstruktiven Ratschläge. Unser Austausch über inhaltliche und organisatorische Fragestellungen hat wesentlich zum Gelingen der Arbeit beigetragen. 


\section{Lebenslauf}

Mein Name ist Friederike Hesse, ich wurde am 02. Juni 1992 in Göttingen als ältestes Kind von Jörg Hesse und Kerstin Hesse geboren.

Von 1998 bis 2002 besuchte ich die Grundschule in Elliehausen und im Anschluss daran die Orientierungsschule (Jahnschule) in Göttingen von 2002 bis 2004. Anschließend wechselte ich auf das Felix-Klein-Gymnasium in Göttingen, an dem ich meine schulische Ausbildung im Juni 2011 mit dem Abitur abschloss.

Zum Wintersemester 2011/12 begann ich mein Studium der Humanmedizin an der Georg-AugustUniversität in Göttingen, an der ich 2013 die Physikums-Prüfung mit der Note 2,0 ablegte. Im Februar 2015 begann ich meine Dissertation in der Arbeitsgruppe von Herrn Prof. Dr. med. Michael Zeisberg in der Abteilung für Nephrologie und Rheumatologie der Universitätsmedizin Göttingen.

Das reguläre Studium der Humanmedizin nahm ich zum Wintersemester 2015/16 wieder auf und absolvierte im Frühjahr 2017 das 2. Staatsexamen (M2) mit der Note 2,0. Ab Mai 2017 trat ich in das Praktische Jahr ein. Zuerst absolvierte ich das Innere-Medizin-Tertial in der Kardiologie und Nephrologie in Großbritannien (King's College London und University of Aberdeen), darauf folgte mein Wahlfach in der Radiologie, welches ich zur Hälfte in der Strahlentherapie an der UMG und in St. Gallen, Schweiz (diagnostische Radiologie) verbrachte. Das letzte Tertial der Chirurgie absolvierte ich erneut an der UMG. Im Mai 2018 legte ich das Dritte Staatsexamen (M3) mit der Note 1,0 ab und erlangte die Approbation zur Ärztin. 